\title{
Aktualisierte S2k-Leitlinie der Deutschen Gesellschaft für Gastroenterologie, Verdauungs- und Stoffwechselkrankheiten (DGVS) „Komplikationen der Leberzirrhose“
}

\author{
AWMF-Nr.: 021-017 \\ Updated S2k-Guideline “Complications of liver cirrhosis". German \\ Society of Gastroenterology (DGVS)
}

Authors

Alexander L. Gerbes ${ }^{1 *}$, Joachim Labenz ${ }^{2 *}$, Beate Appenrodt ${ }^{3,4}$, Matthias Dollinger ${ }^{5}$, Felix Gundling ${ }^{6}$, Veit Gülberg ${ }^{7}$, Axel Holstege ${ }^{8}$, Petra Lynen-Jansen ${ }^{9}$, Christian J. Steib ${ }^{10}$, Jonel Trebicka ${ }^{11}$, Reiner Wiest ${ }^{12}$, Alexander Zipprich ${ }^{13}$

Collaborators:

Matthias J. Bahr, Tony Bruns, Peter Buggisch, Manuel Dafotakis, Guido Gerken, Manfred Gross, André Ignee, Guido Kukuk, Christoph Lübbert, Bernhard Meyer, Johann Ockenga, Mathias Plauth, Andrej Potthoff, Jutta Riemer,

Alexander R. Rosenkranz, Martin Rössle, Bernd Salzberger, Michael Schepke, Andreas A. Schnitzbauer,

Andreas G. Schreyer, Marcus Schuchmann, Beate K. Straub, Andrea Tannapfel, Egbert Trowe, Pia van Leeuwen,

Jens Werner, Matthias Wettstein, Marcus-Alexander Wörns

Weitere beteiligte Fachgesellschaften:

Deutsche Gesellschaft für Allgemein- und Viszeralchirurgie (DGAV), Deutsche Gesellschaft für Innere Medizin e. V.

(DGIM), Deutsche Gesellschaft für Infektiologie e. V. (DGI), Deutsche Gesellschaft für Pathologie e. V./Bundesverband deutscher Pathologen e. V. (DGP/BDP), Deutsche Röntgengesellschaft e. V. (DRG), Deutsche Gesellschaft für Interventionelle Radiologie und minimal-invasive Therapie (DeGIR), Deutsche Gesellschaft für Nephrologie (DGFN), Deutsche Gesellschaft für Ultraschall in der Medizin (DEGUM), Deutsche Gesellschaft für Neurologie e. V. (DGN), Deutsche Gesellschaft für Ernährungsmedizin e. V. (DGEM)

Patientenvertretung:

Lebertransplantierte Deutschland e. V.

Institute

1 Medizinische Klinik und Poliklinik II, Leber Centrum München, Klinikum der Universität München, LMU München

2 Innere Medizin, Diakonie Klinikum Jung-Stilling, Siegen

3 Innere Medizin, St. Elisabeth-Krankenhaus, Köln

4 Klinik für Innere Medizin II, Universitätsklinikum des Saarlandes, Homburg

5 Medizinische Klinik I mit Schwerpunkt Gastroenterologie, Klinikum Landshut, Landshut

6 Klinik für Gastroenterologie, Hepatologie und gastroent. Onkologie, Klinikum Bogenhausen, München

7 Innere Medizin, Krankenhaus Cham Sana Kliniken, Cham

8 Landshut

9 Deutsche Gesellschaft für Gastroenterologie, Verdauungs- und Stoffwechselkrankheiten, Berlin

10 Medizinische Klinik und Poliklinik II, Campus Großhadern, Universitätsklinikum München, München

11 Medizinische Klinik I Gastroent., Hepat., Pneum., Endokrin., Universitätsklinikum Frankfurt, Frankfurt 12 Bern

\author{
13 Universitätsklinik u. Poliklinik, Innere Medizin I \\ mit Schwerpunkt Gastroenterologie, \\ Universitätsklinikum Halle, Halle
}

Bibliografie

DOI https://doi.org/10.1055/a-0873-4658

Online-Publikation: 6.5.2019

Z Gastroenterol 2019; 57: 611-680

(c) Georg Thieme Verlag KG, Stuttgart · New York ISSN 0044-2771

Korrespondenzadresse

Prof. Dr. med. Alexander L. Gerbes

Medizinische Klinik und Poliklinik II, Leber Centrum München,

Klinikum der Universität München, LMU München,

Marchioninistr. 15, 81377 München

gerbes@med.uni-muenchen.de

Prof. Dr. med. Joachim Labenz

Innere Medizin, Diakonie Klinikum Jung-Stilling,

Wichernstr. 40, 57074 Siegen

joachim.labenz@diakonie-sw.de 


\section{ZUSAMMENFASSUNG}

Die Leitlinie Komplikationen der Leberzirrhose der Deutschen Gesellschaft für Gastroenterologie, Verdauungs- und Stoffwechselkrankheiten (DGVS) ersetzt die Leitlinie aus dem Jahr 2011. Sie basiert auf den Empfehlungen der Arbeitsgemeinschaft der Wissenschaftlichen Medizinischen Fachgesellschaften (AWMF) für eine evidenzbasierte Konsensus-Leitlinie der Entwicklungsstufe S2k und wurde interdisziplinär unter Beteiligung aller relevanten Fachgesellschaften und der Patientenvertretung erstellt. Neben den in der Vorgängerversion behandelten Kapiteln Aszites, spontan bakterielle Peritonitis, hepatorenales Syndrom, hepatischer Hydrothorax und hepato- pulmonales Syndrom wurden die Kapitel Diagnostik und Therapie der Hepatischen Enzephalopathie neu aufgenommen.

\section{ABSTRACT}

This guideline provides evidence-based key recommendations for diagnosis and therapy of complications of liver cirrhosis and upgrades the 2011 version. An interdisciplinary team of medical experts and patient support groups developed the guideline following the AWMF recommendations for evidence based consensus guidelines. New chapters concerning diagnosis and therapy of hepatic encephalopathy were added.

\begin{tabular}{|c|c|c|}
\hline \multicolumn{2}{|c|}{ Inhaltsverzeichnis } & \multirow{2}{*}{$\begin{array}{l}\text { Seite } \\
613\end{array}$} \\
\hline & Besonderer Hinweis & \\
\hline 1 & Diagnostik des Aszites & 613 \\
\hline 1.1 & Einleitung & 613 \\
\hline 1.2 & Aszitespunktion & 613 \\
\hline 1.3 & Zytologische Diagnostik & 613 \\
\hline 1.4 & $\begin{array}{l}\text { Aszitespunktion und Substitution von } \\
\text { Gerinnungsfaktoren }\end{array}$ & 615 \\
\hline 1.5 & Aszitespunktion unter Antikoagulation & 616 \\
\hline 1.6 & Technik der Aszitespunktion & 617 \\
\hline 1.7 & Kontraindikationen für eine Aszitespunktion & 617 \\
\hline 1.8 & Komplikationen nach Aszitespunktion & 618 \\
\hline 1.9 & $\begin{array}{l}\text { Weitere Untersuchungen bei initialer } \\
\text { Aszitespunktion }\end{array}$ & 618 \\
\hline 1.10 & Sekundäre Peritonitis & 620 \\
\hline 2 & Therapie des Aszites & 620 \\
\hline 2.1 & Therapieindikation & 620 \\
\hline 2.2 & Nicht-medikamentöse Therapie & 621 \\
\hline 2.3 & Medikamentöse Therapie & 622 \\
\hline 2.4 & $\begin{array}{l}\text { Therapierefraktärer und rezidivierender } \\
\text { Aszites }\end{array}$ & 623 \\
\hline 3 & Spontan bakterielle Peritonitis & 626 \\
\hline 3.1 & Einleitung und Definition & 626 \\
\hline 3.2 & Primärprophylaxe einer SBP & 627 \\
\hline 3.3 & Therapie der SBP & 628 \\
\hline 3.4 & Sekundärprophylaxe und Nachsorge der SBP & 631 \\
\hline 4 & Hepatorenales Syndrom & 632 \\
\hline 4.1 & Definitionen & 632 \\
\hline 4.2 & Nierenversagen bei Leberzirrhose & 632 \\
\hline 4.3 & Albumingabe bei HRS & 633 \\
\hline 4.4 & Vasokonstriktoren bei HRS & 633 \\
\hline 4.5 & TIPS bei HRS & 634 \\
\hline 4.6 & Nieren- und Leberersatzverfahren bei HRS & 635 \\
\hline
\end{tabular}

\begin{tabular}{|c|c|c|}
\hline \multicolumn{2}{|c|}{ Inhaltsverzeichnis } & \multirow{2}{*}{$\begin{array}{l}\text { Seit } \\
635\end{array}$} \\
\hline 4.7 & Lebertransplantation bei HRS & \\
\hline 5 & $\begin{array}{l}\text { Hepatischer Hydrothorax und hepato- } \\
\text { pulmonales Syndrom }\end{array}$ & 636 \\
\hline 5.1 & Einleitung & 636 \\
\hline 5.2 & Diagnose des hepatischen Hydrothorax & 636 \\
\hline 5.3 & $\begin{array}{l}\text { Therapie des (rezidivierenden) hepatischen } \\
\text { Hydrothorax }\end{array}$ & 638 \\
\hline 5.4 & $\begin{array}{l}\text { Diagnostik und Therapie des spontan } \\
\text { bakteriellen Empyems (SBEM) }\end{array}$ & 639 \\
\hline 5.5 & $\begin{array}{l}\text { Diagnostik des hepatopulmonalen } \\
\text { Syndroms }\end{array}$ & 640 \\
\hline 5.6 & Therapie des hepatopulmonalen Syndroms & 641 \\
\hline 6 & $\begin{array}{l}\text { Diagnostik der hepatischen Enzephalopathie } \\
\text { (HE) }\end{array}$ & 642 \\
\hline 6.1 & Einleitung & 642 \\
\hline 6.2 & $\begin{array}{l}\text { Differenzialdiagnosen und auslösende } \\
\text { Faktoren einer HE }\end{array}$ & 643 \\
\hline 6.3 & $\begin{array}{l}\text { Diagnostische Verfahren und } \\
\text { Klassifikationen }\end{array}$ & 644 \\
\hline 6.4 & HE und Fahrtauglichkeit & 647 \\
\hline 7 & $\begin{array}{l}\text { Therapie der hepatischen Enzephalopathie } \\
\text { bei Leberzirrhose }\end{array}$ & 647 \\
\hline 7.1 & $\begin{array}{l}\text { Therapie der akuten Episode einer } \\
\text { hepatischen Enzephalopathie (HE) }\end{array}$ & 647 \\
\hline 7.2 & Rezidivprophylaxe nach einer HE-Episode & 656 \\
\hline 7.3 & Therapie der HE nach TIPS & 658 \\
\hline 7.4 & $\begin{array}{l}\text { Therapie bei verdeckter hepatischer } \\
\text { Enzephalopathie (cHE) }\end{array}$ & 659 \\
\hline 7.5 & $\begin{array}{l}\text { Vorgehen bei Patienten mit Leberzirrhose } \\
\text { ohne HE }\end{array}$ & 660 \\
\hline 7.6 & $\begin{array}{l}\text { Nachsorge von Patienten mit Leberzirrhose } \\
\text { und } \mathrm{HE}\end{array}$ & 661 \\
\hline Liter & rzeichnis & 662 \\
\hline
\end{tabular}




\section{Besonderer Hinweis}

Die Medizin unterliegt einem fortwährenden Entwicklungsprozess, sodass alle Angaben, insbesondere zu diagnostischen und therapeutischen Verfahren, immer nur dem Wissensstand zurzeit der Drucklegung der Leitlinie entsprechen können. Hinsichtlich der angegebenen Empfehlungen zur Therapie und der Auswahl sowie Dosierung von Medikamenten wurde in allen unseren Leitlinien die größtmögliche Sorgfalt beachtet. Gleichwohl werden die Benutzer aufgefordert, die Beipackzettel und Fachinformationen der Hersteller zur Kontrolle heranzuziehen und im Zweifelsfall einen Spezialisten zu konsultieren. Fragliche Unstimmigkeiten sollen bitte im allgemeinen Interesse der OL-Redaktion mitgeteilt werden. Der Benutzer selbst bleibt verantwortlich für jede diagnostische und therapeutische Applikation, Medikation und Dosierung.

In allen unseren Leitlinien sind eingetragene Warenzeichen (geschützte Warennamen) nicht besonders kenntlich gemacht. Es kann also aus dem Fehlen eines entsprechenden Hinweises nicht geschlossen werden, dass es sich um einen freien Warennamen handelt.

Unsere Leitlinien sind in allen ihren Teilen urheberrechtlich geschützt. Jede Verwertung außerhalb der Bestimmung des Urhebergesetzes ist ohne schriftliche Zustimmung der DGVS unzulässig und strafbar. Kein Teil des Werkes darf in irgendeiner Form ohne schriftliche Genehmigung reproduziert werden. Dies gilt insbesondere für Vervielfältigungen, Übersetzungen, Mikroverfilmungen und die Einspeicherung, Nutzung und Verwertung in elektronischen Systemen, Intranets und dem Internet.

Informationen zur Methodik der Leitlinienerstellung und die Interessenkonflikte sind im Leitlinienreport dargestellt (www.dgvs.de/leitlininien).

\section{Diagnostik des Aszites}

\subsection{Einleitung}

Das Auftreten von Aszites signalisiert in der Regel eine schwere Erkrankung und erfordert daher eine diagnostische Abklärung. Neben der Anamnese und der körperlichen Untersuchung gehören Laboruntersuchungen der Leberwerte, Nierenfunktion sowie der Serum- und Urinelektrolyte sowie die Sonografie zur Primärdiagnostik. Anschließend folgt die gezielte ätiologisch ausgerichtete Diagnostik entsprechend der Wahrscheinlichkeit einer speziellen Organerkrankung. Bei etwa 75 \% der Patienten ist die Ursache im Bereich der Leber zu finden [1]. Hierzu gehören auch die vaskulären Erkrankungen der Leber, insbesondere das BuddChiari-Syndrom (BCS) und das sinusoidale Obstruktionssyndrom.

Wesentlich für die Differenzialdiagnostik des Aszites ist die diagnostische Parazentese. Sie muss insbesondere die Fragen klären, ob es sich um einen malignen oder infizierten Aszites handelt. Hier kann der makroskopische Aspekt erste Hinweise geben. Hämorrhagischer Aszites kann ein Zeichen für Malignität sein, jedoch kann dieser auch Folge eines Traumas, einer Pankreatitis oder - sehr selten - einer Peritonealtuberkulose sein. Trüber Aszites kann Ausdruck einer hohen Leukozytenzahl oder eines ho- hen Eiweißgehaltes sein [2]. Milchig-trüber bzw. chylöser Aszites ist pathognomonisch für Aszites mit einer hohen Konzentration von Chylomikronen und Triglyceriden (>200 mg/dl) [3, 4]. Die häufigsten Ursachen des chylösen Aszites sind maligne Erkrankungen und die portale Hypertension [4]. Eine laborchemische und zytologische Aufarbeitung des Punktats ist obligatorisch.

\subsection{Aszitespunktion}

\section{EMPFEHLUNG 1.1}

Eine diagnostische Aszitespunktion soll bei neu aufgetretenem Aszites erfolgen. Außerdem soll sie bei allen Patienten mit Leberzirrhose und Komplikationen sowie bei nicht elektiver stationärer Aufnahme durchgeführt werden.

Starke Empfehlung, starker Konsens

\section{Kommentar}

Bei jedem neu aufgetretenen Aszites erfolgt die diagnostische Punktion zur Klärung der Genese. Bei jeder Verschlechterung des Allgemeinzustandes von Patienten mit Leberzirrhose und Aszites oder neu aufgetretenen Komplikationen der Leberzirrhose oder Verschlechterung der Leberfunktionsparameter sowie anderer laborchemischer Parameter wie Kreatinin, Harnstoff oder Elektrolyte soll eine diagnostische Punktion zum Ausschluss einer spontan bakteriellen Peritonitis (SBP) frühzeitig erfolgen [1, 2]. Eine frühzeitige Aszitespunktion zur Diagnosestellung bei Verdacht auf SBP ist essenziell, um eine optimale Therapie zu gewährleisten [5]. Bei Patienten mit bekanntem Aszites, die nicht elektiv stationär aufgenommen werden, ist ebenfalls eine diagnostische Aszitespunktion indiziert, da eine hohe Prävalenz von Infektionen bei diesen Patienten besteht [6]. Die SBP geht als inflammatorische Reaktion mit einer vermehrten Zytokinausschüttung einher. Klinisch kann es zu einer Aggravation bestehender oder Auftreten neuer Komplikationen wie hepatorenalem Syndrom oder hepatischer Enzephalopathie kommen. Eine nicht diagnostizierte und somit nicht therapierte SBP ist mit einer erhöhten Mortalität assoziiert. Wiederholte diagnostische Aszitespunktionen sind bei Patienten in ambulanter Behandlung im stabilen klinischen Zustand und mit stabilen laborchemischen Parametern nicht notwendig. Die Prävalenz von Infektionen ist bei dieser Patientengruppe sehr niedrig. Bei 400 Punktionen bei ambulanten Patienten wurden in einem Zeitraum von zwei Jahren insgesamt acht Episoden einer spontan bakteriellen Peritonitis (2\%) diagnostiziert [7 - 10]. Bei kurzfristig wiederholten therapeutischen Punktionen ist eine zusätzliche diagnostische Analyse des Punktats nur im Bedarfsfall erforderlich.

\subsection{Zytologische Diagnostik}

\section{EMPFEHLUNG 1.2}

Bei Verdacht auf malignen Aszites soll eine zytologische Diagnostik durchgeführt werden.

Starke Empfehlung, starker Konsens 


\section{EMPFEHLUNG 1.3}

Bei Verdacht auf malignen Aszites sollen große Volumina oder mehrere Proben (mindestens 50 - $100 \mathrm{ml}$ ) verwendet werden. Bei fehlendem Nachweis von malignen Zellen und weiterhin bestehendem Verdacht auf eine maligne Ursache soll eine Wiederholung der Punktion erfolgen.

Starke Empfehlung, starker Konsens

\section{EMPFEHLUNG 1.4}

Bei Punktaten, bei denen eine geringe Zellzahl zu erwarten ist, sollte ein Zytozentrifugenpräparat angefertigt werden.

Empfehlung, starker Konsens

\section{EMPFEHLUNG 1.5}

Befinden sich Gewebspartikel oder Präzipitate im Punktat, sollten diese in Paraffin eingebettet und Schnittpräparate angefertigt werden.

Empfehlung, Konsens

\section{EMPFEHLUNG 1.6}

Die zytologische Diagnostik sollte an May-Grünwald-GiemsaPräparaten erfolgen.

Empfehlung, starker Konsens

\section{EMPFEHLUNG 1.7}

Eine Eisenfärbung kann zusätzlich zum Nachweis hämosiderinspeichernder Makrophagen, eine PAS-Färbung bei Verdacht auf eine Infiltration durch ein monozellulär schleimbildendes Karzinom durchgeführt werden.

Empfehlung offen, starker Konsens

\section{EMPFEHLUNG 1.8}

Eine Gramfärbung ist meist nicht indiziert wegen zu geringer Erregerkonzentration und sollte daher nicht routinemäßig erfolgen.

Empfehlung, starker Konsens

\section{Kommentar}

Bei klinischem Verdacht auf Malignität und bisher fehlendem Nachweis im Punktat sollte eine mehrmalige Wiederholung der Punktion erfolgen, um die Chance zu erhöhen, Tumorzellen aus dem Punktat zu isolieren [1, 2]. Dabei sollten stets möglichst große Volumina bzw. mehrere Proben (mindestens 50-100 ml) verwendet werden [1 - 3]. Aszites aus einer Drainage sollte nicht mehr als wenige Stunden gesammelt werden, um die Gefahr der bakteriellen Kontamination und damit der Autolyse zu minimieren [2]. Bei großer Menge an Punktionsflüssigkeit oder bei Drainageflüssigkeit sollte jeweils die letzte gewonnene Fraktion eingesendet werden, da diese den höheren Zellgehalt an vitalen Zellen aufweist [3]. Der Versand sollte möglichst zügig und nativ in sterilen, bruchsicheren und dicht schließenden Gefäßen erfolgen, unter diesen Bedingungen ist die Ergussflüssigkeit zwei bis drei Tage haltbar, ohne dass die Zellen morphologisch und immunologisch Schaden nehmen [1]. Ist der Transport z. B. aus Infrastrukturgründen nicht möglich, sollte das Punktat ca. eine Stunde lang an einem erschütterungsfreien Ort zum Sedimentieren stehen gelassen werden und anschließend der Sedimentanteil in $100 \mathrm{ml}$ nativer Ergussflüssigkeit eingesandt werden bzw. bei $4^{\circ} \mathrm{C}$ gelagert werden [2]. Da seröse Flüssigkeiten gute Nährmedien sind, halten sich die Zellen darin bis zu $24 \mathrm{~h}$ bei Raumtemperatur, bei $4{ }^{\circ} \mathrm{C}$ auch bis zu $48 \mathrm{~h}$ [2]. Wichtig für eine treffsichere zytologische Diagnostik ist die Mitteilung wesentlicher klinischer Befunde wie Herzinsuffizienz und therapeutischer Maßnahmen wie z. B. Chemo- oder Strahlentherapie [1]. Lavageflüssigkeiten (z. B. intraoperative Abdominallavage) sollten als solche gekennzeichnet werden [2].

\section{Technische Bearbeitung im Labor}

Bei geringen Ergussvolumina oder klaren Transsudaten bzw. bei resuspendierten zellarmen Sedimenten, bei denen eine geringe Zellzahl zu erwarten ist, können Zytozentrifugenpräparate angefertigt werden [1]. Größere Flüssigkeitsmengen sollten in Portionen von $50-1000 \mathrm{ml}$ bei $1500-2500$ Umdrehungen pro min $(700 \mathrm{~g})$ zehn min zentrifugiert werden. Muss das Punktat aufgeteilt werden, sollten die Sedimente gemischt und nochmals zentrifugiert werden. Befinden sich Gewebspartikel oder Präzipitate bzw. Fibrinflocken im Erguss, sollten diese in Paraffin eingebettet werden [2]. Hiervon können dann gefärbte Paraffinschnitte angefertigt werden [1]. Die zytologische Diagnostik erfolgt an May-Grünwald-Giemsa (MGG)-Präparaten; andere Färbemethoden werden kontrovers diskutiert [1, 2]. Eine Eisenfärbung kann zusätzlich zum Nachweis Hämosiderin-speichernder Makrophagen, eine PAS-Färbung bei V.a. eine Infiltration durch ein monozellulär schleimbildendes Karzinom durchgeführt werden [2]. Eine Gramfärbung ist in der Regel nicht indiziert, da die Keimkonzentration meist zu gering ist, sodass nur in Einzelfällen ein Keimnachweis gelingt [6].

\section{Standardisierte lichtmikroskopische Beurteilung}

Die Befundung sollte standardisiert nach der unten folgenden - von den Deutschen Gesellschaften für Pathologie und Zytologie erarbeiteten - Nomenklatur für die extragenitale Zytologie erfolgen $[11-14]$ :

1. Angabe des eingesandten Untersuchungsmaterials, ggf. auch der klinischen Verdachtsdiagnose laut Begleitschein.

2. Beschreibung des erhaltenen Untersuchungsmaterials

(Typ, Makroskopie/Farbe, Menge).

3. Beschreibung der Zellbilder, ggf. mit Hinweisen auf Erhaltungszustand und Repräsentativität. 
4. Stufung der Malignitätswahrscheinlichkeit

- bösartige Zellen nicht nachweisbar (negativ) (0\%)

- bösartige Zellen nicht auszuschließen (zweifelhaft) (ca. 30\%)

- bösartige Zellen wahrscheinlich (dringender Verdacht) (ca. $60 \%$ )

- bösartige Zellen nachweisbar (positiv) (100\%)

- unzureichendes Untersuchungsmaterial (mit Begründung: nekrotische, autolytische und osmotisch geschädigte Zellen)

5. Diagnose im Klartext, möglichst unter Verwendung von „preferred terms“ der ICD-O-M bzw. des SNOMED, ggf. Angabe von Ausschlussdiagnosen, evtl. Hinweis auf mangelhafte Repräsentativität, unzureichenden Erhaltungszustand oder Präparationsartefakte. Weiterhin Kommentare, Empfehlungen, Stellungnahme zu klinischen Fragestellungen. Die Papanicolaou (Pap)-Klassifikation eignet sich nicht für die extragenitale Zytodiagnostik und sollte nicht verwendet werden [14].

\section{Etablierte Zusatztechniken}

Bei malignitätsverdächtigen oder nicht eindeutigen Befunden können zusätzliche immunzytochemische bzw. immunhistochemische (nach Anfertigen eines Zellblocks) Untersuchungen durchgeführt werden, um die Treffsicherheit der zytologischen Untersuchung zu erhöhen. Dabei können auch geringe Anzahlen von Karzinomzellen durch den Nachweis epithelspezifischer Antigene wie BerEP4 identifiziert werden.

\section{Treffsicherheit}

Die konventionelle Ergusszytologie besitzt eine Sensitivität von $58 \%$, eine Spezifität von $97 \%$ und einen mittleren positiven Prädiktionswert von $99 \%$ sowie einen negativen Prädiktionswert von $80 \%$.

Ca. $5 \%$ der zytologischen Diagnosen sind zweifelhaft/unklar. Eine Wiederholung der Ergussgewinnung kann die diagnostische Treffsicherheit jedoch erhöhen [15]. Spezifische Zusatzmethoden können nicht empfohlen werden.

\subsection{Aszitespunktion und Substitution von Gerinnungsfaktoren}

\section{EMPFEHLUNG 1.9}

Eine Substitution von Plasmaderivaten vor Aszitespunktion soll unabhängig von dem Schweregrad der Gerinnungseinschränkung nicht durchgeführt werden.

Starke Empfehlung, starker Konsens

Eine Ausnahme bildet die disseminierte intravasale Gerinnungsstörung (DIC). Hier sollte eine gezielte Substitution der einzelnen Faktoren nach Gerinnungsanalyse erfolgen. Empfehlung, starker Konsens

\section{EMPFEHLUNG 1.10}

Bei einer hochgradigen Thrombozytopenie $<20000 /$ ul kann eine prophylaktische Thrombozyten-Transfusion vor Aszitespunktion durchgeführt werden, ansonsten soll keine prophylaktische Transfusion von Thrombozytenkonzentraten erfolgen. Empfehlung offen, starker Konsens

\section{Kommentar}

Die Studienlage zu Blutungskomplikationen nach Aszitespunktionen bei Leberzirrhose zeigt ein insgesamt sehr niedriges Blutungsrisiko unabhängig vom eingeschränkten Gerinnungsstatus bei chronischer Lebererkrankung.

Die üblichen Gerinnungsanalysen geben das Blutungsrisiko von Patienten mit einer Leberzirrhose nicht wieder, da meist ein ausgewogener Abfall aller Parameter vorliegt, der die Koagulation des Blutes nicht beeinträchtigt oder sogar teilweise eine Hyperkoagulabilität vorliegt $[16,17]$.

In einer Studie mit 1100 Aszitespunktionen zeigten sich keine Blutungskomplikation trotz i) fehlender prophylaktischer Substitution von Gerinnungsfaktoren, ii) minimaler Thrombozytenzahl $<19000 /$ ul $(54 \%<50000 /$ ul) und iii) INR für die Prothrombinzeit bis $8,7(75 \%>1,5$ und $26,5 \%>2,0)$ [18]. Die Aszitespunktion war auch in anderen Studien bei Patienten mit verlängerter PTT (bis 2-mal oberer Normwert) oder niedrigen Thrombozytenzahlen (Minimum $50000 /$ ul) sicher [19, 20]. In der oben genannten Studie traten auch bei noch ausgeprägteren Thrombozytopenien (Minimum 19000/ul keine Blutungskomplikationen auf [18]. Eine weitere Studie zeigte eine niedrige Blutungsrate von 0,99\% bei Ultraschall-gesteuerten Aszitespunktionen bei Patienten mit einer Thrombozytopenie mit mittleren Werten von 38 400/ul auf [21].

Die prophylaktische Substitution von Blutprodukten (Thrombozytenkonzentrate, Fresh Frozen Plasma (FFP), Gerinnungsfaktoren) wird daher im Allgemeinen vor einer Parazentese nicht empfohlen - eine Ausnahme kann die disseminierte intravasale Gerinnungsstörung (DIC) sein [19].

Die Querschnitts-Leitlinie der Bundesärztekammer zur Therapie mit Blutkomponenten und Plasmaderivaten (4. überarbeitete und aktualisierte Auflage 2014) gibt keine spezielle Empfehlung bezüglich einer Thrombozytenkonzentrat-Transfusion bei bestehender portal-hypertensiver Thrombozytopenie vor einer Aszitespunktion [22]. Sie empfiehlt jedoch eine Thrombozyten-Transfusion bei einer Thrombozytenzahl kleiner $20000 /$ ul bei invasiven Prozeduren wie Lumbalpunktion, Gelenkpunktion, transjuguläre Leberbiopsie, Bronchoskopie mit Biopsie oder gastrointestinaler Endoskopie mit Biopsie. Diese Prozeduren haben zwar ein höheres Blutungsrisiko als eine Aszitespunktion [23], bei fehlender Datenlage bezüglich des Blutungsrisikos einer Aszitespunktion bei einer Thrombozytenzahl kleiner $20000 /$ ul sollte diese Empfehlung dennoch analog auf die Aszitespunktion übertragen werden.

Eine Substitution von Plasmaderivaten vor Aszitespunktion empfiehlt die Querschnitts-Leitlinie der Bundesärztekammer bei chronischem Leberschaden nicht. Dies entspricht der amerikanischen Leitlinie zur Aszitespunktion, die ebenfalls zum einen keine Substitution von Gerinnungsfaktoren und zum anderen keine zusätzliche Gerinnungsanalyse vor Punktion empfiehlt [24].

Zusammenfassend konnte die Datenlage kein erhöhtes Blutungsrisiko nach Aszitespunktion adaptiert nach dem Schweregrad der eingeschränkten Gerinnung zeigen [22].

Analog empfiehlt die europäische Gesellschaft für Ultraschalldiagnostik (EFSUMB) ebenfalls keine Grenzen für Gerinnungswerte vor Ultraschall-gesteuerten Organ-Feinnadelpunktionen [25]. Eine explizite Empfehlung bei Aszitespunktionen gibt es allerdings nicht, jedoch besteht auch hier ein deutlich geringeres Blutungsrisiko als bei Organpunktionen [23]. 
Bislang gibt es keine ausreichenden Daten, die den zusätzlichen Einsatz von Thrombelastometrie-Untersuchungen wie z. B. der ROTEM-Analyse mit der Frage nach Notwendigkeit einer Gerinnungssubstitution vor Aszitespunktion rechtfertigen. Vielmehr zeigen Daten, dass die Ergebnisse der ROTEM-Analyse bei Patienten mit Leberzirrhose eher zu einer unnötigen Transfusion von FFPs führen können [26].

Zusammenfassend ist bei niedrigem Blutungsrisiko der Aszitespunktion und veränderter Gerinnungssituation bei chronischem Leberschaden mit zusätzlicher Hyperkoagulabilität trotz Verringerung der Gerinnungsparameter keine Substitution von Plasmaderivaten oder Transfusion von Thrombozytenkonzentraten mit Ausnahme des Zustandes der DIC notwendig. Bei einer Thrombozytopenie von weniger als $20000 / u l$ kann eine prophylaktische Transfusion durchgeführt werden.

\subsection{Aszitespunktion unter Antikoagulation}

\section{EMPFEHLUNG 1.11}

Die Therapie mit Acetylsalicylsäure vor einer Aszitespunktion sollte fortgesetzt werden. Eine Therapie mit Thienopyridinen oder Glykoprotein-IIb/IIla-Inhibitoren sollte vor einer Aszitespunktion pausiert werden.

Empfehlung, starker Konsens

Ergibt sich jedoch aus der Dringlichkeit des Eingriffs wie der Verdacht auf eine spontan bakterielle Peritonitis oder des ansonsten bestehenden hohen zerebrovaskulären Embolierisikos die Notwendigkeit, diesen unter der entsprechenden Medikation durchzuführen, so kann unter der bestehenden Thrombozytenaggregationshemmung eine Punktion erfolgen, sodass die Diagnostik nicht verzögert wird.

Empfehlung offen, starker Konsens

Der Patient soll über das entsprechend erhöhte Blutungsrisiko aufgeklärt werden.

Starke Empfehlung, starker Konsens

\section{EMPFEHLUNG 1.12}

Eine Antikoagulation mit Vitamin-K-Antagonisten oder direkten oralen Antikoagulantien (DOAKs) sollte vor Aszitespunktion - wenn möglich - pausiert werden.

Empfehlung, starker Konsens

Ergibt sich jedoch aus der Dringlichkeit des Eingriffs wie der Verdacht auf eine spontan bakteriellen Peritonitis oder des ansonsten bestehenden hohen cerebrovaskulären Embolierisikos die Notwendigkeit diesen unter der entsprechenden Medikation durchzuführen, so kann unter der bestehenden Antikoagulation eine Punktion erfolgen.

Empfehlung offen, starker Konsens

\section{Kommentar}

Insgesamt gibt es nur sehr wenige Daten zum Blutungsrisiko unter Antikoagulation und unter Thrombozytenaggregationshemmung bei Aszitespunktionen.

\section{Orale Antikoagulanzien}

Es existieren hauptsächlich Daten zum Blutungsrisiko bei Punktionen solider abdomineller Tumoren und parenchymatöser Organe unter einer Antikoagulation mit oralen Antikoagulanzien (Vitamin-K-Antagonisten bzw. DOAKs). Die Blutungsrate bei Aszitespunktion ist generell niedriger als bei Punktionen parenchymatöser Organe [23]. In einer multizentrisch angelegten Studie der Deutschen Gesellschaft für Ultraschall in der Inneren Medizin (DEGUM) wurde das Blutungsrisiko von 8172 Ultraschall-gesteuerten abdominellen Punktionen untersucht. Hier zeigte sich eine insgesamt niedrige Blutungskomplikationsrate: in 0,4\% bedurfte es einer Transfusion, in 0,1\% eines operativen Eingriffs und in $0,05 \%$ eines radiologischen Coilings. Trotz der insgesamt niedrigen Blutungskomplikationsrate zeigte die Studie jedoch eine signifikant höhere Blutungsrate bei einem INR-Wert > 1,5 [27].

Eine Studie von Devarbhavi et al. fand kein erhöhtes Blutungsrisiko nach Aszitespunktion unter fortlaufender Antikoagulation mit Vitamin-K-Antagonisten bei Patienten mit Budd-ChiariSyndrom [28].

\section{Thrombozytenaggregationshemmer}

Für abdominelle bioptische Interventionen ist bekannt, dass das Risiko für Blutungen bei Patienten mit Thrombozytenaggregationshemmern oder Medikamenten mit Wirkung auf die Plasmakoagulation erhöht ist. Bei diagnostischer Punktion sollte daher eine entsprechende Medikation pausiert werden, vorausgesetzt das Absetzen der Medikamente birgt kein unverhältnismäßig hohes Risiko für thromboembolische Ereignisse. Hierzu zählen u. a. Patienten nach Koronar-Intervention, Implantation von künstlichen Herzklappen oder die Antikoagulation bei Vorhofflimmern mit hohem Risiko-Score.

Bei einer retrospektiven Analyse von über 15000 bildgebend gesteuerten Punktionen bei Patienten mit ASS war die Rate an Blutungskomplikationen im Vergleich zu knapp 12000 Patienten ohne ASS nicht signifikant erhöht (0,6 vs. $0,4 \%$; $p=0,34)$ [29].

Die Leitlinie der European Federation of Societies for Ultrasound in Medicine and Biology (EFSUMB) zum interventionellen Ultraschall bezieht sich auf therapeutische Punktionen und gibt keine Empfehlung bezüglich des Absetzens von Antikoagulanzien und Thrombozytenaggregationshemmern vor Aszitespunktionen [25].

Die Society of Interventional Radiology (SIR) empfiehlt das Pausieren von Acetylsalicylsäure nur bei Punktionen mit erhöhtem Blutungsrisiko (z. B. Nierenpunktion, Gallengangsintervention, Nephrostomieanlage, komplexe Radiofrequenzablation u. a.). Dabei wird die Aszitespunktion nicht namentlich genannt, sie zählt aber zu den Eingriffen mit einem niedrigen Blutungsrisiko $[30,31]$. Sie empfiehlt weiter für Thienopyridine und Glykoprotein-IIb/IIla-Inhibitoren oder direkte Thrombininhibitoren ein Pausieren für Punktionen von soliden Tumoren. Vitamin-K-Antagonisten sollten ebenfalls pausiert werden [25].

In Anlehnung an die S2k-Leitlinie Qualitätsanforderungen an die gastrointestinale Endoskopie wird ein Pausieren der Thrombo- 
zytenaggregationshemmung fünf Tage vor dem Eingriff und eine früheste Wiedereinnahme nach der Punktion von 24 Stunden empfohlen [32].

\section{Risikostratifizierung vor einer Aszitespunktion}

Die deutsche Leitlinie für Qualitätssicherung in der Endoskopie [32] und die amerikanische Gesellschaft für Endoskopie (American Society of Gastrointestinal Endoscopy [ASGE]) unterteilen gastrointestinale endoskopische Interventionen unter Antikoagulation in zwei Risikokonstellationen [33]. Eine Entscheidung bezüglich des Fortsetzens oder Pausierens der Antikoagulation geschieht durch Definition des jeweiligen Falls in eine dieser zwei Risikogruppen. Zum einen wird das kardio- und zerebrovaskuläre Risiko in niedrig und hoch gruppiert. Beispielhaft ist das Risiko eines thromboembolischen Ereignisses nach Absetzen der Antikoagulation bei mechanischer Mitralklappe als hoch einzustufen. Es wird an dieser Stelle auf die S2k-Leitlinie Qualitätssicherung in der Endoskopie bezüglich der Risikobewertung für zerebro-/kardiovaskuläre Ereignisse verwiesen [32]. Die andere Risikokonstellation bezieht sich auf das Blutungsrisiko des jeweiligen endoskopischen Eingriffes. Hier wird ebenfalls in hoch und niedrig eingeteilt. Die deutsche S2k-Leitlinie zur Qualitätssicherung in der Endoskopie bewertet im Einzelnen das Blutungsrisiko endoskopischer Interventionen [32]. Jedoch wird in dieser keine Stellung zu der Aszitespunktion und deren Risikobewertung genommen. Bei endoskopischen Interventionen mit niedrigem Blutungsrisiko wie beispielhaft die Biopsie im Rahmen einer Ösophagogastroduodenoskopie oder Koloskopie wird kein Pausieren der Antikoagulation bei bestehender Dringlichkeit des Eingriffes unabhängig von dem Risiko des thromboembolischen Ereignisses empfohlen. Besteht diese Dringlichkeit nicht und handelt es sich um einen elektiven Eingriff sollte - wenn kardio-/zerebrovaskulär vertretbar - die Antikoagulation pausiert werden. Der Patient ist über beide Risiken - der Blutung und des thromboembolischen Ereignisses aufzuklären. Eine solche Strategie ist analog auf das Vorgehen vor Aszitespunktion bei antikoagulierten Patienten zu übertragen.

\subsection{Technik der Aszitespunktion}

\section{EMPFEHLUNG 1.13}

Die Parazentese soll nach Aufklärung des Patienten unter sterilen Bedingungen durchgeführt werden. Starke Empfehlung, starker Konsens

\section{EMPFEHLUNG 1.14}

Die Punktion soll sonografisch-assistiert (nach vorheriger sonografischer Detektion) oder sonografisch-gezielt (unter permanenter Sicht der Nadel) durchgeführt werden. Ausnahme ist die wiederholte großvolumige Punktion mit gleichbleibendem Punktionsort.

Starke Empfehlung, starker Konsens

\section{EMPFEHLUNG 1.15}

Eine Venenverweilkanüle oder eine andere Punktionskanüle soll an geeigneter Stelle (typische Stelle: linker unterer Quadrant des Abdomens) durch die Bauchdecke in den Aszites vorgeschoben werden.

Starke Empfehlung, starker Konsens

\subsection{Kontraindikationen für eine Aszitespunktion}

\section{EMPFEHLUNG 1.16}

Absolute Kontraindikationen für eine Aszitespunktion sind außer einer fehlenden Einverständniserklärung des Patienten ein fehlender Zugangsweg zum Aszites oder eine fehlende diagnostische oder therapeutische Konsequenz. Das Vorliegen einer disseminierten intravasalen Koagulopathie (DIC) ist mit einem erhöhten Blutungsrisiko assoziiert und daher als relative Kontraindikation abzuwägen.

Starke Empfehlung, starker Konsens

\section{Kommentar}

Unter dem Begriff der Aszitespunktion versteht man die Gewinnung von Flüssigkeit aus dem Peritonealraum mit diagnostischer oder therapeutischer Intention. Nach den allgemein geltenden Richtlinien für Krankenhaushygiene und Infektprävention gilt eine Aszitespunktion als invasive Maßnahme und soll daher unter sterilen Bedingungen erfolgen [34]. Die Komplikationsrate einer Aszitespunktion ist als gering einzuschätzen, dennoch ist jeder Patient vor Punktion über mögliche Komplikationen aufzuklären. Zur diagnostischen Punktion können dünnkalibrige Kanülen gewählt werden. Bei der therapeutischen Punktion des Aszites können Venenverweilkanülen [35], 17-G-Metall-Kanülen [36], Pigtailkatheter [37] oder weitere speziell entwickelte Punktionsnadeln mit mehreren Seitenlöchern [38] eingesetzt werden. In Deutschland werden für die Parazentese meist Venenverweilkanülen eingesetzt. Nachteile sind eine geringe Knickstabilität, nur eine Öffnung am Distalende, was zu häufigeren Repositionen führen kann, sowie schwierige Befestigungsmöglichkeiten an der Bauchdecke [35]. Vorteile sind jedoch die generelle Verfügbarkeit und die geringen Kosten. Vor Durchführung der Parazentese erfolgt die Aufklärung des Patienten über den Eingriff. Vor einer diagnostischen Aszitespunktion soll eine Sonografie des Abdomens durchgeführt werden, um die Aszitesmenge zu definieren, den Aszites zu beurteilen (z. B. Fibrinfäden, diffuse Binnenechos), einen optimalen Zugangsweg zu finden und große Bauchwandkollateralen im Punktionsweg auszuschließen [39].

Die Aszitespunktion ist sonografisch assistiert oder sonografisch gezielt (permanente Sicht der Nadel) möglich, hierdurch ist in der Regel eine Fehlpunktion zu vermeiden. Ausnahme ist dabei die wiederholte, großvolumige Aszitespunktion mit gleichbleibendem Punktionsort - hier kann auf die sonografische Beurteilung verzichtet werden.

Bei geringer Punktatmenge kann die Punktion unter direkter sonografischer Steuerung durchgeführt werden [39, 40]. Der Ult- 
raschall erlaubt nicht nur, Fehlpunktionen zu vermeiden [39] und die optimale Punktionsstelle zu finden [40], sondern auch eine Einschätzung des Aszitesvolumens [41, 42]. In einer Studie war die Aszitesausdehnung im linken lateralen unteren Quadranten des Abdomens bei Linksschräglage ausgeprägter als infraumbilical in Rückenlage [40]. Der rechte untere Quadrant des Abdomens kann grundsätzlich auch als Punktionsstelle aufgesucht werden, hat aber den Nachteil eines

z. B. unter Laktulosegabe evtl. geblähten Zökums oder einer Narbe nach Appendektomie mit der Gefahr einer Darmperforation. Weiterhin sollte die Punktionsstelle unter Berücksichtigung des mutmaßlichen Verlaufs der epigastrischen Gefäße erfolgen. „Blindpunktionen“ sollten bei Verfügbarkeit eines Ultraschallgerätes in der Regel nicht durchgeführt werden [39, 40]. Ausnahmen können kurzfristig wiederholte therapeutische Parazentesen bei massivem Aszites unter Beachtung der vormaligen Punktionsstellen darstellen. Eine sonografisch-assistierte Punktion verringert das Blutungsrisiko (0,8\%) um 68\% - nach der Analyse einer großen retrospektiven Analyse [43]. Daten zu einer sonografischassistierten Punktion mit zusätzlicher Doppler-Funktion zur eventuellen Detektion von Gefäßen innerhalb des Punktionsweges gibt es nicht. Es kann möglicherweise eine weitere Reduktion der bereits geringen Blutungsrate bewirken und kann im Einzelfall verwendet werden.

Der Einstich erfolgt unter sterilen Bedingungen mit oder ohne vorherige lokale Anästhesie. Zur Vermeidung einer Fistelbildung werden ein schräger Einstich im $45^{\circ}$-Winkel oder die „Z-Durchstichtechnik“ empfohlen.

\subsection{Komplikationen nach Aszitespunktion}

Diagnostische Aszitespunktionen sind nicht mit schwerwiegenden und häufigen Komplikationen verbunden, eine höhere Komplikationsrate besteht bei den therapeutischen Punktionen [4446]. Die häufigste Komplikation der therapeutischen Parazentesen ist mit $5 \%$ ein protrahierter Austritt von Aszites durch den Stichkanal [44]. Dies kann durch Lagerung des Patienten auf die dem Stichkanal gegenüberliegende Seite, Wahl eines schrägen Stichkanals oder der Z-Durchstichtechnik, vollständigen Ablassens des Aszites oder ggf. eine Tabaksbeutelnaht verhindert werden $[18,44]$. Eine Peritonitis oder ein Bauchdeckenabszess nach Darmperforation fand sich jeweils nur bei einem von 242 Parazentesen [47].

Blutungen (Einblutungen in die Bauchdecke oder intraperitoneale Blutungen) sind neben der oben genannten Fistelbildung die häufigsten Komplikationen, aber mit 0,19-1\% der Parazentesen selten [47 - 50].

Eine große retrospektive Analyse von 69859 Parazentesen hat einen durchschnittliche Blutungsrate von $0,8 \%$ gezeigt. In dieser Analyse konnte weiterhin gezeigt werden, dass eine sonografisch-assistierte Punktion das Blutungsrisiko senkt (siehe Abschnitt Technik der Aszitespunktion).

Nur kasuistisch wurden lebensbedrohliche Blutungsereignisse $(0,016 \%)$ beschrieben [51]. Ein stark erhöhter Kreatininwert (>6 mg/dl) wurde als Risikofaktor für eine Blutungskomplikation beschrieben [20], insgesamt hatten $70 \%$ der Patienten mit Blutungskomplikationen nach Aszitespunktion einen Kreatininwert
$>1,2 \mathrm{mg} / \mathrm{dl}$ bzw. eine GFR von $<60 \mathrm{ml} / \mathrm{min}$ [52], sodass in diesen Fällen eine intensivere Nachsorge nach Aszitespunktion erforderlich ist.

Typischerweise kommt es durch die Fehlpunktion einer oberflächlich gelegenen Bauchhautvene, mesenterischer Varizen oder der inferioren epigastrischen Arterie zu Blutungen. In Zusammenschau der Literatur sind drei Arten der hämorrhagischen Komplikation zu nennen: Bauchwand-Hämatome (52\%), Hämoperitoneum (41\%) und Pseudoaneurysmen (7\%) [53].

Das Vorliegen einer disseminierten intravasalen Koagulopathie (DIC) wird in der Regel als relative Kontraindikation dargestellt.

\subsection{Weitere Untersuchungen bei initialer Aszitespunktion}

\section{EMPFEHLUNG 1.17}

Bei der initialen Aszitespunktion soll die Zellzahl mit Zelldifferenzierung sowie das Gesamteiweiß im Aszites bestimmt und eine mikrobiologische Kultur angelegt werden.

Starke Empfehlung, starker Konsens

Der Serum-Aszites-Albumin-Gradient (SAAG: Bestimmung von Albumin im Aszites und Serum) kann bei der initialen Aszitespunktion zur Differenzierung zwischen portal-hypertensivem und nicht-portal-hypertensivem Aszites bestimmt werden.

Empfehlung offen, starker Konsens

\section{EMPFEHLUNG 1.18}

Eine Beimpfung von aeroben und anaeroben Blutkulturflaschen mit mindestens $10-20 \mathrm{ml}$ Aszitesflüssigkeit pro Kulturflasche sollte bei der initialen Aszitesdiagnostik, bei stationären Patienten sowie bei Verdacht auf eine spontan bakterielle Peritonitis (SBP) erfolgen. Dies sollte unmittelbar am Patientenbett unter sterilen Bedingungen durchgeführt werden.

Empfehlung, starker Konsens

EMPFEHLUNG 1.19

Eine zusätzliche Bestimmung der Cholesterin- und CEA-Spiegel im Aszites kann zur Differenzierung maligner/nicht-maligner Aszites durchgeführt werden.

Empfehlung offen, starker Konsens

\section{EMPFEHLUNG 1.20}

Die Bestimmung des Serum-Aszites-Albumin-Gradienten (SAAG) ist im Regelfall bei Folgepunktionen nicht erforderlich. Empfehlung offen, starker Konsens 


\section{EMPFEHLUNG 1.21}

In der Diagnostik der SBP soll nicht die Anwendung von Leukozytenstreifen (sog. Urinstix) zum semiquantitativen Nachweis von Leukozyten im Aszites als alleiniges Nachweisverfahren verwendet werden. Die Bestimmung von bakterieller DNA im Aszites soll nicht als alleiniger Erregernachweis verwendet werden.

Starke Empfehlung, starker Konsens

\section{Kommentar}

\section{Zellzahl/-differenzierung}

Eine Zellzählung und -differenzierung im Aszites sollte bei jeder initialen Aszitespunktion erfolgen. Sie ist eine valide und schnelle Untersuchung. Dabei gilt eine Gesamtzellzahl > 500/ul als diagnostischer Hinweis auf eine SBP bzw. sekundäre Peritonitis [10]. Die Zelldifferenzierung ist jedoch der „Goldstandard“ in der Diagnostik der SBP. Dabei ist das diagnostische Kriterium für eine SBP eine $\mathrm{Er}$ höhung der segmentkernigen Granulozyten > 250/ul [54 - 56]. Eine maschinelle Zelldifferenzierung ist gegenüber der manuellen Differenzierung, die zeit- und personalaufwendig ist, gleichwertig [10]. Die Erythrozytenzahl im Aszites ist meist niedrig (<1000/ul). Bei hämorrhagischem Aszites (Erythrozyten > 50 000/ul) kann es zu einer falsch hohen Zellzahl kommen. Hier sollte ein Korrekturfaktor für eine sonstige Zellzählung wie folgt angewendet werden: Subtraktion der Granulozytenzahl um jeweils 1 pro 250 Erythrozyten/ul [54]. Lymphozytärer Aszites mit einem Überwiegen des Lymphozytenanteils ist häufig bei Lymphomen, aber auch bei abdomineller Tuberkulose zu finden. Zur weiteren Differenzierung sind zusätzliche immunzytochemische bzw. -histochemische oder mikrobiologische Untersuchungen hilfreich.

\section{Gesamteiweiß im Aszites}

Ein niedriges Gesamteiweiß $(<1,5 \mathrm{~g} / \mathrm{dl})$ im Aszites korreliert mit einer geringen Opsonierungsfähigkeit, die mit einer höheren Inzidenz einer SBP einhergeht und damit potenziell zur Identifikation von Patienten für eine primär prophylaktische AntibiotikaGabe verwendet werden kann [57-60].

\section{Serum-Aszites-Albumin-Gradient (SAAG)}

Die Bestimmung des SAAG (Differenz zwischen der Albuminkonzentration im Serum und im Aszites) kann hilfreich sein zur Differenzierung zwischen portal-hypertensiver und nicht-portal-hypertensiver Genese des Aszites und sollte daher bei der initialen Punktion bestimmt werden. Dabei soll die Bestimmung der beiden Werte (Albumin im Aszites und im Blut) am selben Untersuchungstag erfolgen [61]. Ein SAAG >1,1 g/dl spricht mit einer Treffsicherheit von $97 \%$ für eine portale Hypertension als Ursache des Aszites [62], während ein Gradient < 1,1 g/dl zu etwa $95 \%$ auf eine andere Ursache des Aszites hinweist (Peritonealmetastasen, Pankreatitis, Tuberkulose, Myxödem) [61, 62]. Die Bestimmung des SAAG und des Gesamteiweißes im Aszites kann zur Differenzierung des kardialen Aszites herangezogen werden: Bei kardialer Ursache des Aszites ist der SAAG ebenfalls $>1,1 \mathrm{~g} / \mathrm{dl}$, da es sich hierbei um ein Filtrat handelt. Die Eiweißkonzentration ist jedoch in der Regel bei kardialem Aszites > 2,5 g/dl, bei zirrhotischem Aszites < 2,5 g/dl63.

\section{Mikrobiologische Diagnostik}

Bei Patienten mit Aszites in ambulanter Behandlung mit stabilem Verlauf sind wiederholte diagnostische Untersuchungen im Aszites nicht notwendig, da die Prävalenz von Infektionen sehr niedrig ist (etwa 2\%) [58-61]. Bei Verdacht auf infektiösen Aszites beinhaltet die Diagnostik als grundlegende Untersuchung neben der Zellzahl mit Differenzierung auch die Beimpfung von Bakterienkulturflaschen mit Aszitespunktat. Das positive Ergebnis der Bakterienkultur beweist zum einen die bakterielle Besiedlung des Aszites und gibt Hinweise auf eine evtl. vorliegende Infektion, zum anderen kann nach Antibiogramm gezielt antibiotisch therapiert werden. In prospektiven Studien konnte eine höhere Sensitivität der Bakterienkultur gezeigt werden, wenn a) die Kulturflaschen direkt am Bett des Patienten beimpft werden und b) mindestens $10 \mathrm{ml}$ Punktat beimpft werden [64-66]. Allerdings liegen selbst bei dieser Methodik häufig negative Kulturergebnisse vor: Nur bei 36-59\% der Patienten mit einer SBP nach Goldstandard (segmentkernige Granuloyzten > 250/ul) kann eine bakterielle Besiedlung durch die Bakterienkultur nachgewiesen werden [65 -68]. Ursächlich für die niedrige Zahl positiver Kulturergebnisse ist wahrscheinlich die geringe Konzentration von Bakterien in der Aszitesflüssigkeit, im Gegensatz zu anderen Körperflüssigkeiten wie z. B. im Urin [66]. In mehreren teilweise multizentrischen Studien wurde untersucht, ob durch den Einsatz von Teststreifen, die primär für die Urinanalyse entwickelt wurden, die Diagnose einer SBP schnell und zuverlässig gestellt werden kann. Das Prinzip basiert auf einer Farbreaktion, die durch Leukozytenesterase bei entsprechender Leukoyztenkonzentration im Punktat abläuft. Diese Studien zeigten, dass die diagnostische Methode der Teststreifen eine Sensitivität von 64,7 - 100\% und eine Spezifität von $99-100 \%$ besitzt [53, 69-73]. Vorteile sind ein rasches Ergebnis, eine hohe Verfügbarkeit, eine einfache Handhabung und niedrige Kosten. In einer aktuellen multizentrischen Studie wurde bei 1041 stationären und ambulanten Patienten mit Leberzirrhose und Aszites der Einsatz von Urin-Teststreifen zur Diagnostik der SBP mit der Frage nach Sensitivität und Spezifität dieses Testverfahrens erneut untersucht. Es zeigte sich hier eine deutlich geringere Sensitivität von nur 45,3\% bei einer Spezifität von 99,2\% [74], sodass nach diesen Ergebnissen und bestätigendem Ergebnis einer vergleichbaren Studie [75] sowie nach einer systematischen Analyse aller Studien [76] die Teststreifen lediglich als mögliche Ergänzung zur üblichen Aszitesdiagnostik verwendet werden sollten, wenn ein klinisch-chemisches Labor nicht unmittelbar zur Verfügung steht.

Der Nachweis von bakterieller DNA im Aszites mittels PCR-Verfahren gelingt [77]. Dabei ist jedoch nicht zu differenzieren, ob diese von lebenden oder toten Bakterien oder nur von bakteriellen Bestandteilen anders als bei einem positiven Nachweis einer Bakterienkultur stammt. Die kontroverse Datenlage zeigt keine eindeutige Korrelation zwischen dem Nachweis bakterieller DNA im Aszites und dem Vorhandensein einer SBP nach diagnostischem Goldstandard [78, 79]. Eine prognostische Signifikanz des Nachweises bakterieller DNA konnte die Studienlage ebenfalls nicht klar zeigen $[79,80]$.

Eine zusätzliche Bestimmung bakterieller DNA im Aszites im Rahmen der Diagnostik der SBP wird nicht empfohlen, da es zum aktuellen Zeitpunkt keine ausreichende Datenlage zur klinischen 
Aussagekraft gibt, es ein kostenintensives Verfahren darstellt und nicht ubiquitär in der Routinediagnostik verfügbar ist.

CEA- und Cholesterin-Bestimmung in der Diagnostik des malignen Aszites

Maligner Aszites ist die zweithäufigste Ursache des Aszites und sollte daher in der Diagnostik frühzeitig in Betracht gezogen werden. Standard in der Diagnostik des malignen Aszites ist die zytologische Untersuchung des Aszites (siehe 1.3).

Die Bestimmung von Cholesterin und CEA im Aszites stellen zusätzliche Parameter in der Differenzierung zwischen malignem und nicht malignem Aszites dar [81, 82].

Die Konzentration von Cholesterin im Aszites kann in der diagnostischen Sequenz zur Differenzierung maligne/nicht maligne hilfreich sein (Normwert im Aszites < 45 mg/dl) [82 - 84]. Für diesen Parameter konnte eine Sensitivität bis zu 91 \% und eine Spezifität bis zu $95 \%$ gezeigt werden [82]. Bei einem Cholesterinwert $>45 \mathrm{mg} / \mathrm{dl}$ sollten als weitere diagnostische Schritte eine zytologische Untersuchung des Aszites und eine CEA-Bestimmung im Aszites erfolgen $[81,85]$. Diese diagnostische Kombination erreicht dann einen positiven Vorhersagewert von $92 \%$ [86]. Die CEA-Bestimmung im Aszites alleine hat bei einem Cut-off-Wert von $>5 \mathrm{ng} / \mathrm{ml}$ eine Sensitivität von nur $51 \%$ [85]. Zusammen mit der zytologischen Diagnostik steigt diese auf $80 \%$ bei gleichbleibender Spezifität von $100 \%$ [81].

\subsection{Sekundäre Peritonitis}

\section{EMPFEHLUNG 1.22}

Der Verdacht auf eine sekundäre Peritonitis sollte bei Nachweis von mehr als einer Erregerspezies - auch von Anaerobiern und Pilzen, neu aufgetretenen abdominellen Beschwerden, Nichtansprechen auf eine antibiotische Therapie nach $48 \mathrm{~h}$, stark erhöhter Zellzahl oder einer Eiweißerhöhung im Aszites gestellt werden.

Empfehlung, starker Konsens

\section{EMPFEHLUNG 1.23}

Bei Verdacht auf eine sekundär bakterielle Peritonitis soll zeitnah eine Bildgebung des Abdomens erfolgen. Verfahren der ersten Wahl ist die Computertomografie.

Starke Empfehlung, starker Konsens

\section{Kommentar}

Die sekundäre bakterielle Peritonitis bei Patienten mit einer portalen Hypertension beschreibt eine bakterielle Peritonitis durch eine abdominelle Infektionsquelle (z. B. Abszess, Perforation) und ist mit bis zu $15 \%$ aller Peritonitiden deutlich seltener als die spontan bakterielle Peritonitis [87]. Da die Mortalität der sekundären bakteriellen Peritonitis mit 50-80\% sehr hoch ist $[87,88]$, ist ein invasives Vorgehen (z. B. Operation, Abszessdrainage) in der Regel notwendig.
In einer retrospektiven Analyse waren Bauchschmerzen signifikant häufiger bei Patienten mit einer sekundären als bei Patienten mit einer spontan bakteriellen Peritonitis nachweisbar (79 vs. $49 \%)$ [87].

Die Zellzahl im Aszites ist durchschnittlich höher bei einer sekundären Peritonitis im Vergleich zur SBP [87], einen evaluierten Cut-off-Wert gibt die Studienlage jedoch nicht.

Laborchemisch ergaben sich bei einer sekundär bakteriellen Peritonitis folgende Konstellationen: Eiweißgehalt im Aszites $>1 \mathrm{~g} / \mathrm{l}$, Glukose im Aszites < 2,7 mmol/l, Aszites-LDH oberhalb der oberen Normgrenze des Serum-LDH-Wertes. Die Sensitivität dieser Kriterien liegt zwischen 66 und $97 \%$ und die Spezifität bis zu 90 \% [87, 89 - 91]. Die Erhöhung des Carcinoembrionalen Antigens (CEA) und der alkalischen Phosphatase (AP) können ebenfalls Hinweise auf eine sekundär bakterielle Peritonitis geben.

In einer Untersuchung wurde ein CEA $>5 \mathrm{ng} / \mathrm{ml}$ (Vorkommen in Enterozyten) und die alkalische Phosphatase (AP) > 240 U/l im Aszites bestimmt. Die Sensitivität für das Vorliegen eines dieser Kriterien zur Unterscheidung sekundäre vs. primäre Peritonitis lag bei $92 \%$, wobei nicht nur Patienten mit einer Leberzirrhose einbezogen wurden [92].

Diese Aszitesparameter sind jedoch zu einer genauen Diagnosestellung einer sekundär bakteriellen Peritonitis und insbesondere zur Fokussuche nicht ausreichend.

Bei Verdacht auf sekundäre Peritonitis soll daher immer eine zusätzliche schnittbildgebende radiologische Untersuchung durchgeführt werden. Die intraabdominelle Infektquelle konnte in 91,3 \% der Fälle durch eine abdominelle Computertomografie nachgewiesen werden [87].

\section{Therapie des Aszites}

\subsection{Therapieindikation}

\section{EMPFEHLUNG 2.1}

Der klinisch nachweisbare Aszites sollte behandelt werden. Empfehlung, Konsens

\section{STATEMENT 2.2}

Ziel einer Aszitestherapie ist die deutliche Reduktion der Aszitesmenge und symptomatische Kontrolle des Aszites, nicht das vollständige Verschwinden des Aszites in der Bildgebung. Starker Konsens

\section{Kommentar}

Eine zu aggressive diuretische Therapie eines gering ausgeprägten und asymptomatischen Aszites kann zur Entwicklung oder Verschlechterung einer hepatischen Enzephalopathie oder zum prärenalen Nierenversagen führen [93]. Daher ist in dieser Situation eine milde Aszitestherapie unter regelmäßigen Kontrollen der Klinik und 
der renalen Retentionsparameter zu empfehlen. Eine frühe Therapie scheint insgesamt die Prognose zu verbessern [94].

Die Entwicklung eines klinisch nachweisbaren Aszites definiert ein Voranschreiten der Leberzirrhose mit einer Verschlechterung der Prognose [95] vor allem bei Patienten mit refraktärem oder intraktablem Aszites [96, 97]. Sekundärkomplikationen wie die spontan bakterielle Peritonitis und das hepatorenale Syndrom können akut lebensbedrohlich sein [98]. Die Indikation und die Intensität der symptomatischen Therapie eines Aszites sollten von der Klinik des Patienten abhängig sein.

\subsection{Nicht-medikamentöse Therapie}

\section{EMPFEHLUNG 2.3}

Patienten mit Leberzirrhose und Aszites sollen eine ausreichend eiweißhaltige Ernährung (empfohlene Eiweißzufuhr: $1,2-1,5 \mathrm{~g} / \mathrm{kg} / \mathrm{d}$ ) mit ausreichendem Energiegehalt (30 $35 \mathrm{kcal} / \mathrm{kg} / \mathrm{d}$ ) erhalten.

Starke Empfehlung, starker Konsens

\section{EMPFEHLUNG 2.4}

Alle Patienten sollen aufgeklärt werden, dass eine zusätzliche Salzzufuhr zu einer Verschlechterung des Krankheitsbildes führen kann.

Starke Empfehlung, starker Konsens

\section{EMPFEHLUNG 2.5}

Für Patienten, die mit einer diuretischen Therapie gut zu führen sind, ist der Nutzen einer diätetischen Kochsalzrestriktion nicht erwiesen. Patienten mit refraktärem oder schwierig zu behandelndem Aszites sollten eine diätetische Kochsalzrestriktion (max. $5 \mathrm{~g} / \mathrm{d} \mathrm{NaCl}$, entsprechend $85 \mathrm{mmol}$ Natrium) einhalten. Empfehlung, starker Konsens

\section{EMPFEHLUNG 2.6}

Bei Patienten mit einem Serum-Natrium $\geq 125 \mathrm{mmol} / \mathrm{l}$ ist eine Flüssigkeitsrestriktion nicht erforderlich, bei Patienten mit einer ausgeprägten Hyponatriämie (<125 mmol/l) kann eine Flüssigkeitsrestriktion auf $1,5 \mathrm{l} / \mathrm{d}$ sinnvoll sein.

Offene Empfehlung, starker Konsens

\section{Kommentar}

Patienten mit Leberzirrhose und Aszites sind häufig mangelernährt. Sie zeigen dabei einerseits Eiweißmangel und Muskelschwund (Sarkopenie) sowie andererseits einen Überschuss an extrazellulärem Wasser [99]. Die Mangelernährung und die Sarkopenie scheinen nicht nur für das Auftreten einer hepatischen En- zephalopathie wichtig zu sein [100], sondern auch für das Überleben der Patienten [101 - 103]. Ein normaler oder erhöhter BMI schließt eine Mangelernährung nicht aus und ist bei Zirrhosepatienten durch die Wassereinlagerung oft irreführend [99]. In vielen Fällen kann die Mangelernährung schon mittels Anamnese und klinischer Untersuchung diagnostiziert werden [104], bei adipösen Patienten wird dafür allerdings eine Analyse der Körperzusammensetzung benötigt [105]. Die Sarkopeniediagnostik aus einem CT-Schnittbild [101, 102, 105] benötigt ionisierende Strahlen; demgegenüber erlaubt die Bestimmung des Phasenwinkels mittels bioelektrischer Impedanzanalyse (BIA) eine Analyse der Körperzusammensetzung und die Bestimmung des Sterblichkeitsrisikos auf nicht invasivem Wege [106-109]. Die Handgriffstärke ist bei eiweißmangelernährten Zirrhosepatienten vermindert [99, 110], sie ist ein guter Prädiktor für Komplikationen im folgenden Jahr [110 - 112] und eine geeignete Methode für die Erfolgskontrolle einer Ernährungstherapie [113]. Die Behandlung der Mangelernährung mit ausreichender Zufuhr von Eiweiß $(1,2-1,5 \mathrm{~g} / \mathrm{kg} / \mathrm{d})$, Energie $(30-35 \mathrm{kcal} / \mathrm{kg} / \mathrm{d})$, Vitaminen (insbesondere der B-Gruppe) und Spurenelementen (insbesondere Zink) ist Bestandteil der Basistherapie und sollte primär oral erfolgen oder über Ernährungssonde und nur bei Versagen oder Nichtanwendbarkeit parenteral [114]. Als Bezugsgröße wird das aktuelle Körpergewicht und bei Adipösen und Patienten mit Aszites das Idealgewicht empfohlen [100, 114]. Patienten sollten instruiert werden, zusätzlich eine Spätmahlzeit zu sich zu nehmen bzw. die verordnete Trinknahrung nach 20:00 Uhr, weil auf diese Weise der Eiweißstatus effizienter verbessert werden kann [115]. Die adäquate Ernährungstherapie kann nicht nur die Körperzusammensetzung, sondern auch das Überleben verbessern [104, 115, 116]. Unzureichende Nahrungs- und vor allem Eiweiß-Aufnahme (spontan oder ärztlich verordnet) induzieren eine katabole Stoffwechsellage und begünstigen die Ausbildung einer hepatischen Enzephalopathie und sollten daher vermieden werden [117]. Eine Ernährung mit ausreichendem Energiegehalt $(30-35 \mathrm{kcal} / \mathrm{kg} / \mathrm{d}$ ) ist bei Patienten mit morbider Adipositas und/oder NASH-Zirrhose nicht angezeigt.

In den letzten Jahren hat sich gezeigt, dass Adipositas bei Zirrhosepatienten ein unabhängiger ungünstiger Prognosefaktor ist $[118,119]$, insbesondere auch, wenn diese Patienten eine Lebertransplantation erhalten [120-122]. Lebensstilintervention mit Gewichtsreduktion durch Sport und Ernährungsumstellung kann bei adipösen Zirrhosepatienten die portale Hypertension senken [123].

Bei Leberzirrhose sind die Geschmackserkennung und Geschmackschwellen für salzig, süß und sauer gestört und werden durch Hypomagnesiämie (z. B. durch Diuretika) verstärkt [124]. Eine Diät mit strenger Kochsalzrestriktion ( $50 \mathrm{mmol}$ entsprechend ca. 3 g Natrium/d) brachte in einer Studie keinen Vorteil gegenüber einer nur moderaten Kochsalzrestriktion $(120 \mathrm{mmol} / \mathrm{d}$, entsprechend etwa $7 \mathrm{~g} \mathrm{Salz)} \mathrm{[125]} \mathrm{und} \mathrm{könnte} \mathrm{die} \mathrm{Nahrungsauf-}$ nahme eher verringern und damit den Katabolismus erhöhen [126]. Ferner kommt eine alleinige moderate diätetische Kochsalzrestriktion (5-6g/d entspricht $85-100 \mathrm{mmol} / \mathrm{d}$ ) als Basismaßnahme bei Zirrhose ausschließlich für Patienten mit einer Natriumausscheidung von mehr als $80 \mathrm{mmol} / 24 \mathrm{~h}$ infrage, denn nur bei ausreichender Natriumausscheidung im Urin kann eine 
negative $\mathrm{NaCl}$-Bilanz erreicht werden. Patienten mit geringerer Natriumausscheidung im Urin bedürfen der Gabe von Diuretika. Um die Rate der Aszitesneubildung und damit die Frequenz der Parazentese zu minimieren, können Patienten mit refraktärem Aszites eine kochsalzarme Kost erhalten. Zusätzlich kann die ExtraGabe von verzweigtkettigen Aminosäuren und ein abendlicher Snack mit komplexen Kohlenhydraten die Morbidität und Mortalität im Vergleich zur strikten natriumarmen Kost verbessern [127].

Bei Patienten mit Leberzirrhose und Aszites ist die Verdünnungshyponatriämie häufig und vor allem Patienten mit Serum-Natriumwerten unter $135 \mathrm{mmol} / \mathrm{l}$ haben eine gesteigerte Mortalität mit abnehmenden Serum-Natriumwerten [128, 129]. Das führte letztlich zur Modifikation des MELD-Scores zum MELD-Na score [130], welcher in den USA seit Januar 2016 zur Allokation der Lebertransplantation verwendet wird. Da in der Regel eine Verdünnungshyponatriämie ohne einen Ganzkörper-Natriummangel vorliegt, ist eine Kochsalzgabe bei zirrhotischem Aszites nicht indiziert, ebenso wenig wie ein rascher Ausgleich bei chronischer Hyponatriämie, um das Risiko ernsthafter Komplikationen, wie einer zentralen pontinen Myelinolyse, zu vermeiden [131]. Eine Flüssigkeitsrestriktion erscheint sinnvoll ab einem Serumnatrium $<120-125$ mmol/l [1]. Flüssigkeitsrestriktion bedeutet häufig aber eine signifikante Einschränkung der Lebensqualität des Patienten und sollte daher längerfristig nur bei im Einzelfall erwiesener Wirksamkeit und Notwendigkeit angeordnet werden.

\subsection{Medikamentöse Therapie}

\section{EMPFEHLUNG 2.7}

Der orale Aldosteronantagonist Spironolacton (initial $100 \mathrm{mg} / \mathrm{d}$ ) soll als Diuretikum der ersten Wahl eingesetzt werden. Bei unzureichender Aszitesmobilisation sollte ein Schleifendiuretikum (Furosemid, Torasemid) hinzugegeben werden.

Starke Empfehlung, starker Konsens

\section{EMPFEHLUNG 2.8}

Die Kombinationstherapie aus Spironolacton und einem Schleifendiuretikum kann bei Patienten mit ausgeprägtem oder länger bestehendem Aszites auch initial erfolgen. Die zusätzliche Gabe von Clonidin und/oder Midodrin kann vor allem bei Patienten mit refraktärem Aszites ein verbessertes Ansprechen bewirken.

Empfehlung offen, starker Konsens

\section{EMPFEHLUNG 2.9}

Bei ausgeprägter Hyponatriämie (<125 mmol/l), klinisch manifester hepatischer Enzephalopathie (ab Grad II) oder einer deutlichen Nierenfunktionsverschlechterung sollte auf Diuretika verzichtet werden.

Empfehlung, starker Konsens

\section{EMPFEHLUNG 2.10}

Die Anwendung von Vaptanen zur Langzeitbehandlung des Aszites ist kontraindiziert. Ferner sollte die Gabe von Prostaglandin-Inhibitoren, ACE-Inhibitoren, alpha-1-Rezeptor-Blockern und Aminoglykosiden bei Patienten mit einer Leberzirrhose und Aszites vermieden werden.

Empfehlung, starker Konsens

\section{EMPFEHLUNG 2.11}

Die Indikation einer nicht-selektiven Betablocker-Therapie bei Patienten mit refraktärem Aszites und Varizen sollte sorgfältig überprüft werden, insbesondere bei Patienten mit spontan bakterieller Peritonitis. Bei Anzeichen einer zunehmenden Nierenfunktionsstörung, ausgeprägten Hypotonie oder Hyponatriämie sollte diese unterbrochen oder reduziert werden. Empfehlung, starker Konsens

\section{Kommentar}

Das primäre Diuretikum zur Behandlung des moderaten Aszites ist der kompetitive Aldosteronantagonist Spironolacton, welcher am distalen Tubulus die Rückresorption von Natriumionen hemmt und dadurch kaliumsparend wirkt. Die Anfangsdosis einer oralen Monotherapie beträgt 1-mal tgl. 100 - 200 mg Spironolacton [132, 133]. Furosemid ist als Monotherapie dem Spironolacton unterlegen und sollte daher nur in begründeten Einzelfällen benutzt werden $[132,133]$. Die tägliche Gewichtskontrolle überwacht den Erfolg, wobei ein Gewichtsverlust von $\leq 500 \mathrm{~g} / \mathrm{d}$ bei Patienten ohne periphere Ödeme bzw. $\leq 1000 \mathrm{~g} / \mathrm{d}$ bei Patienten mit peripheren Ödemen anzustreben ist [134]. Darunter sollten regelmäßige Kontrollen der Serumelektrolyte sowie des Serumkreatinins erfolgen. Das Ziel der Therapie ist erreicht, wenn klinisch kein oder nur eine geringe Menge Aszites vorliegt und keine peripheren Ödeme mehr nachweisbar sind. Eine Dosissteigerung ist indiziert, wenn der Gewichtsverlust $<1 \mathrm{~kg}$ in der ersten Woche bzw. $2 \mathrm{~kg} /$ Woche in den folgenden Wochen beträgt.

Eine additive Therapie mit einem Schleifendiuretikum (Furosemid $20-40 \mathrm{mg} / \mathrm{d}$ ) wird eingeleitet, wenn der Patient auf $200 \mathrm{mg} / \mathrm{d}$ Spironolacton in den ersten zwei bis drei Wochen nicht ausreichend anspricht. Bei nicht ausreichendem Ansprechen kann die Diuretikatherapie bis auf $400 \mathrm{mg} / \mathrm{d}$ Spironolacton und $160 \mathrm{mg} / \mathrm{d}$ Furosemid gesteigert werden [135]. Bei diesen hohen Dosen ist aber mit Elektrolyt- und Nierenfunktionsstörungen zu rechnen. Furosemid sollte, wenn möglich, oral appliziert werden, da die intravenöse Gabe ein höheres Risiko für eine Nierenfunktionsstörung aufweist [136]. Allerdings zeigen neuere Daten ein besseres Ansprechen auf das hoch-dosierte Furosemid in Kombination mit Kochsalzlösung oder -Tabletten als die üblichen Diuretika-Regimes [137, 138]. Diese Daten müssen aber erst noch bestätigt werden, bevor hierzu eine definitive Empfehlung ausgesprochen werden kann. Das neuere Schleifendiuretikum Torasemid zeigt sich mindestens gleich effektiv und sicher wie Furosemid bei Patienten mit Leberzirrhose und Aszites [139, 140]. 
Obwohl die Studienlage zu dem Vergleich einer sequenziellen vs. kombinierten Therapie bei moderatem Aszites nicht eindeutig ist, lässt sich zusammenfassen, dass die initiale Kombinationstherapie eher bei Patienten mit länger bestehendem Aszites und erniedrigter GFR zu weniger Nebenwirkungen (v. a. Hyperkaliämen) führt [141], wobei die sequenzielle Therapie vor allem bei Patienten mit neu aufgetretenem Aszites mit normalem Serumkreatinin weniger Nebenwirkungen aufwies [133]. Zudem ist die initiale Kombinationstherapie bei massivem Aszites indiziert [142], meist in der Kombination aus $100 \mathrm{mg}$ Spironolacton sowie $40 \mathrm{mg}$ Furosemid als einmalige morgendliche Gabe [143]. Sollte diese Dosierung nicht ausreichend sein, kann in diesem Verhältnis weiter gesteigert werden (z. B. $200 \mathrm{mg}$ Spironolacton und $80 \mathrm{mg}$ Furosemid). Auf diese Weise kann das Risiko einer Spironolactoninduzierten Hyperkaliämie gering gehalten werden. Mittels einer kombinierten Therapie aus kochsalzreduzierter Diät, Spironolacton und Furosemid lässt sich bei bis zu $90 \%$ der Patienten mit Aszites und Leberzirrhose ein Therapieerfolg erzielen [132, 135]. Wenn eine ausreichende Aszitesmobilisation erreicht wurde, sollte die Diuretikadosis so weit wie möglich reduziert werden. Bei Patienten, die nicht ausreichend auf die diuretische Therapie ansprechen, sollte die Natriumexkretion im 24-h-Sammelurin gemessen werden, um echtes Nicht-Ansprechen von Nicht-Compliance zu unterscheiden. Bei einer 24-h-Natriumausscheidung über $85 \mathrm{mmol}$ ohne Gewichtsverlust liegt die Kochsalzaufnahme vermutlich über $5 \mathrm{~g} / \mathrm{d}$. Bei refraktärem oder intraktablem Aszites könnte die Kombination der Diuretika-Therapie mit Midodrin ( $7,5 \mathrm{mg} / 8 \mathrm{~h})$ oder/und Clonidin $(0,1 \mathrm{mg} / 12 \mathrm{~h})$ ein besseres Ansprechen ohne wesentliche Nebenwirkungen erzielen [144 - 146].

Ein Teil der männlichen Patienten entwickelt unter Spironolacton eine schmerzhafte Gynäkomastie, die einen Abbruch der Therapie erforderlich machen kann. Amilorid $(10-40 \mathrm{mg} / \mathrm{d}$ ) wäre eine Alternative, obwohl es weniger effektiv als Kaliumcanrenoat (aktiviertes Spironolacton) zu sein scheint [147]. Der Aldosteronantagonist Epleneron, der seltener zur Gynäkomastie führt als Spironolacton, ist bisher nur in der experimentellen Leberfibrose untersucht worden [148]. Weitere verwendete Diuretika sind Triamteren, Hydrochlorothiazid und Xipamid; diese sind eher als Reservemedikamente anzusehen [149].

Einen neuen Therapieansatz stellen selektive, orale VasopressinV2-Rezeptorantagonisten, die sog. Vaptane, dar. Sie steigern die Wasserausscheidung ohne gleichzeitige Natriurese und sind daher für den Einsatz bei Hyponatriämie entwickelt worden. In Kombination mit Spironolacton konnte für Satavaptan eine signifikante Gewichtsabnahme verglichen mit Placebo sowie eine Besserung der vorbestehenden Hyponatriämie gezeigt werden [150 - 152]. Leider zeigte die Langzeitbehandlung eine gesteigerte Mortalität [153]. Die bereits zugelassene Substanz, Tolvaptan, zeigte sich ebenfalls effektiv in der kurzzeitiger Anwendung (7 - 30 Tage), vor allem für die Behandlung der Ödeme, allerdings mit höherer Nebenwirkungsrate [154-158], zudem wurde auch ein RoteHand-Brief zu diesem Medikament in Jahr 2013 veröffentlicht.

Die Gabe von Prostaglandin- und Angiontensin-ConvertingEnzyme-Inhibitoren können ein Nierenversagen bei Patienten mit einer Leberzirrhose induzieren und sollten deshalb vermieden werden [159-163]. Bereits die niedrig-dosierte oder einmalige Gabe von ACE-Inhibitoren sowie die kurzzeitige Gabe auch von moderne- ren COX-Inhibitoren kann merkliche Veränderungen in der Nierenfunktion induzieren und sollten deshalb bei Patienten mit einer Leberzirrhose und Aszites vermieden werden [164-167].

Diskutiert wird, ob durch nicht-selektive Betablocker bei Patienten mit Leberzirrhose und Therapie-refraktärem Aszites die Mortalitätsrate ansteigt. Während zwei Arbeitsgruppen [168, 169] eine höhere Mortalität bei Patienten mit Therapie-refraktärem Aszites bzw. mit spontan bakterieller Peritonitis nachweisen konnten, kommen zwei neuere Studien $[170,171]$ bei Patienten mit Aszites auf der Transplantationsliste bzw. Patienten mit akut-auf-chronischem Leberversagen zu dem Ergebnis, dass durch die NSBB-Therapie die Mortalität im Gegenteil sinkt. Dementsprechend kann eine abschließende Empfehlung für oder gegen eine Therapie mit NSBB bei Therapie-refraktärem Aszites nicht gegeben werden, jedoch rät die Baveno-Konferenz zur Vorsicht, vor allem bei Anzeichen einer Nierenfunktionsstörung (systolischer Blutdruck < $90 \mathrm{mmHg}$, Hyponatriämie < $130 \mathrm{mmol} / \mathrm{l}$, Acute kidney injury definiert nach der IAC) [172, 173].

Die Anwendung von Protonenpumpeninhibitoren bei Patienten mit Leberzirrhose und Aszites kann mit Komplikationen assoziiert sein. Protonenpumpeninhibitoren sollten daher nur nach strenger Indikationsstellung bei Patienten mit Leberzirrhose und Aszites verwendet werden. Bei der Indikation der gastrointestinalen Blutung ist die Gabe einer hochdosierten PPI-Therapie mit einem erhöhten Risiko für eine spontan bakterielle Peritonitis verbunden, ohne größere Vorteile in den klinischen Endpunkten [174]. Die Analyse größerer Serien von Patienten mit Aszites (zwischen 500 und mehr als 1500 Patienten) konnte den Zusammenhang zwischen PPI-Einnahme und der Entwicklung einer spontan bakteriellen Peritonitis und/oder einer hepatischen Enzephalopathie weder ausschließen noch bestätigen. Während in einigen retrospektiven und prospektiven Kollektiven ein Zusammenhang statistisch gesehen werden konnte [175177], ließ sich in anderen retrospektiven und prospektiven Kohorten kein Zusammenhang erkennen [178, 179]. Insgesamt sollte aber die Indikation einer PPI-Therapie bei Patienten mit refraktärem Aszites streng überprüft werden. Neuere Daten aus einer großen italienischen multizentrischen randomisierten Studie zeigen, dass die Langzeitanwendung von Albumin möglicherweise bei Patienten mit Aszites das Überleben verbessert [180, 181].

Auch wenn diese Studie noch Bestätigung braucht, hat die Langzeitgabe von Albumin bereits jetzt einen Stellenwert in den EASL-Leitlinien [182].

\subsection{Therapierefraktärer und rezidivierender Aszites}

\section{DEFINITION 2.1}

Der therapierefraktäre Aszites ist als Diuretika-resistenter oder intraktabler Aszites definiert. Diuretika-Resistenz bedeutet inadäquates Ansprechen auf eine hoch dosierte diuretische Therapie (Spironolacton max. $400 \mathrm{mg} / \mathrm{d}$ und Furosemid max. 160 mg/d) in Kombination mit einer Natriumrestriktion [183]. Beim intraktablen Aszites bestehen Komplikationen wie hepatische Enzephalopathie, prärenales Nierenversagen oder ausgeprägte Hyponatriämie, die eine adäquate diuretische Therapie verhindern [183].

Starker Konsens 


\section{DEFINITION 2.2}

Rezidivierender Aszites ist definiert als Aszites, der trotz Empfehlung zur Natriumrestriktion und Diuretika-Gabe in adäquater Dosierung mindestens dreimal in einem Zeitraum von einem Jahr wieder auftritt [183].

Starker Konsens

\section{EMPFEHLUNG 2.12}

Bei therapierefraktärem oder rezidivierendem Aszites soll immer die Lebertransplantation erwogen werden, und die TIPSAnlage bei fehlenden Kontraindikationen wiederholten großvolumigen Parazentesen vorgezogen werden.

Starke Empfehlung, starker Konsens

\section{STATEMENT 2.13}

Eine TIPS-Anlage zur Aszitestherapie ist in der Regel kontraindiziert bei vorbestehender chronischer hepatischer Enzephalopathie $\geq$ Grad 2 oder einem Serum-Bilirubin $>5$ mg/dl (weitere Kontraindikationen siehe Kommentar).

Empfehlung, Konsens

\section{EMPFEHLUNG 2.14}

Für die TIPS-Anlage sollte prinzipiell ein PTFE-beschichteter Stent (Stentgraft) eingesetzt werden. Eine Empfehlung für die optimale Antikoagulation nach TIPS-Anlage kann bislang nicht ausgesprochen werden.

Empfehlung, starker Konsens

\section{EMPFEHLUNG 2.15}

Die Anpassung der Medikation (v. a. Diuretika), Vorbeugung, frühe Erkennung und Behandlung von möglichen Komplikationen (hepatische Enzephalopathie, kardiale Dysfunktion) nach TIPS sollte durch eine engmaschige Betreuung der Patienten erfolgen.

Empfehlung, starker Konsens

\section{EMPFEHLUNG 2.16}

Die (peritoneovesikale) Aszitespumpe kann in erfahrenen Zentren als Alternative der großvolumigen Parazentese in Erwägung gezogen werden.

Offene Empfehlung, Konsens

\section{EMPFEHLUNG 2.17}

Bei Durchführung einer großvolumigen Parazentese $(>5 \mathrm{I})$ soll eine intravenöse Albumingabe (6 - $8 \mathrm{~g} /$ Liter Aszites) erfolgen. Starke Empfehlung, starker Konsens

\section{EMPFEHLUNG 2.18}

Die Parazentese sollte Ultraschall-assistiert erfolgen. Empfehlung, starker Konsens

\section{Kommentar}

Abgesehen von der Lebertransplantation, die bei therapierefraktärem oder intraktablem Aszites immer erwogen werden sollte, stehen die wiederholte großvolumige Parazentese und der transjuguläre intrahepatische portosystemische Shunt (TIPS) zur Verfügung. Die sogenannte Aszitespumpe stellt eine gute und sichere Alternative zu wiederholten großvolumigen Parazentesen dar [184-187]. Für getunnelte Katheter ist die veröffentlichte Datenlage bei Leberzirrhose bislang gering [188]. Die Anlage eines peritoneovenösen Shunts ist weniger effektiv als der TIPS und mit mehr Komplikationen behaftet und sollte nur ausgewählten Einzelfällen vorbehalten bleiben [189].

\section{Großvolumige Parazentese}

Bei fast allen Patienten müssen wiederholte Parazentesen durchgeführt werden. Diese sollen mindestens Ultraschall-assistiert, ggf. auch Ultraschall-gesteuert erfolgen. Durch eine Ultraschall-gestützte Punktion in Echtzeit reduziert sich nachweislich das Risiko von Gefäßverletzungen in der Bauchwand (V. epigastrica inferior, Paraumbilikalvenen). Die permanente Visualisierung der Nadelspitze verringert darüber hinaus Fehlpunktionen $[43,190]$.

Die Parazentese ist ein relativ sicheres Verfahren [44], die Aszites-Neubildung wird dadurch allerdings nicht verhindert. Beachtet werden muss, dass eine großvolumige Parazentese zu hämodynamischen Veränderungen führen kann, die als zirkulatorische Dysfunktion nach Parazentese bezeichnet wird [191-193]. Zentraler pathophysiologischer Aspekt dabei ist eine Aggravation der schon vorbestehenden Verminderung des effektiven zentralen Blutvolumens mit der Folge einer weiteren Stimulation vasokonstriktorischer Systeme. Die klinische Manifestation dieser Veränderungen ist die Verschlechterung der Nierenfunktion bis hin zum hepatorenalen Syndrom. Da das Auftreten einer zirkulatorischen Dysfunktion nach Parazentese mit einer reduzierten Lebenserwartung assoziiert ist [192], sollte dieser vorgebeugt werden. Die Gabe von Albumin ist nach kontrollierten Studien die beste Vorbeugung einer zirkulatorischen Dysfunktion nach großvolumiger (>5I) Parazentese und daher anderen Plasmaexpandern vorzuziehen [192]. Albumin kann laut einer Pilotstudie auch den längerfristigen Schäden der zirkulatorischen Dysfunktion vorbeugen [194]. Ist das abpunktierte Aszitesvolumen kleiner als 5 I, ist keine Gabe von Humanalbumin notwendig. Allerdings zeigen neuere Daten, dass eine regelmäßige Albuminsubstitution 
möglicherweise das Überleben der Patienten mit Aszites verbessern kann [180, 181].

\section{TIPS-Anlage}

Die Rationale der TIPS-Anlage besteht vorwiegend darin, den portalen Druck und damit die Transsudation in die Peritonealhöhle zu reduzieren. Vier Wochen nach TIPS-Anlage zeigten sich Natriumausscheidung und Nierenfunktion verbessert [195 - 199].

Im Vergleich zur wiederholten großvolumigen Parazentese ist die TIPS-Anlage zur Aszitestherapie deutlich effektiver [199203] und zeigte zumindest in einer Studie eine Verbesserung der Lebensqualität [204]. Bezüglich der Mortalität ist nun die Datenlage etwas klarer. Nach mehreren Arbeiten mit einem Überlebensvorteil [201, 205] und einer Metaanalyse auf der Basis individueller Patientendaten [202], wurde kürzlich eine randomisiertkontrollierte Studie publiziert, welche zeigte, dass TIPS einen deutlichen Überlebensvorteil gegenüber der großvolumigen Parazentese hat [203]. Diese Studie setzte im Gegensatz zu einer früheren randomisiert-kontrollierten Studie ausschließlich beschichtete Stentgrafts ein [203]. In einer Metaanalyse wurde deutlich, dass der Überlebensvorteil des TIPS bei refraktären und/oder rezidivierendem Aszites in Studien mit beschichteten Stents deutlicher ist [206].

Es existiert eine ausreichende Datenlage, dass durch die Verwendung von beschichteten Stentgrafts das Risiko für eine kurzfristige (bis zu sechs Monate nach Anlage) Stentdysfunktion signifikant gesenkt werden kann. Es gibt hierzu zwei Metaanalysen und sechs weitere Studien, die eindeutig zeigen, dass ein Stentgraft den konventionellen Stents bzgl. Shuntdysfunktion überlegen ist [207 - 212]. Die Rate der langfristigen Dysfunktion ist jedoch nicht abschließend geklärt. Unklarheit besteht bisweilen aber über das richtige Antikoagulationsregime nach TIPS-Anlage, bzw. ob überhaupt eine Antikoagulation nach Stentgraftimplantation noch erforderlich ist. Dies ist Gegenstand zukünftiger Studien.

\section{Einschränkungen und Kontraindikationen für die TIPS-Anlage}

Hepatische Enzephalopathie. Bei Patienten mit refraktärem Aszites ist die HE multifaktorieller Genese (eingeschränkte Leberund Nierenfunktion, Exsikkose, reduzierte arterielle Organperfusion [202], Infekt, Hypoglykämie). Auch die Sarkopenie scheint einen deutlichen Einfluss auf die Entwicklung der HE nach TIPS zu haben [213]. Während die Leberperfusion durch eine TIPS-Anlage in der Regel verschlechtert wird, werden andere HE-relevante Faktoren verbessert. Daher unterscheidet sich das kumulative Auftreten der ersten HE-Episode nicht zwischen den Behandlungsgruppen (TIPS vs. wiederholte Parazentese) [202]. Allerdings erhöht der TIPS die Anzahl der HE-Episoden insgesamt sowie die Anzahl schwerer HE-Episoden [202]. Auch die kürzlich publizierte randomisiert-kontrollierte Studie zeigte keinen Unterschied im Auftreten der HE (34\% HE im ersten Jahr in beiden Gruppen, p =0,868) [203].

Bei Vorliegen von Risikofaktoren für eine HE (höheres Lebensalter, vorbestehende HE, mittlerer arterieller Blutdruck $<80 \mathrm{mmHg}$, MELD-Score > 15), aber dringlicher TIPS-Indikation ist eine limitierte Drucksenkung des portosystemischen Druckgradienten (z. B. 30 $50 \%$ ) anzustreben. Eine kürzlich publizierte Studie konnte zeigen, dass ein kleinerer Stentdiameter ( $8 \mathrm{~mm}$ ) im Vergleich zu größeren Stentdiametern $(10 \mathrm{~mm})$ die HE-Rate nach TIPS-Anlage deutlich senkt [214]. Die Daten dieser chinesischen Studie stimmen mit der
Rate an HE in der deutschen Blutungsstudie mit 8 mm cTIPS von ca. $18 \%$ überein [215], wobei die Verwendung von $10 \mathrm{~mm}$ Stents ca. doppelt so häufig HE-Episoden zeigte, und mit der jüngst publizierten niederländischen Studie mit $10 \mathrm{~mm}$ cTIPS übereinstimmt [216]. Auch wenn diese Studien an Patienten mit Varizenblutungen vorgenommen wurden, zeigen sie dennoch, dass kleinere Stents zu bevorzugen sind.

Leberfunktion. Ein Bilirubin über $3 \mathrm{mg} / \mathrm{dl}$ korreliert eng mit einer erhöhten Mortalität nach TIPS-Anlage [217]. Jede Erhöhung des Bilirubins um $1 \mathrm{mg} / \mathrm{dl}$ über $3 \mathrm{mg} / \mathrm{dl}$ hinaus steigert das Risiko der 30-Tages-Mortalität um 40 \% [218]. Deshalb ist eine Erhöhung des Gesamtbilirubins über $3 \mathrm{mg} / \mathrm{dl}$ als relative und eine Erhöhung über $5 \mathrm{mg} / \mathrm{dl}$ als absolute Kontraindikation einer TIPS-Anlage zur Behandlung von Aszites anzusehen [219]. Zudem ist die Kombination aus der Thrombozytenzahl $(<150 \mathrm{G} / \mathrm{l})$ und Bilirubin (>3 mg/dl) bei Patienten mit refraktärem Aszites als prognostisch ungünstiges Zeichen anzusehen [220].

Malignome. Maligne Raumforderungen der Leber (HCC) stellten in den meisten Studien ein Ausschlusskriterium für die TIPSAnlage dar. Daher wird ein Malignom in der Leber von vielen Experten als Kontraindikation gegen eine TIPS-Anlage gesehen. In Einzelfällen eines rein palliativen Therapieansatzes gibt es z. B. bei Spannungsaszites mit der Notwendigkeit hochfrequenter Parazentesen auch bei Patienten mit HCC positive Erfahrungen nach TIPS-Implantation. Es muss sichergestellt sein, dass der Aszites durch die portale Hypertension und nicht den malignen Tumor bedingt ist und dass der TIPS-Trakt nicht durch das HCC läuft.

Kardiale Funktion. In der klinischen Praxis spielt die Herzinsuffizienz bei der TIPS-Indikation eine untergeordnete Rolle. Bei offensichtlicher, sehr schlechter kardialer Pumpfunktion kann nach Wegfall der portalen Perfusion durch den TIPS eine mangelhafte arterielle Leberperfusion resultieren. Deshalb wird für die TIPSAnlage eine untere Grenze der Ejektionsfraktion von $40 \%$ festgelegt. Diese Grenze ist willkürlich, da keine entsprechenden Studienergebnisse vorliegen.

Auch eine vorbestehende Rechtsherzinsuffizienz sowie eine signifikante pulmonalarterielle Hypertonie können Kontraindikationen für eine TIPS-Anlage darstellen: Nach TIPS-Anlage kommt es zu einem vorübergehenden Anstieg des ZVD und einem kräftigen Anstieg des Herzminutenvolumens um etwa $4 \mathrm{l} / \mathrm{min}$, das nach wenigen Stunden auf etwa $1 \mathrm{l} / \mathrm{min}$ abfällt. Dies erklärt eine evtl. Verschlechterung der diastolischen Funktion, wie dies in verschiedenen Studien gezeigt wurde. Ein echokardiografischer Grenzwert existiert bislang nicht. Es konnte allerdings gezeigt werden, dass die Mortalität nach TIPS-Anlage bei einer E/A-Ratio < 1 deutlich höher ist als bei einer E/A-Ratio > 1 [221].

Pfortaderthrombose. Die langfristig komplett verschlossene oder kavernös transformierte Pfortader stellt in der Regel eine technische Herausforderung, jedoch keine Kontraindikation für die TIPS-Anlage dar [222]. Hierbei spielt es keine große Rolle, ob frische oder ältere Thrombosen oder Teilverschlüsse vorliegen.

\section{Die peritoneovesikale Aszitespumpe}

Eine potenzielle Alternative zur regelmäßigen Parazentese ist die operativ eingesetzte sogenannte Aszitespumpe. Die bisherigen Studien zeigten für die automatisierte peritoneovesikale Aszitespumpe, dass hierdurch die Anzahl der Parazentesen gesenkt werden kann. Zudem konnte in einer ersten Studie gezeigt 
werden [184], dass mit steigender Erfahrung auch die häufigen Komplikationen wie Infektionen, Katheterdiskonnektionen, und Re-Interventionen gesenkt werden. Allerdings treten eine transiente Verschlechterung der Nierenfunktion und vor allem aber Elektrolytentgleisungen nach wie vor bei diesen Patienten auf [184-187]. Insofern wird aktuell evaluiert, ob insbesondere durch die regelmäßige Albuminsubstitution die Elektrolytentgleisungen bzw. die Verschlechterung der Nierenfunktion verhindert werden kann [187]. Obwohl dieses Verfahren noch in klinischen Studien im Vergleich zum TIPS evaluiert wird, gibt es bereits publizierte Daten, dass die Pumpe zwar keinen Überlebensvorteil gegenüber der großvolumigen Parazentese bringt [184, 185], allerdings eine Verbesserung der Lebensqualität und des Ernährungszustandes erreicht werden kann [186], welche auch durch die Interimsanalysen der randomisiert-kontrollierten Studie MOSAIC in den USA bestätigt wurden. Voraussetzung für die Anlage einer Aszitespumpe ist eine Lebenserwartung von mehr als 6 Monaten. Die Aszitespumpe kann bei Vorliegen von Kontraindikationen für die TIPS-Anlage in Erwägung gezogen werden. Dabei ist eine engmaschige ambulante Betreuung der Patienten nach Anlage der Pumpe erforderlich.

\section{Getunnelte Katheter}

Darüber hinaus besteht die Möglichkeit, getunnelte Katheter in den Aszites einzubringen. Erste klinische Erfahrungen existieren zu sogenannten getunnelten Kathetern, die in die Bauchhöhle eingebracht werden. Hierbei hat sich gezeigt, dass durchaus relevante aszendierende Infektionen in den Aszites auftreten können, die zu einer schweren Peritonitis führen können. Bislang existiert hierzu eine Studie, die allerdings kein eindeutig gehäuftes Auftreten von Infektionen zeigt [188]. Somit sollte das Verfahren weiterhin vor allem in klinischen Studien evaluiert werden. Für gut ausgewählte Patienten stellen getunnelte Katheter möglicherweise eine Therapiealternative dar.

\section{Spontan bakterielle Peritonitis}

\subsection{Einleitung und Definiton}

\section{DEFINITION 3.1}

Eine spontan bakterielle Peritonitis (SBP) ist definiert über den Nachweis von $>250$ polymorphonukleären (PMN)-Zellen, $d$. h. neutrophilen Granulozyten, pro $\mathrm{mm}^{3}$ Aszites. Bei einer SBP handelt es sich um eine bakterielle Entzündung der Peritonealhöhle ohne Hinweis auf eine anderweitige intraabdominelle Ursache der Infektion (z. B. Cholezystitis, Divertikulitis etc.), Peritonealmetastasen oder Tuberkulose. Ein Bakteraszites ist definiert als mikrobiologischer Nachweis einer Kolonisation des Aszites mit Bakterien ohne erhöhte PMN-Zahl im Aszites (d. h. $<250 \mathrm{PMN} / \mathrm{mm}^{3}$ ).

\section{Kommentar}

Diese Definition beruht auf folgenden Gesichtspunkten:

1. Da mehr als $40 \%$ der mikrobiologischen Aszitesuntersuchungen bei SBP kulturnegativ bleiben und eine verzögerte Antibiotikatherapie (durch Warten auf ein Kulturergebnis) fatale Auswirkungen für den Patienten haben kann, wird die Indikation zur empirischen Antibiotikatherapie durch die AszitesPMN-Konzentration gestellt.

2. Der initial verwendete Grenzwert zur Detektion und Definition einer SBP von > $500 \mathrm{PMN} / \mathrm{mm}^{3}$, der für eine kulturpositive SBP eine Spezifität von $98 \%$ und eine Sensitivität von $90 \%$ erzielt [55] wurde aufgrund der suboptimalen Sensitivität korrigiert. Bei einem Grenzwert von 250 PMN/mm³ wird hierbei die höchste Sensitivität erzielt und hierdurch das Risiko, eine tatsächliche Therapieindikation fälschlicherweise zu übersehen, minimiert. Ein Bakteraszites definiert dagegen eine Kolonisation des Aszites mit Bakterien ohne Nachweis einer inflammatorischen Reaktion im Peritonealraum, d. h. PMN-Zahl $<250 / \mathrm{mm}^{3}$ [223]. Beides, SBP und Bakteraszites, stellen eine Therapie-Indikation dar.

Die SBP ist die häufigste bakterielle spontane Infektion bei der Leberzirrhose und wird in prospektiven Fallserien mit etwa $24 \%$ aller bakteriellen Infektionen bei hospitalisierten Patienten angegeben [224]. Während im ambulanten Sektor bei asymptomatischen Patienten, auch bei Vorliegen eines therapierefraktären Aszites, eine Prävalenz der SBP von 3,5\% [9] oder weniger [7, 8] berichtet wird, steigt die Zahl bei hospitalisierten Patienten auf $8-36 \%$ an [54, 225]. Hierbei unterscheidet sich auch das Keimspektrum entscheidend. Im ambulanten Sektor dominieren Gram-negative Keime, während nosokomial vor allem Gram-positive Erreger ursächlich sind [224].

Risikofaktoren für das Auftreten einer SBP sind a) eine bereits stattgehabte SBP [226, 227], b) eine gastrointestinale Blutung $[228,229]$ und c) ein niedriger Gesamteiweißgehalt im Aszites $(<1,5$ bzw. $<1,0 \mathrm{~g} / \mathrm{dl})[230,231]$. Bei Verwendung eines Grenzwerts von $<1,5 \mathrm{~g} / \mathrm{dl}$ liegt die Wahrscheinlichkeit, eine erste SBP innerhalb eines Jahres zu entwickeln, bei 14-23\%. Weitere Risikofaktoren, die mit einer zusätzlichen unabhängigen Erhöhung des Risikos einer ersten SBP-Episode einhergehen, sind Bilirubinerhöhung (>3,2 mg/dl) und Thrombopenie (<98 000/mm3) [59]. Zudem steigt das Risiko einer SBP mit zunehmendem MELD-Score [232] sowie dem Einsatz von Protonenpumpenhemmern [233]. Ferner scheint das Vorliegen einer NOD2-Genmutation das Auftreten einer SBP zu begünstigen [234].

Die Wahrscheinlichkeit des Rezidivs einer SBP nach Erstmanifestation ohne Einleitung einer Prophylaxe beträgt zwischen 30 und $68 \%$ innerhalb eines Jahres [226, 227]. Als unabhängige Risikofaktoren hierfür wurden ebenfalls der Gesamteiweißgehalt des Aszites $(<1 \mathrm{~g} / \mathrm{dl})$, aber auch eine Prothrombin-Aktivität $<45 \%$ oder Bilirubin $>4 \mathrm{mg} / \mathrm{dl}$ identifiziert [227]. Die Prävalenz des monomikrobiellen Bakteraszites bei asymptomatischen ambulanten Patienten liegt bei 2 - $3 \%$ [ 7 - 9] hingegen bei hospitalisierten Patienten bis zu 11 \% [225, 235]. Für das Wiederauftreten eines Bakteraszites finden sich in der Literatur keine zuverlässigen prospektiven Daten. 
Die Krankenhausmortalität einer ersten SBP-Episode wird je nach begleitenden Risikofaktoren mit 10 - $50 \%$ angegeben [ 225 , 227, 236 - 240]. Die 1-Jahres-Mortalität nach Auftreten einer ersten SBP liegt zwischen $31 \%$ und $93 \%$ [9, 227, 241 - 243]. Als prädiktive Risikofaktoren für einen ungünstigen Verlauf ließen sich in unterschiedlichen Kollektiven verschiedene Faktoren identifizieren, welche u. a. beinhalten: Alter des Patienten [239, 242], Child-Pugh-Score [240, 242, 244], Intensivaufenthalt [239, 240], nosokomiale SBP [240], hepatische Enzephalopathie [245, 246], Serum-Kreatinin und -Bilirubin [247], fehlende Infektresolution und kultureller Erregernachweis [248, 249] sowie Auftreten einer Bakteriämie [250]. Der Verlauf eines Bakteraszites ist variabel, kann spontan reversibel sein oder in eine SBP übergehen [223, 235]. Dabei beträgt die Krankenhausmortalität 21 - 50 \% [235].

\subsection{Primärprophylaxe einer SBP}

\section{EMPFEHLUNG 3.1}

Bei Vorliegen eines Aszites mit erniedrigtem Gesamteiweißgehalt $(<1,5 \mathrm{~g} / \mathrm{dl})$ kann eine Primärprophylaxe mit Antibiotika erfolgen.

Empfehlung offen, starker Konsens

Bei Patienten mit zusätzlichem Vorliegen eines der beiden Kriterien (1. schwere Leberinsuffizienz, d. h. Child-Pugh-Score $>9$ mit Bilirubin $>3 \mathrm{mg} / \mathrm{dl}$ oder 2 . Niereninsuffizienz mit Serum-Kreatinin $>1,2 \mathrm{mg} / \mathrm{dl}$, Harnstoff $>25 \mathrm{mg} / \mathrm{dl}$ oder Natrium $<130 \mathrm{mEq} / \mathrm{l}$ ) sollte eine antibiotische Primärprophylaxe erfolgen.

Empfehlung, starker Konsens

Bei einer gastrointestinalen Blutung bei Leberzirrhose (mit oder ohne Aszites) soll immer eine antibiotische Primärprophylaxe erfolgen.

Starke Empfehlung, starker Konsens

\section{Kommentar}

Keine neue relevante Literatur bei unveränderter Empfehlung.

\section{EMPFEHLUNG 3.2}

Eine Primärprophylaxe sollte mit Norfloxacin erfolgen und kontinuierlich täglich durchgeführt werden. Rifaximin kann als Alternative in begründeten Fällen eingesetzt werden* Empfehlung, starker Konsens

\section{Kommentar}

* Die Datenlage zur Wahl der/s Antibiotikum/a in der Primärprophylaxe bei gastrointestinaler Blutung bei Leberzirrhose ist in der DGVS-Leitlinie Gastrointestinale Blutung von 2017 detailliert beschrieben [251].

In der vormaligen Leitlinie fokussierte die Datenlage zur Wahl der/s Antibiotikum/a in der Primärprophylaxe der SBP vornehmlich auf Norfloxacin und Chinolone. Insgesamt ist die Datenlage zu Norfloxacin in der Primär- und Sekundärprophylaxe der SBP deutlich breiter als die zu Ciprofloxacin. Dabei wird Norfloxacin nur in geringem Maße systemisch absorbiert, während Ciprofloxaxin eine gute systemische Bioverfügbarkeit aufweist. Zusätzlich ist Norfloxacin möglicherweise hinsichtlich der extraintestinalen Selektion chinolon-resistenter Keime günstiger einzuschätzen als Ciprofloxacin. Zudem ist die Gabe von systemisch absorbierten Chinolonen wie Ciprofloxacin mit möglichen Nebenwirkungen behaftet, welche für Norfloxacin nicht in dem Maße berichtet sind, wie Tendinitiden etc. Daher kann diese Substanzklasse zwar effektiv eingesetzt werden, Norfloxacin ist aber gegenüber Ciprofloxacin zu bevorzugen.

Nun liegen verschiedene Studien zur Evaluation der Wirksamkeit von Rifaximin vor. Rifaximin ist ein semi-synthetisches Antibiotikum mit vernachlässigbarer systemischer Resorption und Breitband-antibiotischer Wirkung gegenüber Gram-negativen und Gram-positiven aeroben und anaeroben Keimen. Argumente, welche in der Literatur für die Anwendung von Rifaximin genannt werden, sind, dass i) Rifaximin zusätzlich zur antibakteriellen Wirkung (inklusive Reduktion der Expression von bakteriellen Virulenzfaktoren) auch indirekte positive Effekte auf den Patienten hat (wie Hemmung der mukosalen Bakterien-Adhäsion und anti-inflammatorische Prozesse) [252], ii) nur selten die Antibiotika-Empfindlichkeit der Darmflora beeinflusst [253] bzw. bei Zirrhosepatienten nicht mit einer erhöhten Entwicklungsrate an resistenten Bakterien einhergeht [254] und iii) im Falle der Entwicklung einer Rifaximin-resistenten Keimpopulation diese nach Absetzen der Medikation rasch wieder verschwindet [255].

Die einzige randomisierte, multizentrische Studie zum Einsatz von Rifaximin in der Primärprophylaxe einer SBP stammt aus Saudi-Arabien und Ägypten und untersuchte Rifaximin (2-mal $550 \mathrm{mg} / \mathrm{Tag}$ ) und Norfloxacin (400 mg/Tag) jeweils als Mono-Therapie im Vergleich zu einem alternierenden Regime der beiden Antibiotika (Gabe jeweils für einen Monat) [256]. Die eingeschlossenen 239 Patienten erfüllten die von Fernandez et al. Publizierten [257] und der Empfehlung hier zugrundeliegenden Indikationskriterien. Die Rifaximin-Behandlung unterschied sich hinsichtlich des primären Studienendpunktes des Auftretens einer SBP statistisch nicht von der alternierend behandelten Patientengruppe oder der Norfloxacin-Therapie. Dagegen schnitt die Norfloxacin-Behandlung signifikant schlechter ab als die alternierend behandelte Studiengruppe. Kritisch anzumerken gilt, dass unklar bleibt i) warum 52 Patienten in der finalen Analyse nicht aufgenommen wurden aufgrund von z. B. gastrointestinaler Blutung oder Auftreten einer SBP und ii) inwiefern die statistische Methodik für multiples Testen der Analyse von drei Studiengruppen korrekt angewendet wurde. Ferner fällt auf, dass im Vergleich mit den Daten von Fernandez et al. mit einer 1-Jahres-SBP-Inzidenz von nur $7 \%$ unter Norfloxacin die SBP-Inzidenz von 22,8 bzw. 43,6\% in der Per-Protokoll- oder Intention-to-Treat-Analyse über einen Zeitraum von sechs Monaten deutlich höher ausfällt, ohne dass ein Grund hierfür ersichtlich ist. Insgesamt unterstützen die Daten die Anwendung von Rifaximin, sind aber unseres Erachtens nicht ausreichend, das alternierende Schema und/oder Rifaximin als Erstlinien-Antibiotikum (und damit dem Norfloxacin gleichberechtigt) zu empfehlen. Ferner ist festzuhalten, dass Rifaximin für diese Indikation nicht zugelassen ist und daher Off-label-Use darstellt. Weitere Fall-Kontroll-Serien und retrospektive Daten unterstützen 
den Einsatz von Rifaximin in der genannten Indikation und sollen hier kurz diskutiert werden:

Eine retrospektive Evaluation von 404 konsekutiven Zirrhosepatienten der Pittsburgh-Gruppe [258] verglich Patienten, welche Rifaximin (vornehmlich zur HE-Behandlung/-Prophylaxe) erhielten $(n=49)$ und solche ohne Rifaximin (oder andere Antibiotika-Gabe; $n=355$ ). Dabei wies die Rifaximin-Gruppe zu Beginn der Datenerhebung (nach der ersten Parazentese) eine signifikant höhere Child-Punktzahl auf. Dagegen unterschieden sich die Studiengruppen nicht im MELD-Score, Aszites-Eiweißgehalt (im Mittel je ca. $1 \mathrm{~g} / \mathrm{dL}$ ), Nierenfunktion, Alter und Geschlecht. Während einer Nachbeobachtung von im Median 4,2 Monaten traten in der Rifaximin-behandelten Patientengruppe signifikant weniger SBP-Episoden auf (10,2 vs. $31,8 \%, p=0,002)$. Ausgedrückt in SBP-Fällen pro Patientenjahr fanden sich 0,09 vs. $0,4 / J a h r(p<0,001)$. In der multivariaten Regressionsanalyse resultierte die RifaximinBehandlung auch nach Korrektur für MELD-Score, Child-Klasse, Serum-Natrium und Aszites-Gesamteiweiß in einer Reduktion der SBP-Rate um $72 \%$ (HR 0,28; $95 \% \mathrm{Cl} 0,11-0,71 ; \mathrm{p}=0,007$ ). Daraus errechnet sich eine beeindruckende NNT von 5 , um eine SBP-Episode durch Rifaximin zu verhindern. Interessanterweise blieben alle SBP-Fälle, welche unter Rifaximin auftraten, in der Kultur negativ, während in der Studiengruppe ohne Rifaximin-Behandlung $31 \%$ der SBP-Fälle in der Kultur positiv waren (49 bzw. $51 \%$ Gram-negative bzw. -positive Erreger, respektive). Zudem zeigte sich in der multivariaten Cox-Regressionsanalyse nach Adjustierung für den MELD-Score der Gebrauch von Rifaximin als signifikant mit dem transplantationsfreien Überleben assoziiert (HR 0,54; $95 \% \mathrm{Cl}[0,3-0,97], \mathrm{p}=0,039)$. Limitiert werden diese an sich sehr optimistischen Daten durch: a) retrospektives Studiendesign, b) fehlendes definiertes Verlaufs-Protokoll z. B. hinsichtlich SBP-Screening, c) hohe Drop-out-Rate in der Rifaximin-Gruppe (nach zwölf Monaten Follow-up nur mehr 9/49 Patienten unter Beobachtung), d) keinerlei Dokumentation über die Compliance der Medikamenteneinnahme und schließlich e) einer in der Rifaximin-Gruppe signifikant häufigere Ko-Medikation mit Lactulose (nämlich $100 \%$ der Rifaximin-behandelten Patienten vs. $38 \%$ der Kontrollgruppe).

Vlachogiannakos et al. [259] berichten über die Nachbeobachtung von 23 Patienten mit dekompensierter Zirrhose, welche ursprünglich an einer RCT zur Evaluation der Wirkung von Rifaximin auf den hepatovenösen Druckgradienten teilgenommen hatten und als Responder klassifiziert wurden. Für jeden RifaximinPatient/in wurden zwei sog. Kontrollpatienten/innen ge-,,matched" für Alter, Geschlecht und Child-Score ausgewählt. Die gesamte Kohorte wurde nachbeobachtet bis zum Erreichen eines der Endpunkte Lebertransplantation, Tod oder fünf Jahre nach Einschluss in die Studie.

Nach einer medianen Nachbeobachtung von 24 Monaten war unter Rifaximin folgender Benefit im Vergleich zur Kontrollgruppe zu verzeichnen: geringere Wahrscheinlichkeit für das Auftreten einer SBP (4,5 vs. $46 \%, p=0,027$ ), einer Varizenblutung (35 vs. $59,5 \%, p=0,01$ ), einer hepatischen Enzephalopathie (53 vs. $68,5 \%, p=0,034$ ) sowie eines HRS ( 49 vs. $95,5 \%, p=0,037$ ). Ferner fand sich unter Rifaximin eine signifikant bessere 5-JahresÜberlebenswahrscheinlichkeit (61 vs. $13,5 \%, p=0,012$ ). Dieser Unterschied bestätigte sich als signifikant auch nach Wertung der transplantierten Patienten als verstorben zum Zeitpunkt der Tx. Neben dem Child-Pugh-Score fand sich die Anwendung von Rifaximin als unabhängig prädiktiv für das Überleben (HR 0,258; $95 \% \mathrm{Cl}[0,075-0,891], \mathrm{p}=0,032)$.

Der Einsatz von Trimethoprim-Sulfamethoxazol scheint vergleichbar effektiv zu Norfloxacin zu sein. Neben den vormals in der S3-Leitlinie diskutierten Daten (retrospektive Beobachtung [260] und randomisiert-kontrollierter Studie von suboptimaler Qualität (mit Jadad-Score 2 von 5 [261]) liegt nun eine weitere randomisierte Untersuchung vor, welche erneut keine Unterschiede in der Effektivität der Vermeidung einer SBP aufzeigt [262]. Hierbei gilt anzumerken, dass auch Patienten mit Indikation für eine Sekundärprophylaxe eingeschlossen wurden und Trimethoprim-Sulfamethoxazol mit einem ungünstigeren Nebenwirkungsprofil assoziiert war.

Die Empfehlung einer täglichen Applikation der AntibiotikaProphylaxe bleibt mit derselben Datenlage wie in der vorgängigen Leitlinie bestehen.

Zur Wahl der Antibiotikatherapie bei gastrointestinaler Blutung siehe die DGVS-Leitlinie [251]: In Kürze zusammengefasst: Das lokale antimikrobielle Resistenzprofil sollte in der Wahl der Erstlinien-Antibiose berücksichtigt werden. Intravenöse Gabe Ceftriaxone $1 \mathrm{~g} / 24 \mathrm{~h}$ sollte angewendet werden bei Patienten mit fortgeschrittener Leberzirrhose, erhöhter Prävalenz chinolon-resistenter bakterieller Infektionen und Patienten mit vorgängiger ChinolonProphylaxe.

\subsection{Therapie der SBP}

\section{EMPFEHLUNG 3.3}

Unmittelbar nach Diagnosestellung einer SBP soll eine empirische Antibiotikatherapie eingeleitet werden. Eine ambulant erworbene unkomplizierte SBP soll mittels Cephalosporinen der Gruppe 3a behandelt werden.

Starke Empfehlung, starker Konsens

Bei Patienten mit nosokomial erworbener SBP und/oder Vorliegen von Risikofaktoren für ein Therapieversagen (lokale Resistenzlage, antibiotische Vorbehandlung in den letzten 12 Wochen) und zusätzlichen individuellen Faktoren (klinischer Schweregrad, MRE-Trägerstatus) kann eine empirische Therapie mit Carbapenemen durchgeführt werden. Empfehlung offen, starker Konsens

\section{Kommentar}

Unverändert zur letzten Version der Leitlinie gilt, dass unmittelbar mit der Diagnosestellung einer SBP eine Antibiotikatherapie eingeleitet werden soll. Ferner gilt zu betonen, dass dies ein nicht nur klinisch relevantes, sondern ein kritisches und potenziell vital bedrohliches Ereignis darstellt. Daher ist eine entsprechende medizinische Überwachung und Kontrolle angezeigt. Dies sollte zumindest im Rahmen der auch hier in der Leitlinie empfohlenen Verlaufs-Parazentese 48 Stunden nach Therapiebeginn sowie der Albumin-Gabe im Rahmen der HRS-Prophylaxe (siehe jeweils Empfehlungen unten) erfolgen. 
Bei der Auswahl von Antiinfektiva zur Behandlung der SBP sollten Risikofaktoren für den Erwerb multiresistenter Erreger berücksichtigt werden. Deshalb sollte zwischen der ambulant erworbenen und der nosokomialen Situation unterschieden werden. Bei einer ambulant erworbenen ersten Episode einer SBP soll diese mit einem Cephalosporin der 3. Generation behandelt werden, wenn es sich um eine unkomplizierte SBP handelt und der Patient keine wesentliche Antibiotika-Vortherapie aufweist [263, 264]. Eine unkomplizierte SBP liegt vor bei Fehlen von Schock, Ileus, gastrointestinaler Blutung, schwergradiger Enzephalopathie oder Serumkreatinin $<3 \mathrm{mg} / \mathrm{dl}$ [265]. Die Empfehlung deckt sich mit aktuellen internationalen Empfehlungen [263, 264]. Randomisierte kontrollierte Studien mit unterschiedlichen Therapieregimen liegen für die ambulant erworbene unkomplizierte SBP nicht vor. Eine Chinolontherapie kann kalkuliert aufgrund der Resistenzraten von E. coli und anderen Enterobakterien nicht mehr empfohlen werden.

Für die nosokomiale SBP ist die Therapieentscheidung schwieriger. Es ist ein deutlicher Anstieg von multiresistenten Gramnegativen Erregern (vor allem E. coli) bei Patienten mit SBP zu erkennen [266, 267]. So betrug die Rate multiresistenter Bakterienisolate aus Aszites im Zeitraum 1991-1995 noch 8\% und im Vergleichszeitraum $1996-2001$ bereits 38\% [224]. Dabei ist insbesondere die Durchführung einer SBP-Prophylaxe z. B. infolge dauerhafter Chinolon-Einnahme mit einer hohen Rate an Chinolonresistenz bei gram-negativen Isolaten assoziiert (65 vs. 29\%) [224]. Aktuelle deutsche Daten mit einer prospektiven [268] und mehreren retrospektiven Studien [269, 270] zeigen eine Zunahme der Resistenz gegenüber Cephalosporinen der 3. Generation. Hierbei ist allerdings zu beachten, dass diese Studien in hohem Anteil vortherapierte Patienten und Patienten mit nosokomial-erworbener SBP eingeschlossen haben [268-270]. Bei Unterscheidung von Patienten mit ambulant-erworbener SBP, vortherapierten Patienten und Patienten mit nosokomial-erworbener SBP [271 - 273] zeigen neuere Studien eine Resistenz von 7,1\% gegenüber Drittgenerations-Cephalosporinen in der ambulanten Situation [274]. Auch in Deutschland zeigt sich eine Zunahme der Resistenzraten gegenüber Drittgenerations-Cephalosporinen bei E. coli und Gram-negativen Enterobakterien. Generell sind diese jedoch noch so niedrig, dass bei der unkomplizierten ambulant-erworbenen SBP eine Therapie mit Cephalosporinen der 3. Generation empfohlen werden kann [275 - 278].

Ein Unterschied in der Wirksamkeit zwischen einer hohen (4-mal $2 \mathrm{~g}$ i. v.) und einer niedrigen (2-mal $2 \mathrm{~g}$ i. v.) Cefotaximdosis konnte nicht gezeigt werden. Aus pharmakokinetischen Erwägungen ist jedoch der häufigeren Verabreichung von Cefotaxim (z. B. 3-mal 1-2g i.v.) oder Ceftriaxon mit deutlich längerer Halbwertszeit und 1-mal täglicher Gabe (1-mal $2 \mathrm{~g}$ i.v.) der Vorzug bei der Behandlung der SBP zu geben.

Bei nosokomialer Situation muss zunehmend mit (multi-)resistenten Erregern der SBP gerechnet werden, was mit einer deutlich erhöhten Mortalität assoziiert zu sein scheint [263, 264]. Insbesondere ist bei der in den letzten Jahren stark gestiegenen Chinolon-Resistenz von E. coli die Möglichkeit der Resistenz gegen diese Antibiotika-Klasse zu beachten. Resistenzen gegen Cephalosporine der 3. Generation sind zunehmend häufiger bei nosokomialer oder komplizierter SBP, wobei auch hier als entscheidender Risiko- faktor die Vortherapie mit Antibiotika zu nennen ist [263, 264, 279, 280]. Allerdings liegen keine prospektiven randomisierten Therapiestudien mit hoher Qualität (zwei kleine Studien mit Limitationen) [281, 282] zum Einsatz alternativer Antibiotikaregimes vor. In der einzigen randomisierten prospektiven Studie zur Primärtherapie bei nosokomialer SBP zeigt sich kein klinischer Nachteil für Patienten mit initialer Behandlung mit Drittgenerations-Cephalosporin, wobei die Studie aufgrund der sehr kleinen Patientenzahl ( $n=32 ; n=16$ pro Untersuchungsarm) nur bedingt aussagefähig ist und ein strenges Eskalationsregime bei Therapieversagen angewandt wurde [281].

Zusätzlich muss bei nosokomialer SBP neben einer Zunahme von intrinsisch Cephalosporin-resistenten Enterokokken [269, 270, 283] vermehrt mit schwer therapierbaren Gram-positiven Erregern gerechnet werden (z. B. MRSA und Vancomycin-resistente Enterokokken). Auch dies betrifft vornehmlich Patienten mit Antibiotika-Vortherapie. So ist eine Chinolon-Prophylaxe bei Zirrhosepatienten mit einem erhöhten Risiko einer MRSA-Besiedlung assoziiert [284, 285].

Vergleichbar hohe Raten von Antibiotika-resistenten Erregern konnten in Studien aus Deutschland nachgewiesen werden [268, 269]. Daher sollte bei jeglicher Antibiotikatherapie von Patienten mit nosokomialer oder komplizierter SBP die lokale Resistenzlage vor Ort und die Vortherapien Berücksichtigung finden. Vorgeschlagen zur empirischen Therapie bei nosokomial erworbenen Infektionen sind zum Zeitpunkt der Erstellung der Leitlinie in erster Linie Piperacillin/Tazobactam (bei niedrigen Raten von Erregern mit Resistenzen gegen Drittgenerations-Cephalosporinen) und Carbapeneme [263, 264]. Dabei wird optional die empirische Gabe eines Glykopeptids additiv besonders vor dem Hintergrund der Nephrotoxizität kontrovers diskutiert und sollte zurückhaltend erfolgen. Ob der Einsatz von Piperacillin/Tazobactam aufgrund der Wirksamkeit bei ampicillinsensiblen Enterokokken einen Vorteil gegenüber dem Einsatz eines Cephalosporins der 3. Generation bietet, ist bisher nicht systematisch untersucht worden.

Nach Erhalt der Resistenztestung sollte die Antibiotikatherapie gezielt umgestellt werden, und zwar auf ein Präparat, welches das Isolat mit möglichst schmalem Spektrum und hoher antimikrobieller Aktivität erfasst.

Zur Therapie der Rekurrenz einer SBP unter Sekundärprophylaxe liegen keine prospektiv randomisierten Studien vor. In diesem Zusammenhang sollten die obengenannten Empfehlungen zur nosokomial erworbenen SBP angewendet werden.

Eine Behandlung mit Aminoglykosiden sollte wegen des hohen Risikos von additiver Nephrotoxizität bei Patienten mit Leberzirrhose und SBP nach Möglichkeit vermieden werden. Dies gilt insbesondere, wenn bereits eine eingeschränkte Nierenfunktion vorliegt, z. B. bei HRS. Ferner scheint die Effektivität der SBP-Behandlung mit Aminoglykosiden ohnehin geringer zu sein als mit $\beta$-Laktam-Antibiotika [286 - 288]. Patienten mit bekannter Penicillin-Allergie können mit geringem Kreuzallergie-Risiko mit Cephalosporinen, solche mit Cephalosporin-Allergie ggf. mit Carbapenemen behandelt werden. Gegenüber Chinolonen besteht bei Penicillinallergie keinerlei Kreuzallergie. 


\section{EMPFEHLUNG 3.4}

Der Erfolg der Antibiotikatherapie der SBP sollte klinisch sowie mittels diagnostischer Kontrollpunktion des Aszites ca. $48 \mathrm{~h}$ nach Beginn der Therapie beurteilt werden. Empfehlung, starker Konsens

\section{Kommentar}

Durch die o. g. Antibiotika wird in etwa $90 \%$ der Fälle eine Ausheilung der SBP erzielt. Dies ist mit einem Abklingen bestehender Symptome und Verschwinden von Infektzeichen (falls vorher vorhanden) begleitet. Allerdings sind diese Kriterien nicht zuverlässig. Daher wird als Parameter für den Therapieerfolg die Kinetik der PMN-Zahl im Aszites verwendet und eine Verlaufspunktion des Aszites nach $48 \mathrm{~h}$ Antibiotikatherapie empfohlen. Hierbei gilt es zu betonen, dass die Höhe der peripheren Leukozytose nicht mit der PMN-Zahl im Aszites und/oder deren Verlauf korreliert [289]. Als Kriterium für einen adäquaten Therapieerfolg wird ein Abfall der PMN-Konzentration im Aszites positiv prädiktiv für das Ausbleiben einer Rezidiv-SBP genutzt [290]. Obwohl keine gezielte Untersuchung einen klaren minimalen Grenzwert für den Abfall der PMN in der Verlaufspunktion des Aszites definiert hat, wurde vormals eine Abnahme um wenigstens $25 \%$ des Ausgangswerts als sinnvoll erachtet [54]. Dies beruht auf einer retrospektiven Beobachtung zur Halbwertszeit der PMN im Aszites nach Einleitung einer Antibiotikatherapie bei Vorliegen einer SBP [291]. Ferner zeigte eine prospektive Evaluation, dass der prozentuale Abfall der PMN-Zahl im Aszites nach 48 h einer Antibiotikabehandlung bei Patienten, welche überlebten, mit $92 \pm 9 \%$ signifikant stärker ausfiel als bei Patienten, die verstarben (66 $\pm 38 \%$ ) [292]. Im Falle einer klinischen Besserung und Nachweis eines PMN-Abfalls auf $<250 / \mathrm{mm}^{3}$ Aszites sollte die antibiotische Behandlung nach fünf Tagen beendet werden und eine Sekundärprophylaxe (s. u.) eingeleitet werden. Eine Verlängerung der Behandlungsdauer auf zehn Tage bringt in diesem Fall keinen Vorteil [293]. Sinkt die PMN-Zahl im Aszites in der Kontrollparazentese $48 \mathrm{~h}$ nach Beginn der Antibiotikatherapie nicht um mindestens $25 \%$ des Ausgangswerts ab, sollte die Behandlung modifiziert werden. Ferner sollte jegliche klinische Verschlechterung im Verlauf der Therapie frühzeitig Anlass zum Überdenken des Antibiotikaregimes geben. Dabei ist im Falle einer Kultur-positiven SBP das Antibiogramm und in der empirischen Therapiesituation das Resistenzspektrum vor Ort zu berücksichtigen. Ferner sollte das Vorliegen einer sekundären Peritonitis differenzialdiagnostisch in dieser Situation betrachtet werden.

\section{EMPFEHLUNG 3.5}

Begleitend zur antibiotischen Therapie soll die Gabe von Albumin intravenös am Tag der Diagnosestellung und am dritten Tag nach Diagnosestellung durchgeführt werden. Starke Empfehlung, starker Konsens

\section{Kommentar}

Begleitend zur antibiotischen Therapie ist die Gabe von Albumin am Tag der Diagnosestellung mit einer Dosis von 1,5 g/kg KG und am dritten Tag nach Diagnosestellung mit $1 \mathrm{~g} / \mathrm{kg}$ KG empfohlen [294, 295]. Diese Empfehlung basiert auf randomisierten kontrollierten Studien (zwei europäische und zwei asiatische RCT) und einer Metaanalyse. Zu beachten ist, dass die Albumindosis zwischen den europäischen und asiatischen Studien variiert. Während die europäischen Studien die obengenannte Dosis untersuchten, wurde in den asiatischen Studien in einer Studie niedrigerer gewichtsunabhängiger Dosen (50 ml $20 \%$ Albumin am ersten und dritten Tag, entsprechend $0,14 \mathrm{~g} / \mathrm{kg} \mathrm{KG}$ für einen 70 kg schweren Patienten) bzw. niedriger Dosen über einen längeren Zeitraum $(0,5-1 \mathrm{~g} / \mathrm{kg} \mathrm{KG}$ in den ersten sechs Stunden und anschließend jeden dritten Tag für 21 Tage) verwendet. Eine randomisierte Untersuchung verglich die Standarddosis mit einer reduzierten Albumindosis $(1,0 \mathrm{~g} / \mathrm{kg}$ am Diagnosetag und $0,5 \mathrm{~g} / \mathrm{kg}$ am dritten Tag nach Diagnosestellung). Nach dieser Untersuchung ergaben sich keine Unterschiede in Bezug auf das Auftreten einer Nierenfunktions-Einschränkung (13,3 [2/24 Pat.] vs. $7,1 \%$ [1/22 Pat.], $p=0,9)$ oder Mortalität (37,5 [9/24 Pat.] vs. $36,4 \%$ [8/22 Pat.], $p=0,9)$. Allerdings sind diese Daten nur als Kurzmitteilung (Letter) publiziert und die Patientengruppen sind klein ( $n=24$ vs. $n=22$ ) [296]. Daher wird aufgrund der robusteren Datenlage durch zwei RCT die Gabe von Albumin am Tag der Diagnosestellung mit einer Dosis von $1,5 \mathrm{~g} / \mathrm{kg} \mathrm{KG}$ und am dritten Tag nach Diagnosestellung mit $1 \mathrm{~g} / \mathrm{kg}$ KG empfohlen.

In der wichtigsten randomisierten kontrollierten Studie mit europäischen Patienten wurde die Gabe von Albumin in der obengenannten Dosis zusätzlich zu einer antibiotischen Therapie bei Patienten mit einer spontan bakteriellen Peritonitis verglichen [294]. In der Gruppe mit Albumin- und Antibiotikatherapie kam es zu einem signifikant niedrigeren Auftreten eines hepatorenalen Syndroms Typ I verglichen mit der Gruppe mit Antibiotikatherapie ohne Albumingabe (10 vs. 33 \%) [294]. Weiterhin konnte in dieser Studie eine signifikante Abnahme der Krankenhausmortalität (10 vs. $29 \%$ ) und der Drei-Monats-Mortalität (22 vs. $41 \%$ ) in der Albumin-Antibiotikagruppe verglichen zur Antibiotikagruppe beobachtet werden [294]. Die Therapie mit Albumin war besonders effektiv in der Hochrisikogruppe von Patienten mit höherem Bilirubin $(\geq 68 \mu \mathrm{mol} / \mathrm{l}[4 \mathrm{mg} / \mathrm{dl}])$ und höherem Kreatinin $(\geq 88 \mu \mathrm{mol} / \mathrm{l}$ [1 mg/dl]). Inwieweit eine Albumingabe allen Patienten mit SBP oder nur in der Hochrisikogruppe gegeben werden sollte, ist nicht eindeutig geklärt. Daten die eine Gabe nur in der Hochrisikogruppe als vorteilhaft zeigen, liegen nur in Form einer Kurzmitteilung (Letter) vor, sodass keine endgültige Empfehlung dazu gegeben werden kann [297].

Die Ergebnisse zur Albumingabe bei SBP wurden in einer Metaanalyse aus dem Jahr 2013 untersucht/zusammengefasst. In dieser Metaanalyse wurden im Wesentlichen die vier obengenannten RCT inkorporiert. Die Ergebnisse zeigten eine signifikante Verbesserung der Nierenfunktion in der Gruppe der Patienten mit Gabe von Albumin und Antibiotika verglichen mit der Gruppe von Patienten mit ausschließlicher Therapie mit Antibiotika (OR 0,21 [Cl 0,11 - 0,42]) [298]. In der Metaanalyse konnte auch ein Vorteil im Überleben mit längeren Überlebenszeiten in der Gruppe der Patienten mit Albumingabe gezeigt werden (OR 0,34 [Cl 0,19-0,60]). 
Eine weitere randomisierte Studie beschäftigte sich mit der Frage der Gabe eines Plasmaexpanders anstelle von Albumin [295]. Die Ergebnisse zeigen, dass die positiven Effekte auf die Systemzirkulation (Anstieg der Blutdruckes, Anstieg des rechtsatrialen Druckes, Anstieg des systolischen Volumens, Anstieg der Herzleistung und Anstieg des peripheren Gefäßwiderstandes) nur in der Gruppe mit Albumingabe vorhanden waren [295]. Im Gegensatz dazu zeigten die Patienten in der Gruppe des Plasmaexpanders keine relevanten Veränderungen der Systemhämodynamik. Es wird daher von einem Ersatz des Albumins durch einen Plasmaexpander abgeraten.

\subsection{Sekundärprophylaxe und Nachsorge der SBP}

\section{EMPFEHLUNG 3.6}

Nach erfolgreicher Therapie einer SBP soll eine Sekundärprophylaxe mittels Norfloxacin $400 \mathrm{mg}$ pro Tag erfolgen.

Starke Empfehlung, starker Konsens

Alternativen zu Norfloxacin in der Sekundärprophylaxe stellen Rifaximin, Trimethoprim-Sulfamethoxazol oder Ciprofloxacin dar.

Empfehlung offen, starker Konsens

Bei Patienten mit durchgemachter SBP sollte die Indikation zur Lebertransplantation geprüft werden.

Empfehlung, starker Konsens

\section{Kommentar}

Die Wahrscheinlichkeit des erneuten Auftretens einer SBP nach Erstmanifestation ohne Einleitung einer Prophylaxe beträgt bis zu $69 \%$ innerhalb eines Jahres [227]. Das höchste Risiko der Rekurrenz wiesen in dieser Studie Patienten mit einem Aszitesprotein $\leq 10 \mathrm{~g} / \mathrm{l}$ und/oder einem Quick-Wert $\leq 45 \%$ auf [227]. Insgesamt liegen aktuell vier kontrollierte Studien vor, welche die Wirksamkeit einer sekundären antibiotischen Prophylaxe prospektiv, kontrolliert, ausschließlich an einem Patientenkollektiv mit durchgemachter SBP untersucht haben. Dabei liegt nur eine Placebokontrollierte Studie vor, welche durch den Einsatz von Norfloxacin (400 mg/Tag) die Einjahreswahrscheinlichkeit eines SBP-Rezidivs von $68 \%$ in der Placebo-Gruppe auf $20 \%$ in der Verumgruppe signifikant senken konnte [226].

Drei weitere randomisierte Studien verglichen den Einsatz einer antibiotischen Sekundärprophylaxe gegen den Standard Norfloxacin unter unverblindeten [299, 300] oder einfach verblindeten [301] Bedingungen. Bauer et al. [299] verglichen den täglichen Einsatz von Rufloxacin (400 mg/Woche) mit dem von Norfloxacin $(400 \mathrm{mg} / \mathrm{Tag})$ ohne signifikante Unterschiede in der Einjahreswahrscheinlichkeit eines SBP-Rezidivs (36\% unter Rufloxacin vs. $26 \%$ unter Norfloxacin, n. s.). Allerdings zeigten sich unter einer nur einmal wöchentlichen Rufloxacin-Gabe signifikant mehr SBP-Fälle durch Enterobacteriaceae (22 vs. $0 \%$ ). Mostafa et al. [301] verglichen Rifaximin ( $800 \mathrm{mg} / \mathrm{Tag})$ mit Norfloxacin (400 mg/Tag) und beobachteten eine SBP-Rekurrenz bei $0 \%$ der Patienten mit Rifaximin versus $17 \%$ der Patienten mit Norfloxacin innerhalb des Beobachtungszeitraumes von sechs Monaten $(p=0,01)$. In der bislang größten Studie in der Sekundärprophylaxe der SBP untersuchten Elfert et al. [300] die Wirksamkeit von Rifaximin (1200 mg/Tag) im Vergleich zu Norfloxacin (400 mg/Tag). Innerhalb von sechs Monaten entwickelten $4 \%$ der mit Rifaximin behandelten Patienten im Vergleich zu 14\% der mit Norfloxacin Patienten eine erneute SBP $(p=0,04)$. Primärer Endpunkt dieser vier kontrollierten Studien war das Wiederauftreten einer SBP und nicht Mortalität. Obwohl auf Nicht-Unterlegenheit von Rifaximin gegenüber Norfloxacin in der Effektivität der SBPRezidivprophylaxe angelegt, zeigte sich in der Studie von Elfert et al. [300] für den sekundären Endpunkt Sechs-Monats-Mortalität ein Vorteil von Rifaximin (14\%) gegenüber Norfloxacin (24\%; $\mathrm{p}=0,04)$.

Insgesamt sechs weitere Interventionsstudien untersuchten die Wirksamkeit von Ciprofloxacin [230], Trimethoprim-Sulfamethoxazol [261, 262, 302], Rifaximin [303] oder Norfloxacin [304] zur Verhinderung einer SBP, schlossen jedoch Patienten mit und ohne stattgehabte SBP ein.

Obwohl die randomisierte, adäquat gepowerte Studie von Elfert et al. [300] eine Überlegenheit von Rifaximin gegenüber Norfloxacin in der Sekundärprophylaxe suggeriert, lassen i) das monozentrische, unverblindete Design, ii) der Ausschluss von Patienten mit hepatischer Enzephalopathie, iii) die erhobene, jedoch nicht berichtete Therapieadhärenz und iv) das gewählte Dosierungsschema eine generelle Empfehlung als Erstlinientherapie in der Sekundärprophylaxe derzeit noch nicht zu. An dieser Aussage ändern auch i) das zuletzt erschienene Review mit Zusammenfassung aller Rifaximin-Daten im Vergleich zu Norfloxacin, welches zumindest keine Unterlegenheit für Rifaximin nahelegt [305] wie auch ii) die erwähnte Metaanalyse [306] mit Subgruppen-Analyse zur Effektivität von Rifaximin in der Sekundärprophylaxe und Zusammenfassung der beiden genannten Studien [300, 301] (mit berichteter OR 0,2, $95 \%$ KI 0,07-0,59) nichts, da die Metaanalyse die Schwächen der einzelnen Datensets nicht ausgleichen kann. Aktuell scheint jedoch ein alleiniger Einsatz bei Patienten, die eine SBP durchgemacht haben und Rifaximin zur Rezidivprophylaxe einer hepatischen Enzephalopathie erhalten und bei Patienten mit Kontraindikationen zur Chinolontherapie und ggf. bei Patienten, bei denen Chinolonresistenzen unter Norfloxacintherapie auftreten, aufgrund der positiven Studienergebnisse gerechtfertigt.

Die sinnvolle Dauer einer antibiotischen Prophylaxe zur Verhinderung eines SBP-Rezidivs wurde bisher in keiner prospektiven Studie ausreichend evaluiert. Allerdings erscheint aufgrund des erhöhten Risikos der Selektion resistenter Keime eine zeitliche Limitierung sinnvoll, z. B. dann, wenn eine Verbesserung der Child-Pugh-Klasse und/oder Resolution des Aszites erreicht wird. 


\section{Hepatorenales Syndrom}

\subsection{Definitionen}

\section{DEFINITION 4.1}

Das hepatorenale Syndrom (HRS) ist definiert als potenziell reversible Nierenfunktionsstörung bei Patienten mit Leberzirrhose und Aszites oder bei Patienten mit alkoholischer Steatohepatitis. Es werden zwei Formen unterschieden [307]:

HRS Typ I ist charakterisiert durch rasches Nierenversagen, definiert als Verdoppelung des Serumkreatinins auf über $2,5 \mathrm{mg} / \mathrm{dl}(226 \mathrm{mmol} / \mathrm{l})$ in weniger als zwei Wochen.

HRS Typ II ist oft mit refraktärem Aszites vergesellschaftet und zeigt ein moderates Nierenversagen mit Serumkreatininwerten zwischen 1,5 und $2,5 \mathrm{mg} / \mathrm{dl}$ (133 bis $226 \mathrm{mmol} / \mathrm{l}$ ) bei stabilem oder langsam fortschreitendem Verlauf.

\section{DIAGNOSTISCHE KRITERIEN}

- Zirrhose mit Aszites (oder alkoholische Steatohepatitis)

- Serumkreatinin >1,5 mg/dl (>133 mmol/l).

- Keine Besserung des Serumkreatinins auf Werte $<1,5 \mathrm{mg} / \mathrm{dl}$ nach mindestens zweitägiger Pausierung aller Diuretika und Volumenexpansion mit Albumin. Die empfohlene Albumindosierung beträgt $1 \mathrm{~g} / \mathrm{kg}$ Körpergewicht pro Tag bis zu einem Maximum von $100 \mathrm{~g} /$ Tag.

- Ausschluss eines Schockgeschehens

- Keine laufende oder kürzlich erfolgte Therapie mit nephrotoxischen Medikamenten.

- Ausschluss einer parenchymatösen Nierenerkrankung (keine Proteinurie $>500 \mathrm{mg} /$ Tag und

- unauffälliges Urinsediment und keine Mikrohämaturie $>50$ Erythrozyten/HPF und unauffällige Nierensonografie).

Akute Nierenschädigung (Acute Kidney Injury, AKI) umfasst alle Ursachen einer Nierenfunktionsverschlechterung gemessen an einem Anstieg des Serumkreatinins über $50 \%$ des Ausgangswertes innerhalb einer Woche oder einem Anstieg $\geq 26,4 \mu \mathrm{mol} / \mathrm{l}$ ( $\geq 0,3 \mathrm{mg} / \mathrm{dl}$ ) innerhalb $48 \mathrm{~h}$. Chronische Nierenerkrankung ist definiert durch eine glomeruläre Filtrationsrate $(G F R)<60 \mathrm{ml} / \mathrm{min}$ berechnet mit der Modification of Diet in Renal Disease 6 (MDRD6)-Formel, bestehend über mindestens drei Monate. Akut auf chronische Nierenschädigung ist definiert als eine akute Nierenschädigung bei vorbestehender Nierenerkrankung, definiert durch die Kombination der o.g. diagnostischen Kriterien.

\section{Kommentar}

Ein Nierenversagen kann aufgrund der niedrigen Muskelmasse von Patienten mit Leberzirrhose auch bei einem niedrigeren Kreatinin vorliegen. Im klinischen Alltag soll deshalb bei raschem
Anstieg des Serumkreatinins oder signifikantem Abfall der Diurese bereits vor Erreichen der o. g. Grenzwerte eine rasche Diagnostik und gegebenenfalls therapeutische Intervention erfolgen. Die neuen diagnostischen Kriterien sollen Nierenfunktionsstörungen bei Patienten mit Leberzirrhose früher erkennen lassen und durch eine frühzeitige Behandlung zu einer verbesserten Prognose führen $[308,309]$.

\subsection{Nierenversagen bei Leberzirrhose}

\section{STATEMENT 4.1}

Nierenversagen ist die häufigste Manifestation (> $50 \%$ ) eines Akut-auf-chronischen Leberversagens.

Starker Konsens

\section{STATEMENT 4.2}

Akut-auf-chronisches Leberversagen ist mit einer erhöhten Mortalität verbunden und der CLIF-C ACLF-Score erlaubt diesbezüglich eine exaktere Prognose als MELD, MELD-Na und Child-Pugh-Score.

Starker Konsens

\section{EMPFEHLUNG 4.3}

Bei akuter Dekompensation einer chronischen Lebererkrankung kann Cystatin C im Serum oder Plasma zur Beurteilung eines AKI bzw. der Prognose bestimmt werden. Empfehlung offen, Konsens

\section{Kommentar}

In einer richtungsweisenden, prospektiven Europäischen multizentrischen Studie [310] an über 1300 Patienten mit Leberzirrhose/fortgeschrittener chronischer Lebererkrankung konnte gezeigt werden, dass ein ACLF selbst bei gut erhaltener Leberfunktion auftreten kann und vor allem durch extrahepatische Organversagen determiniert wird. Als akute Auslöser werden vor allem entzündliche Prozesse postuliert. Eine rasche Verschlechterung ist mit einer hohen Mortalität verbunden, es wurde jedoch auch das Potenzial zur Reversibilität demonstriert. Mit $56 \%$ lag in dieser Studie das Nierenversagen (definiert an einem Serumkreatinin zwischen 1,5 und 1,9 mg/dl) an erster Stelle der Organkomplikationen.

Aus diesen Daten wurde der sogenannte „CLIF-C ACLF-Score“ ermittelt [311], welcher sich in seiner Aussagekraft bezüglich der Mortalität hinsichtlich anderer etablierter Klassifikationen überlegen zeigte.

Dies konnte inzwischen auch in mehreren externen Kohortenstudien validiert werden [312, 313].

Gegenüber dem Serumkreatinin, welches insbesondere bei kachektischen Patienten mit fortgeschrittener Lebererkrankung häufig verspätet eine akute Nierenschädigung erkennen lässt, 
weist Cystatin C eine höhere Sensitivität auf [314]. Zudem zeigen aktuelle Studien, dass Cystatin C ein geeigneter Biomarker für die Vorhersage von Nierenschädigung, hepatorenalem Syndrom, Akut-auf-chronischem Leberversagen und der kurzfristigen Mortalität von Patienten mit dekompensierter Leberzirrhose ist [315-317].

\subsection{Albumingabe bei HRS}

\section{EMPFEHLUNG 4.4}

Die intravenöse Albumingabe zum Ausschluss eines Volumenmangels bzw. zur Sicherung der Diagnose eines hepatorenalen Syndroms sollte in einer Dosierung von $1 \mathrm{~g}$ pro kg Körpergewicht, bis maximal $100 \mathrm{~g} /$ Tag über zwei Tage erfolgen. Empfehlung, starker Konsens

\section{EMPFEHLUNG 4.5}

Die Kombinationsbehandlung aus Albumininfusion 20 $40 \mathrm{~g} /$ Tag und Vasokonstriktortherapie ist Therapie der ersten Wahl bei hepatorenalem Syndrom.

Die fortgesetzte alleinige Albumininfusion soll nicht durchgeführt werden. Andere Plasmaexpander können in dieser Indikation aufgrund der unzureichenden Datenlage auch weiterhin nicht empfohlen werden.

Starke Empfehlung, starker Konsens

\section{Kommentar}

Während in der ersten Fassung der diagnostischen Kriterien des HRS u. a. das fehlende Ansprechen auf Volumenexpansion mit 1,5 I isotoner Kochsalzlösung gefordert wurde [183], wurde dies in der Revision durch die Volumenexpansion mit Humanalbumin in einer Dosierung von $1 \mathrm{~g}$ pro kg Körpergewicht bis zu einem Maximum von $100 \mathrm{~g}$ pro Tag über zwei Tage geändert [307]. Hintergrund war die pathophysiologische Überlegung, dass isotone Kochsalzlösung bei Patienten mit HRS rasch in die Peritonealhöhle filtriert wird und somit eine Erhöhung des zentralen Blutvolumens schlechter möglich ist als mit Albumin. Auch in der aktualisierten Empfehlung des International Club of Ascites wird sich für dieses Vorgehen ausgesprochen, sofern ein Absetzen aller Diuretika und potenziell nephrotoxischen Medikamente nicht zu einer Stabilisierung der Nierenfunktion führt [172].

In mehreren kontrollierten Studien zum Nutzen von Terlipressin wurden die Patienten im Kontrollarm mit Albumininfusionen behandelt [318-321]. Hierbei kam es in einer Studie bei keinem der ausschließlich mit Albumin behandelten Patienten zu einem Ansprechen und alle Patienten aus dem Kontrollarm waren an Tag 15 zum Studienende verstorben [318]. Bessere Ansprechraten ergaben sich in den Kontrollarmen der Studien von Sanyal et al. (komplettes Ansprechen bei 13\%) [319], Martin-Llahí M et al. (Besserung der Nierenfunktion bei 9\%) [320] und Neri et al. (komplettes Ansprechen bei 19\%, partielles Ansprechen bei 16\%) [321].
Zusammenfassend führt die alleinige Albumininfusion somit nur bei wenigen Patienten mit HRS zu einer Besserung der Nierenfunktion.

Die Frage, ob eine Albumininfusion zusätzlich zur Terlipressingabe erforderlich ist, wurde in einer Fall-Kontroll-Studie an Patienten mit HRS Typ I oder II untersucht [322]. In dieser Studie wurde bei 13 Patienten, die Terlipressin mit Albumin erhielten, ein Abfall der Serumkreatininkonzentration von $3,6 \pm 0,5 \mathrm{mg} / \mathrm{dl}$ auf 1,5 \pm $0,2 \mathrm{mg} / \mathrm{dl}$ zum Studienende beobachtet, wohingegen die mittlere Kreatininkonzentration bei acht Patienten, die nur Terlipressin erhielten, weitgehend konstant blieb $(3,4 \pm 0,3 \mathrm{mg} / \mathrm{dl}$ vs. 3,4 \pm $0,7 \mathrm{mg} / \mathrm{dl}$ ). Hieraus kann gefolgert werden, dass der Effekt der Vasokonstriktortherapie mit Terlipressin durch die regelmäßige Albumininfusion signifikant verbessert werden kann.

Lediglich eine Fallserie zum Einsatz von Gelatinepolysuccinat in Kombination mit Terlipressin [323] zeigte eine Verbesserung der Nierenfunktion bei 5 von 7 Patienten mit HRS Typ I oder II. Hierbei kam es zu einem Abfall der mittleren Serumkreatininkonzentration von 3,9 $\pm 0,4 \mathrm{mg} / \mathrm{dl}$ auf $1,9 \pm 0,3 \mathrm{mg} / \mathrm{dl}$. Direkte Vergleichsstudien zwischen Albumin und synthetischen Plasmaexpandern existieren für Patienten mit HRS nicht, sodass eine Gleichwertigkeit zur Albumininfusion nicht belegt ist. Gerade bei sehr schlechter Nierenfunktion sollte die Gabe von Hydroxyäthylstärke aber mit größter Zurückhaltung betrieben werden, da sie insbesondere bei septischen Patienten zu einem akuten Nierenversagen führen kann [324].

\subsection{Vasokonstriktoren bei HRS}

\section{EMPFEHLUNG 4.6}

Sofern keine Kontraindikationen vorliegen, sollen Patienten mit hepatorenalem Syndrom Typ I mit Terlipressin und Albumin behandelt werden, da dies das kurzfristige Überleben signifikant verbessert.

Starke Empfehlung, starker Konsens

\section{EMPFEHLUNG 4.7}

Diese Therapie soll mit einer Terlipressindosis von 2-4 mg/ Tag begonnen werden und über einen Zeitraum von mindestens 3 Tagen durchgeführt werden. Terlipressin soll maximal in einer Dosis von $12 \mathrm{mg} /$ Tag eingesetzt werden. Starke Empfehlung, starker Konsens

\section{EMPFEHLUNG 4.8}

Statt einer wiederholten Bolusapplikation kann Terlipressin beim hepatorenalen Syndrom auch als kontinuierliche Infusion verabreicht werden (initiale Dosis $3 \mathrm{mg}$ über 24 Stunden).

Empfehlung offen, starker Konsens 


\section{EMPFEHLUNG 4.9}

Ein Nutzen dieser Therapie für Patienten mit HRS Typ II ist bislang nicht klar belegt, deswegen sollten diese Patienten analog zu Patienten mit refraktärem Aszites behandelt werden. Empfehlung, starker Konsens

\section{EMPFEHLUNG 4.10}

Unter intensivmedizinischem Monitoring kann bei hepatorenalem Syndrom auch zunächst ein Therapieversuch mit kontinuierlicher Noradrenalin-Gabe gemacht werden. Für andere Vasokonstriktoren ist ein Nutzen beim hepatorenalen Syndrom nicht belegt.

Empfehlung offen, starker Konsens

\section{EMPFEHLUNG 4.11}

Wird aus anderer Indikation eine kontinuierliche Noradrenalin-Gabe durchgeführt, soll keine additive Terlipressingabe erfolgen.

Starke Empfehlung, Konsens

\section{Kommentar}

Der Nutzen der Vasokonstriktortherapie, insbesondere mit Terlipressin, ist durch zahlreiche Studien belegt und mittlerweile in drei Metaanalysen bestätigt [325 - 327]. In der Analyse von Fabrizi et al. flossen 5 Studien ein, in denen je 126 Patienten mit HRS entweder mit Terlipressin oder Placebo behandelt wurden. Es zeigte sich eine signifikante Verbesserung der Nierenfunktion mit Terlipressin (OR 8,09 95 \% Cl 3,52 - 8,59), ischämische Nebenwirkungen traten häufiger auf (OR 2,9195\% Cl 1,09-7,72), ein Überlebensvorteil wurde nicht beobachtet (OR 2,06 $95 \% \mathrm{Cl}$ $0,94-4,54)$. Eine weitere Metaanalyse [326] fasste zehn Studien zusammen, in denen 188 Patienten mit HRS mit Vasokonstriktoren (Terlipressin, Midodrin + Octreotid und Noradrenalin) und 190 ausschließlich mit Albumin behandelt wurden. Es fand sich eine reduzierte Mortalität bei allen Vasokonstriktoren vs. Albumin (OR 0,82 95\% Cl 0,70-0,96), in der Subgruppenanalyse nur an Tag 15, nicht jedoch nach 30, 90 oder 180 Tagen. Stratifiziert nach der Art der Behandlung ergab sich eine reduzierte Mortalität nur bei Terlipressin (OR 0,81 95\% Cl 0,68-0,97). Die Metaanalyse von Sagie et al. wertete vier Studien aus, in denen ausschließlich Patienten mit HRS Typ 1 behandelt wurden, davon erhielten 111 Terlipressin und 112 Placebo plus Albumin. Es zeigte sich eine signifikante Verbesserung der Nierenfunktion unter Terlipressin (OR 3,66 $95 \% \mathrm{Cl} 2,15$ - 6,23); schwere Nebenwirkungen bei 6,8\% und ein tendenzieller Überlebensvorteil an Tag 90 (OR 1,86 $95 \% \mathrm{Cl}$ $1,0-3,4)$.

Aufgrund der geringen Zahl an Patienten mit HRS Typ II, die in kontrollierten Studien untersucht wurden, kann auch in Anbetracht der signifikanten Nebenwirkungen für diese Patienten derzeit keine Therapieempfehlung ausgesprochen werden. Für Patienten mit HRS Typ I scheint nach mindestens dreitägiger Terlipressingabe die kurzfristige Überlebenswahrscheinlichkeit verbessert, was für Patienten auf der Transplantationswarteliste relevant sein kann.

Dass die kontinuierliche Gabe von Terlipressin [328] der intermittierenden Bolusgabe hinsichtlich des Nebenwirkungsprofils überlegen ist, konnte unlängst in einer prospektiven randomisierten Studie gezeigt werden [329].

Bezüglich anderer Vasokonstriktoren kann lediglich für Noradrenalin eine Empfehlung ausgesprochen werden [330], welches in einer Metaanalyse eine vergleichbare Erfolgsrate zeigte wie Terlipressin. Die Verabreichung von Noradrenalin sollte jedoch nur auf Intensivtherapiestationen erfolgen. Für Midodrin plus Octreotid kann derzeit aufgrund der sehr niedrigen Fallzahlen keine eindeutige Empfehlung ausgesprochen werden.

Die Kontrolle des Ansprechens auf die Vasokonstriktortherapie erfolgt klinisch (Zunahme der Diurese) und laborchemisch (Abfall des Serumkreatinins). Zeigt sich innerhalb von drei Tagen kein Ansprechen, sollte die Terlipressindosis stufenweise auf die Höchstdosis von $12 \mathrm{mg}$ gesteigert werden. Fehlendes Ansprechen auf diese Dosis macht einen Therapieerfolg unwahrscheinlich. Zeigt sich ein Ansprechen auf die Vasokonstriktortherapie, sollte bis zu einer Normalisierung der Nierenfunktion, zumindest aber bis zum Erreichen eines Serumkreatinins $<1,5 \mathrm{mg} / \mathrm{dl}$ behandelt werden. Wichtig ist in jedem Fall die Kombination der Therapie mit Albumininfusionen [322].

\subsection{TIPS bei HRS}

\section{EMPFEHLUNG 4.12}

Die Anlage eines transjugulären intrahepatischen portosystemischen Shunts (TIPS) sollte bei allen Patienten mit HRS erwogen werden.

Empfehlung, starker Konsens

\section{Kommentar}

Nach TIPS-Anlage wird eine Verbesserung der Nierenfunktion bei Patienten mit refraktärem Aszites beobachtet [331, 332]. In bislang vier prospektiven unkontrollierten Studien wurde der Effekt des TIPS auf die Nierenfunktion bei Patienten mit HRS untersucht [197, 333 - 335]. In der ersten Studie wurden sieben Patienten mit HRS Typ I (Serumkreatinin 2,7 - 7,9 mg/dl, Bilirubin 0,8-19 mg/dl) einer TIPS-Anlage unterzogen. Eine Verbesserung der Nierenfunktion wurde bei sechs von sieben Patienten bereits nach sieben Tagen beobachtet. Bei diesen sechs Patienten kam es bis Tag 30 nach TIPS zu einem weiteren, deutlichen Abfall des Kreatinins auf $1,8 \pm 0,8 \mathrm{mg} / \mathrm{dl}$ (vs. $5,0 \pm 0,8 \mathrm{mg} / \mathrm{dl}$ vor TIPS). Das mediane Überleben dieser Patienten betrug 4,7 \pm 2,0 Monate.

Eine weitere Kohorte [197] umfasste 41 Patienten, davon 21 mit HRS Typ I und 20 mit HRS Typ II. 14 Patienten mit HRS Typ I (66\%) und 17 mit HRS Typ II (85\%) wurden einer TIPS-Anlage unterzogen, die restlichen Patienten wurden wegen Kontraindikationen (Bilirubin $\geq 15 \mathrm{mg} / \mathrm{dl}$, Child-Pugh Score $>12$ Punkte oder spontane hepatische Enzephalopathie) nicht mit einem TIPS 
versorgt und der spontane Krankheitsverlauf beobachtet. Bei 24 von 31 Patienten zeigte sich eine Verbesserung der Nierenfunktion mit Mobilisierung des Aszites, was mit einer signifikanten Verlängerung des Überlebens verbunden war (50\% vs. $0 \%$ nach zwölf Monaten). Das Überleben von Patienten mit HRS Typ II nach TIPS-Anlage war signifikant besser als das von Patienten mit HRS Typ I (59 vs. 14\% nach zwölf Monaten). In einer Multivarianzanalyse wurden das Serumbilirubin und der Child-Pugh Score vor TIPS, nicht aber das Serumkreatinin als Prädiktoren für das Überleben identifiziert.

In einer weiteren Studie wurden 14 Patienten mit HRS Typ I zunächst medikamentös mit Midodrin und Octreotid behandelt. Vier Non-Responder verstarben, von den zehn Respondern erhielten fünf einen TIPS. Alle fünf Patienten zeigten eine kontinuierliche Verbesserung der Nierenfunktion über einen Verlauf von sechs bis 30 Monaten, wobei ein Patient im Beobachtungszeitraum lebertransplantiert wurde.

Bei 18 Patienten mit HRS Typ II wurde sowohl eine Verbesserung der Nierenfunktion als auch eine komplette (acht Patienten) oder partielle Mobilisierung (zehn Patienten) des Aszites berichtet. Angaben zum medianen Überleben fehlen jedoch in dieser Studie [335].

Zusammenfassend führt die Anlage eines TIPS sowohl bei Patienten mit HRS Typ I als auch Typ II zu einer (längerfristigen) Verbesserung der Nierenfunktion und dadurch möglicherweise auch zu einer Überlebensverlängerung. Kontraindikationen, wie eine vorbestehende Enzephalopathie $\geq$ Grad 2 oder eine eingeschränkte Leberfunktion (Bilirubin $>3-5 \mathrm{mg} / \mathrm{dl}$ ) müssen jedoch beachtet werden.

\subsection{Nieren- und Leberersatzverfahren bei HRS}

\section{EMPFEHLUNG 4.13}

Da Nierenersatzverfahren allein die Prognose bei HRS nicht verbessern, können sie bei Vorliegen von Dialysekriterien vor allem als Überbrückung bis zur Lebertransplantation eingesetzt werden.

Empfehlung offen, starker Konsens

\section{EMPFEHLUNG 4.14}

Die extrakorporale Albumindialyse hat keinen Einfluss auf Nierenfunktion und Überleben bei Patienten mit HRS. Leberersatzverfahren sollten daher bei Patienten mit HRS nur im Rahmen kontrollierter Studien zum Einsatz kommen.

Empfehlung, starker Konsens

\section{Kommentar}

Zum möglichen Nutzen von intermittierender Hämodialyse bzw. kontinuierlicher Hämofiltration existiert lediglich eine Outcome-Research Studie [336]. In dieser Studie war das mediane Überleben unter Nierenersatztherapie 21 Tage. Neben Parametern der Leberfunktion war in einer Multivarianzanalyse die mechanische Beatmung ein unabhängiger Prädiktor für eine frühe Sterblichkeit. Die Autoren schlussfolgern, dass durch intermittierende Hämodialyse Patienten mit HRS bis zur Lebertransplantation überbrückt werden können, bei Patienten mit zusätzlicher respiratorischer Insuffizienz Nierenersatzverfahren aber sinnlos sind.

In einer prospektiven, randomisierten Studie wurde die extrakoporale Albumindialyse (MARS ${ }^{\circledR}$ ) in Kombination mit Hämodiafiltration bei 8 Patienten mit der medikamentösen „Standardtherapie“ plus Hämodiafiltration bei 5 Patienten verglichen [337]. Keiner der Patienten erhielt einen TIPS oder Vasokonstriktoren. Die Kaplan-Meier-Analyse ergab einen signifikanten Überlebensvorteil bis Tag 30 bei Abfall des Serumkreatinins unter laufender Behandlung mit MARS. In einer neueren Untersuchung [338] wurden sechs Patienten mit HRS Typ I, die auf eine Therapie mit Vasokonstriktoren plus Albumin nicht angesprochen hatten, einer fünftägigen Behandlung mit MARS unterzogen. Hierbei konnte keine Verbesserung von renalem Blutfluss, glomerulärer Filtrationsrate oder Diurese gezeigt werden. Entsprechend konnte in einer prospektiven kontrollierten Studie zur Behandlung mit MARS bei Patienten mit Akut-auf-chronischem-Leberversagen kein Überlebensvorteil nachgewiesen werden [339].

Auch unter dem extrakorporalen Leberunterstützungsverfahren Prometheus ${ }^{\circledR}$ zeigte sich eine temporäre Besserung der Nierenfunktionswerte [340]. Eine randomisierte kontrollierte Studie konnte keine Überlebensverlängerung für das Gesamtkollektiv der Patienten mit Akut-auf-chronischem-Leberversagen nachweisen, in einer Subgruppenanalyse war das Überleben von Patienten mit HRS Typ I oder einem MELD-Score über 30 durch die Behandlung mit Prometheus allerdings signifikant verlängert [341].

Zusammenfassend senken extrakorporale Leberunterstützungsverfahren die Serumkonzentration harnpflichtiger Substanzen. Sie haben jedoch keinen langfristigen Einfluss auf die renale Hämodynamik und Diurese bei Patienten mit HRS. Leberersatzverfahren sollten daher derzeit bei Patienten mit HRS nur im Rahmen kontrollierter Studien zum Einsatz kommen.

\subsection{Lebertransplantation bei HRS}

\section{EMPFEHLUNG 4.15}

Die Lebertransplantation ist die einzige potenziell kurative Therapie des HRS und soll bei geeigneten Patienten angestrebt werden.

Starke Empfehlung, starker Konsens

\section{EMPFEHLUNG 4.16}

Auch bei beabsichtigter Lebertransplantation sollten Albumin und Terlipressin verabreicht werden, da Patienten mit Niereninsuffizienz bei Transplantation eine deutlich schlechtere postoperative Prognose haben.

Empfehlung, starker Konsens 


\section{EMPFEHLUNG 4.17}

Bei Patienten mit HRS und einer längerdauernden Dialysepflichtigkeit sollte die Indikation zur Leber- und Nierentransplantation erwogen werden.

Empfehlung, Konsens

\section{Kommentar}

Da die eingeschränkte Leberfunktion mit ihren Folgen die Ursache des hepatorenalen Syndroms ist, stellt die Lebertransplantation die einzige kausale Therapie dar. Nach Normalisierung der Leberfunktion sowie der durch die zirrhotische Leber gestörten Physiologie und Hämodynamik kann es nach Lebertransplantation zu einer deutlichen Besserung oder Normalisierung der Nierenfunktion bei einem Patienten mit HRS kommen [342].

Bei Patienten, die im Zustand eines HRS transplantiert werden, kommt es jedoch in der perioperativen Situation vorübergehend sogar zu einer Verschlechterung der Nierenfunktion, bedingt durch das operative Trauma, eine weitere Nierenschädigung im Rahmen des Ischämie/Reperfusions-Syndroms der Leber, einer perioperativen Flüssigkeitsrestriktion (zur Erreichung eines niedrigen ZVDs) sowie der postoperativen Immunsuppression mit nephrotoxischen Medikamenten (wie z. B. Calcineurin-Inhibitoren). Diese problematischen Aspekte sollen daher perioperativ im Management berücksichtigt werden (z. B. Flüssigkeitsmanagement, Art/Dosis der Immunsuppression etc.).

Da das HRS oft ein Zeichen einer Dekompensation der Leberzirrhose darstellt, ist es ein indirekter Parameter, der auf eine ungünstige Ausgangssituation der Transplantation hinweist. In der Tat ist das Überleben nach Transplantation direkt beeinflusst durch die präoperative Nierenfunktion [343, 344].

Das Kreatinin stellt einen der drei Parameter dar, aus denen sich der MELD-Score errechnet. Dieser Score diente ursprünglich zur Abschätzung des Überlebens von Patienten mit Leberzirrhose ohne Transplantation. Der MELD-Score wird inzwischen in vielen Ländern (und auch in Deutschland) als Basis der Organallokation zur Lebertransplantation (d. h. zur Zuteilung von Organen verstorbener Organspender) angewendet. Da die „klinische Dringlichkeit“ bei der Allokation im Vordergrund steht, bedeutet dies, dass nur Patienten mit hohem MELD-Score (i.d. R. über 30) die Chance haben, ein Organ alloziert zu bekommen. Dies sind häufig Patienten mit einer eingeschränkten Nierenfunktion oder einem HRS.

Eine Stabilisierung der Nierenfunktion durch konservative Maßnahmen führt daher in vielen Fällen zu einer deutlichen Stabilisierung des Patienten - aber auch dazu, dass der MELD-Score wieder abfällt, und der Patient damit eine deutlich geringere Chance hat, ein Organangebot zu erhalten. Andererseits führt eine Verbesserung der Nierenfunktion vor Transplantation zu einer geringeren postoperativen Morbidität und Mortalität [345]. Ein Unterlassen konservativer Maßnahmen zur Stabilisierung der Nierenfunktion vor Lebertransplantation kann daher nicht empfohlen werden, insbesondere weil ein hoher MELD-Score nicht zwangsläufig zu einem raschen Organangebot führt. Da der für eine Transplantation erforderliche MELD-Score in Deutschland aufgrund des Spendermangels höher ist als in anderen Ländern,

sind die Ergebnisse auch schlechter, d. h. die Mortalität ist höher. Falls bei einem solchen Lebertransplantationskandidaten die Notwendigkeit zu einer Nierentransplantation gesehen wird, soll bei Vorliegen eines HRS und einer glomerulären Filtrationsrate $<15 \mathrm{ml} / \mathrm{min}$ die Nierentransplantation sequenziell nach erfolgreicher Lebertransplantation und nicht simultan erfolgen [346]. Eine Indikation zu einer zusätzlichen Nierentransplantation sollte in folgenden Situationen erwogen werden: länger bestehendes Nierenversagen mit der Notwendigkeit zum Einsatz von Nierenersatzverfahren (da dann die Wahrscheinlichkeit einer Erholung der Nierenfunktion von Patienten mit HRS nach Lebertransplantation reduziert ist). Dies ist in Anlehnung an die Empfehlungen der UNOS [347] gegeben bei Dialysepflichtigkeit von $\geq$ sechs Wochen und/oder organischem Nierenversagen. Für eine sequenzielle Transplantation erhalten die gelisteten Patienten nach erfolgreicher alleiniger Lebertransplantation 500 Zusatzpunkte im Zeitraum von Tag 90 bis Tag 360, sofern sie eine glomeruläre Filtrationsrate (GFR) von $<15 \mathrm{ml} / \mathrm{min}$ aufweisen.

\section{Hepatischer Hydrothorax und hepatopulmonales Syndrom}

\subsection{Einleitung}

Grundsätzlich können pathophysiologisch pulmonale Beeinträchtigungen bei Leberkranken folgendermaßen unterteilt werden:

1. Pulmonalvaskuläre Erkrankungen (Hepatopulmonales Syndrom, portopulmonale Hypertonie)

2. Veränderungen des Lungenparenchyms (COPD, interstitielle Lungenerkrankungen etc.)

3. extrapulmonale Beeinträchtigung der Ventilation (Aszites, hepatischer Hydrothorax)

Im Rahmen der vorliegenden Leitlinie werden neben dem Aszites der hepatische Hydrothorax und das hepatopulmonale Syndrom behandelt. Für Diagnose und Therapie anderer pulmonaler Erkrankungen wie der portopulmonalen Hypertonie wird auf die entsprechenden Leitlinien der verantwortlichen Fachgesellschaften verwiesen [348].

\subsection{Diagnose des hepatischen Hydrothorax}

\section{EMPFEHLUNG 5.1}

Zur initialen Darstellung des Hydrothorax sollte eine RöntgenThorax-Aufnahme oder eine Ultraschalluntersuchung durchgeführt werden.

Empfehlung, starker Konsens

\section{EMPFEHLUNG 5.2}

Sowohl bei Erstdiagnose als auch bei klinischer Verschlechterung soll eine Pleurapunktion bei relevantem Erguss erfolgen. Starke Empfehlung, starker Konsens 


\section{EMPFEHLUNG 5.3}

Die Punktion sollte sonografisch assistiert durchgeführt werden.

Empfehlung, starker Konsens

\section{EMPFEHLUNG 5.4}

Im Pleurapunktat sollte die Zellzahl, nach Möglichkeit mit Zelldifferenzierung, der pH-Wert und das Gesamteiweiß im Pleuraerguss bestimmt sowie bei Infektverdacht eine mikrobiologische Kultur angelegt werden.

Empfehlung, Konsens

\section{Kommentar}

Als hepatischer Hydrothorax werden Pleuratranssudate bei Patienten mit Leberzirrhose und/oder portaler Hypertension nach Ausschluss einer primären Herz- oder Lungenerkrankung definiert [349]. Ca. 4-15\% der Patienten mit fortgeschrittener Leberzirrhose entwickeln einen Hydrothorax [350, 351]. In der bisher größten Untersuchung konnte mittels Computertomografie bei 49 (4,7\%) von 1038 Patienten ein hepatischer Pleuraerguss nachgewiesen werden, in der Mehrzahl der Fälle rechtsseitig (70\%), seltener bilateral (18\%) oder linksseitig (12\%) [351]. Pathophysiologisch beruht der Hydrothorax auf denselben Mechanismen wie der Aszites [352, 353]. Bei den meisten Patienten mit Hydrothorax lassen sich mikro- und makroskopisch Zwerchfelläsionen nachweisen [354]. Die derzeit favorisierte Hypothese zur Pathogenese geht daher von einer transdiaphragmalen Passage der Flüssigkeit aus dem Peritoneal- in den Pleuraraum entweder über Zwerchfelldefekte oder über Lymphgefäße aus. Typischerweise finden sich bei den Patienten daher gleichzeitig Aszites und Hydrothorax, ein isoliertes Auftreten eines hepatischen Hydrothorax ist aber aufgrund des negativen intrathorakalen Drucks möglich [355].

Die führenden klinischen Symptome des hepatischen Hydrothorax sind Dyspnoe in Ruhe (34\%) oder nach Belastung (7\%) sowie nichtproduktiver Husten (22\%) [350]. Weiterhin klagen Patienten über Schwindel (11\%), Pleuraschmerz (8\%) und Müdigkeit als Folge der Hypoxämie (7\%). Differenzialdiagnostisch müssen andere Komplikationen der Zirrhose wie das hepatopulmonale Syndrom und die porto-pulmonale Hypertonie ebenso in Betracht gezogen werden wie nicht-hepatische Erkrankungen, z. B. Herzinsuffizienz, Tuberkulose, Bronchialkarzinom oder parapneumonischer Pleuraerguss [356, 357].

Zur initialen Darstellung des Pleuraergusses eignet sich neben dem Röntgen-Thorax die Sonografie [358]. Zusätzlich sollte bei jedem Patienten sowohl bei Erstdiagnose als auch bei Wiedervorstellung eine diagnostische Pleurapunktion durchgeführt werden, um 1) andere Erkrankungen und 2) eine Infektion (Empyem) auszuschließen [350, 357]. Häufige Komplikationen diagnostischer Pleurapunktionen sind der Pneumothorax (1,0 - 5,2\%), Blutungen $(<1 \%)$ und vasovagale Reaktionen $(<1 \%)$ [358, 359]. Dabei konnte in einer 2010 publizierten Metaanalyse nachgewiesen werden, dass die sonografische Kontrolle der Punktionsstelle die Inzidenz eines Interventions-assoziierten Pneumothorax signifikant senkt (Odds Ratio 0,3) [358]. Eine andere Studie zeigte, dass Blutungen auch bei moderaten Gerinnungsstörungen (INR <3, Thrombozyten $\geq 25000 / \mathrm{mm}^{3}$ ) nicht vermehrt auftraten; eine prophylaktische Substitution von Blutprodukten (Thrombozytenkonzentrate, „fresh frozen Plasma“ (FFP), Gerinnungsfaktoren) wurde daher bei diesen Patienten nicht empfohlen [359]. Da für Punktionen bei ausgeprägten Gerinnungsstörungen (INR > 3, Thrombozyten $<25000 / \mathrm{mm}^{3}$ ) jedoch keine auswertbaren Publikationen vorliegen, muss unter diesen Umständen eine entsprechende Substitution erwogen werden.

Die Diagnose eines hepatischen Hydrothorax basiert auf dem Nachweis eines Transsudats unter gleichzeitigem Ausschluss einer primären renalen, kardialen oder pneumologischen Erkrankung. Die Punktion dient zuvorderst dem Ausschluss einer Infektion sowie der Unterscheidung zwischen Transsudat und Exsudat. Folgende Parameter sollten daher aus dem Pleurapunktat bestimmt und mit den entsprechenden Werten im Serum verglichen werden: Zellzahl/-differenzierung sowie Eiweiß- oder Albuminkonzentration. Der hepatische Hydrothorax ist gekennzeichnet durch eine Gesamtzellzahl segmentkerniger Granulozyten < 250 pro $\mathrm{mm}^{3}$, eine totale Proteinkonzentration $<2,5 \mathrm{~g} / \mathrm{dl}$ und einen $\mathrm{Al}$ bumingradienten $>1,1 \mathrm{~g} / \mathrm{dl}$ zwischen Serum und Pleuraflüssigkeit bzw. ein Albuminquotient (Pleura/Serum) <0,6 (Sensitivität 87\%, Spezifität 92\%) [360, 361]. Weitere optionale Parameter sind ein Proteinquotient $<0,5$ (Pleura/Serum), ein LDH (Lactatdehydrogenase)-Gradient < 0,6 (Pleura/Serum) sowie vergleichbare Werte für $\mathrm{pH}$ und Glukose in Serum und Pleuraflüssigkeit. Im Falle eines Transsudats müssen schließlich für die Diagnose hepatischer Hydrothorax noch eine renale und eine kardiale Ursache (Echo, Kreatinin-/Eiweißausscheidung im Urin) sowie eine Lungenembolie klinisch/laborchemisch, ggf. auch durch weitere diagnostische Verfahren ausgeschlossen werden. Bei einem Exsudat muss eine Differenzialdiagnose zwischen spontan bakteriellem Empyem und anderen Erkrankungen erfolgen [362].

In unklaren Fällen - insbesondere bei linksseitigem/isoliert auftretendem Pleuraerguss - oder bei spezifischer klinischer Fragestellung kann zusätzlich nach einer Verbindung zwischen Peritoneal- und Pleuraraum gesucht werden. Die Datenlage zu den einzelnen Verfahren ist aber insgesamt unbefriedigend und stützt sich lediglich auf Fallserien, eine Empfehlung kann daher nicht ausgesprochen werden. Am besten untersucht ist die szintigrafische Darstellung des Übertritts von radiomarkiertem Albumin nach intraperitonealer Applikation mit einer Spezifität bis $100 \%$ bei einer Sensitivität von $70 \%$, die jedoch durch vorherige Pleurapunktion zur Reduktion des intrapleuralen Drucks erhöht werden kann [363, 364]. Eine potenzielle Alternative bietet sich mit Doppler- und Kontrastmittelsonografie an. Die verfügbaren Einzelfallberichte lassen aber eine Einschätzung der Sensitivität und Spezifität dieser Methoden noch nicht zu [365, 366]. Der direkte Nachweis eines makroskopisch sichtbaren diaphragmalen Defekts durch Thorakoskopie mit/ohne Einsatz von Farbstoffen sollte dagegen aufgrund seiner hohen Invasivität der Vorbereitung eines therapeutischen Eingriffs vorbehalten bleiben [354]. 


\subsection{Therapie des (rezidivierenden) hepatischen Hydrothorax}

\section{STATEMENT 5.5}

Die Behandlung des klinisch relevanten hepatischen Hydrothorax unterscheidet sich nicht von der Standardtherapie bei Aszites.

Starker Konsens

\section{EMPFEHLUNG 5.6}

Aufgrund der geringeren Komplikationsrate sollte ein symptomatischer Hydrothorax zuerst - sofern Aszites vorhanden mittels therapeutischer, abdomineller Parazentese, bei weiter bestehenden Symptomen mittels therapeutischer Thorakozentese behandelt werden.

Empfehlung, starker Konsens

\section{EMPFEHLUNG 5.7}

Das Volumen des drainierten Pleurapunktats sollte 1,5-2 I/ Punktion nicht überschreiten, eine Volumensubstitution ist nicht notwendig.

Empfehlung, starker Konsens

Bei wiederholter Thorakozentese kann ein getunneltes Drainagesystem palliativ oder als Überbrückung bis zur Lebertransplantation eingesetzt werden.

Empfehlung offen, starker Konsens

Kontinuierlich drainierende Systeme sollten wegen vermehrt auftretender renaler und septischer Komplikationen vermieden werden.

Empfehlung, starker Konsens

Falls doch eine Thoraxdrainage notwendig wird, kann eine intravenöse Albumingabe (6-8g/Liter Pleuraerguss) durchgeführt werden.

Empfehlung offen, starker Konsens

\section{EMPFEHLUNG 5.8}

Bei rezidivierendem hepatischem Hydrothorax sollte die Anlage eines transjugulären intrahepatischen portosystemischen Shunts (TIPS) erwogen werden.

Empfehlung, starke Konsens

\section{EMPFEHLUNG 5.9}

Bei Kontraindikationen für eine TIPS-Anlage kann eine Videoassistierte Thorakoskopie mit Pleurodese und/oder Verschluss erkennbarer Läsionen des Zwerchfells erwogen werden.

Empfehlung offen, starker Konsens

\section{STATEMENT 5.10}

Ein hepatischer Hydrothorax stellt keine Kontraindikation für eine Lebertransplantation dar.

Starker Konsens

\section{Kommentar}

Da dem hepatischen Aszites und dem hepatischen Hydrothorax gemeinsame pathogenetische Mechanismen zugrunde liegen, können die Prinzipien der Standardtherapie eines Aszites auf den hepatischen Hydrothorax übertragen werden, auch ohne dass spezifische Untersuchungen hierzu vorliegen [353]. Aufgrund der anatomischen Begrenzung können bereits bei geringer Flüssigkeitsmenge im Pleuraraum Symptome wie Dyspnoe, nichtproduktiver Husten, Schmerzen oder Müdigkeit durch Hypoxämie auftreten [350]. In Fallberichten wurde auch über respiratorisches Versagen und Spannungshydrothorax mit kardialem Versagen berichtet [367]. Laut neuerer Studien ist ein hepatischer Hydrothorax daher mit einer höheren Morbidität und Mortalität assoziiert als Aszites alleine [368]. Der hepatische Hydrothorax stellt somit grundsätzlich eine behandlungsbedürftige Erkrankung dar, eine Therapie sollte in jedem Fall unter Berücksichtigung von Nutzen, Risiken und Kontraindikationen evaluiert werden. Die Standardtherapie richtet sich nach den Therapieprinzipien und Kontraindikationen der Standardtherapie bei Aszites.

Da eine therapeutische Parazentese häufig zu einer Besserung der Symptome führt [369] und therapeutische Thorakozentesen mit einer höheren Komplikationsrate einhergehen [370], sollte bei symptomatischem Hydrothorax zuerst eine Parazentese durchgeführt werden.

Bei weiterbestehenden Symptomen kann kurzfristig eine Besserung durch Thorakozentesen erreicht werden. Das Risiko insbesondere eines Pneumothorax erhöht sich aber bei Patienten mit Leberzirrhose mit jeder Wiederholung. So steigt die Komplikationsrate von 7,7\% bei der ersten auf $34,7 \%$ bei der vierten Thorakozentese an [370].

Die bisher gültige Empfehlung, das Volumen des drainierten Pleurapunktats auf 1,5-2 I/Punktion zu beschränken, stützt sich auf wenige Fallberichte über Reexpansions-Lungenödeme bei großvolumigen Thorakozentesen [371]. Andere Komplikationen wie renale Dysfunktion, Elektrolyt-Verschiebungen und Infektionen wurden jedoch in dieser Studie nicht untersucht, treten aber bei $80 \%$ der Patienten mit Leberzirrhose nach Anlage einer kontinuierlichen Thoraxdrainage wegen des Verlusts großer Flüssigkeitsmengen auf [372, 373]. Die interventionsassoziierte Mortalität innerhalb des stationären Aufenthaltes (Median acht Tage) nach Anlage der Thoraxdrainage erreichte in einer Serie $16 \%$ bei Child-B- und $40 \%$ bei Child-C.Patienten. Getunnelte Drainagesysteme scheinen dagegen aufgrund der kontrollierten Entnahme geringerer Volumina keine renalen Komplikationen hervorzurufen und sind lediglich mit einem höheren Infektionsrisiko behaftet [374]. In den bisher publizierten kleinen Fallstudien konnte sogar bei 30 - 60 \% der Patienten eine spontane Pleurodese nach drei bis vier Monaten erreicht und der Katheter entfernt werden [374, 375]. Aufgrund der derzeitigen Datenlage muss daher eine 
Beschränkung des drainierten Ergussvolumens empfohlen werden, eine Volumensubstitution scheint dann nicht notwendig. Wird eine kontinuierliche Thoraxdrainage verwendet, sollte analog zum Vorgehen bei Aszites 6-8g Albumin pro Liter entferntem Pleuraerguss substituiert werden. Getunnelte Drainagesysteme können die Komplikationsrate wiederholter Thorakozentesen reduzieren, sollten aber aufgrund fehlender Langzeitdaten nur palliativ oder zur Überbrückung bis zur Lebertransplantation eingesetzt werden.

Als Therapie der Wahl eines rezidivierenden hepatischen Hydrothorax muss derzeit die Anlage eines transjugulären intrahepatischen portosystemischen Shunts (TIPS) angesehen werden, die kausal die portale Hypertension als pathogenetische Ursache des Hydrothorax beseitigt [376]. Zwar beruhen die publizierten Daten auf einer Reihe von unkontrollierten Fallserien, umfassen aber das bisher größte Kollektiv behandelter Patienten [377 382]. 2015 fasste eine Metaanalyse die sechs qualitativ besten Studien mit insgesamt 198 Patienten zusammen [383]. Bei $56 \%$ der Patienten zeigte sich ein komplettes Therapieansprechen, bei $18 \%$ ein partielles. Die frühe Letalität innerhalb von 45 Tagen lag bei $18 \%$, die Gesamtmortalität bei $50 \%$ bei einem durchschnittlichen Nachverfolgungszeitraum zwischen sechs und 14 Monaten. Prädiktive Indikatoren der Mortalität waren wie bei anderen Indikationen zur TIPS-Anlage Alter, Child-Pugh- oder MELD-Score, renale Dysfunktion und TIPS-Versagen.

Trotz häufiger Rechtsinsuffizienz bei Patienten mit hepatischem Hydrothorax [360] wurde dagegen ein pulmonales Versagen post-TIPS nur vereinzelt beschrieben.

Je nach Fallserie sind jedoch Kontraindikationen für die TIPSAnlage häufig, teils erfüllen nur 15\% der Patienten die entsprechenden Voraussetzungen [350]. Alternativ wurde daher in einer Reihe von Fallberichten bzw. Fallserien die Pleurodese mittels sklerosierender Substanzen untersucht. Problematisch ist dabei, dass ein standardisiertes Verfahren hierfür derzeit fehlt. Aufgrund eher enttäuschender Erfolgsraten wird heutzutage die Applikation via therapeutischer Video-assistierter Thorakoskopie (VATS) der Applikation via Thoraxdrainage vorgezogen [384-387]. Weitere Variablen sind unterschiedliche sklerosierende Substanzen (Talkum, OK-432, Pikibanil, Minozyklin), ein Naht- oder plastischer Verschluss erkennbarer Läsionen des Zwerchfells, die prä- oder peri-operative Parazentese, der Einsatz splanchnischer Vasokonstriktoren (Somatostatin, Octreotid) sowie die post-operative Beatmung mit Überdruck (CPAP) zur Reduktion des intrathorakalen Unterdrucks [388-390]. In zwei Metaanalysen mit 189 bzw. 180 Patienten zeigte sich eine initiale Erfolgsrate von $70-75 \%$ bei jedoch hoher Rückfallquote von 25 \% [391, 392]. Wegen der hohen Invasivität der Methode und der anschließenden kontinuierlichen Thoraxdrainage treten Komplikationen in bis zu 80 \% der Fälle auf, insbesondere Infektionen wie Empyeme und renales Versagen tragen zu der hohen Gesamtletalität von 20 - 30 \% bei.

Einzig kurative Methode zur Behandlung sowohl des hepatischen Hydrothorax als auch der zugrundeliegenden Leberinsuffizienz stellt die Lebertransplantation dar, jedoch wird der Hydrothorax trotz der erhöhten Mortalität [368] in den bisherigen Allokationsmodellen nicht berücksichtigt und kann daher nicht als alleinige Indikation zur Transplantation herangezogen werden. Während aber in früheren Untersuchungen der hepatische
Hydrothorax keinen Einfluss auf das post-operative Management oder die langfristige Überlebensrate (70\% nach fünf Jahren) nach Lebertransplantation zeigte [393, 394], berichtete eine asiatische Gruppe in einer neueren Publikation über eine höhere Rate an post-operativen Infektionen und eine Dreijahres-Überlebensrate von lediglich $60 \%$ [395].

\subsection{Diagnostik und Therapie des spontan bakteriellen Empyems (SBEM)}

\section{EMPFEHLUNG 5.11}

Bei Verdacht auf ein SBEM oder bei klinischer Verschlechterung des Patienten sollte eine diagnostische Pleurapunktion unter sterilen Bedingungen mit Bestimmung des $\mathrm{pH}$-Werts und der Zellzahl/-differenzierung sowie einer Gramfärbung und Beimpfung von Kulturflaschen durchgeführt werden. Empfehlung, starker Konsens

\section{EMPFEHLUNG 5.12}

Die medikamentöse Standardtherapie beim SBEM kann analog zur Standardtherapie bei einer SBP erfolgen.

Empfehlung offen, starker Konsens

\section{EMPFEHLUNG 5.13}

Bei hohem Komplikationsrisiko (nachweisbarem Eiter oder gekammertem Erguss) kann das SBEM mittels kontinuierlicher Thoraxdrainage unter Albuminsubstitution behandelt werden, falls notwendig zusätzlich mittels lokaler Fibrinolyse oder Video-assistierter Thorakoskopie (VATS).

Empfehlung offen, starker Konsens

\section{Kommentar}

Das spontan bakterielle Empyem (SBEM) ist eine spezifische Komplikation des hepatischen Hydrothorax und setzt eine bakterielle Infektion, aber nicht notwendigerweise einen eitrigen Pleuraerguss voraus [362]. Risikofaktoren für die Entwicklung eines SBEM sind eine schlechte Leberfunktion, niedrige Eiweiß- und Albuminkonzentrationen in Serum und/oder Pleuraflüssigkeit sowie eine bereits vorliegende spontan bakterielle Peritonitis (SBP) [396, 397]. Inzidenz (13 - 30\%) und Letalität (20 - 38\%) sind vergleichbar mit Inzidenz und Letalität einer SBP [398-400]. Da sich auch das Keimspektrum (E. coli, Klebsiellen, Streptokokken und Enterokokken) bei beiden Erkrankungen und die pathophysiologischen Eigenschaften der intraperitonealen und -pleuralen Flüssigkeiten ähnelt, wird bei dem SBEM ein ähnlicher pathogenetischer Mechanismus mit bakterieller Translokation wie bei der SBP vermutet [362]. Patienten mit SBEM leiden häufig unter unspezifischen Symptomen (Fieber, Enzephalopathie, hepatorenale Dekompensation), eine diagnostische Pleurapunktion unabhängig von einer diagnostischen Aszitespunktion wird daher sowohl bei Erstdiag- 
nose eines Pleuraergusses als auch bei klinischer Verschlechterung des Patienten empfohlen. Da eigenständige Daten fehlen, erfolgt die Diagnostik des SBEM üblicherweise analog zur SBP und beinhaltet die Bestimmung der Granulozyten im Pleurapunktat sowie den mikrobiologischen kulturellen Nachweis der Erreger, der jedoch nur in 2/3 der Fälle gelingt [396, 397]. Eine Granulozyten-Konzentration über $250 / \mu l$ verbunden mit einem positiven Erregernachweis bzw. eine Granulozyten-Konzentration von über 500/ $\mu$ l verbunden mit einem negativen Erregernachweis gelten als diagnostisch für das Vorliegen eines SBEM.

Die Verwendung von Teststreifen für Leukozytenesterase als Schnelltest kann aufgrund der geringen Datenlage nicht empfohlen werden [400].

Auch die Basistherapie wird analog zur SBP mittels intravenöser Gabe eines Cephalosporins der 3. Generation für mindestens sieben bis zehn Tage sowie Albumin-Substitution durchgeführt [401]. Je nach lokaler Resistenzlage muss das verwendete Antibiotika-Regime jedoch insbesondere bei nosokomialen Infektionen angepasst werden, da das initiale Therapieversagen der Antibiose neben der Aufnahme auf der Intensivstation und der Leberfunktion gemessen am MELD-Score als unabhängige Risikofaktoren für die Letalität bei SBEM gelten [401]. Im Gegensatz zum komplizierten parapneumonischen Erguss der ambulant erworbenen Pneumonie [402] stellt das nicht-eitrige SBEM bei hepatischem Hydrothorax aufgrund der hohen peri-interventionellen Komplikations- und Rezidivrate noch keine Indikation zur kontinuierlichen Thoraxdrainage dar [362]. Lediglich das eitrige SBEM sollte analog des Pleuraempyems (trüber bis eitriger Erguss, pH-Wert $<7,2$ ) entsprechend den aktuellen Leitlinien invasiv mittels Thoraxdrainage ggf. unterstützt durch lokale Fibrinolyse (Streptokinase) oder VATS bei gekammertem Erguss behandelt werden [402]. Abweichend von der angesprochenen Leitlinie sollte jedoch die Thoraxdrainage bei Patienten mit Leberzirrhose wegen der damit verbundenen Morbidität und Mortalität (renale Dysfunktion, Elektrolyt-Verschiebungen) mit einer Volumensubstitution mittels Albumin- und Elektrolytlösungen kombiniert werden [372, 373]. Eine Kontrolle des Therapieerfolges durch eine diagnostische Pleurapunktion sollte in jedem Fall vor Beendigung der Antibiose erfolgen. Für eine antibiotische Sekundär-Prophylaxe wie bei der SBP liegen keine Daten vor, eine Empfehlung kann daher nicht gegeben werden.

\subsection{Diagnostik des hepatopulmonalen Syndroms}

\section{EMPFEHLUNG 5.14}

Als Screening-Test für moderate und schwere Verlaufsformen des hepatopulmonalen Syndroms eignet sich die Pulsoxymetrie (Sättigung <96\%), die bei Patienten in der Vorbereitung auf eine Lebertransplantation durchgeführt werden soll. Starke Empfehlung, starker Konsens

\section{EMPFEHLUNG 5.15}

Bei Verdacht auf ein hepatopulmonales Syndroms (Dyspnoe, Sättigung < $96 \%$ ) soll neben dem Nachweis einer Lebererkrankung oder portalen Hypertension eine arterielle Blutgasanalyse (Kriterium altersabhängiger $\mathrm{AaDO}_{2}$ ) und eine Kontrastmittel-Echokardiografie (Kriterium intrapulmonaler Shunt) durchgeführt werden.

Starke Empfehlung, starker Konsens

\section{EMPFEHLUNG 5.16}

Bei pulmonalen Begleiterkrankungen kann eine MAA-Lungenszintigrafie zur Quantifizierung des intrapulmonalen Shunts erfolgen.

Empfehlung offen, starker Konsens

\section{EMPFEHLUNG 5.17}

Der Schweregrad des hepatopulmonalen Syndroms soll mittels arterieller Blutgasanalyse (Kriterium $\mathrm{PaO}_{2}$ ) bestimmt werden.

Starke Empfehlung, starker Konsens

\section{Kommentar}

Das hepatopulmonale Syndrom (HPS) gehört zu den pulmonalvaskulären Erkrankungen und ist definiert als Gasaustauschstörung infolge einer intrapulmonalen Gefäßweitstellung bei Patienten mit fortgeschrittener Lebererkrankung, portaler Hypertension oder portosystemischer Shuntbildung [403]. Die meisten klinischen Daten liegen für die Leberzirrhose vor, das HPS wurde aber auch bei akuten Lebererkrankungen wie der ischämischen oder viralen Hepatitis, bei der idiopathischen portalen Hypertension oder bei Pfortaderthrombosen und dem Budd-Chiari-Syndrom beschrieben [404, 405].

Eine isolierte intrapulmonale vaskuläre Gefäßdilatation lässt sich dabei bereits bei 50 - 60\% der Patienten mit fortgeschrittener Leberzirrhose nachweisen, meist jedoch ohne Einfluss auf die arterielle Oxygenierung [406, 407]. Ein HPS mit Gasaustauschstörung ist seltener mit einer Prävalenz von 5 - $30 \%$ bei fortgeschrittener Leberzirrhose abhängig von genetischen und sozialen Faktoren mit der höchsten Erkrankungsrate bei Kaukasiern und einer niedrigen Inzidenz bei Rauchern [408]. Pathophysiologisch entsteht das manifeste HPS bei fehlender arterieller Oxygenierung durch Veränderungen der pulmonalen Gefäße. Dabei spielen sowohl die Dilatation vorhandener Gefäße durch vasoaktive Substanzen wie Stickstoff- oder Kohlenmonoxid als auch eine pulmonale Neoangiogenese eine Rolle, die schließlich zu einem Ventilations-Perfusions-Missverhältnis mit gesteigerter Lungendurchblutung bei gleichbleibender alveolärer Ventilation führen. Im Verlauf der Erkrankung entwickelt sich eine alveolokapilläre 
Diffusionslimitierung sowie ein ausgeprägter Rechts-Links-Shunt, die schließlich die Hypoxie verursachen [403, 409].

Klinisch zeichnet sich das HPS durch eine - mit der Schwere der Erkrankung zunehmende - Dyspnoe aus, die bei der Hälfte der Patienten zum Zeitpunkt der Diagnose insbesondere nachts symptomatisch wird und bei $20 \%$ bereits zur chronischen Hypoxie mit Uhrglasnägeln, Trommelschlegelfinger und Zyanose führt [408, 410]. Bei $25-30 \%$ der Patienten findet sich bei prädominanter Gefäßdilatation in den basalen Lungenabschnitten eine Platypnoe (verstärkte Atemnot im Sitzen, welche sich im Liegen bessert) oder Orthodeoxie (Abnahme des Sauerstoffpartialdrucks $\left(\mathrm{PaO}_{2}\right)$ beim Lagewechsel von liegender in die sitzende Position), die jedoch beide nicht spezifisch für das HPS sind [411]. Der Schweregrad eines hepatopulmonalen Syndroms wird anhand des arteriellen $\mathrm{PaO}_{2}$ bestimmt und in mild $\left(\mathrm{PaO}_{2} \geq 80 \mathrm{mmHG}\right)$, moderat $\left(\mathrm{PaO}_{2}=60-79 \mathrm{mmHG}\right)$, schwer $\left(\mathrm{PaO}_{2}=50-59 \mathrm{mmHG}\right)$ und sehr schwer $\left(\mathrm{PaO}_{2}<50 \mathrm{mmHG}\right)$ unterteilt [403]. Auch extrapulmonale Komplikationen eines manifesten Rechts-Links-Shunts wie zerebrale Abszesse, intrakranielle Blutungen und eine Polyzythämie wurden bereits beschrieben, haben aber keinen Einfluss auf den Schweregrad [412]. Differenzialdiagnostisch müssen neben den pulmonalen Komplikationen der Leberzirrhose wie hepatischer Hydrothorax und portopulmonale Hypertonie vor allem kardiale und pulmonale Ursachen der Dyspnoe ausgeschlossen werden, die jedoch auch als Begleiterkrankung die Symptomatik zusätzlich beeinflussen können [412].

Aufgrund der häufig asymptomatischen Patienten wird derzeit als kostengünstiger Screening-Test die Pulsoxymetrie mit einem Cut-off von 96 \% Sättigung bei Raumluft favorisiert, die bei Kandidaten für eine Lebertransplantation eine Hypoxämie mit einem Sauerstoffpartialdruck $\left(\mathrm{PaO}_{2}\right)<70 \mathrm{mmHg}$ (Meereshöhe) mit einer Sensitivität von $100 \%$ und mit einem $\mathrm{PaO}_{2}<60 \mathrm{mmHg}$ (Meereshöhe) mit einer Spezifität von $88 \%$ identifiziert [413]. Der Test wird insbesondere für Patienten in der Vorbereitung zur Transplantation empfohlen, da entsprechende Patienten in vielen Ländern inklusive Deutschland einen Sonderstatus (StandardExceptions) bei der Organallokation erhalten [414, 415].

Die Diagnose eines hepatopulmonalen Syndroms basiert auf der Trias Lebererkrankung bzw. portale Hypertension/portosystemischer Shunt, Gasaustauschstörung und intrapulmonale Gefäßdilatation [403]. Nach der Diagnose einer entsprechenden Lebererkrankung sollte daher die alveoläre Gasaustauschstörung entsprechend der derzeitig festgelegten Kriterien mittels arterieller Blutgasanalyse nachgewiesen werden [403, 414]. Eine erhöhte alveolar-arterielle Sauerstoffpartialdruckdifferenz $\left(\mathrm{AaDO}_{2}\right)$ $\geq 15 \mathrm{mmHg}$ in einem Alter $\leq 64$ Jahren bzw. $\geq 20 \mathrm{mmHg}$ in einem Alter > 64 Jahre gilt als diagnostisch und wurde kürzlich in einer Kohorte von 194 Zirrhosepatienten validiert [416]. Die Blutabnahme sollte bei sitzendem Patienten in Ruhe unter Raumlauft erfolgen, die obligatorische Lungenfunktionstestung maximal geringe Veränderungen zeigen. Als Goldstandard zum Nachweis einer intrapulmonalen Gefäßdilatation gilt schließlich die transthorakale Kontrastmittelechokardiografie [403, 406, 414]. Hierfür wird ein normalerweise nicht-lungengängiges Ultraschall-Kontrastmittel derzeit empfohlen ist eine aufgeschüttelte 0,9-prozentige Kochsalzlösung-peripher-venös injiziert und der funktionelle Shunt über die dilatierten Lungengefäße durch die Detektion des
Kontrastmittels im linken Herzen verifiziert. Intrakardiale können dabei von intrapulmonalen Shunts zeitlich anhand des Kontrastmittelübertritts vom rechten zum linken Herzen unterschieden werden, typischerweise ein bis zwei Herzschläge bei intrakardialen und zwei bis fünf Herzschläge bei intrapulmonalen pathologischen Veränderungen [417]. Zwar gilt die transösophageale Kontrastmittelechokardiografie als sensitiver für milde Verläufe des HPS, jedoch sollte diese wegen der höheren Invasivität nur bei eingeschränkter transthorakaler Beurteilbarkeit der Untersuchung zur Anwendung kommen [418].

Eine alternative Methode zur Darstellung intrapulmonaler Shunts ist die Lungenperfusionsszintigrafie mittels ${ }^{99}$ mTechnetium-makroaggregiertem Humanalbumin (MAA) und basiert auf demselben Prinzip wie die Kontrastmittelechokardiografie [419]. Nach Injektion können die MAA-Partikel aufgrund ihrer Größe nur bei einem Rechts-Links-Shunt die Lunge passieren und extrapulmonal in Gehirn, Milz oder Nieren nachgewiesen werden. Vorteil der Methode ist die Möglichkeit, das Ausmaß des Shunts zu quantifizieren und bei pulmonalen Begleiterkrankungen die Relevanz des HPS für die Hypoxie nachzuweisen [420, 421]. Gegen den Test spricht die wesentlich geringere Sensitivität verglichen mit der Kontrastmittelechokardiografie, auch konnte die bisher postulierte Korrelation mit der Prognose nicht bewiesen werden [422]. Eine intrapulmonale Vasodilatation lässt sich schließlich auch radiologisch mittels Computertomografie oder spezifischer invasiv mittels pulmonaler Arteriografie darstellen [420, 423]. Hierbei lassen sich diffuse (HPS Typ I) von fokalen (HPS TypII)-Shunts differenzieren. Aufgrund der hohen Invasivität und sonst mangelnder Konsequenz sollte die Methode jedoch der Vorbereitung einer Embolisation vorbehalten bleiben [424].

\subsection{Therapie des hepatopulmonalen Syndroms}

\section{EMPFEHLUNG 5.18}

Die Lebertransplantation stellt die einzig etablierte Therapie des hepatopulmonalen Syndroms dar. Alle geeigneten Patienten mit einem $\mathrm{PaO}_{2}<60 \mathrm{mmHg}$ sollen hierfür evaluiert werden.

Starke Empfehlung, starker Konsens

\section{EMPFEHLUNG 5.19}

Zur symptomatischen Behandlung der Hypoxie soll eine Sauerstofftherapie erfolgen.

Starke Empfehlung, starker Konsens

\section{Kommentar}

Die Studienlage zur Prognose des HPS ist widersprüchlich, neuere Studien zeigen keinen Einfluss der Erkrankung auf die Mortalität, solange der Schweregrad nicht berücksichtigt wird [420, 425]. Im Gegensatz dazu steigt die Morbidität und Mortalität der Patienten in Studien mit vorwiegend moderatem oder schwerem HPS mit einem Fünfjahresüberleben unter $25 \%$ unabhängig von 
der Schwere der Lebererkrankung [408, 426, 427]. In einer der Studien konnte zusätzlich ein Progress der Erkrankung mit einem durchschnittlichen Abfall des $\mathrm{PaO}_{2}$ um $5 \mathrm{mmHg} /$ Jahr nachgewiesen werden [426]. Das HPS stellt daher laut derzeitiger Empfehlungen grundsätzlich eine behandlungsbedürftige Erkrankung dar, eine Therapie sollte in jedem Fall unter Berücksichtigung von Nutzen, Risiken und Kontraindikationen evaluiert und symptombzw. stadienorientiert erfolgen [403, 420].

Trotz einer Vielzahl von unterschiedlichen Ansätzen und Präparaten sind die Ergebnisse für eine konservative Behandlung des HPS enttäuschend und beruhen lediglich auf einzelnen Fallberichten $[412,425]$. Es existiert daher derzeit keine etablierte medikamentöse Therapie [414]. Lediglich eine symptomatische Behandlung der Hypoxie bei einer Sauerstoffsättigung unter $88 \%$ sollte analog zu anderen Lungenerkrankungen erfolgen [414]. Auch die Effektivität einer invasiven Senkung der portalen Hypertension mittels eines transjugulären intrahepatischen portosystemischen Shunts (TIPS) ist umstritten, eine Empfehlung kann auf Grundlage der derzeitigen Evidenz nicht gegeben werden [414, 428].

Die chirurgische oder angiografische Sanierung portosystemischer Shunts mittels Ligatur, Embolisation oder Cavoplasty zeigte dagegen in nicht-zirrhotischen Patienten mit portaler Hypertension oder Budd-Chiari-Syndrom eine Besserung des HPS in mehreren Fallserien und kann bei entsprechender Konstellation erwogen werden [405]. Ebenso konnte in kleinen Fallserien ein palliativer Effekt einer Embolisation der intrapulmonalen Shunts demonstriert werden, für eine Empfehlung reicht aber die Datenlage derzeit noch nicht aus [429].

Einzig kurative Methode zur Behandlung sowohl des HPS als auch der zugrundeliegenden Leberinsuffizienz stellt die Lebertransplantation dar, die stadienabhängig in den meisten Fällen innerhalb von sechs bis zwölf Monaten zu einer kompletten Revision der Erkrankung führt [430]. Aufgrund der hohen, von der Leberfunktion unabhängigen Mortalität der Patienten mit schwerem oder sehr schwerem HPS erhalten Kandidaten für die Lebertransplantation mit einem $\mathrm{PaO}_{2}<60 \mathrm{mmHg}$ einen Sonderstatus bei der Organallokation, um die Wartezeit anzupassen [414]. Zwar werden diese schwerkranken Patienten aufgrund der pulmonalen Veränderungen als Hochrisiko für die Operation eingestuft, jedoch konnte ein verbessertes perioperatives Management diesen Nachteil in neueren Publikationen ausgleichen [431].

\section{Diagnostik der hepatischen Enzephalo- pathie (HE)}

\subsection{Einleitung}

\section{EMPFEHLUNG 6.1}

Patienten mit einer Leberzirrhose sollen bei Erstdiagnose sowie im Verlauf auf Symptome einer manifesten HE klinisch beurteilt werden.

Starke Empfehlung, starker Konsens

\section{Kommentar}

Die hepatische Enzephalopathie (HE) ist die Summe aller Störungen des Zentralnervensystems, die als Komplikation akuter oder chronischer Lebererkrankungen und/oder portosystemischer Kollateralkreisläufe auftreten können [432 - 436]. Der Gegenstand dieser Leitlinie ist die HE bei Leberzirrhose, welche durch eine zunehmende psychomotorische Verlangsamung bis hin zum Koma gekennzeichnet ist und ein breites Spektrum sehr variabel auftretender intellektueller, emotionaler, kognitiver, psychischer und motorischer Störungen umfasst [432, 435].

Pathophysiologisch liegt der HE eine reduzierte Kapazität der zirrhotischen Leber zur Ammoniakentgiftung zugrunde. Entzündungsmediatoren, reaktive Sauerstoff- und Stickstoff-Spezies führen zu RNA-Oxidation, Astrozytenseneszenz, Genexpressions-Veränderungen und Proteinmodifikationen [437-440]. Daraus resultiert ein geringgradiges chronisches Gliaödem, welches eine Dysfunktion der Astroglia und gestörte glioneuronale Kommunikation zur Folge hat. Auf neurophysiologischer Ebene ist die HE durch ein abnormes, niederfrequentes Kopplungsverhalten zentraler Neurone und peripherer Motoneurone gekennzeichnet, welches eine Erklärung für die zahlreichen unterschiedlichen kognitiven und motorischen Störungen darstellt [441 - 448].

Die Prävalenz einer klinisch manifesten HE zum Zeitpunkt der Diagnose-Stellung einer Leberzirrhose liegt zwischen 10 und $21 \%$ [449 - 451]. Die kumulative Prävalenz einer manifesten HE bei Patienten mit Zirrhose liegt bei ca. 30 - 45 \% [432, 452, 453] und ist mit zahlreichen negativen Auswirkungen im täglichen Leben verbunden [453]. Diese umfassen u. a. eine reduzierte Fahrtauglichkeit [454 - 457] sowie verschiedenste Defizite in Bezug auf die Arbeits- und intellektuelle Leistungsfähigkeit [432, 435, 453, 458, 459]. Jepsen et al. konnten zeigen, dass $45 \%$ der Patienten mit $\mathrm{HE}$ innerhalb von einem Monat, $64 \%$ innerhalb eines Jahres und $85 \%$ innerhalb von fünf Jahren verstarben [451]. Das Vorliegen einer HE ist somit ein starker Prädiktor für die Mortalität [451, 460, 461]. Entgegen der früher postulierten obligaten Reversibilität der HE konnte inzwischen gezeigt werden, dass HE-Episoden nach einer initialen Verbesserung möglicherweise mit persistierenden und sich langsam akkumulierenden Defiziten in Bereichen des Arbeitsgedächtnisses und des Lernens verbunden sind und zu einer progressiven neurologischen Degeneration führen können $[462,463]$.

Aufgrund der Häufigkeit und prognostischen Bedeutung sollte bei jeder stationären Aufnahme eines Patienten mit Zirrhose im Krankenhaus sowie im ambulanten Bereich bei entsprechender Klinik (z. B. erhöhte Tagesmüdigkeit, Konzentrationsdefizite) eine Untersuchung auf HE durchgeführt werden, auch im Verlauf der Erkrankung eine regelmäßige Re-Evaluation der HE erfolgen und eine Therapieindikation je nach Befund immer wieder geprüft werden [432-436].

\section{EMPFEHLUNG 6.2}

Bei Patienten mit Zirrhose ohne klinische Anzeichen einer HE sollte eine Testung auf das Vorliegen einer minimalen $\mathrm{HE}$ (mHE) erwogen werden.

Empfehlung, Konsens 


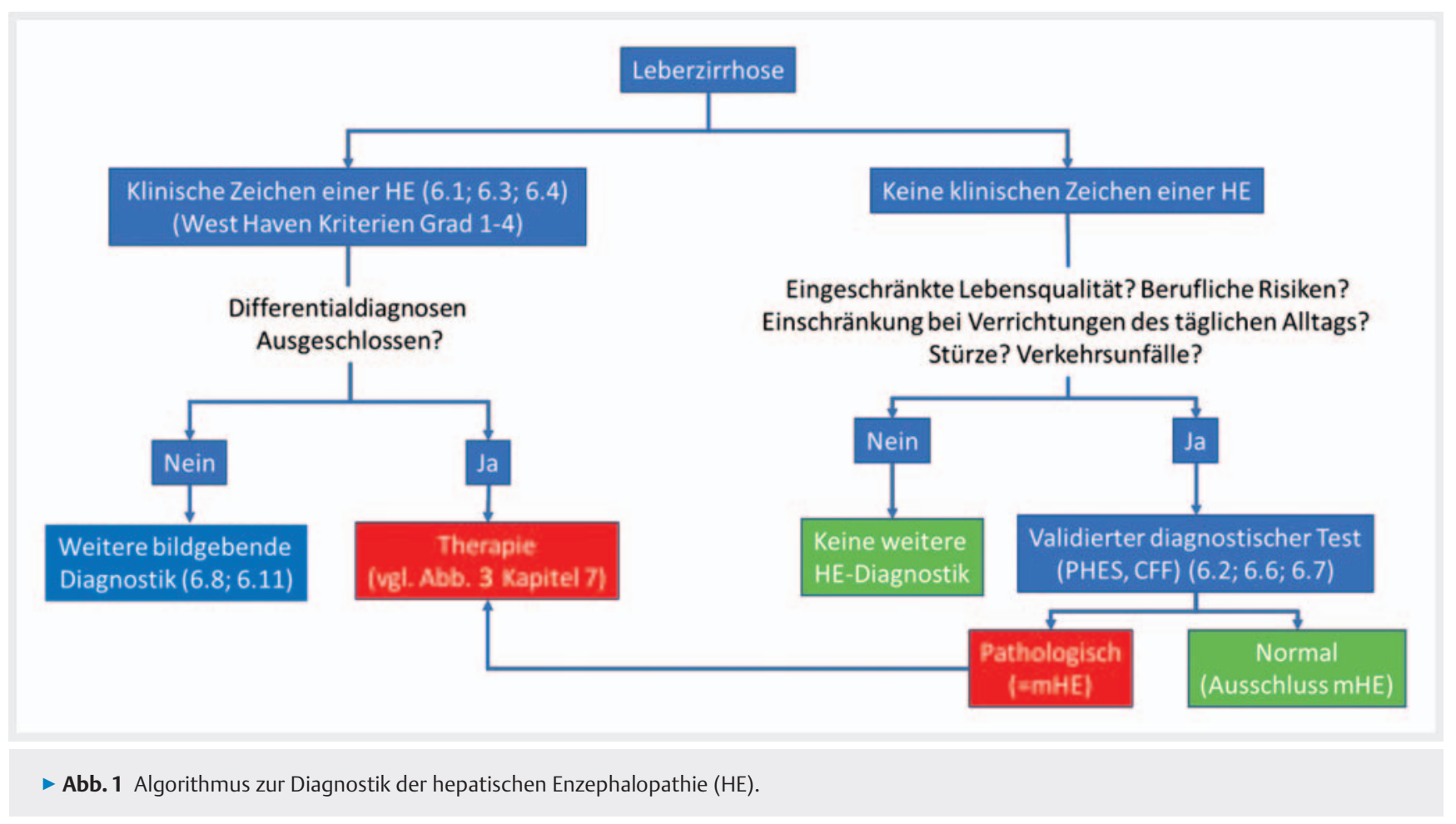

\section{Kommentar}

Bei 20 - 85 \% der klinisch unauffälligen Patienten mit Leberzirrhose lassen sich Hinweise auf kognitive Dysfunktionen feststellen [432 - 436, 449 - 453, 464]. Diese minimale HE (mHE) definiert sich somit als ein klinisch unauffälliger neurologischer Zustand, aber mit nachweisbaren Auffälligkeiten in apparativen und psychometrischen Tests [432, 434-436, 465-469]. Die mHE ist über den pathologischen Ausfall eines psychometrischen Tests definiert, d. h. der Test zur Diagnose des Syndroms definiert auch gleichzeitig die Erkrankung. Die mHE kann jedoch ein Prädiktor für die Ausbildung einer manifesten $\mathrm{HE}$ sein und ist häufig mit einer Reduktion der Lebensqualität verbunden [450, 470 -477]. Bei Patienten mit einer mHE kommt es im Vergleich zu Patienten ohne $\mathrm{mHE}$ häufiger zu Episoden einer manifesten $\mathrm{HE}$ (nach drei Jahren 46 vs. $21 \%$ ) [460]. Zu den negativen Auswirkungen zählen auch Einschränkungen der Fahrtauglichkeit [454 - 457].

Eine Detektion und Behandlung der mHE kann der Entwicklung einer manifesten HE vorbeugen [450]. In die Entscheidungsfindung zur Durchführung einer HE-Diagnostik sollten neben der gezielten Frage nach Ereignissen wie z. B. Stürzen und Verkehrsunfällen Fremdbeobachtungen von Familienangehörigen (z. B. Verwahrlosungstendenz, Persönlichkeitsveränderungen) sowie das soziale und berufliche Umfeld einbezogen werden ( $\bullet$ Abb. 1). Auch bei neurologisch-psychiatrisch unauffälligen Patienten sollte aufgrund der weitreichenden Konsequenzen und der gut belegten Defizite z. B. beim Führen eines Kraftfahrzeuges, bedingt bereits durch eine $\mathrm{mHE}$, bei entsprechender Berufsanamnese ein Screening veranlasst werden.
- Tab. 1 Wichtige Differenzialdiagnosen, welche vor der Diagnose einer $\mathrm{HE}$ ausgeschlossen werden müssen (adaptiert nach [436, 478]).

- Entgleisung bei Diabetes mellitus (Hypo-, Hyperglykämie, Ketoazidose, Laktat-Azidose)

- Elektrolytstörungen (z. B. Hyponatriämie, Hyperkalzämie)

- Infektionen (z. B. Neuroinfektionen und septische Enzephalopathie)

- Alkohol-, Drogen-, Mischintoxikation (z. B. Benzodiazepine, Neuroleptika, Opioide)

- Neurologische Erkrankungen (Epilepsie, Wernicke-Enzephalopathie)

- Strukturelle zerebrale Ursachen (z. B. Blutungen, Raumforderungen)

- Psychiatrische Erkrankungen (z. B. Dementielle Syndrome, Psychose)

\subsection{Differenzialdiagnosen und auslösende Faktoren einer $\mathrm{HE}$}

\section{EMPFEHLUNG 6.3}

Für die Diagnosestellung einer HE sollen bei Patienten mit Zirrhose wichtige Differenzialdiagnosen ausgeschlossen werden ( $\triangleright$ Tab. 1).

Starke Empfehlung, starker Konsens

\section{Kommentar}

Die Symptome einer HE sind unspezifisch. Dementsprechend stellt die HE eine Ausschlussdiagnose dar. Differenzialdiagnostisch müssen daher vor Diagnosestellung einer HE andere neurologisch-psychiatrische Störungen im Gefolge oder auch unabhängig von einer Leberzirrhose soweit möglich ausgeschlossen werden $(\triangleright$ Tab. 1) $[436,478]$. 
- Tab. 2 West-Haven-Kriterien (gestörter mentaler Zustand) sowie Klassifikation der International Society of Hepatic Encephalopathy and Nitrogen Metabolism nach (ISHEN) zur klinischen Graduierung einer manifesten Hepatischen Enzephalopathie (adaptiert nach [432, 436]).

\begin{tabular}{|l|l|l|}
\hline HE-Graduierung & Klinische Symptome & Graduierung nach ISHEN \\
\hline Grad 0 & keine Abnormalitäten & verdeckte (covert) HE \\
\hline Grad 1 & $\begin{array}{l}\text { mentale Verlangsamung, Antriebsstörung, Konzentrationsschwäche, } \\
\text { Schlafbedürfnis, Störung der Feinmotorik (z. B. Schriftbildveränderung) }\end{array}$ & verdeckte (covert) HE \\
\hline Grad 2 & $\begin{array}{l}\text { starke Müdigkeit (leichte Somnolenz), Lethargie, zeitlich desorientiert, } \\
\text { verwaschene Sprache, flapping tremor }\end{array}$ & offensichtliche (overt) HE \\
\hline Grad 3 & $\begin{array}{l}\text { starke Somnolenz oder Sopor, zeitlich und örtlich desorientiert, unzusammen- } \\
\text { hängende Sprache, Hyper- oder Hyporeflexie, Asterixis, Krämpfe, Rigor }\end{array}$ & offensichtliche (overt) HE \\
\hline Grad 4 & Koma, Muskeleigenreflexe erloschen, Muskelsteife & offensichtliche (overt) HE \\
\hline
\end{tabular}

\section{EMPFEHLUNG 6.4}

Bei Nachweis einer HE soll nach auslösenden Faktoren gesucht werden ( $\triangleright$ Tab. 3$)$

Starke Empfehlung, starker Konsens

\section{Kommentar}

Zahlreiche Faktoren können z. B. über die Induktion von inflammatorischen Zytokinen oder Veränderungen der Elektrolyte ein Gliaödem auslösen oder verschlechtern. Die Identifizierung und umgehende Therapie dieser präzipitierenden Trigger ist eine wichtige therapeutische Maßnahme und wird im Therapiekapitel eingehend kommentiert [435, 436, 478] ( Tab. 3).

\subsection{Diagnostische Verfahren und Klassifikationen}

\section{EMPFEHLUNG 6.5}

Eine manifeste HE soll klinisch anhand der West-HavenKriterien diagnostiziert und klassifiziert werden.

Starke Empfehlung, starker Konsens

\section{Kommentar}

Eine klinische Graduierung des Schweregrades der HE ist mithilfe der West-Haven-Kriterien möglich, welche das am häufigsten angewandte Graduierungssystem zur Beurteilung der HE bei Patienten mit Leberzirrhose darstellt und sich durch hohe Praktikabilität im klinischen Alltag auszeichnet [432 - 436, 465, 479] $(\triangleright$ Tab. 2).

Die West-Haven-Kriterien ermöglichen eine Graduierung von Veränderungen des Bewusstseins, der intellektuellen Funktionen und des Verhaltens anhand der Schwere der einzelnen Symptome in einem kategorialen Klassifikationsschema von HE Grad 1 bis 4 ( $\triangleright$ Tab. 2). Patienten mit Grad 1 der HE zeigen gering ausgeprägte, klinisch manifeste Symptome wie verringerte kognitive Leistungen, eine verkürzte Aufmerksamkeitsspanne und Beeinträchtigungen der Additions-/Subtraktionsfähigkeit, während in Grad 2 der HE Lethargie, Verwirrtheit, unangemessenes Verhalten, Flapping Tremor sowie eine verwaschene Sprache dominie- ren. Bei HE Grad 3 treten zusätzlich Somnolenz (nur noch Fluchtreflexe, fehlender vestibulookulärer Reflex, abgeschwächte Pupillenreaktion), Desorientiertheit, bizarre Verhaltensmuster, muskuläre Steifigkeiten und Kloni bzw. Hyperreflexionen auf. Bei Grad 4 der HE (Koma) reagiert der Patient auf keinerlei verbale, optische oder starke äußere Stimuli (wiederholte Schmerzreize) mehr; eine Dezerebration kann vorhanden sein [432 - 436].

In der aktuellen Leitlinie der Fachgesellschaften EASL und AASLD werden von der International Society of Hepatic Encephalopathy and Nitrogen Metabolism (ISHEN) die minimale HE und die HE Grad 1 zusammen als „verdeckte HE“ (covert HE, cHE), die HE Grade 2 - 4 als „offensichtliche HE“ (overt HE, oHE) zusammengefasst ( Tab.2) [436, 479]. Der Begriff „covert“ soll entsprechend der ISHEN Einteilung beschreiben, dass der mentale oder motorische Defekt durch den Kliniker oder Patienten selbst zumeist noch nicht zu erkennen ist. Die Leitlinienkommission schloss sich nach umfassender Diskussion den EASL/AASLD-Leitlinien der ISHEN-Kommission an. Eine weitere Möglichkeit der Graduierung, die aber in der Leitlinienkommission der DGVS keinen Konsens für eine Empfehlung fand, ist die Einteilung der HE in eine geringgradige $\mathrm{HE}$, die durch psychometrische Tests und Flimmerfrequenzanalyse kontinuierlich graduiert werden kann, und eine schwergradige HE, bei der die Glasgow-Koma-Skala angewendet werden kann. Sie wird insbesondere in Westeuropa und Indien angewandt [435, 436, 480, 481]

Zusätzlich kann die HE nach dem zeitlichen Verlauf eingeteilt werden. Dabei unterscheidet man zwischen einer episodischen, einer rezidivierenden und einer persistierenden Verlaufsform ( $\checkmark$ Abb. 2). Bei der episodischen HE hat der Patient maximal eine Episode in sechs Monaten und ist zwischen den HE-Episoden (mit oder ohne präzipitierende[n] Faktor[en]) klinisch asymptomatisch [432 - 436]. Der Begriff der rezidivierenden HE findet Verwendung, wenn mindestens zwei Episoden einer manifesten, episodischen $\mathrm{HE}$ innerhalb eines halben Jahres auftreten [432, 434 436]. Patienten mit einer persistierenden $\mathrm{HE}$ weisen durchgehend klinische Symptome auf. Die persistierende HE schließt kognitive Defizite ein, die sich oft auf die sozialen und beruflichen Belange der betreffenden Person negativ auswirken [432 - 436, 478]. 


\begin{tabular}{|c|c|c|c|c|}
\hline Typ $^{1}$ & \multicolumn{2}{|l|}{ Grad } & zeitlicher Verlauf & $\begin{array}{l}\text { spontan oder ausgelöst durch } \\
\text { präzipitierende Faktoren }\end{array}$ \\
\hline A & MHE & \multirow[t]{2}{*}{ verdeckt (covert) } & episodisch & \multirow[t]{3}{*}{ spontan } \\
\hline \multirow{2}{*}{ B } & 1 & & \multirow{2}{*}{ rezidivierend } & \\
\hline & 2 & \multirow[t]{3}{*}{ offensichtlich (overt) } & & \\
\hline \multirow{2}{*}{ C } & 3 & & \multirow{2}{*}{ persistierend } & \multirow{2}{*}{$\begin{array}{l}\text { ausgelöst durch präzipitierende } \\
\text { Faktoren (Spezifizierung) }\end{array}$} \\
\hline & 4 & & & \\
\hline
\end{tabular}

- Abb.2 Einteilung der manifesten und minimalen hepatischen Enzephalopathie (HE) nach der zugrundeliegenden Erkrankung, dem Schweregrad der Störung, dem klinischen Verlauf und dem Vorhandensein bzw. Fehlen auslösender Faktoren (nach [432, 435, 436]).

\section{EMPFEHLUNG 6.6}

Zur Diagnostik einer cHE sollten neurophysiologische oder psychometrische Tests durchgeführt werden.

Empfehlung, Konsens

\section{Kommentar}

Die cHE umfasst die mHE und die HE Grad 1. Per Definition kann die mHE nur über validierte neurophysiologische oder psychometrische Tests erfasst werden, während die HE Grad 1 gemäß der West-Haven-Kriterien eine klinische Diagnose ist. Die Tests zur Diagnose einer mHE wurden formal bisher nicht für die HE Grad 1 validiert.

Die Diagnosestellung einer gering ausgeprägten HE kann schwierig sein, wenn subjektive Symptome wie reduzierte Lebensqualität, Schlafstörungen und erhöhte Tagesmüdigkeit im Vordergrund stehen. Hinweise auf eine cHE können sich z. B. aus der Anamnese oder Fremdanamnese ergeben.

Wissenschaftliche Untersuchungen haben gezeigt, dass die $\mathrm{HE}$ nicht zu einer undifferenzierten allgemeinen zerebralen Leistungsminderung führt, sondern dass einzelne kognitive Funktionen wie Aufmerksamkeit, Arbeitsgedächtnis, der sekundäre Gedächtnisspeicher oder die Kontrolle der Bewegung frühzeitig stark beeinträchtigt sein können, während andere über einen längeren Verlauf kaum Defizite aufweisen [466, 476, 482 - 485].

Aufgrund der komplexen multifaktoriellen Pathophysiologie der HE, die häufig durch differente präzipitierende Faktoren ausgelöst wird, gibt es keinen diagnostischen Goldstandard, weshalb zur sicheren Detektion, Graduierung und Verlaufskontrolle multimodale diagnostische Testverfahren erforderlich sind. Die Strategien zur Diagnose der HE bzw. MHE reichen von einfachen klinischen Skalen bis zu komplexen psychometrischen und neurophysiologischen Test-Tools. Bezüglich der verschiedenen diagnostischen Testverfahren ist die Studienlage allerdings sehr heterogen [432, 436]. Die klinisch eingesetzte mHE-Diagnostik wird maßgeblich von der jeweiligen nationalen bzw. lokalen Expertise beeinflusst und zeigt im internationalen Vergleich große Unterschiede bezüglich der Verfügbarkeit und Validität [436, 486 , 487]. So findet der Continuous Reaction Time Test vorwiegend in Dänemark Anwendung und der Inhibitory Control Test in den USA [488 - 490]. Bei der Methodenwahl zur Diagnostik der HE sind daher die lokale Expertise sowie die praktische Umsetzbarkeit im klinischen Alltag wichtig. Die Anwendung von zwei ergänzenden Verfahren („Two Test Strategy“) verbessert die Diagnosesicherheit, wird jedoch bisher nur zur diagnostischen Objektivierung in Studien empfohlen [491].

In Deutschland sind der Psychometric Hepatic Encephalopathy Score (PHES-Test), welcher aus einer Testbatterie von fünf neuropsychologischen Tests besteht, sowie neurophysiologische Tests wie die kritische Flimmerfrequenzanalyse (CFF) die am weitesten verbreiteten diagnostischen Verfahren; die Durchführung eines EEG ist dagegen nicht allgemein etabliert [486, 487, 492 - 495].

\section{EMPFEHLUNG 6.7}

Für die Beurteilung der mHE sollten bevorzugt die kritische Flimmerfrequenzanalyse (CFF) und/oder der vollständig durchgeführte Psychometric Hepatic Encephalopathy Score (PHES) eingesetzt werden.

Empfehlung, Konsens

\section{Kommentar}

Keiner der derzeitig verfügbaren Tests kann das vollständige Spektrum der cHE in allen Teilbereichen abbilden. Während computergestützte Testbatterien und die Repeatable Battery for the Assessment of Neuropsychological StatusUpdate (RBANS ${ }^{\circledR}$ ) in der Regel wissenschaftlichen Fragestellungen vorbehalten sind, haben sich der PHES-Test und die Bestimmung der CFF in klinischen Studien bewährt und erscheinen für die Routinediagnostik praktikabel [480].

Der PHES-Test ist eine Testbatterie von fünf neuropsychologischen Tests. Die Testbatterie erfasst motorische Geschwindigkeit und Genauigkeit, visuelle Wahrnehmung, visuell-räumliche Orientierung, visuelle Konstruktion, Konzentration, Aufmerksamkeit und in geringerem Umfang auch das Gedächtnis. Der originale PHES-Test subsummiert die Resultate aus den Zahlenverbindungstests A und B (ZVT-A, -B), dem Zahlensymboltest (ZST), dem Liniennachfahrtest (LTT, Zeit, Fehler) und dem Test „Kreise punktieren“, denen jeweils entsprechend ihres Testwertes und ihrer SD zum altersentsprechenden Mittelwert des jeweiligen Tests Punktewerte zwischen +1 und - 3 zugeordnet werden. Die individuellen Punktewerte werden summiert und ergeben den PHES- 
Test-Score, welcher somit zwischen +6 und -18 schwankt. Ein Cut-Off-Score von - 4 wurde für die Summe der einzelnen Testergebnisse erarbeitet, da er am besten zwischen normalen und pathologischen Resultaten trennte [491 - 494, 496, 497]. Der PHESTest ist ein geeignetes psychometrisches Verfahren zur Diagnostik der minimalen HE und zur Quantifizierung der HE als Kontinuum sowie zur Verlaufsbeurteilung [432, 435, 436, 491 - 497].

Die Bestimmung der kritischen Flimmerfrequenz (critical flimmer frequency, CFF) ist eine zuverlässige, gut validierte und sensible Methode zur Quantifizierung und Verlaufsbeurteilung der mHE und korreliert auch mit der Prognose [480, 498 - 505]. Aufgrund der guten Reproduzierbarkeit, raschen Durchführbarkeit und Unabhängigkeit von Training und Bildungsgrad ist die CFF ein geeignetes Instrument zur Detektion von mHE. Es wird vermutet, dass die Flimmerfrequenzanalyse darauf beruht, dass bei $\mathrm{HE}$ die Gliazellen der Retina ähnlichen morphologischen Alterationen unterworfen sind wie die Astrozyten [432, 435, 436, 457, 480, 498 - 505]. Wesentliche Grundlage ist eine intrafoveale Stimulation mit einer Leuchtdiode. Das definierte Licht wird dabei im Bereich von $60 \mathrm{Hertz}(\mathrm{Hz})$ bis $25 \mathrm{~Hz}$ in Schritten von $0,1 \mathrm{~Hz}$ in absteigender Richtung einer Testperson vorgegeben und erlaubt die Ermittlung des Schwellenwertes der Flimmerfrequenz. Der parallele Abfall der Flimmerfrequenz bei gleichzeitiger Zunahme der motorischen, kognitiven und mentalen Störungen zirrhotischer Patienten erlaubt die Quantifizierung der HE im Sinne eines Kontinuums über einen weiten Bereich des klinischen Spektrums. Die CFF, die beim Gesunden in der Regel zwischen $50 \mathrm{~Hz}$ und $39 \mathrm{~Hz}$ liegt, wird bei Patienten mit HE je nach Ausprägungsgrad zum Teil erst ab einer deutlich niedrigeren Hertz-Zahl wahrgenommen [498 - 505].

Evozierte Potenziale und EEG-Veränderungen sind bei HE nicht spezifisch und können auch bei anderen metabolischen, neurodegenerativen oder strukturellen Erkrankungen auftreten. Das EEG kann aber Differenzialdiagnosen der HE, wie z. B. komplex-fokale Anfälle, aufdecken [506 - 513]. Anwendbar, allerdings etwas komplizierter in der Handhabung, sind eine Summe von Reaktionstests („Scan Package“), Testbatterien wie die Cognitive Drug Research oder der Inhibitory-Control-Test [488-490]. Auch der Stroop-Test ist prinzipiell geeignet. Die EncephalApp basiert auf dem Stroop-Effekt, sollte aber aufgrund vielfältiger limitierender Einflussfaktoren (u. a. Farbempfindlichkeit, Bildungsgrad) und unzureichender Validierung derzeit nicht zur Diagnostik der mHE eingesetzt werden [514-519]. Psychometrische Einzeltests (z. B. Zahlenverbindungstest) sind als Suchtest für einzelne Bereiche des kognitiven Defekts bei HE anwendbar, erlauben aber keine zuverlässige Beurteilung der vielfältigen bei HE gestörten Hirnfunktionen bzw. eine Diagnosestellung. Das Gleiche gilt auch für die früher gebräuchlichen Rechentests (z. B. Subtraktion über Zehnergrenzen) oder eine Schriftprobe. Zu den interessanten Tests, die allerdings auch nur eine Dimension im Rahmen des kognitiven Defekts untersuchen, zählt aktuell der AnimalNaming-Test, bei dem in einem vorgegebenen Zeitintervall unterschiedliche Tiere aufgezählt werden sollen [520 - 524].
EMPFEHLUNG 6.8

Eine Bestimmung des Plasma-Ammoniaks sollte nicht routinemäßig erfolgen.

Empfehlung, Konsens

\section{Kommentar}

Laborchemische Diagnosetests wie die Bestimmung der Ammoniakkonzentration im arteriellen oder venösen Blut zeigen aufgrund vielfältiger Störfaktoren (u. a. bei der Probenentnahme und -analytik) eine zu geringe Sensitivität und Spezifität und erlauben weder eine sichere Detektion der HE noch eine verlässliche Graduierung des Schweregrads [525 - 528]. Aktuelle Konsensus-Arbeiten verzichten daher, von differenzialdiagnostischen Fragestellungen abgesehen, auf eine Empfehlung der Ammoniakbestimmung für die Diagnostik der HE [526].

Für die Bestimmung des Ammoniakpartialdrucks wurde gezeigt, dass erhöhte Werte positiv mit der Schwere der HE korrelieren [529, 530]. In Einzelfällen kann daher eine Bestimmung in der Differenzialdiagnostik der HE hilfreich sein und in der individuellen Therapiesteuerung eingesetzt werden.

\section{EMPFEHLUNG 6.9}

Bildgebende Verfahren wie z. B. MRT oder CT sollten in der differenzialdiagnostischen Abgrenzung bei unklarer neurologisch-psychiatrischer Symptomatik Anwendung finden. Empfehlung, Starker Konsens

\section{Kommentar}

Eine bildgebende Diagnostik mittels CT kann in der differenzialdiagnostischen Abgrenzung anderer Ursachen einer gestörten Hirnfunktion hilfreich sein, insbesondere zum Ausschluss von strukturellen Ursachen wie z. B. intrakraniellen Blutungen bei somnolenten oder komatösen Patienten. Mit speziellen MR-Techniken können bei HE eine Zunahme des zerebralen Wassergehaltes und Veränderungen der Diffusion gemessen werden [531, 532]. In der MR-Spektroskopie wird abhängig vom Grad der HE eine Zunahme der Glutamin-Konzentration und Abnahme von Myo-Inositol gefunden. Magnetresonanztomografie und Magnetresonanzspektroskopie ermöglichen bei HE die Diagnostik von funktionellen und metabolischen Veränderungen des Gehirns. Die Kernspintomografie zeigt häufig Hyperintensitäten im Globus pallidus, welche auch auf Manganablagerungen zurückzuführen sind [531-536]. Diese Veränderungen korrelieren jedoch nicht mit dem Schweregrad der HE und werden gelegentlich auch bei Patienten mit Zirrhose ohne manifeste HE gefunden. Magnetenzephalografie, Magnetresonanzspektroskopie und Positronenemissionstomografie zeigen bei HE ebenfalls Veränderungen, sind jedoch bisher rein wissenschaftlichen Fragestellungen vorbehalten [445, 531 - 536]. 


\subsection{HE und Fahrtauglichkeit}

\section{EMPFEHLUNG 6.10}

Ein Beratungsgespräch sollte mit dem Patienten mit Zirrhose und $\mathrm{HE}$ über die Konsequenzen der Diagnose (u. a. im Hinblick auf eine negative Beeinträchtigung der Fahrtauglichkeit) geführt werden.

Empfehlung, starker Konsens

\section{Kommentar}

Die Defizite in den Bereichen Aufmerksamkeit, Daueraufmerksamkeit, Wahrnehmung, Vigilanz, Motorik und Gedächtnisleistung im Rahmen einer HE können zu einer negativen Beeinträchtigung der Fahrtauglichkeit führen. Untersuchungen unter Verwendung verschiedener neuropsychologischer Tests zeigten eine erheblich beeinträchtigte Fahrtauglichkeit bei Patienten mit Zirrhose und HE in 38 - 85\% [454-457]. Die Fahreignungsprobe durch eine Realfahrt mit einem Sachverständigen (Fahrlehrer) bleibt aber der Goldstandard für die Bewertung der Fahrleistung, da computerisierte Tests die Fahrtüchtigkeit nicht verlässlich vorhersagen können [457]. Während Srivastara et al. in einer Realfahrstudie keine Einschränkungen der Fahrtauglichkeit bei HE belegen konnten [454], waren in der Studie von Kircheis et al. unter Realfahrtbedingungen nur $48 \%$ der Patienten mit mHE und nur $38 \%$ der Patienten mit manifester HE in der Lage, ein Fahrzeug korrekt zu führen, verglichen mit $87 \%$ bei Kontrollpersonen [457]. Die derzeit verfügbaren diagnostischen Tests bei mHE sind nicht in der Lage, die Fahrtüchtigkeit mit hinreichender Sicherheit zu beurteilen [457]. Aufgrund der insgesamt heterogenen Datenlage kann derzeit keine Stellungnahme zu einem generellen Fahrverbot bei Patienten mit HE gegeben werden. Trotzdem sollten Patienten mit Zirrhose und $\mathrm{HE}$ über die potenzielle Beeinträchtigung ihrer Fahrtauglichkeit informiert und gegebenenfalls die Objektivierung durch eine Fahreignungstest veranlasst werden. Die einfache Frage nach Verkehrsunfällen im vorangegangenen Jahr kann Hinweis auf Beeinträchtigungen in diesem Bereich geben [537].

\section{Therapie der hepatischen Enzephalo- pathie bei Leberzirrhose}

\subsection{Therapie der akuten Episode einer hepatischen Enzephalopathie (HE)}

\subsubsection{Therapie auslösender Faktoren}

\section{EMPFEHLUNG 7.1}

Einer HE-Episode können eine oder mehrere mögliche auslösende Ursachen zugrunde liegen ( $\triangleright$ Tab.3). Diese sollen bei jedem Patienten mit Leberzirrhose und $\mathrm{HE}$ gesucht und spezifisch therapiert werden.

Starke Empfehlung, starker Konsens
- Tab. 3 Auslöser einer HE bei Leberzirrhose [538, 540, 542].

\begin{tabular}{|l|l|}
\hline HE Auslöser & \\
\hline Infektionen & SBP, Harnwegsinfekt, Pneumonie, etc. \\
\hline GI-Blutung & Varizenblutung, Ulkus-Blutung, etc. \\
\hline Elektrolytentgleisung & Hypokaliämie, Hyponatriämie \\
\hline Medikamente & $\begin{array}{l}\text { Diuretika, Sedativa (Benzodiazepine), PPI, } \\
\text { Regarofinib }\end{array}$ \\
\hline Exsikkose & $\begin{array}{l}\text { Diuretika, Parazentese, abführende } \\
\text { Maßnahmen, reduzierte Flüssigkeitsaufnahme }\end{array}$ \\
\hline Obstipation & \\
\hline Operation/Trauma & \\
\hline Azidose & $>100$ g Protein/Tag an mindestens einem Tag \\
\hline Eiweißexzess & in den letzten vier Tagen [538] \\
\hline
\end{tabular}

\section{Kommentar}

Nachdem eine hepatische Enzephalopathie (HE) gesichert wurde, sind alle Anstrengungen darauf auszurichten, eine oder mehrere mögliche auslösende Ursachen zu finden ( $\downarrow$ Tab. 3) und spezifisch zu therapieren [538 - 540]. In bis zu $90 \%$ der episodisch auftretenden $\mathrm{HE}$ findet sich eine auslösende Ursache, deren erfolgreiche Therapie fast immer zu einer Besserung oder Beseitigung der HE führt [541, 542].

\section{Infektionen}

Infektionen konnten wiederholt als Auslöser für eine HE-Episode nachgewiesen werden [543-545]. In einer prospektiv angelegten Kohortenstudie waren Infektionen in $39 \%$ der Fälle der Auslöser für eine HE. Sie betrafen in 26,7\% die Atemwege oder die ableitenden Harnwege. In den übrigen Fällen fand sich eine spontan bakterielle Peritonitis [539]. In einer ähnlichen prospektiven Studie an 150 Patienten mit Leberzirrhose entwickelten 17\% ohne Infektion und $42 \%$ mit Infektion (ohne SIRS) eine klinisch manifeste HE-Episode („overt HE“) [546]. Eine Sepsis war bei 29 \% der Patienten von einer klinischen HE-Episode begleitet. Die Prozentsätze für eine klinisch nicht zuverlässig fassbare $\mathrm{HE}$ („covert HE“) lagen in diesen Patientenkohorten bei $25 \%$ (ohne Infektion), 37 \% (mit Infektion) bzw. 61 \% (bei Sepsis). Während in der Kontrollgruppe (Patienten mit Infektionen ohne Leberschaden) keiner eine Enzephalopathie entwickelte, zeigte sich auch in der Kontrollgruppe bei $42 \%$ der Patienten mit Sepsis ein pathologischer Ausfall psychometrischer Tests. Infektionen steigerten das Mortalitätsrisiko der HE deutlich [547].

Die Therapie der Infektion führt zu einer Besserung der HE-Episode. So verschwand unmittelbar nach Beseitigung eines infizierten Bilioms nach TIPS-Anlage die hepatische Enzephalopathie bei einer Patientin mit Leberzirrhose [548].

\section{Gastrointestinale Blutungen}

Nach einer oberen gastrointestinalen Blutung kam es bei 44,7\% der Patienten mit einer Leberzirrhose zu weiteren Komplikationen [549]. Eine erste HE-Episode oder die Verschlechterung einer vorbestehenden HE konnte bei über der Hälfte dieser Patienten nachgewiesen werden. Das Auftreten einer HE nach 
oberer gastrointestinaler Blutung war ein unabhängiger negativer Prognoseindikator. In einer Kohorte von Patienten mit Leberzirrhose war die Varizenblutung mit 23,3\% nach Infektionen der zweithäufigste Auslöser für eine oHE [539]. Die Wirksamkeit einer Primärprävention der HE bei Patienten mit Leberzirrhose und oberer gastrointestinaler Blutung unterstützt den kausalen Zusammenhang von gastrointestinaler Blutung und Auftreten einer HE-Episode [550 - 553].

\section{Obstipation}

In 15,6-40\% der Fälle von Patienten mit Leberzirrhose und HE konnte die Ursache der oHE auf eine Verstopfung zurückgeführt werden [539, 540]. Ein weiteres Indiz für die mögliche kausale Rolle der Obstipation für die Entstehung der HE ist, dass ausschließlich abführende Maßnahmen zum Verschwinden oder zu einer Besserung der HE führten [554]. Die Obstipation kann durch abführende Maßnahmen (Lactulose, PEG-Lösung), Volumengabe bei Exsikkose, Elektrolytausgleich oder Umstellung verursachender Medikamente therapiert werden.

\section{Verschlechterung der Nierenfunktion und Exsikkose}

Bei 32 - 74\% der Patienten mit neu aufgetretener HE fand sich als Ursache ein akutes Nierenversagen [540]. Eine Exsikkose wiesen $46-76 \%$ der Patienten mit HE auf, was wohl zu dem akuten Nierenversagen ursächlich beigetragen hat. Diuretikaeinnahme, zu hohe Dosierung von Lactulose, verminderte Flüssigkeitsaufnahme unter sedierender Medikation, großvolumige Parazentesen und ein vorbestehender Diabetes mellitus sind hierfür die möglichen Gründe. Ein erhöhter Kreatininwert erwies sich in einer Studie an 70 Patienten mit Leberzirrhose als unabhängiger Risikofaktor für das Auftreten einer HE [542, 555].

Die Verschlechterung der Nierenfunktion ist bei diesen Patienten mit erhöhter Mortalität assoziiert. In einer retrospektiven Studie beeinflusste ein terminales Nierenversagen die Mortalität von Patienten mit einer HE aber weniger als die von Patienten mit Aszites oder einer Varizenblutung [556]. Ein terminales Nierenversagen hatte weniger Auswirkungen auf die Dreijahres Mortalität von Patienten mit HE als ein hepatorenales Syndrom, ein akutes oder chronisches Nierenversagen [557]. Möglicherweise beeinflusst die Dialysebehandlung bei terminaler Niereninsuffizienz auch die HE über eine Erniedrigung des Ammoniakspiegels und anderer an der Pathogenese der HE beteiligten Substanzen im Blut. Ein Abfall des Kreatininwertes unter Einsatz des MARSSystems (Molecular adsorbent recirculating System) zeigte dagegen keine Auswirkungen auf die HE [558]. Bei Patienten mit Leberzirrhose und Verschlechterung der Nierenfunktion sollte im Hinblick auf die Assoziation mit einer HE deren Ursache geklärt und behandelt werden.

\section{Medikamente}

Diuretika können die Entwicklung einer HE über die Entstehung einer Exsikkose, einer Hyponatriämie oder Hypokaliämie begünstigen [540]. 15\% der beobachteten HE-Episoden konnten entsprechend in einer Studie auf die Einnahme von Diuretika zurückgeführt werden [542].

Benzodiazepine interagieren mit GABA Rezeptoren, die in der Pathophysiologie der HE eine wichtige Rolle spielen. Flumazenil kann diese Interaktion antagonisieren. Auch ohne Gabe von Benzodiazepinen können endogene Neurosteroide für die Auslösung einer HE Episode über die Bindung an diesen Rezeptor verant- wortlich sein [559]. In einer Metaanalyse [560] zur Wirkung von Flumazenil bei oHE zeigte sich eine vorübergehende klinische Besserung nach Flumazenil-Gabe bei Patienten auch ohne vorherige Einnahme eines Benzodiazepins [560 - 563]. Wurde vor Auftreten der HE ein Benzodiazepin eingenommen, empfiehlt sich dessen Bindung an den GABA-Rezeptor mit Flumazenil zu antagonisieren. Auch Opiate und andere zentral nervös angreifende Substanzen können eine HE begünstigen oder verschlimmern [538].

Die Einnahme von Protonenpumpenhemmern war statistisch signifikant häufiger assoziiert mit dem Auftreten einer HE. Die Daten in den Studien wurden jedoch retrospektiv gesammelt, sodass derzeit die Empfehlung zu einem Absetzen des Präparates bei vorhandener Indikation nicht gegeben werden kann [177, 564, 565]. Eine Metaanalyse aller vorliegenden Studien wies ebenfalls keinen statistisch signifikanten Zusammenhang zwischen PPI-Einnahme und Auslösung einer HE nach [566].

Seltene Assoziationen mit einer HE-Episode wurden unter Einnahme des Tyrosinkinaseinhibitors Regarofinib [567] oder dem Proteinkinaseinhibitor Imatinib beobachtet [568].

Bei Verdacht auf einen Zusammenhang zwischen Medikamenteneinnahme und Auftreten einer HE sollte deren Applikation sofort beendet werden.

\section{Proteinexzess}

Klinische Beobachtungen wiesen bei $35 \%$ der Patienten mit Leberzirrhose nach stark erhöhter Proteinzufuhr eine hepatische Enzephalopathie nach $[568,569]$. Mehr als $100 \mathrm{~g}$ Eiweiß an mindestens einem der letzten vier Tage vor Auftreten einer HE wurde als möglicher Auslöser für eine HE angesehen [538]. Eine Mahlzeit mit $20 \mathrm{~g}$ Eiweiß löste bei Patienten mit dekompensierter Leberzirrhose keine HE aus [570]. Das Verhältnis von verzweigtkettigen zu aromatischen Aminosäuren stieg bis zu vier Stunden nach der Proteinzufuhr bei diesen Patienten an. Die Zufuhr von $30-40 \mathrm{~g}$ pflanzlichen Eiweißes erwies sich als unschädlich [100, 117].

\section{Epilepsie}

21 von 1120 Patienten mit Leberzirrhose und Aszites litten an einer Epilepsie [571]. Sie hatten ein fast vierfach erhöhtes Risiko für eine HE.

\section{Sarkopenie}

Eine Sarkopenie konnte bei 40 - 60\% der Patienten mit Leberzirrhose nachgewiesen werden, wobei mit zunehmendem Schweregrad der Lebererkrankung auch der Schweregrad der anthropometrisch eingeschätzten Sarkopenie zunahm. HE-Episoden sind bei Leberzirrhose und Sarkopenie signifikant häufiger [572, 573]. Dies gilt auch für das Auftreten einer HE nach TIPS-Anlage [213].

\section{Elektrolytstörungen, Azidose}

$65 \%$ der HE-Episoden wiesen in einer Studie einen auslösenden Faktor auf [542]. Bei $21 \%$ fand sich eine Hyponatriämie $(<130 \mathrm{mEq} / \mathrm{l})$. Die Hyponatriämie war in dieser Arbeit in allen Rechenmodellen ein unabhängiger Vorhersageparameter für das Auftreten einer HE. Ein Abfall der Serum-Natriumkonzentration um mindestens $5 \mathrm{mEq} / \mathrm{l}$ in den ersten drei Monaten der Beobachtungszeit war in 75 \% der Fälle von einer HE gefolgt, während nur bei $39 \%$ der Patienten ohne Abfall des Serumnatriums diese Komplikation beobachtet wurde [542]. Verschiedene Arbeiten unterstützen die Annahme, dass die Hyponatriämie einen prognostisch ungünstigen Faktor für die HE darstellt [128, 574, 575]. Ein erniedrigtes Serumnatrium (<135 mEq/l) vor einer TIPS-Implantation war ebenfalls 
mit einem achtfach erhöhten Risiko für eine spätere HE verbunden [576]. Störungen des Säure-Basen-Haushaltes und Hypokaliämie sind weitere Risikofaktoren für diese Komplikation [538 - 540, 577].

\subsubsection{Allgemeinmaßnahmen bei einer HE-Episode - Intensivmedizinische Überwachung}

\section{STATEMENT 7.2}

Patienten mit Zirrhose und $\mathrm{HE} \geq$ Grad 3 nach West-Haven bedürfen einer intensiven medizinischen Überwachung.

Starker Konsens

\section{Kommentar}

Patienten mit HE und akutem Leberversagen (ALV) und Akutauf-chronischem-Leberversagen (ACLF) oder mit dekompensierter Leberzirrhose und HE Grad 3 oder 4 sollten intensiv medizinisch überwacht werden. Bei komatösen Patienten (ab Grad 3) ist frühzeitig die Intubation und Beatmung einzuleiten [578, 579]. Ist eine orale Nahrungszufuhr nicht möglich, sollte bei Fehlen von größeren Ösophagusvarizen zur Vermeidung einer Aspiration eine Magensonde gelegt werden, worüber Medikamentengaben und eine enterale Ernährung erfolgen. Die EASL (European Association for the Study of the Liver)-Leitlinie rät bei ALV und progressiver HE von einer Magensonde wegen Überfüllung des Magens, der Gefahr von Mikroaspirationen und möglicher Auslösung einer oberen gastrointestinalen Blutung ab [579].

Beim ALV sind weitere spezifische Maßnahmen bei HE erforderlich, da sich rasch ein erhöhter Hirndruck bei fortschreitendem zerebralem Ödem mit tödlicher Hirnstammeinklemmung entwickeln kann [579, 580]. Oft ist in dieser Situation eine Lebertransplantation angezeigt, sodass die Patienten frühzeitig in ein Transplantationszentrum verlegt werden sollten. Auch bei Patienten mit chronischem Leberversagen und HE ist die Indikation zur Lebertransplantation stets zu prüfen.

Bei desorientierten Patienten mit HE können Stürze mit Verletzungen auftreten, was eine entsprechende Überwachung erfordert. Die Anlage eines Blasenkatheters erlaubt eine bessere Flüssigkeitsbilanzierung. Elektrolyte, Blutgase, Blutzucker und Volumenbilanz sind im Verlauf regelmäßig zu kontrollieren.

\section{Kalorien- und Proteinzufuhr}

\section{EMPFEHLUNG 7.3}

Die Energiezufuhr bei Patienten mit Leberzirrhose und hepatischer Enzephalopathie sollte bei $30-35 \mathrm{kcal} / \mathrm{kg}$ Körpergewicht (Idealgewicht) täglich liegen.

Empfehlung, starker Konsens

\section{EMPFEHLUNG 7.4}

Die tägliche Eiweißzufuhr sollte bei 1,2-1,5 g/kg Körpergewicht (Idealgewicht) täglich liegen.

Empfehlung, starker Konsens

\section{EMPFEHLUNG 7.5}

Eine regelhafte Proteinrestriktion soll nicht durchgeführt werden.

Starke Empfehlung, starker Konsens

Klug-Entscheiden-Empfehlung

\section{EMPFEHLUNG 7.6}

Die Nahrungsaufnahme sollte in häufigeren kleinen Mahlzeiten mit einem abendlichen zusätzlichen Imbiss vor dem Schlafengehen erfolgen. Nüchternphasen über vier bis sechs Stunden sollten vermieden werden.

Empfehlung, starker Konsens

\section{EMPFEHLUNG 7.7}

Bei Intoleranz von tierischen Eiweißen sollte auf Milchprodukte, pflanzliche Eiweiße oder selten auf eine Nahrungsergänzung mit verzweigtkettigen Aminosäure-Präparaten umgestellt werden.

Empfehlung, starker Konsens

\section{EMPFEHLUNG 7.8}

Die vorübergehende Gabe von Multivitamin- oder Zinkpräparaten kann bei HE aufgrund einer Leberzirrhose erfolgen. Empfehlung offen, starker Konsens

\section{Kommentar}

Bis zu 60 \% der Patienten mit Leberzirrhose sind mangelernährt [581]. Der Energieverbrauch im Ruhezustand ist bei Patienten mit Leberzirrhose erhöht, was unter anderem auf einen Ersatz der Glykogenolyse durch die Energie verbrauchende Gluconeogenese zurückzuführen ist [582]. Die hepatische Glukosefreisetzung durch gesteigerte Gluconeogenese hat einen erhöhten Aminosäureverbrauch und Proteinabbau zur Folge. Dies bewirkt zusätzliche Aminosäureverluste und die Freisetzung von Ammoniak [100]. Die empfohlene Energiezufuhr variiert zwischen 30 $45 \mathrm{kcal} / \mathrm{kg}$ Körpergewicht täglich [100, 579, 583]. Dabei sollte das ideale Körpergewicht als Berechnungsgrundlage dienen. Die Leitlinienkommission folgt in ihrer Empfehlung der ESPEN (European Society for Clinical Nutrition and Metabolism)-Leitlinie [583].

Die Eiweißzufuhr sollte bei 1,2 - 1,5 g/kg Körpergewicht pro Tag liegen [583]. Eine Proteinrestriktion wird auch bei Vorliegen einer $\mathrm{HE}$ nicht empfohlen, da eine Eiweißzufuhr von unter $0,8 \mathrm{~g} / \mathrm{kg}$ Körpergewicht proTag zu einer katabolen Stoffwechselsituation mit Anstieg der Stickstoffbelastung im Kreislauf führt.

Allenfalls bei Patienten mit HE und oberer gastrointestinaler Blutung kann für drei bis fünf Tage auf eine Proteinzufuhr verzich- 
tet werden [584]. Das Auftreten weiterer HE-Episoden wird durch eine normale Proteinkost unter Fortführung einer HE-Standardtherapie in der Regel nicht begünstigt [117, 570].

Eine gestörte Muskelproteinsynthese und ein durch Autophagie vermittelter Proteinabbau tragen zur Sarkopenie bei Zirrhose bei. Da die Muskulatur wichtig für die Verwertung von Ammoniak im Blut ist [585], begünstigt ihr Abbau die Entstehung einer $\mathrm{HE}$ [586]. Entsprechend ist das Vorliegen einer Sarkopenie bei Patienten mit Leberzirrhose ein prognostisch ungünstiger Parameter für das Auftreten einer HE $[213,587]$.

Ziel diätetischer Maßnahmen sollte daher die Erhaltung der Muskulatur oder deren Zunahme sein [588]. Die Steigerung der Kalorienzufuhr durch orale oder parenterale Zufuhr oder Nahrungsergänzungsmittel erwiesen sich jedoch in zwei Metaanalysen ohne sicheren Vorteil für das Überleben der Patienten [589, 590]. Positive Auswirkungen auf die Muskelmasse ergaben sich bei oraler zusätzlicher Nahrungszufuhr [590]. Wichtig erscheint die Verteilung mehrerer kleiner Mahlzeiten über den Tag, um die energieverbrauchende Gluconeogenese und den AminosäurenAbbau zu unterdrücken [100]. Nüchternphasen von drei bis sechs Stunden sollten vermieden werden. Eine abendliche zusätzliche Nahrungsaufnahme erwies sich in einer systematischen Analyse von mehreren Studien im Hinblick auf metabolische und klinische Effekte günstiger als nur die am Tag zugeführten Nahrungsportionen [591]. Möglicherweise kann hierdurch die anabole Resistenz durchbrochen, eine Sarkopenie gebessert, das Auftreten einer HE-Episode vermieden und deren Schweregrad reduziert werden. Langzeitaussagen zu dieser Maßnahme sind aber derzeit noch nicht möglich.

Hohe Dosen von Leucin [100] und anderen verzweigtkettigen Aminosäuren [592] können hilfreich sein. Körperliche Aktivität verbessert die Arbeitskapazität und möglicherweise die Muskelmasse [593]. Körperliches Training kann aber auch die Ammoniakkonzentration im Muskel erhöhen, was die funktionellen Konsequenzen der Hyperammoniämie und die verminderte ATPSynthese des Muskels verschlimmern kann. Ein Absenken des Ammoniaks im längeren zeitlichen Verlauf kann eine zukünftige mögliche Strategie auch bei fehlendem Nachweis einer HE bei Zirrhose sein, um die Muskelmasse anzuheben [594].

Eiweiß enthaltende pflanzliche Produkte weisen mehr Fasern im Vergleich zu tierischem Eiweiß auf, was das Mikrobiom des Darmes modifizieren (Präbiotikum), die Darmpassage beschleunigen, den intraluminalen pH absenken und die Stickstoff Ausscheidung mit dem Stuhl erhöhen kann [100, 595]. Die Ernährung mit ausschließlich pflanzlichen Eiweißen (30 - $35 \mathrm{kcal} / \mathrm{kg}$ Körpergewicht/Tag, 1,0 - 1,5 g vegetarische Proteine/kg Körpergewicht/ Tag) erwies sich als besser im Vergleich mit einer unveränderten Ernährungsweise bei Patienten mit gesicherter Leberzirrhose und mHE [595, 596].

Unter modifizierter Kost stieg nach sechs Monaten der Prozentsatz der Patienten ohne mHE auf $71,1 \%$ gegenüber $22,8 \%$ unter normaler Kost [597].

Bei dokumentierter Intoleranz von Nahrungsproteinen kann somit auf pflanzliche Proteine oder Milchprodukte [598] gewechselt werden [436]. Die parenterale oder orale Verabreichung von verzweigtkettigen Aminosäurelösungen zeigte in einer Metaanalyse positive Effekte auf die HE [598]. Mortalität, Lebensqualität oder Ernährungsparameter wurden allerdings hierdurch nicht beeinflusst. In Einzelfällen kann bei unzureichender Eiweißzufuhr und Unverträglichkeit von pflanzlichen oder Milchprodukten eine zusätzliche Gabe von verzweigtkettigen Aminosäurepräparaten erfolgen.

\section{Zink-Supplementation}

Ein Zinkmangel $(<0,66 \mu \mathrm{g} / \mathrm{ml})$ kann bei über $80 \%$ der Patienten mit Leberzirrhose nachgewiesen werden [599]. Im Gegensatz zu anderen Nahrungsergänzungsmitteln oder Vitaminen sprechen die Daten für die Verabreichung von Zink bei Nachweis eines entsprechenden Mangels. Die Datenlage zur Durchführung der Zink-Substitution bei HE ist nicht klar. Auf den Zahlenverbindungstest zeigten sich in einer Metaanalyse positive Effekte, wohingegen die Gabe von Zink keine Wirkung in einer Studie zur Sekundärprophylaxe hatte [600]. Konkrete Empfehlungen zur Dosierung können nicht gegeben werden. Nach Erreichen eines normalen Zinkspiegels kann aber eine Erhaltungsdosis von z. B. 220 mg Zinksulfat (entsprechen 50 mg elementarem Zink) täglich verabreicht werden.

\section{Vitamin-Supplementation}

Niedrige Vitamin-A-Spiegel sind bei HE und Leberzirrhose nachgewiesen worden [601]. Bei chronischen Lebererkrankungen finden sich niedrige Plasmaspiegel von Vitamin D, E und B1 in Abhängigkeit vom Schweregrad und der Ätiologie der zugrundeliegenden Lebererkrankung [602]. Auch wenn es keine gesicherten Daten für eine positive Wirkung der Gabe von Multivitaminpräparaten auf die HE bei Leberzirrhose gibt, kann diese zumindest in den ersten Tagen nach Auftreten einer HE erfolgen [436].

\subsubsection{Medikamentöse Therapie}

\section{EMPFEHLUNG 7.9}

Lactulose soll als Medikament der ersten Wahl zur Therapie einer oHE-Episode eingesetzt werden.

Starke Empfehlung, starker Konsens

\section{EMPFEHLUNG 7.10}

Zusätzlich zur oralen Gabe oder bei nicht möglicher oraler Zufuhr kann Lactulose als Einlauf (300 ml Lactulose/700 ml Wasser) verabreicht werden. Empfehlung offen, starker Konsens

EMPFEHLUNG 7.11

In Einzelfällen kann eine Kombinationstherapie mit Rifaximin erwogen werden.

Empfehlung offen, Konsens 


\section{EMPFEHLUNG 7.12}

Rifaximin als Monotherapie soll nur bei Unverträglichkeit von Lactulose zur Therapie einer HE-Episode $\geq 1$ nach WestHaven-Kriterien eingesetzt werden.

Starke Empfehlung, Konsens

\section{EMPFEHLUNG 7.13}

Die intravenöse Gabe von verzweigtkettigen Aminosäuren kann zusätzlich oder alternativ bei Patienten in der Akuttherapie bei oHE eingesetzt werden, die nicht auf eine Therapie mit Lactulose allein angesprochen haben.

Empfehlung offen, starker Konsens

\section{EMPFEHLUNG 7.14}

Intravenös appliziertes L-Ornithin-L-Aspartat kann zusätzlich oder alternativ bei Patienten mit akuter HE-Episode eingesetzt werden, die nicht auf eine Therapie mit Lactulose angesprochen haben.

Empfehlung offen, starker Konsens

\section{STATEMENT 7.15}

Für den Einsatz von oral appliziertem L-Ornithin-L-Aspartat gibt es keine ausreichende Evidenz für eine klinische Wirksamkeit bei HE.

Konsens

\section{EMPFEHLUNG 7.16}

Wegen des höheren Risikos von Nebenwirkungen sollte auf Neomycin und Paromomycin in der Therapie der HE verzichtet werden.

Empfehlung, Konsens

\section{EMPFEHLUNG 7.17}

Die Anwendung von Probiotika zur Therapie und Prophylaxe der HE sollte nicht erfolgen.

Empfehlung, Konsens

\section{EMPFEHLUNG 7.18}

Flumazenil kann bei Patienten mit oHE zur Klärung der HE-Auslösung nach möglicher Exposition mit Benzodiazepinen zusätzlich zu einer Standardtherapie eingesetzt werden. Empfehlung offen, starker Konsens

\section{EMPFEHLUNG 7.19}

Für den Einsatz von Glycerolphenylbutyrat oder Ornithinphenylazetat bei oHE kann aufgrund der Datenlage zum jetzigen Zeitpunkt keine Empfehlung gegeben werden.

Empfehlung offen, starker Konsens

\section{EMPFEHLUNG 7.20}

Bei HE kann in Einzelfällen die Verabreichung von 4I PEGLösung hilfreich sein.

Empfehlung offen, starker Konsens

\section{Kommentar}

Probleme der Studien zur medikamentösen Therapie der hepatischen Enzephalopathie

Die Studien, die den Einsatz von Medikamenten bei hepatischer Enzephalopathie untersuchten, wiesen zum Teil stark voneinander abweichende Ergebnisse auf. Ursachen hierfür sind eine nicht einheitliche Diagnostik der HE, abweichende Definitionen für das Vorliegen einer HE, variierende Patientenkollektive und variable Gestaltung der Standardtherapie in der Verum- und Kontrollgruppe.

Die Besserung einer oHE wird anhand der West-Haven-Kriterien und die einer $\mathrm{mHE}$ mithilfe verschiedener psychometrischer Tests oder der Bestimmung der kritischen Flimmerfrequenz diagnostiziert. Die Tests zur Diagnostik der mHE sind jedoch wenig spezifisch und sensitiv und korrelieren untereinander nur schlecht [504, 603]. Oft werden die Tests nicht korrekt durchgeführt, insbesondere wenn nur der NCT des portosystemischen Enzephalopathie-Syndrom-Testes (PSES) eingesetzt wird. Weiterhin wird das Vorliegen einer mHE über Tests definiert, die auch zu ihrer Diagnostik verwandt werden.

Das Überleben von Patienten mit einem MELD-Score > 10 war schlechter für Patienten mit gleichzeitig vorhandener mHE, wenn diese mittels kritischer Flimmerfrequenz $(<39 \mathrm{~Hz})$, nicht aber durch psychometrische Tests diagnostiziert wurde [504]. Die kritische Flimmerfrequenz zeigte in der Diagnostik der oHE mit $41 \%$ eine deutlich geringere Sensitivität als die psychometrischen Tests [604]. Die Testergebnisse werden durch Alter, Lerneffekte, Alkoholkonsum und Begleiterkrankungen beeinflusst [605].

Das Stadium 1 der West-Haven-Kriterien ist allenfalls für Verwandte des Patienten, aber kaum für den Arzt diagnostizierbar, weshalb dieses Stadium zuletzt der „covert HE“ zugeordnet wurde $[605,606]$. Trotz dieser Schwierigkeit wurde das Stadium 1 in 
vielen Studien als klinisch sicher einschätzbar verwandt, was deren Ergebnisse relativiert. Grundsätzlich wird verlangt, dass mindestens zwei verschiedene Tests in Studien zur Anwendung kommen sollen [607]. Diese 2015 festgelegte Forderung wurde in älteren Studien meist nicht berücksichtigt. Die eingesetzten Tests sollten zudem in Studienzentren validiert und auf die zu untersuchende Population standardisiert sein.

Die West-Haven-Kriterien zur Einschätzung der HE sind umso ungenauer je niedriger das HE Stadium ist und unterliegen somit der subjektiven Einschätzung des Untersuchers [578]. Der Übergang von einem Stadium zum anderen ist fließend und erlaubt kaum eine genaue Kategorisierung [607].

Studienergebnisse sollten sich auf klar definierte Patientenpopulationen beziehen. Patienten mit mHE, cHE $(=\mathrm{mHE}+\mathrm{HE} 1$ [West-Haven-Klassifikation]) und oHE (= West-Haven-Klassifikation $>1$ ) sollten getrennt betrachtet werden. Die zu vergleichenden Studienkollektive sollten nach Alter, Schweregrad der Lebererkrankung, Alkoholexposition und Begleiterkrankungen möglichst gleichförmig zusammengesetzt sein. HE Typ A, B und $C$ oder bei ACLF müssen bei Therapiestudien getrennt betrachtet werden. Auch hat das Vorliegen von auslösenden Faktoren einen so starken Einfluss auf Studienergebnisse, dass ihr Vorliegen als Ausschlusskriterium gelten sollte. In vielen Studien wurde dies nicht berücksichtigt. Die Einschlusskriterien sollten ebenfalls klar festlegen, ob eine Therapie bei Patienten mit akuter HE-Episode, in der Primär- oder Sekundärprävention getestet wird.

Die Therapie in der Placebo- und Verum-Gruppe (Standard of Care) beeinflusst die Konsequenzen, die für den zukünftigen Einsatz des getesteten Medikaments gezogen werden. Erhalten Verum- und Kontrollgruppe Lactulose, kann bei positivem Studienergebnis nur die Kombination von Lactulose mit der getesteten Substanz eingesetzt werden. Selbst in aktuellen Studien [608] erhielt die Vergleichsgruppe eine Standardtherapie, die nicht den Vorgaben der europäisch/amerikanischen Leitlinie [603] entsprach.

Die Definition der Studienendpunkte ist von besonderer Bedeutung für den Wert von Studienergebnissen [607]. Aussagen zur therapeutischen Wirksamkeit erfordern als Endpunkt die Besserung der HE. Geht nur der Schweregrad der HE zurück, kann dennoch weiterhin eine HE vorliegen. Weiterhin ist als Endpunkt der alleinige Nachweis der Absenkung des Ammoniakgehaltes im Blut durch die getestete Substanz für die klinische Wirksamkeit unerheblich, da weder das Vorliegen noch der klinische Schweregrad einer HE mit diesem Laborparameter korrelieren [603, 609, 610].

Eine Proteinbelastung $[611,612]$ im Rahmen einer Studie wie bei der Testung von LOLA soll heute nicht mehr durchgeführt werden.

\section{Therapeutische Beeinflussung der intestinalen Ammoniakauf- nahme}

Ammoniak wird bei Patienten mit Leberzirrhose nicht nur beim endogenen Abbau z. B. von Proteinen in der Muskulatur, sondern insbesondere auch aus intestinalen Nahrungsproteinen oder Blut freigesetzt. Enterozyten katalysieren die Umwandlung von Glutamin in Glutamat und Ammoniak mittels einer intestinalen Glutaminase [613]. Darmbakterien (Enterobacter, Clostridium und Proteusspezies) verfügen über eine Urease, die bei einer intestinalen
Blutung aus in den Darm gelangten Harnstoff Ammoniak und $\mathrm{CO}_{2}$ entstehen lassen. Die Ammoniakaufnahme über den Darm wird durch die zugeführte absolute Eiweißmenge, die Art des aufgenommenen Proteins (pflanzliche vs. tierische Proteine), den $\mathrm{pH}$ im intestinalen Lumen und die Zusammensetzung des Mikrobioms beeinflusst. Hieraus ergeben sich mehrere therapeutische Ansatzpunkte, über die die Aufnahme intestinalen Ammoniaks und dessen Serumspiegel beeinflusst werden können.

\section{Lactulose (nicht-absorbierbare Disaccharide)}

Lactulose oder Lactitol sind Disaccharide, die im menschlichen Dünndarm nicht gespalten und daher auch nicht intestinal resorbiert werden können. Daher gelangen sie ungespalten bis in den Dickdarm, wo sie bakteriell verstoffwechselt werden. Sie sind osmotisch wirksam und haben dadurch eine die Darmpassage beschleunigende Wirkung. Der intraluminale $\mathrm{pH}$ wird abgesenkt, wodurch aus Ammoniak Ammoniumionen werden, die nicht resorbiert werden können. Kurzkettige Fettsäuren, die beim bakteriellen Stoffwechsel von Lactulose freigesetzt werden, begünstigen das Wachstum bestimmter Bakterienstämme, die den Ammoniak zur Proteinsynthese verwenden und somit binden [614]. Die Freisetzung von Ammoniak aus Glutamin wird zudem durch Lactulose über eine Hemmung der Glutaminase vermindert. Die bei Leberzirrhose nachgewiesene Dysbiose im Kolon wird ebenfalls günstig beeinflusst (Rolle der Disaccharide als sog. Präbiotikum) [615].

Nicht-absorbierbare Disaccharide zeigten in einer Metaanalyse [616] von 38 randomisierten Studien mit 1828 Teilnehmern eine statistisch signifikante Besserung der akuten HE. Weiterhin zeigten sich im Hinblick auf die Mortalität Vorteile für Lactulose gegenüber Placebo oder keine Intervention, wenn nur acht gut angelegte Studien berücksichtigt wurden. Auch wenn die eingeschlossenen Studien meist mäßiger Qualität waren, ergibt sich dennoch eine klare Empfehlung zu ihrem bevorzugten Einsatz bei der Behandlung der manifesten HE und zur Sekundärprävention, also zur Vermeidung eines Rezidivs nach einer Indexepisode [616]. Lactulose führt zu einer Abnahme der Gesamtmortalität und hat günstige Auswirkungen auf Komplikationen des chronischen Leberversagens wie Varizenblutung, schwere Infektionen, spontan bakterielle Peritonitis und hepatorenales Syndrom. Zwischen Lactitol und Lactulose fanden die Autoren keinen Unterschied im Hinblick auf evaluierbare Endpunkte [617].

Die Metaanalyse [616] wies auch auf positive Effekte bei der Behandlung der mHE und dem Einsatz in der Primärprävention hin. Neun Studien mit insgesamt 434 Patienten gingen in eine zweite Metaanalyse ein, die die Wirkung von Lactulose bei $\mathrm{mHE}$ untersuchte [618]. Lactulose erwies sich im Hinblick auf die Besserung psychometrischer Tests, der Häufigkeit des Übergangs in eine oHE und der Lebensqualität gegenüber Placebo oder keiner Therapie als signifikant besser. Lediglich die Mortalität wurde nicht beeinflusst.

Beim Vergleich mit schwer resorbierbaren Antibiotika und Rifaximin erwies sich Lactulose in mehreren Metaanalysen als gleichwertig [619-621]. Es fand sich kein Unterschied im Hinblick auf eine Besserung bei akuter oder chronischer HE. Auch die Nebenwirkung einer Diarrhö fand sich gleich häufig bei Anwendung beider Medikamente [619]. Lediglich Bauchschmerzen 
fanden sich signifikant häufiger unter Lactulose. Die zweite Metaanalyse fand mehr Diarrhöen und weniger Bauchschmerzen unter Lactulose gegenüber Rifaximin [620]. Die Tagestherapiekosten liegen für Rifaximin aktuell bei 14,00€/Tag (2-mal $550 \mathrm{mg})$ und für Lactulose bei 0,39€/T (3-mal $20 \mathrm{ml})$ [622].

Nebenwirkungen der Therapie mit nicht absorbierbaren Disacchariden sind Blähungen, Bauchschmerzen, Flatulenz und Durchfall, sodass die Präparate bei einigen Patienten aus diesen Gründen abgesetzt werden müssen. Beim Sirup mit Beimengungen von weiteren Zuckern sind diese Nebenwirkungen offenbar stärker ausgeprägt als bei rein kristallinen Präparationen (Lactitol). Diese Annahme konnte allerdings in einer Metaanalyse von sechs Studien, die das Vorkommen nicht schwerer Nebenwirkungen von Lactulose im Vergleich zu Lactitol untersuchten, nicht bestätigt werden [616]. Die Dosierung der Lactulose richtet sich nach Stuhlfrequenz und Konsistenz. Es sollten zwei bis drei weiche Stühle pro Tag abgesetzt werden. Die verabreichten Mengen liegen zwischen 3-mal $10 \mathrm{ml}$ und 3-mal $30 \mathrm{ml}$ p. o. pro Tag. Die Dosis kann je nach Stuhlverhalten auch auf zwei tägliche Gaben beschränkt werden [603].

\section{Probiotika}

Probiotika sind lebende Mikroorganismen, die die Zusammensetzung des intestinalen Mikrobioms modifizieren können, wenn genügend Bakterien p. o. in das Kolon gelangen. Sie sollen die bei Leberzirrhose und HE nachgewiesene Dysbiose [623] über eine Verminderung pathogener Bakterienstämme mit reduzierter Endotoxin- und Ammoniakfreisetzung bessern. Die unter den nicht- absorbierbaren Disacchariden (=Präbiotika) nachgewiesenen Effekte lassen sich vom gedanklichen Ansatz her auf die Wirkungen der Probiotika weitgehend übertragen [615, 624].

Randomisierte kontrollierte Studien und verschiedene Metaanalysen lassen derzeit allerdings noch keine eindeutige Bewertung dieses Therapieansatzes bei HE zu [603, 624-627]. Die Cochrane-Metaanalyse berücksichtigte 21 Studien mit $1420 \mathrm{~Pa}$ tienten [626]. 14 Studien verglichen die Gabe von Probiotika mit Placebo oder keiner Therapie und sieben setzten Lactulose als Vergleichstherapie ein. VSL\#3 wurde am häufigsten in den Studien als Probiotikum eingesetzt. Beim Vergleich mit Placebo fand sich keine Beeinflussung der Gesamtmortalität (alle Ursachen). Ein Therapieversagen fand sich seltener unter Probiotika. Sie besserten geringfügig die Lebensqualität und senkten den Ammoniakgehalt des Blutes. Beim Vergleich mit Lactulose erwiesen sich Probiotika in allen untersuchten Parametern als nicht besser. Die in die Metaanalyse eingeschlossenen Studien wiesen ein hohes Risiko für systemische und zufallsbedingte Fehler auf. Beim Vergleich mit Placebo, aber nicht mit Lactulose ergaben sich insgesamt Hinweise auf eine bessere Wirkung bei akuter HE. Für eine genauere Einschätzung der Wirkung von Probiotika bei HE fehlt derzeit eine ausreichende Datenlage.

Probiotika zeigten sich wirksam in der Therapie der $\mathrm{mHE}$ beim Vergleich mit Placebo oder keiner Therapie [627].

\section{Stuhltransfer}

Entsprechend der Bedeutung des Mikrobioms bei Patienten mit Leberzirrhose und HE lag es nahe, die therapeutische Wirkung eines Stuhltransfers zu prüfen. Bajaj und Mitarbeiter untersuchten die Wirkung des Stuhltransfers in der Sekundärprophylaxe der HE und behandelten in einer randomisierten Studie insgesamt $20 \mathrm{~Pa}$ tienten, die unter einer Standardtherapie mindestens zwei akute HE-Episoden entwickelt hatten. Sie selektionierten einen einzigen Stuhlspender, der eine für Patienten mit HE „optimale“ Darmflora im Stuhl aufwies [608]. Vor der Verabreichung des Stuhls mittels Einlauf wurde über fünf Tage antibiotisch mit einer Kombination von Metronidazol, Ciprofloxacin und Ampicillin behandelt. Der primäre Endpunkt war das Auftreten von Nebenwirkungen, was in der Gruppe mit Stuhltransfer deutlich günstiger ausfiel. Ein vermindertes Auftreten einer HE als sekundärer Endpunkt fand sich ebenfalls nur in dieser Gruppe. Weitere HE-Episoden wurden ausschließlich bei sechs von insgesamt zehn Kontrollpatienten beobachtet. Obwohl auch die Patienten der Kontrollgruppe Rifaximin und Lactulose erhielten, überrascht die hohe Rezidivrate von $60 \%$ in dieser Gruppe. Die aktuelle Datenlage erlaubt derzeit keine Empfehlung für dieses Verfahren außerhalb von klinischen Studien.

\section{Schwer resorbierbare Antibiotika}

Schwer resorbierbare Antibiotika, wie Paromomycin, Neomycin und Rifaximin, beeinflussen die Darmflora, indem pathogene Darmbakterien mit Endotoxin- oder Ammoniakbildung abgetötet werden. Die fast ausschließlich im Darmlumen wirkenden Antibiotika verändern somit die quantitative und qualitative Zusammensetzung des intestinalen Mikrobioms mit positiven Auswirkungen auf Therapie und Prävention einer HE.

Rifaximin hat ein breites antimikrobielles Spektrum mit Wirkung gegen intestinale Gram-positive und Gram-negative Organismen, was sowohl Aerobier als auch Anaerobier einschließt. Es beeinflusst Funktion und Aktivitäten der intestinalen Bakterien mit Anstieg langkettiger Fettsäuren und von Intermediärprodukten des Kohlenhydratstoffwechsels [628]. Die intestinale bakterielle Zusammensetzung, die bakterielle Translokation [629] und Hämodynamik werden jedoch bei dekompensierter Leberzirrhose durch eine vierwöchige Behandlung mit Rifaximin nicht oder kaum beeinflusst [630].

In einer Metaanalyse von zehn Studien [631], die Rifaximin mit anderen Therapien bei einer akuten HE-Episode verglichen, fand sich bei neun von zehn analysierten Studien kein statistisch signifikanter Unterschied gegenüber der jeweiligen Kontrolltherapie. Die anhand dieser Daten durchgeführte Metaanalyse zeigte in der Akutbehandlung keinen Vorteil für Rifaximin allein im Vergleich zu einer Standardtherapie, zumal die einzige Studie [632] mit signifikantem Ergebnis nicht Rifaximin, sondern dessen Kombination mit Lactulose gegen Lactulose allein verglich. Zudem war in dieser Studie in beiden Gruppen eine außergewöhnlich hohe Mortalität vorhanden und der Nachweis eines auslösenden Faktors für eine HE war kein Ausschlusskriterium [632]. 17 Patienten in der Kontrollgruppe litten an einer Sepsis, während dies nur bei sieben in der Rifaximingruppe der Fall war. Dies und die Tatsache, dass in der Metaanalyse [631] von den Herstellern des Präparates (Salix und Alfa Wasserman) zur Verfügung gestellte bis dahin nicht publizierte Daten eingingen, schmälern die Aussagekraft dieser Metaanalyse weiter.

Drei weitere Metaanalysen [619 - 621] konnten ebenfalls keine Überlegenheit von Rifaximin gegenüber Kontrolltherapien bei akuter HE-Episode nachweisen. 
Der primäre Einsatz von Rifaximin bei einer manifesten $\mathrm{HE}$ wurde in der gemeinsamen Leitlinie von AASLD und EASL nicht empfohlen, da hierfür keine soliden Daten zur Verfügung standen [603]. Rifaximin ist in Deutschland zur Behandlung der ersten HE-Episode nicht zugelassen. Eine Monotherapie mit Rifaximin soll entsprechend der Leitlinienkommission nicht bei der Erstbehandlung, sondern nur in den wenigen Fällen einer Unverträglichkeit von Lactulose (s. Empfehlung 7.14, „Off-Label-Use“) erfolgen. Bei fehlendem Ansprechen von Lactulose allein kann zusätzlich Rifaximin gegeben werden (Empfehlung 7.11). Diese Empfehlung beruht auf einer einzigen positiven Studie, die die oben angeführten Schwächen aufweist, und entspricht zudem einer nicht zugelassenen Indikation [632] (s. auch Abschnitt 7.1.4) Rifaximin ist nur in der Sekundärprävention in Kombination mit Laktulose zugelassen.

Paromomycin, Neomycin und Rifaximin waren in einer Metaanalyse gleichwertig [620]. Das Nebenwirkungsspektrum von Paromomycin und Neomycin ist aber ungünstiger als das von Rifaximin [633]. Auch die schwer resorbierbaren Antibiotika werden in geringen Mengen intestinal resorbiert. Insbesondere bei Paromomycin und Neomycin besteht bei längerer Einnahme das Risiko für schwerwiegende Nebenwirkungen wie Oto- oder Nephrotoxizität. Auch Rifaximin wird bei Patienten mit Leberzirrhose wegen der durchlässigeren Darmwand leichter in die Blutbahn aufgenommen, was zu höheren Blutplasmakonzentrationen $(10 \mathrm{ng} / \mathrm{ml}) \mathrm{im}$ Vergleich zu gesunden Kontrollpersonen (1 ng/ml) führt [634]. Interaktionen am CYP3A4 bei gleichzeitiger Einnahme von Statinen können in sehr seltenen Fällen das Risiko für eine Myopathie erhöhen [635]. Trotz bekannter Aktivität gegen Clostridium difficile wurden unter Rifaximin Infektionen mit diesem Erreger beobachtet [636].

\section{Laxanzien und abführende Maßnahmen}

Schon früh wurden abführende Maßnahmen mit Einläufen und wiederholten Gaben von Magnesiumcitrat [637] oder die orthograde intestinale Lavage mit einer Mannitlösung bei HE und Leberzirrhose vorgeschlagen [552, 553]. In der Primärprophylaxe bei Patienten mit oberer gastrointestinaler Blutung erwies sich die Applikation der Mannitlösung als genauso effektiv wie die Kombination von Paromomycin und Lactulose [553] oder besser als keine Therapie [638].

Eine kleinere Studie zeigte bei Patienten mit akuter HE Vorteile für reine Abführmaßnahmen mittels Polyäthylenglykol (PEG)-Lösung im Vergleich zur Gabe von Lactulose [554]. Im klinischen Alltag dürfte es nicht einfach sein, 4 I PEG-Lösung bei Patienten mit dekompensierter Leberzirrhose und HE zu verabreichen. Die Studie zeigt aber, dass alleinige abführende Maßnahmen positiv in die Pathophysiologie der HE eingreifen. Naderian und Mitarbeiter [639] kamen zu einem ähnlichen Ergebnis, wobei sie leichte Vorteile im Sinne einer schnelleren Besserung der HE für die Kombination von PEG-Lösung und Lactulose nachweisen konnten.

Eine Empfehlung zum routinemäßigen Einsatz der PEG-Lösung bei HE oder in der Primärprophylaxe kann zum jetzigen Zeitpunkt jedoch nicht gegeben werden. Eine Alternative zur oralen Lavage können möglicherweise Lactulose-Einläufe (300 ml Lactulose auf $1000 \mathrm{ml} \mathrm{H}^{2} \mathrm{O}$ ) sein [640-642].

\section{Substanzen zur Bindung von Ammoniak}

Erhöhte Serumammoniakspiegel können durch exogene Zufuhr von L-Ornithin-L-Aspartat (LOLA) bei Patienten mit Leberzirrhose gesenkt werden [643]. LOLA stimuliert möglicherweise den Einbau von Ammoniak in Harnstoff oder Glutamin über das erhöhte Angebot an Vorstufen zur Harnstoffsynthese und Glutaminbildung. Auch nicht natürliche Substanzen wie Glycerolphenylbutyrat oder Ornithin-phenylazetat binden Ammoniak in Form von Phenylazetylglutamin, das renal eliminiert wird [644].

\section{L-Ornithin-L-Aspartat (LOLA)}

Die Wirkung von LOLA auf den Ammoniakgehalt des Blutes wurde in einigen [612, 645], aber nicht in allen Studien [645] gezeigt. Der Nachweis der Ammoniakabsenkung allein lässt zudem keinen Rückschluss auf die klinische Wirksamkeit zu [646]. Gelegentlich setzte der Einschluss von Patienten in diese Studien einen erhöhten Ammoniakspiegel voraus, was deren Aussagekraft wegen einer möglichen Patientenselektion beeinträchtigen kann.

Die Autoren einer aktuellen Metaanalyse [647] kommen zu dem Schluss, dass unzureichende Informationen vorliegen, um eine endgültige Bewertung trotz einiger positiver Effekte von LOLA vornehmen zu können, da die bisher vorliegenden Studienergebnisse zufälligen und systematischen Fehlern unterliegen können. LOLA zeigte in dieser Metaanalyse keine Wirkung bei mHE oder in der HE-Prävention. Der Nachweis von positiven Effekten von intravenös appliziertem LOLA bei HE (akute oder chronische HE) war von geringer Qualität und erfordert zusätzliche randomisierte Studien.

In einer weiteren Metaanalyse zur Wirkung von LOLA bei akuter $\mathrm{HE}$ und $\mathrm{mHE}$ gingen acht randomisierte und kontrollierte Studien mit 646 Patienten ein [646]. Es ergaben sich Vorteile für alle eingeschlossenen Patienten mit HE beim Vergleich von LOLA mit Placebo oder keine Behandlung (vier Studien, RR für Rückbildung der HE 1,33; $95 \%$ Konfidenzintervall 1,04-1,69). In den Studien bewirkte eine mindestens zehntägige Gabe von LOLA eine signifikante Absenkung des Ammoniakspiegels. Die Wirkung auf den Ammoniakgehalt des Blutes korrelierte jedoch nicht mit einer Besserung der HE. Wenn nur Studien mit hoher Qualität eingeschlossen wurden, fand sich in dieser Metaanalyse kein statistisch signifikanter Vorteil von LOLA auf die mHE oder akute HE bei Patienten mit Leberzirrhose [646].

Eine kürzlich publizierte randomisierte kontrollierte Studie an 193 Patienten mit HE untersuchte die zusätzliche i. v. Gabe von LOLA im Vergleich mit Lactulose und Ceftriaxon allein [645]. Das Vorliegen von Auslösern für eine HE-Episode war in dieser Studie kein Ausschlusskriterium. LOLA als zusätzliches Medikament zu Ceftriaxon und Lactulose gegeben zeigte nur in den ersten vier Tagen nach Therapiebeginn eine bessere Wirkung auf den HEGrad. Am fünften Tag zeigte sich gegenüber der Placebogruppe kein Unterschied mehr. Die Dauer des Krankenhausaufenthaltes konnte durch die zusätzliche Gabe von LOLA um etwas mehr als einen halben Tag verkürzt werden.

Insbesondere für die orale Gabe von LOLA gibt es keine gesicherten Daten [603, 609]. Die beste Studie [611], die die orale Gabe von LOLA mit Placebo verglich, schloss überwiegend Patienten mit mHE und HE Grad 1 und nur 7 bzw. 11 Patienten mit HE Grad 2 in die jeweilige Vergleichsgruppe ein. Auch bei mHE erwies sich die orale Gabe als unwirksam [648]. 
Zwei Studien mit oraler Gabe $[611,649]$ und eine weitere mit i. v.-Gabe [612] gingen in eine dritte Metaanalyse ein [650]. Ein positiver Effekt wurde für Patienten mit HE-Schweregrad 1 und 2 und nicht für die mHE nachgewiesen. Die Besserung von Grad 1 auf 0 ist allerdings nach heutiger Auffassung klinisch nicht sicher einschätzbar.

Der Einsatz von i. v. LOLA bei akutem Leberversagen (HE Typ A) zeigte weder eine Wirkung auf die Ammoniakspiegel im Serum noch auf das Überleben der Patienten [651].

\section{Glycerolphenylbutyrat und Ornithinphenylazetat}

Glycerolphenylbutyrat und Ornithinphenylazetat sind ebenfalls in der Lage, den Ammoniakspiegel im Blut über eine vermehrte renale Ausscheidung von Ammoniak-haltigen Metaboliten abzusenken [644]. Unter Glycerylphenylbutyrat war in der Sekundärprävention der Prozentsatz der Patienten mit einem erneuten HE-Rezidiv statistisch signifikant niedriger als unter nur fortgeführter Standard-HE-Therapie [652]. Auch die Zeit bis zum nächsten HE-Rezidiv und die Zahl der Hospitalisationen war unter dieser Substanz statistisch signifikant günstiger. Glycerylphenylbutyrat wurde von Patienten mit Leberzirrhose gut vertragen [653].

Ornithinphenylazetat in einer Dosierung von $10 \mathrm{~g} /$ Tag führte zu keiner Absenkung der Ammoniakspiegel bei Patienten mit Leberzirrhose [654]. Die Substanz erwies sich bei Patienten mit Leberzirrhose als sicher [655]. Klinische Studien liegen zu dieser Substanz noch nicht vor.

\section{Verzweigtkettige Aminosäuren (BCAA)}

Valin, Leuzin und Isoleuzin sind verzweigtkettige Aminosäuren (BCAA, branched-chain amino acids), die für die zelluläre Proteinsynthese erforderlich sind. Bei Patienten mit Leberzirrhose ist die Relation von BCAA zu aromatischen Aminosäuren im Serum zuungunsten der BCAA verschoben. Bei diesen Patienten scheint sich die Gabe von BCAA günstig auf die Albuminsynthese, die Insulinresistenz und die Synthese von Muskelproteinen auszuwirken [656, 657]. Bei HE können BCAA die Stickstoffbindung in Proteinen und eine verminderte Freisetzung von Ammoniak bei anaboler Stoffwechsellage bewirken.

Eine Metaanalyse [592] schloss 16 randomisierte klinische Studien mit 827 Teilnehmern ein, die die Wirkung von verzweigtkettigen Aminosäuren auf die HE nach oraler oder intravenöser Gabe untersuchten. Die Analyse belegte einen statistisch signifikanten Effekt dieser Therapie auf die HE bei Patienten mit Leberzirrhose. Mortalität, Lebensqualität oder Ernährungsparameter wurden allerdings hierdurch nicht beeinflusst. Der positive Effekt von BCAA auf die HE blieb auch erhalten, wenn Studien mit geringer Qualität ausgeschlossen wurden. Es fand sich kein Unterschied zur Wirkung von Lactulose oder Neomycin.

Die orale Zufuhr von BCAA führte bei Patienten mit Leberzirrhose zu keiner Abnahme des Auftretens typischer Komplikationen wie eine HE [658], obwohl sich der MELD-Score signifikant besserte. In einer weiteren Studie besserte sich der Child-PughScore unter kontinuierlicher Verabreichung von BCAA [659]. Die orale Zufuhr von BCAA und von Leuzin hatte zudem günstige Effekte auf die Skelettmuskulatur dieser Patienten [660].

\subsubsection{Medikamentöse Kombinationstherapien}

Eine retrospektive Studie verglich die alleinige Gabe von Lactulose mit der Kombination von Lactulose und Rifaximin [661]. Die Krankenhausaufenthaltsdauer unterschied sich nicht, aber es kam im Verlauf zu weniger stationären Wiederaufnahmen bei Einsatz der Kombination. Die Mortalität war in beiden Gruppen statistisch nicht signifikant verschieden. 76\% der Patienten, die Rifaximin zusätzlich zu Lactulose in einer randomisierten, kontrollierten Studie [632] erhielten, zeigten eine vollständige Besserung der HE. Unter Lactulose allein wurde dies nur bei $44 \%$ der Patienten erreicht $(P=0,004)$. Die Kombination beider Substanzen reduzierte die Mortalität (23,8 vs. 49,1\%; $\mathrm{P}<0,05)$ und die Dauer des Krankenhausaufenthaltes. Im Gegensatz dazu waren diese beiden Endpunkte in der retrospektiven Studie [661] nicht signifikant verschieden. Erklärungen für die abweichenden Ergebnisse beider Studien können das unterschiedliche Studiendesign und die ungewöhnlich hohe Mortalität der Patienten in der Studie von Sharma et al. [632] sein. Zwei weitere, prospektiv angelegte Studien zum Vergleich der Kombination von Laktulose und Rifaximin mit Laktulose allein ergaben jeweils keinen Unterschied im Hinblick auf den Prozentsatz der Patienten ohne HE $[662,663]$. Da von den vier aufgeführten Studien [632, 661 -663] nur eine einen Vorteil für die Kombinationstherapie von Laktulose mit Rifaximin ergab, kann diese entsprechend der Empfehlung der Leitlinienkommission nur in Einzelfällen bei nicht ausreichendem Ansprechen einer Monotherapie mit Lactulose erfolgen. In der Akuttherapie der HE ist zudem Rifaximin weder allein noch in Kombination mit Lactulose zugelassen.

Ein ähnliches Ergebnis wie für die Kombination von Lactulose mit Rifaximin [632] konnte durch die Kombination von Albumin (1,5 g/kg Körpergewicht/Tag) mit Lactulose (3-mal $30-60 \mathrm{ml} /$ Tag) erzielt werden [664]. $75 \%$ der Patienten in der Kombinationsgruppe und 53 \% unter Lactulose allein zeigten eine vollständige Besserung der akuten $\mathrm{HE}$.

LOLA als zusätzliches Medikament zu Ceftriaxon und Lactulose gegeben [645], zeigte nur in den ersten vier Tagen nach Therapiebeginn eine bessere Wirkung auf den HE Grad. Am fünften Tag zeigte sich gegenüber der Placebogruppe kein Unterschied mehr. Die Dauer des Krankenhausaufenthaltes konnte durch die zusätzliche Gabe von LOLA um etwas mehr als einen halben Tag verkürzt werden.

Eine weitere Studie verglich die kombinierte Gabe von LOLA, Lactulose und Metronidazol mit Lactulose und Metronidazol bei Patienten mit HE und Leberzirrhose [665]. Bei 79,1 \% (34/43) besserte sich die akute HE-Episode unter adjuvanter LOLA-Gabe im Vergleich zu 55,6\% (25/45) unter Standardtherapie. In dieser Studie wurden allerdings überwiegend Patienten mit reversibler Ursache für eine $\mathrm{HE}$ eingeschlossen.

Bei einer akuten HE Episode wird in der Mehrzahl der Fälle ein therapierbarer Auslöser der HE vorliegen (s. Abschnitt 7.1). In den wenigen Fällen, wo keine Ursache für die HE gefunden werden kann, ist eine Monotherapie in mindestens der Hälfte der Fälle erfolgreich [662 - 665]. Nur in dem geringen Prozentsatz von Patienten mit Therapieversagen kann auf eine Kombinationstherapie gewechselt werden. Mortalität und weitere Komplikationen der Leberzirrhose werden auch durch Lactulose allein günstig be- 
einflusst [617]. In der amerikanisch/europäischen Leitlinie wird entsprechend eine Monotherapie mit Lactulose als Therapie der ersten Wahl empfohlen [603]. BCAA, i.v. LOLA und Rifaximin sind mögliche Kombinationspartner bei akuter HE bei Therapieversagen von Lactulose allein.

\subsection{Rezidivprophylaxe nach einer HE-Episode}

\section{EMPFEHLUNG 7.21}

Bei Patienten mit Zirrhose und durchgemachter HE soll eine Rezidivprophylaxe erfolgen.

Starke Empfehlung, Konsens

\section{EMPFEHLUNG 7.22}

Lactulose sollte als Medikament zur Sekundärprophylaxe eingesetzt werden.

Empfehlung, starker Konsens

\section{EMPFEHLUNG 7.23}

Rifaximin sollte additiv zur Lactulose in der Sekundärprophylaxe der HE > Grad 1 nach West-Haven-Kriterien ohne Auslöser eingesetzt werden, wenn unter alleiniger Gabe von Lactulose ein Rezidiv aufgetreten ist. Eine Monotherapie mit Rifaximin sollte nur erfolgen, wenn eine Therapie mit Lactulose nicht möglich ist. Empfehlung, starker Konsens

\section{Kommentar}

Therapiestudien zur Sekundärprävention einer HE zeigten eine Rezidivrate von 47 - 57 \% für eine zweite HE-Episode [636, 666, 667]. Maßnahmen zur Sekundärprophylaxe einer HE dienen der Verhinderung einer wiederholten HE-Episode, die mit erneuter Hospitalisation, Morbidität, Mortalität und Gesundheitskosten einhergeht [636, 666 - 668]. Der Beginn der Sekundärprophylaxe wurde nach einer ersten HE-Episode empfohlen [436, 669]. Wenn die HE durch die Therapie der auslösenden Ursache ( $>$ Tab. 3) erfolgreich beseitigt wurde, kann entsprechend der EASL/AASLD Leitlinie auf eine Sekundärprophylaxe verzichtet werden [436]. Die Sekundärprävention wird ansonsten dauerhaft fortgesetzt. Allerdings könnte ein Auslassversuch bei Besserung der Leberfunktion und/oder Zunahme der Muskelmasse gemacht werden [436].

In randomisierten kontrollierten Studien zur Sekundärprävention wurden verzweigtkettige Aminosäuren [670], Probiotika [667, 671], ein Stuhltransfer [608] (siehe oben), nicht absorbierbare Disaccharide [616, 666, 667], Ammoniak bindende Substanzen $[647,652]$ und Rifaximin $[631,636]$ getestet, wobei sich Vorteile für einige dieser Substanzen gegenüber Placebo ergaben. Meistens stellten jedoch HE-Auslöser kein Ausschlusskriterium dar, was die Qualität der Studien einschränkt. Zudem enthielt in der größten Studie sowohl der Verum- als auch der Placebo-Arm
Lactulose, sodass nur eine Beurteilung der Kombination der Testsubstanz mit Lactulose gegen Lactulose allein möglich war [636].

Eine Metaanalyse, die die Wirkung nicht absorbierbarer Disaccharide in der Sekundärprophylaxe untersuchte, fand eine statistisch signifikante Risikoabsenkung von 53 \% für das erneute Auftreten einer HE-Episode [608]. Die kostengünstige Lactulose sollte daher das Medikament der ersten Wahl in der Sekundärprävention sein [436].

Rifaximin erwies sich in der Sekundärprophylaxe in zwei von drei in eine Metaanalyse eingeschlossenen Studien im Vergleich zu einer Kontrolltherapie ohne Vorteil [631]. Eine dieser beiden negativen Studien $[672,673]$ bestand ausschließlich aus Patienten nach TIPSImplantation mit HE [673]. Der Einschluss der einzig positiven Studie [636], die die Kombination von Rifaximin mit Lactulose gegenüber Lactulose allein untersucht hatte, führte in der Metaanalyse zu einem statistisch signifikanten Vorteil für Rifaximin gegenüber einer Standardtherapie [631]. Diese Studie von Bass et al. [636] weist jedoch erhebliche Mängel auf [634, 674]. So wurde die Randomisierung in den 70 beteiligten Zentren nicht spezifiziert. Ein Drittel der Patienten war bei Studieneinschluss nicht in vollständiger Remission, sondern wies den HE-Grad 1 auf [634]. Primäres Zielkriterium war die Zeit zwischen Therapiebeginn bis zum „Durchbruch“ einer HE-Episode. Eine Durchbruchepisode lag vor, wenn der zu Beginn erhobene Conn-Score von 0 oder 1 auf mindestens 2 oder der initiale Conn-Score von 0 auf 1 und gleichzeitig der Asterixis-Score um einen Schweregrad stieg. Gerade bei niedrigen Schweregraden des Conn-Scores ist die klinische Einschätzung sehr subjektiv und wenig reproduzierbar [674]. Dies gilt auch für die quantitative Beurteilung einer Asterixis mit wenigen (,few“ = Grad 1) und gelegentlichen („occasional“ = Grad 2) grobschlägigen Zitterbewegungen [636]. Bei etwa 30 - 40 \% der Fälle erfolgte die Einschätzung des Conn-Scores indirekt durch den jeweiligen Studienleiter vor Ort allein aufgrund von schriftlichen Aufzeichnungen oder Aussagen von Dritten und bei weiteren $20 \%$ auch indirekt auf Aussagen des Patienten selbst [674]. Unklar ist, warum die vorausberechnete Zahl einzuschließender Patienten um fast 100 Patienten überschritten wurde [636]. Bei der Einschätzung der Studienergebnisse muss weiterhin berücksichtigt werden, dass nicht nur das Studienprotokoll unter Mitwirkung des Herstellers von Rifaximin (Fa. Salix) entworfen wurde, sondern auch Monitoring und Datenanalyse durch Mitarbeiter dieser Firma erfolgten [636]. Nur 5 der 17 Autoren der Studie erhielten keine finanziellen Zuwendungen oder waren keine Mitarbeiter der Fa. Salix [636]. In der Metaanalyse [631] wurden zudem bisher nicht veröffentliche Patientendaten verwandt, die den Autoren von der Fa. Salix zur Verfügung gestellt wurden.

In der Sekundärprophylaxe sollte entsprechend dieser Studienlage Rifaximin allein (2-mal $550 \mathrm{mg} / \mathrm{Tag}$ ) nur dann eingesetzt werden, wenn die alleinige Gabe eines nicht-absorbierbaren Disaccharids bei einer HE ohne Auslöser nicht ausreichend wirksam ist oder Lactulose nicht vertragen wird [436]. Die tägliche Einmalgabe von Rifaximin in der Rezidivprophylaxe war in einer Studie gleich wirksam wie die Gabe von zwei Dosen pro Tag [675]. In einer retrospektiven Auswertung von Langzeitdaten von Patienten unter Rifaximin oder Rifaximin und Lactulose zur Sekundärprävention fand sich kein statistisch signifikanter Unterschied für das erneute Auftreten einer HE-Episode in beiden Gruppen [676] (s. auch Kapitel 7.1.4). 
L-Ornithin-L-Aspartat zeigte in einer Metaanalyse keine Wirkung in der Rezidivprophylaxe [647]. In einer kürzlich publizierten Studie zur Sekundärprophylaxe der HE zeigte dagegen die orale Gabe von täglich $6 \mathrm{~g}$ LOLA im Vergleich zur Gabe von Placebo eine Verhinderung von HE-Rezidiven (9/73 [12,3\%] vs. 20/72 [27,7\%]) [677]. Für alle beobachteten Rezidive fand sich jedoch ein Auslöser. LOLA hatte in dieser Studie zudem keinen Einfluss auf die Mortalität oder die Zahl der wegen einer HE hospitalisierten Patienten. Ein Vergleich mit Laktulose erfolgte nicht. Die Studie ist monozentrisch und nicht konsequent prospektiv angelegt, sodass aufgrund dieser Daten keine Empfehlung zur oralen Rezidivprophylaxe mit LOLA gegeben werden kann [678].

Zur Sekundärprävention erwies sich die Gabe von Zink oder die diätetische Verabreichung von verzweigtkettigen Aminosäuren ebenfalls als nicht wirksam [600, 670]. Zum Einsatz weiterer Ammoniak bindender Substanzen oder Probiotika in der Sekundärprävention kann aufgrund der derzeitigen Studienlage keine gesicherte Aussage gemacht werden.

Bei therapierefraktärem Verlauf kann ein dominanter portosystemischer Shunt gesucht (siehe unten) und ggfs. operativ oder interventionell verschlossen werden [679]. Darüber hinaus sollte die Indikation zur Lebertransplantation geprüft werden.

\section{EMPFEHLUNG 7.24}

Bei Patienten mit durchgemachter oHE-Episode soll auf eine Ernährung mit ausreichend Kalorien- und Eiweißgehalt sowie einen abendlichen Imbiss geachtet werden.

Starke Empfehlung, starker Konsens

\section{Kommentar}

Die Allgemeinmaßnahmen im Rahmen der Rezidivprophylaxe entsprechen denen, die unter Allgemeinmaßnahmen bei akuter HE aufgeführt sind. Dies betrifft insbesondere die Ernährung [100], Verteilung der Mahlzeiten [591] und ggfs. die Bevorzugung von pflanzlichen Eiweißen [680].

\section{EMPFEHLUNG 7.25}

Bei Besserung der Leberfunktion oder des Ernährungszustandes nach durchgemachter HE-Episode kann die Sekundärprävention beendet werden.

Empfehlung offen, starker Konsens

\section{Kommentar}

Gute Daten zur Therapiedauer bei Patienten mit HE existieren nicht. In einer Studie zur Behandlung der mHE mit Rifaximin oder Lactulose wurde über drei Monate behandelt [681]. Sechs Monate nach Beendigung der Therapie kam es bei 47,6\% in der Rifaximinund bei $42,1 \%$ in der Lactulose-Gruppe zu einem Rezidiv der mHE. Der Prozentsatz der Patienten, die eine HE-Episode erlitten, war in beiden Therapiegruppen mit 7,1 und 7,9\% gleich. Immerhin war nach Absetzen der Medikamente bei etwa der Hälfte der Patienten die mHE nicht mehr nachweisbar. Bei der Vermeidung eines
Übergangs in eine manifeste HE erwiesen sich beide Medikamente im Verlauf als gleichwertig.

Eine Rezidivprophylaxe mit Lactulose senkte das Auftreten einer HE von 46,8\% in der Kontrollgruppe auf 19,2\% [666]. Nur $20-33 \%$ dieser Rezidive wiesen keinen Auslöser auf, sodass die Mehrzahl der wiederholten HE Episoden durch auslösende Komplikationen verursacht wurden. Die Fortführung der Rezidivprophylaxe mit Lactulose allein oder in Kombination mit Rifaximin versagte bei 45,9 bzw. 22,1\% der Patienten [636], wobei Lactulose als Monotherapie in dieser Studie wesentlich schlechter abschnitt als in der zuerst erwähnten Studie [666].

Unklar ist, welche Patienten unter einer Rezidivprophylaxe ein Therapieversagen zeigen, ob es hierfür prognostische Parameter gibt und ob auch eine HE mit Auslöser in der Sekundärprävention vermieden werden kann.

In der AASLD/EASL-Leitlinie [603] wird empfohlen, bei einer erfolgreich behandelten Ursache der HE Episode auf eine Sekundärprävention zu verzichten. Zur Einschätzung des Rezidivrisikos scheint die Beurteilung der Leberfunktion und des Ernährungszustandes (Vorliegen einer Sarkopenie) im weiteren Verlauf wichtig zu sein (siehe Kapitel 7.1). Gelingt es, diese Parameter zu verbessern, kann entsprechend dieser Leitlinie eine Rezidivprophylaxe beendet werden.

\section{EMPFEHLUNG 7.26}

Bei Patienten mit und ohne Leberzirrhose und therapierefraktärer HE soll nach dominanten portosystemischen Shunts mittels Sonografie, Angio-CT oder MRT gesucht werden. Starke Empfehlung, starker Konsens

\section{EMPFEHLUNG 7.27}

Bei Vorliegen einer Leberzirrhose (MELD-Score < 11) mit therapierefraktärer HE und Nachweis eines großen dominanten portosystemischen Shunts kann die Indikation zu einem interventionellen oder operativen Verschluss gestellt werden. Empfehlung offen, starker Konsens

\section{Kommentar}

Erworbene oder angeborene Shunts bei strukturell nicht veränderter Leber sind sehr selten. Dies gilt entsprechend auch für das damit verbundene Auftreten einer HE Typ B [682]. Bei portosystemischen Shunts nach einer Pfortaderthrombose fand sich jedoch bei bis zu einem Drittel der Patienten eine mHE [683, 684]. Patienten mit hereditären hämorrhagischen Teleangiektasien (Morbus Rendu-Osler-Weber) wiesen in 32-78\% der Fälle vaskuläre Veränderungen in der Leber auf [685]. Zwar können portosystemische Shunts bei diesen Patienten zu einer HE bei Abwesenheit einer Leberschädigung führen, von einer Shuntembolisation wird jedoch in diesen Fällen abgeraten, da dies nur eine vorübergehende Maßnahme bei Patienten mit M. Osler darstellt und mit hoher Mortalität und Morbidität assoziiert ist [685]. Stattdessen sollte eine Lebertransplantation in Erwägung gezogen werden [686]. 
$20 \%$ der Kinder bei extraheptischem Pfortaderverschluss wiesen eine $\mathrm{mHE}$ auf, die bei $75 \%$ mit Lactulose erfolgreich behandelt werden konnte [687]. Bei Kindern mit HE und angeborenen portosystemischen Shunts bei Pfortaderagenesie oder Hypoplasie kann nach genauer bildgebender Diagnostik und je nach Shunttyp neben einem interventionellen Shuntverschluss $[688,689]$ auch ein operativer Shuntverschluss eine Therapieoption darstellen [688].

Bei 46 - 70\% der Patienten mit Leberzirrhose und therapierefraktärer HE können größere dominante portosystemische Shunts die Ursache für eine therapierefraktäre HE sein [690-692]. Ein spontaner splenorenaler Shunt fand sich bei 11 (10,5\%) von 105 Patienten mit Leberzirrhose [693]. 18,2\% dieser Patienten wiesen eine $\mathrm{HE}$ auf.

Spontane portosystemische Shunts können durch Ultraschall (Farbdoppler, Kontrastmittelsonografie), Angio-CT und/oder MRT nachgewiesen werden [692-695]. Sie sind meist auf splenorenale Shunts, rekanalisierte (Para) Umbilicalvenen, portocavale, mesorenale oder mesocavale Shunts zurückzuführen. Eine europäische Kohortenstudie wies auf eine verbesserte Selbstständigkeit der Patienten, Abnahme der Krankenhausaufenthalte und Abnahme des Schweregrades der HE-Episoden bei drei Vierteln der Patienten hin, bei denen wegen therapierefraktärer HE ein großer portosystemischer Shunt verschlossen wurde [696]. Bei 59,4\% verschwand die HE vollständig. Ein MELD-Score von 11 oder höher vor der Intervention war der wichtigste prognostische Parameter für das Wiederauftreten einer HE nach dem Eingriff. Die Embolisation des Shunts erfolgte mit Coils, Amplatzer Plugs oder einer Kombination dieser Verfahren. In Einzelfällen erwies sich auch ein chirurgischer Eingriff als hilfreich [697]. Nach interventionellen Therapieverfahren [693] zeigten sich keine wesentlichen Auswirkungen auf die portale Hypertension. Die Zahl der Patienten mit gastroösophagealen Varizen oder Aszites blieb vor und nach dem Eingriff gleich.

\subsection{Therapie der HE nach TIPS}

\section{STATEMENT 7.28}

Die medikamentöse Therapie einer akuten oHE-Episode nach TIPS-Anlage entspricht der bei oHE und Leberzirrhose.

Starker Konsens

\section{STATEMENT 7.29}

Bei fehlendem Ansprechen der HE nach TIPS sind Stentreduktionsverfahren und/oder eine Lebertransplantation indiziert. Starker Konsens

\section{EMPFEHLUNG 7.30}

Vor einer TIPS-Implantation soll eine gründliche Selektion der Patienten erfolgen, da dies die wirksamste Maßnahme zur Prophylaxe einer HE nach TIPS darstellt.

Starke Empfehlung, starker Konsens

\section{EMPFEHLUNG 7.31}

Die medikamentöse Primärprävention einer HE nach TIPSImplantation sollte nicht durchgeführt werden.

Empfehlung, starker Konsens

\section{Kommentar}

Die Prävalenz der HE nach TIPS wird zwischen 15 und $48 \%$ angegeben $[698,699]$. In einer Metaanalyse von drei Studien senkten gecoverte Stents das Risiko für das Auftreten einer HE signifikant im Vergleich zu nicht gecoverten Stents [212]. Die Verwendung eines gecoverten TIPS-Stents mit kleinerem Durchmesser ( 8 vs. $10 \mathrm{~mm}$ Durchmesser) hatte jedoch überraschenderweise in einer Studie keinen Einfluss auf das Vorkommen einer klinisch manifesten HE [700]. Weitere Studien konnten dagegen einen Vorteil für die Verwendung eines dünnkalibrigen Stents mit 8 mm Durchmesser auf die Inzidenz der oHE und Rezidivblutungen aus Varizen nachweisen [214, 215].

Das Auftreten einer HE nach TIPS-Implantation korrelierte mit Stentdurchmesser, Shuntfluss und portosystemischem Druckgradienten. Ein niedriger Druckgradient < 12 mm HG nach Anlage des TIPS begünstigte eine HE [701] und ein höherer Wert eine Varizenblutung. Dieser Grenzwert sollte z. B. über die Verwendung dünnkalibriger Stents (6-8 mm) eingehalten werden [698]. Bei modernen gecoverten Stents führt das Unterschreiten einer unteren Grenze des portosystemischen Druckgradienten $<5 \mathrm{~mm}$ zu einem deutlich erhöhten Risiko für eine $\mathrm{HE}$ oder ein Leberversagen [702]. Vorhersageparameter für eine HE sind: Alter über 65 Jahre [703, 704], frühere HE [673, 705], Child-Pugh-Score > 10, MELDScore $>14$ [706], niedriges Serumnatrium [576] und eine Hyperbilirubinämie [698]. Neben dem MELD-Score stellte auch das Vorliegen einer Sarkopenie einen unabhängigen Risikofaktor für das Auftreten einer HE nach TIPS-Anlage dar [213]. Die gründliche Selektion von Patienten für eine TIPS-Implantation ist entscheidend, um eine spätere HE-Episode zu vermeiden.

Eine medikamentöse Primärprophylaxe der HE nach TIPS-Implantation erwies sich in einer Studie mit Rifaximin oder Lactitol im Vergleich zu keiner Therapie als unwirksam, sodass hierauf verzichtet werden sollte [673].

Die Behandlung einer HE nach TIPS Implantation erfolgt wie bei Patienten mit Zirrhose ohne TIPS [698]. Hierbei muss zunächst eine auslösende Ursache gesucht und therapiert werden. In einer Studie an Patienten mit Post-TIPS-HE ließen sich 78\% der Patienten erfolgreich mit Lactulose behandeln [699].

3-7\% der Patienten nach TIPS-Implantation sprechen auf eine medikamentöse Therapie der HE jedoch nicht an und sind entsprechend therapierefraktär [707, 708]. Interventionelle Verfahren wie die TIPS-Okklusion oder Stentreduktion können in solchen Einzelfällen bei einer akuten HE-Episode hilfreich sein [709, 710]. Von 189 Patienten bekamen 12 nach TIPS-Implantation eine HE, die auf eine medikamentöse Therapie nicht ansprach [706]. Die Platzierung eines Ballon-dilatierbaren, uhrglasförmigen Stents in den liegenden TIPS führte innerhalb von im Mittel 22 Stunden zum Verschwinden der HE. In einem Fall kam es zum Rezidiv des Aszites, weshalb der Reduktionsstent dilatiert werden musste. 
Vor Einsatz interventioneller Verfahren sollte eine klare kausale Verbindung zwischen TIPS-Implantation und Auftreten der HE hergestellt werden: Die HE sollte zeitlich nah an dem Eingriff aufgetreten sein, der erzielte portosystemische Gradient ist niedrig und/oder die Leberfunktion verschlechtert sich nach dem Eingriff [710]. Der Vorteil einer Besserung der HE muss gegen das Risiko einer erneuten Varizenblutung oder Aszitesbildung abgewogen werden. Ansonsten muss auch die Lebertransplantation bei diesen Patienten in Betracht gezogen werden.

\subsection{Therapie bei verdeckter hepatischer Enzephalo- pathie (cHE, mHE)}

\section{EMPFEHLUNG 7.32}

Patienten mit HE $\leq 1$ (West-Haven-Klassifikation) sollen die gleichen diätetischen Maßnahmen wie Patienten mit $\mathrm{HE}>1$ empfohlen werden.

Starke Empfehlung, starker Konsens

\section{EMPFEHLUNG 7.33}

Patienten mit mHE sollten nicht allein auf Basis pathologischer psychometrischer Tests therapiert werden.

Empfehlung, Konsens

\section{EMPFEHLUNG 7.34}

Die Therapie sollte bei Patienten mit gesicherter $\mathrm{mHE}$ bei Angabe einer reduzierten Lebensqualität, bei objektiver Einschränkung bei Verrichtungen des täglichen Alltags oder bei Vorliegen beruflicher Risiken durchgeführt werden. Empfehlung, starker Konsens

\section{EMPFEHLUNG 7.35}

Wird eine Therapie der mHE im Einzelfall als notwendig erachtet, soll als Therapie der ersten Wahl Lactulose verwendet werden.

Starke Empfehlung, starker Konsens

\section{Kommentar}

\section{Probiotiko}

25 Patienten mit Leberzirrhose und durch psychometrische Teste gesicherter mHE erhielten über 60 Tage probiotischen Joghurt $(n=17)$ oder keine Therapie $(n=8)$ [711]. Unter JoghurtKonsum besserte sich bei $71 \%$ die mHE (drei psychometrische Tests) gegenüber $0 \%$ bei den Kontrollen. 2 der Patienten in der Kontrollgruppe und keiner in der Verumgruppe entwickelten eine HE-Episode. Es handelte sich um einen käuflichen Joghurt mit S. thermophilus, L. bulgaricus, L. acidophilus, Bifidobakterien und L. casei. Probiotika zeigten sich in einer weiteren Studie gleich wirksam wie LOLA oder Lactulose [712]. Saji und Mitarbeiter [713] konnten dagegen keine Wirkung auf die mHE bei Leberzirrhose beobachten.

Eine Metaanalyse von 9 Studien, die Probiotika (lebende Bakterien), Präbiotika (Lactulose) oder Synbiotika (beide Therapieformen) eingesetzt hatten, fand positive Effekte für den Einsatz dieser Therapien bei mHE [714]. Besserung der mHE und weniger Übergänge in eine klinisch manifeste HE unter Probiotika waren auch das Ergebnis einer weiteren Metaanalyse, die jedoch keinen Unterschied zu Lactulose, Rifaximin oder LOLA nachweisen konnte [627].

\section{Lactulose}

9 Studien mit 434 Patienten gingen in eine Metaanalyse ein, die bei Patienten mit mHE die Wirkung von Lactulose untersucht hatten [618]. Lactulose verbesserte die psychometrischen Testergebnisse und die Progression zu einer klinisch manifesten HE. Dies bestätigte sich in einer weiteren aktuelleren Metaanalyse [616].

\section{LOLA}

64 Patienten mit mHE wurden in eine kontrollierte, randomisierte Studie eingeschlossen, bei der sich keine Wirksamkeit von einer oralen Gabe von LOLA bei mHE zeigte [648]. In einer weiteren Studie fand sich in dieser Situation kein statistisch signifikanter Unterschied in der Wirkung von Rifaximin, Probiotika oder LOLA [715]. Alle drei Therapieregime erwiesen sich besser als Placebo. Beim Vergleich von oral verabreichtem LOLA mit Placebo, Lactulose oder Probiotika [712] fand sich eine Besserung der mHE gegenüber der Behandlung mit Placebo. Die aktiven Therapieregime unterschieden sich jedoch auch in dieser Untersuchung nicht im Hinblick auf eine Besserung der mHE. Die Entwicklung einer manifesten $\mathrm{HE}$ aus einer mHE konnten alle drei aktiven Therapieregime gegenüber Placebo nicht vermeiden [712].

LOLA zeigte in zwei Metaanalysen keine Wirkung bei $\mathrm{mHE}$ [646, 647]. Dieses Ergebnis bestätigte sich in der zweiten Metaanalyse, wenn nur Studien mit hoher Qualität berücksichtigt wurden [646].

\section{Rifaximin}

Rifaximin erwies sich in einer randomisierten Studie an Patienten mit mHE besser als Placebo [716]. Patienten mit mHE boten am Fahrsimulator unter Einnahme von Rifaximin weniger Fahrfehler als die Gruppe, die mit Placebo behandelt wurde [717]. $91 \%$ verbesserten ihre kognitiven Leistungen unter Rifaximin gegenüber 61 \% unter Placebo. Rifaximin erwies sich bei der Behandlung der $\mathrm{mHE}$ als gleich wirksam wie Lactulose [681, 716]. Wurde die Therapie der mHE nach drei Monaten beendet, erlitten sowohl die mit Lactulose als auch die mit Rifaximin behandelten Patienten in knapp $50 \%$ der Fälle ein Rezidiv der mHE [681].

\section{Therapie bei $\mathrm{mHE}$}

Für Patienten mit mHE wurden eine Vielzahl von Nachteilen mit Auswirkungen auf Prognose, Mortalität, Lebensqualität, Übergang in eine manifeste HE, Fallneigung und Fahrvermögen [718, 719] berichtet. Es gibt zahlreiche Tests zum Nachweis einer $\mathrm{mHE}$, die allerdings wenig standardisiert sind und nicht immer zur gleichen Aussage führen. Auch kann die Frage nach der Fahrtüchtigkeit allein mit dem Vorliegen eines pathologischen psychometrischen Testes nicht beantwortet werden [457, 720]. Zu kurz 


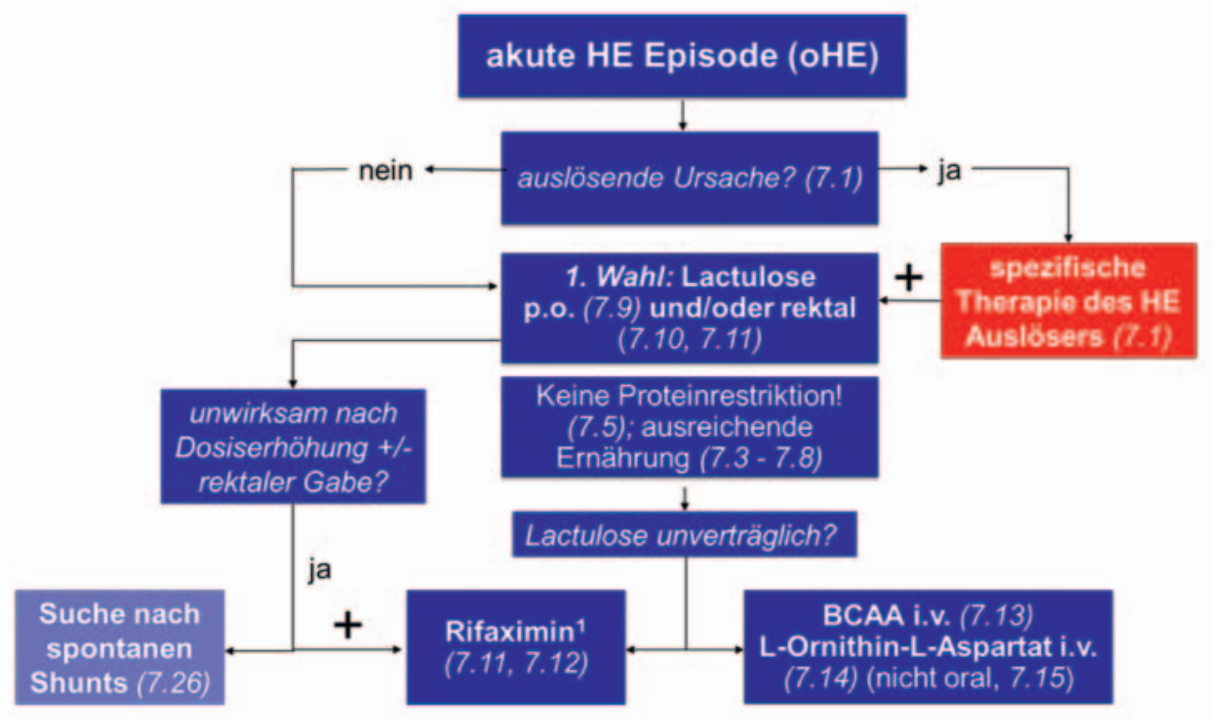

- Abb. 3 Therapiealgorithmus bei akuter HE-Episode. Hinter den Empfehlungen des Algorithmus sind die Ziffern der konsentierten Empfehlungen angegeben. ${ }^{1}$ Rifaximin ist zur Therapie der oHE nicht zugelassen; für die Kombination von Lactulose mit Rifaximin bei dieser Indikation gibt es nur wenig Evidenz (siehe Kapitel 7.1.4). Abkürzungen: BCAA: verzweigtkettige Aminosäuren, oHE: klinisch erkennbare hepatische Enzephalopathie. Modifiziert nach Holstege (2017), Hepatische Enzephalopathie. Gastroenterologie up2date 13: 1 - 18.

angelegte Studien, stark variierende Endpunkte und der Einsatz verschiedener Substanzen in den bisherigen Studien führten zu keiner Therapieempfehlung für die mHE in der gemeinsamen Leitlinie von EASL und AASLD [603].

Die Untersuchung auf eine mHE mithilfe psychometrischer Tests oder der CFF kann erfolgen, wenn Patienten mit Leberzirrhose über eine beeinträchtigte Lebensqualität berichten oder wenn von Verwandten Verhaltensauffälligkeiten bemerkt wurden [603]. Dies gilt insbesondere für Patienten mit früherer HE-Episode, Child-C-Zirrhose (MELD > 10) oder wenn eine mHE ein besonderes berufliches Risiko darstellt (z. B. Berufskraftfahrer). Dies kann zu einer gezielteren Beratung der Patienten und ihrer Angehörigen bzgl. Prognose und Therapie führen. Eine regelhafte Testung auf eine mHE wurde in der zitierten Leitlinie jedoch nicht empfohlen [603]. Wenn eine Therapie als sinnvoll bei einem Patienten mit mHE und entsprechendem Beschwerdebild oder Risikoprofil erachtet wird, sollte sie mit Lactulose eingeleitet werden, da sich in den bisher publizierten Studien keine andere Substanz als besser herausstellte.

\section{Therapiedauer bei mHE}

Es gibt nur eine Studie, die die Therapiedauer bei Patienten mit mHE untersuchte. Sechs Monate nach Ende einer drei Monate dauernden Therapie kam es unabhängig vom eingesetzten Medikament bei knapp $50 \%$ der Behandelten zu einem Rezidiv der mHE. In Analogie zur Behandlung der klinisch manifesten HE ist eine Therapiepause wahrscheinlich nur dann sinnvoll, wenn sich Ernährungszustand und/oder die Leberfunktion gebessert haben [681].

\subsection{Vorgehen bei Patienten mit Leberzirrhose ohne HE}

\section{EMPFEHLUNG 7.36}

Eine Primärprophylaxe der HE soll bei Patienten mit Leberzirrhose und oberer gastrointestinaler Blutung durchgeführt werden.

Starke Empfehlung, starker Konsens

\section{EMPFEHLUNG 7.37}

Bei Patienten mit Leberzirrhose und akuter Ösophagusvarizenblutung sollte Lactulose in der Primärprophylaxe eingesetzt werden.

Empfehlung, Konsens

\section{Kommentar}

Unter der Primärprophylaxe werden therapeutische Maßnahmen zur Vermeidung des erstmaligen Auftretens einer HE bei Risikopatienten verstanden (s. A Ab. 3). Die einzige Indikation zu diesem Vorgehen ergibt sich bei Patienten mit Leberzirrhose und nachgewiesener oberer gastrointestinaler Blutung, die eine entsprechend hohe Wahrscheinlichkeit für das Auftreten einer HE aufweisen. Das Auftreten einer HE nach oberer gastrointestinaler Blutung stellt zudem einen unabhängigen negativen Prognoseindikator dar (s. Gastrointestinale Blutungen).

Lactulose erwies sich im Vergleich zu Placebo in dieser Situation als statistisch signifikant wirksam: 3,2 bzw. 16,9\% entwickelten eine HE [550]. Davon waren insbesondere Patienten mit schlechter Leberfunktion (Child-Pugh-Klassifikation) betroffen. In 


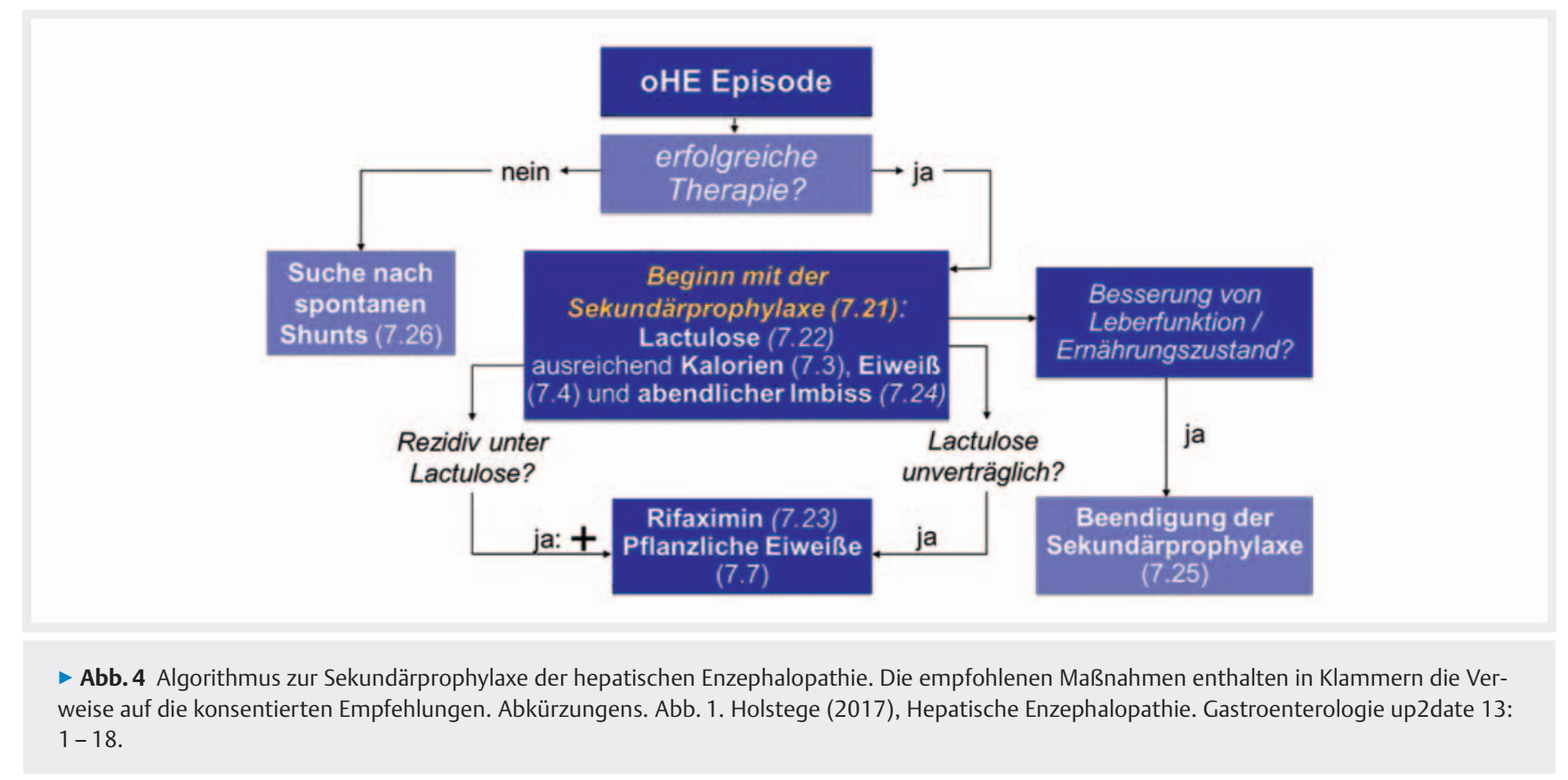

einer zweiten Studie konnte das Auftreten einer HE nach gastrointestinaler Blutung von $40 \%$ unter Placebo auf $14 \%$ unter Lactulose abgesenkt werden [551]. Rifaximin erwies sich beim Vergleich mit Lactulose in der Primärprävention als nicht besser [721]. Rifaximin ist zur Primärprophylaxe zudem nicht zugelassen.

Eine intestinale Lavage unter Verwendung einer Mannitlösung war ebenfalls in der Lage, das Risiko für das Auftreten einer HE nach oberer gastrointestinaler Blutung zu verringern [552] und erwies sich als gleich wirksam wie die Kombination von Paromomycin und Lactulose [553].

Bei Verdacht auf eine gastrointestinale Blutung bei Patienten mit Leberzirrhose ist diese endoskopisch weiter abzuklären und zu therapieren. Frisches oder altes Blut im Magen wird bei der endoskopischen Abklärung abgesaugt. Mittels oraler (über eine Magensonde, Intensivstation: stündlich $45 \mathrm{ml}$ Lactulose oder auf Normalstation alle zwei Stunden $30 \mathrm{ml}$ Lactulose bis die Darmtätigkeit in Gang kommt oder bei klinischer Besserung) und rektaler Gabe von Lactulose $(300 \mathrm{ml}$ Lactulose mit $700 \mathrm{ml}$ Wasser alle zwei Stunden) kann für eine rasche enterale Passage des Blutes und Darmreinigung gesorgt werden [578].

Eine Metaanalyse der Studien mit nicht absorbierbaren Disacchariden bestätigte ihre Wirksamkeit in der Primärprophylaxe mit einer NNT (number needed to treat) von 7 [616]. Insgesamt zeigten vier Studien [550 - 552, 721], dass durch abführende Maßnahmen nach einer oberen gastrointestinalen Blutung bei Patienten mit Leberzirrhose eine HE verhindert werden kann. Da jeder fünfte Patient nach einer Varizenblutung eine HE-Episode erleiden kann [539] und dies eine Prognoseverschlechterung bedeutet [549], entschied sich die Leitlinienkommission aufgrund dieser Daten zu einer stärkeren Empfehlung für den Einsatz von Lactulose, als sie in der S2K-Leitlinie zur gastrointestinalen Blutung [251] in dieser Situation gegeben wurde. Rifaximin ist im Gegensatz zu Lactulose für diese Indikation nicht zugelassen, so- dass zu diesem Präparat bei Gleichwertigkeit mit Lactulose keine Empfehlung gegeben wurde.

\subsection{Nachsorge von Patienten mit Leberzirrhose und HE}

\section{EMPFEHLUNG 7.38}

Bei Patienten unter Therapie nach durchgemachter HE-Episode, rekurrierender oder chronischer $\mathrm{HE}$ soll eine individuell angepasste Verlaufsbeurteilung erfolgen.

Starke Empfehlung, starker Konsens

\section{EMPFEHLUNG 7.39}

Eine Überwachungsuntersuchung dieser Patienten kann der Erfassung kognitiver und neurologischer Störungen, des Ernährungsstatus, der Lebensqualität und der Überprüfung und Anpassung der HE-Therapie dienen.

Empfehlung offen, starker Konsens

\section{Kommentar}

Patienten mit persistierender $\mathrm{HE}$ sind regelmäßig auf kognitive oder neurologische Störungen zu untersuchen, sodass die Therapie gegebenenfalls angepasst werden kann (s. A Abb.4). Bei stabilen Patienten mit durchgemachter HE werden halbjährliche Nachsorgeintervalle, die auch zum HCC-Screening empfohlen werden, als ausreichend angesehen. Auf Nebenwirkungen und Wirkungen der HE-Therapie ist zu achten. Die Indikation zu einer Lebertransplantation ist im Verlauf immer wieder zu prüfen. Dies gilt auch für die Suche nach einem dominanten portosystemischen Shunt als Ursache für eine therapierefraktäre HE. Auslöser für eine HE ( Tab.3) müssen erkannt und rechtzeitig spezifisch 
therapiert werden (z. B. Ligatur von großen Ösophagusvarizen oder Beseitigung von Elektrolytstörungen). Auch der Ernährungsstatus sollte verbessert werden und bei Gewichtsabnahme oder progressiver Sarkopenie Empfehlungen zur Ernährung gegeben werden. Nach Möglichkeit sollte eine Fremdanamnese in die Beurteilung der kognitiven Leistungsfähigkeit und der Lebensqualität des Patienten mit einbezogen werden [603].

\section{EMPFEHLUNG 7.40}

Die Überwachung von Patienten mit HE und Leberzirrhose sollte in enger Abstimmung zwischen einem Facharzt für Allgemeinmedizin oder Facharzt für Innere Medizin und einem Facharzt für Gastroenterologie erfolgen.

Empfehlung, starker Konsens

\begin{tabular}{|c|c|}
\hline \multicolumn{2}{|c|}{ ABKÜRZUNGSVERZEICHNIS } \\
\hline AASLD & $\begin{array}{l}\text { American Association for the Study of Liver } \\
\text { Diseases (engl.) }\end{array}$ \\
\hline ACLF & Akut-auf-chronischen-Leberversagen \\
\hline AKI & akute Nierenschädigung \\
\hline ALV & akutes Leberversagen \\
\hline AP & Alkalische Phosphatase \\
\hline BCS & Budd-Chiari-Syndrom \\
\hline $\mathrm{BIA}$ & bioelektrische Impedanzanalyse \\
\hline BMI & Body-Mass-Index (engl.) \\
\hline CEA & Carcino-Embryonales Antigen \\
\hline $\mathrm{CHE}$ & covert Hepatische Enzephalopathie \\
\hline CFF & critical flimmer frequency (engl.) \\
\hline $\mathrm{Cl}$ & Confidence Interval (engl.) \\
\hline COPD & chronic obstructive pulmonary disease (engl.) \\
\hline CT & Computertomografie \\
\hline DIC & $\begin{array}{l}\text { Disseminierte Intravasale Koagulopathie } \\
\text { (Coagulation, engl.) }\end{array}$ \\
\hline DNA & Desoxyribonukleinsäure (acid, engl.) \\
\hline DOAK & Direkte orale Antikoagulantien \\
\hline e-PTFE & expandiertes Polytetrafluorethen \\
\hline EASL & $\begin{array}{l}\text { European Association for the Study of the } \\
\text { Liver }\end{array}$ \\
\hline EFSUMB & $\begin{array}{l}\text { European Federation of Societies for } \\
\text { Ultrasound in Medicine and Biology (engl.) }\end{array}$ \\
\hline ESBL & Extended-Spectrum- $\beta$-Lactamase (engl.) \\
\hline FFP & Fresh Frozen Plasma (engl.) \\
\hline Gl-Blutung & Gastrointestinale Blutung \\
\hline GFR & Glomeruläre Filtrationsrate \\
\hline $\mathrm{HCC}$ & Hepatocellular carcinoma (engl.) \\
\hline $\mathrm{HE}$ & Hepatische Enzephalopathie \\
\hline HRS & Hepatorenales Syndrom \\
\hline INR & International Normalized Ratio (engl.) \\
\hline ISHEN & $\begin{array}{l}\text { International Society of Hepatic Encephalo- } \\
\text { pathy and Nitrogen Metabolism (engl.) }\end{array}$ \\
\hline KG & Körpergewicht \\
\hline $\mathrm{LDH}$ & Lactatdehydrogenase \\
\hline LOLA & L-Ornithin-L-Aspartat \\
\hline
\end{tabular}

MARS Molecular Adsorbents Recirculation System (engl.)

MELD-Score Model of End Stage Liver Disease-Score (engl.)

MGG May-Grünwald-Giemsa

mHE minimale Hepatische Enzephalopathie

MRSA Methicillin-resistenter Staphylococcus

MRT Magnetresonanztomografie

NCT Nationales Zentrum für Tumorerkrankungen

NNT Number Needed to Treat (engl.)

NOD2 Nucleotide-binding Oligomerization Domain containing 2 (engl.)

OR Odds Ratio (engl.)

oHE overt Hepatische Enzephalopathie

Pap Papanicolaou-Klassifikation

PAS Periodic Acid-Schiff Stain (engl.)

PHES Psychometric Hepatic Encephalopathy Score (engl.)

PMN-Zellen Polymorphonukleäre-Zellen

PNH Paroxysmale Nächtliche Hämoglobinurie

PT Prothrombinzeit (time, engl.)

PTT Partielle Thromboplastinzeit (time, engl.)

SAAG Serum-Aszites-Albumin-Gradient

SBP Spontan Bakterielle Peritonitis

SBEM Spontan Bakterielles Empyem

SIR Society of Interventional Radiology

TIPS transjugulärer intrahepatischer portosystemischer Shunt

VATS Videoassistierte Thorakoskopie

ZVD zentraler Venendruck

ZST Zahlensymboltest

ZVT Zahlenverbindungstest

Interessenkonflikt

Die potenziellen Interessenkonflikterklärungen und deren Bewertungen sind im Leitlinienreport dargestellt.

Literatur

[1] Runyon BA, Committee APG. Management of adult patients with ascites due to cirrhosis: an update. Hepatology 2009; 49: 2087-2107

[2] Arroyo V, Fernandez-Esparrach G, Gines P. Diagnostic approach to the cirrhotic patient with ascites. J Hepatol 1996; 25: 35-40

[3] Cardenas A, Chopra S. Chylous ascites. Am J Gastroenterol 2002; 97 : $1896-1900$

[4] Almakdisi T, Massoud S, Makdisi G. Lymphomas and chylous ascites: review of the literature. Oncologist 2005; 10: 632-635

[5] Kim JJ, Tsukamoto MM, Mathur AK et al. Delayed paracentesis is associated with increased in-hospital mortality in patients with spontaneous bacterial peritonitis. Am J Gastroenterol 2014; 109: 1436-1442

[6] Runyon BA. Early events in spontaneous bacterial peritonitis. Gut 2004 53: $782-784$

[7] Castellote J, Girbau A, Maisterra S et al. Spontaneous bacterial peritonitis and bacterascites prevalence in asymptomatic cirrhotic outpatients un- 
dergoing large-volume paracentesis. J Gastroenterol Hepatol 2008; 23: $256-259$

[8] Jeffries MA, Stern MA, Gunaratnam NT et al. Unsuspected infection is infrequent in asymptomatic outpatients with refractory ascites undergoing therapeutic paracentesis. Am J Gastroenterol 1999; 94: 2972 2976

[9] Evans LT, Kim WR, Poterucha J] et al. Spontaneous bacterial peritonitis in asymptomatic outpatients with cirrhotic ascites. Hepatology 2003; 37: 897-901

[10] Angeloni S, Nicolini G, Merli M et al. Validation of automated blood cell counter for the determination of polymorphonuclear cell count in the ascitic fluid of cirrhotic patients with or without spontaneous bacterial peritonitis. Am J Gastroenterol 2003; 98: 1844-1848

[11] Böcking A, Motherby H, Pomjanski N. Treffsicherheit der Ergusszytologie samt adjuvanten Untersuchungsmethoden. Dtsch Arztebl International 2000; 97: 2626-2630

[12] Motherby H, Nadjari B, Friegel $P$ et al. Diagnostic accuracy of effusion cytology. Diagn Cytopathol 1999; 20: 350-357

[13] Moore KP, Aithal GP. Guidelines on the management of ascites in cirrhosis. Gut 2006; 55 (Suppl. 6): vi1-v12

[14] Schlake W, Kreipe H. Mitteilungen Deutsche Gesellschaft für Pathologie. Erklärung zur Zytopathologie. Unter Mitarbeit von: A. Böcking, R. Bollmann, S. Falk, V. Fritzsche, A. Wellmann. Der Pathologe 2007; 28: 393

[15] Spriggs Al, Boddington MM. The Cytology of Effusions: Pleural, Pericardial and Peritoneal and of Cerebrospinal Fluid; Elsevier Science; 2016

[16] Mannucci PM. Abnormal hemostasis tests and bleeding in chronic liver disease: are they related? No. J Thromb Haemost 2006; 4: 721-723

[17] Zakeri N, Tsochatzis EA. Bleeding Risk with Invasive Procedures in Patients with Cirrhosis and Coagulopathy. Curr Gastroenterol Rep 2017; 19: 45

[18] Grabau CM, Crago SF, Hoff LK et al. Performance standards for therapeutic abdominal paracentesis. Hepatology 2004; 40: 484-488

[19] McVay PA, Toy PT. Lack of increased bleeding after paracentesis and thoracentesis in patients with mild coagulation abnormalities. Transfusion 1991; 31: $164-71$

[20] Runyon BA. Paracentesis of ascitic fluid. A safe procedure. Arch Intern Med 1986; 146: 2259-2261

[21] Kurup AN, Lekah A, Reardon ST et al. Bleeding Rate for UltrasoundGuided Paracentesis in Thrombocytopenic Patients. J Ultrasound Med 2015; 34: $1833-1838$

[22] Bundesärztekammer. Querschnitts-Leitlinien zur Therapie mit Blutkomponenten und Plasmaderivaten: mit 19 Tabellen. Dt. Ärzte-Verlag. 2009

[23] Wolfe KS, Kress JP. Risk of Procedural Hemorrhage. Chest 2016; 150: 237-246

[24] Runyon BA, Aasld. Introduction to the revised American Association for the Study of Liver Diseases Practice Guideline management of adult patients with ascites due to cirrhosis 2012. Hepatology 2013; 57: 1651 1653

[25] Dietrich CF, Lorentzen T, Appelbaum L et al. EFSUMB Guidelines on Interventional Ultrasound (INVUS), Part III - Abdominal Treatment Procedures (Short Version). Ultraschall in Med 2016; 37: 27 - 45

[26] Lentschener C, Flaujac C, Ibrahim F et al. Assessment of haemostasis in patients with cirrhosis: Relevance of the ROTEM tests?: A prospective, cross-sectional study. Eur J Anaesthesiol 2016; 33: 126-133

[27] Strobel D, Bernatik T, Blank W et al. Incidence of bleeding in 8172 percutaneous ultrasound- guided intraabdominal diagnostic and therapeutic interventions - results of the prospective multicenter DEGUM interventional ultrasound study (PIUS study). Ultraschall in Med 2015; 36: $122-131$

[28] Devarbhavi H, Murali AR. Safety of Ascitic Paracentesis in Patients with Budd-Chiari Syndrome on Oral Anticoagulation and Elevated International Normalized Ratio. J Clin Exp Hepatol 2015; 5: 310-313
[29] Atwell TD, Smith RL, Hesley GK et al. Incidence of bleeding after 15181 percutaneous biopsies and the role of aspirin. Am J Roentgenol 2010; 194: 784-789

[30] Patel IJ, Davidson JC, Nikolic B et al. Consensus guidelines for periprocedural management of coagulation status and hemostasis risk in percutaneous image-guided interventions. J Vasc Interv Radiol 2012; 23: $727-736$

[31] Patel IJ, Davidson JC, Nikolic B et al. Addendum of newer anticoagulants to the SIR consensus guideline. J Vasc Interv Radiol 2013; 24: 641-645

[32] Denzer U, Beilenhoff U, Eickhoff A et al. S2k guideline: quality requirements for gastrointestinal endoscopy, AWMF registry no. 021-022. Z Gastroenterol 2015; 53: E1 -E227

[33] Acosta RD, Abraham NS, Committee ASoP et al. The management of antithrombotic agents for patients undergoing Gl endoscopy. Gastrointest Endosc 2016; 83: 3-16

[34] KRINKO. Anforderungen der Hygiene bei Operationen und anderen invasiven Eingriffen. Robert Koch-Institut. 2000

[35] Schlottmann K, Gelbmann C, Grune S et al. A new paracentesis needle for ascites and pleural effusion compared with the venous indwelling catheter. A prospective, randomized study. Med Klin (Munich) 2001; 96: $321-324$

[36] Gines P, Arroyo V, Rodes J. Treatment of ascites and renal failure in cirrhosis. Baillieres Clin Gastroenterol 1989; 3: 165-186

[37] Shaheen NJ, Grimm IS. Comparison of the Caldwell needle/cannula with Angiocath needle in large volume paracentesis. Am J Gastroenterol 1996; 91: $1731-1733$

[38] Boccia S, Rollo V, Accorsi L et al. Paracentesis: a new needle for an old technique. Endoscopy 1991; 23: 83-84

[39] Nazeer SR, Dewbre H, Miller AH. Ultrasound-assisted paracentesis performed by emergency physicians vs the traditional technique: a prospective, randomized study. Am J Emerg Med 2005; 23: 363-367

[40] Sakai H, Sheer TA, Mendler MH et al. Choosing the location for nonimage guided abdominal paracentesis. Liver Int 2005; 25: 984-986

[41] Cattau EL Jr, Benjamin SB, Knuff TE et al. The accuracy of the physical examination in the diagnosis of suspected ascites. JAMA 1982; 247: $1164-1166$

[42] Irshad A, Ackerman S], Anis M et al. Can the smallest depth of ascitic fluid on sonograms predict the amount of drainable fluid? J Clin Ultrasound 2009; 37: $440-444$

[43] Mercaldi C], Lanes SF. Ultrasound guidance decreases complications and improves the cost of care among patients undergoing thoracentesis and paracentesis. Chest 2013; 143: 532-538

[44] De Gottardi A, Thevenot T, Spahr L et al. Risk of complications after abdominal paracentesis in cirrhotic patients: a prospective study. Clin Gastroenterol Hepatol 2009; 7: 906-909

[45] Martinet O, Reis ED, Mosimann F. Delayed hemoperitoneum following large-volume paracentesis in a patient with cirrhosis and ascites. Dig Dis Sci 2000; 45: 357-358

[46] Arnold C, Haag K, Blum HE et al. Acute hemoperitoneum after largevolume paracentesis. Gastroenterology 1997; 113: 978-982

[47] Pache I, Bilodeau M. Severe haemorrhage following abdominal paracentesis for ascites in patients with liver disease. Aliment Pharmacol Ther 2005; 21: $525-529$

[48] Mallory A, Schaefer JW. Complications of diagnostic paracentesis in patients with liver disease. JAMA 1978; 239: 628-630

[49] Lin CH, Shih FY, Ma MH et al. Should bleeding tendency deter abdominal paracentesis? Dig Liver Dis 2005; 37: 946 - 951

[50] Webster ST, Brown KL, Lucey MR et al. Hemorrhagic complications of large volume abdominal paracentesis. Am J Gastroenterol 1996; 91: $366-368$

[51] Minocha A. A fatal case of paracentesis. Am J Gastroenterol 1999; 94: 856 
[52] Sharzehi K, Jain V, Naveed A et al. Hemorrhagic complications of paracentesis: a systematic review of the literature. Gastroenterol Res Pract 2014; 2014: 985141

[53] Campillo B, Richardet JP, Dupeyron C. Diagnostic value of two reagent strips (Multistix 8 SG and Combur 2 LN) in cirrhotic patients with spontaneous bacterial peritonitis and symptomatic bacterascites. Gastroenterol Clin Biol 2006; 30: 446 - 452

[54] Rimola A, Garcia-Tsao G, Navasa M et al. Diagnosis, treatment and prophylaxis of spontaneous bacterial peritonitis: a consensus document. International Ascites Club. Journal of hepatology 2000; 32: 142-153

[55] Albillos A, Cuervas-Mons V, Millan I et al. Ascitic fluid polymorphonuclear cell count and serum to ascites albumin gradient in the diagnosis of bacterial peritonitis. Gastroenterology 1990; 98: 134-140

[56] Jones SR. The absolute granulocyte count in ascites fluid. An aid to the diagnosis of spontaneous bacterial peritonitis. West J Med 1977; 126: $344-346$

[57] Runyon BA. Low-protein-concentration ascitic fluid is predisposed to spontaneous bacterial peritonitis. Gastroenterology 1986; 91: 1343 1346

[58] Llach J, Rimola A, Navasa M et al. Incidence and predictive factors of first episode of spontaneous bacterial peritonitis in cirrhosis with ascites: relevance of ascitic fluid protein concentration. Hepatology 1992; 16: $724-727$

[59] Guarner C, Sola R, Soriano G et al. Risk of a first community-acquired spontaneous bacterial peritonitis in cirrhotics with low ascitic fluid protein levels. Gastroenterology 1999; 117: 414-419

[60] Canete N, Erice E, Bargallo A et al. Natural History of Spontaneous Bacterial Peritonitis: A Longitudinal Study in 263 Cirrhotic Patients After the First Ascites Decompensation. Journal of Hepatology 2007; 46: S90 s91

[61] Pare P, Talbot J, Hoefs JC. Serum-ascites albumin concentration gradient: a physiologic approach to the differential diagnosis of ascites. Gastroenterology 1983; 85: 240-244

[62] Runyon BA, Montano AA, Akriviadis EA et al. The serum-ascites albumin gradient is superior to the exudate-transudate concept in the differential diagnosis of ascites. Ann Intern Med 1992; 117: 215-220

[63] Dittrich S, Yordi LM, de Mattos AA. The value of serum-ascites albumin gradient for the determination of portal hypertension in the diagnosis of ascites. Hepato-gastroenterology 2001; 48: 166-168

[64] Runyon BA, Canawati HN, Akriviadis EA. Optimization of ascitic fluid culture technique. Gastroenterology 1988; 95: 1351 - 1355

[65] Castellote J, Xiol X, Verdaguer R et al. Comparison of two ascitic fluid culture methods in cirrhotic patients with spontaneous bacterial peritonitis. Am J Gastroenterol 1990; 85: 1605 - 1608

[66] Bobadilla M, Sifuentes ], Garcia-Tsao G. Improved method for bacteriological diagnosis of spontaneous bacterial peritonitis. J Clin Microbiol 1989; 27: 2145-2147

[67] Caly WR, Strauss E. A prospective study of bacterial infections in patients with cirrhosis. J Hepatol 1993; 18: $353-358$

[68] Kuiper JJ, van Buuren HR, de Man RA. Limited role for routine ascitic culture as a diagnostic tool for spontaneous bacterial peritonitis in the era of prophylactic antibiotics. Journal of Hepatology 2007; 46: S96

[69] Butani RC, Shaffer RT, Szyjkowski RD et al. Rapid diagnosis of infected ascitic fluid using leukocyte esterase dipstick testing. Am J Gastroenterol 2004; 99: $532-537$

[70] Castellote ], Lopez C, Gornals J et al. Rapid diagnosis of spontaneous bacterial peritonitis by use of reagent strips. Hepatology 2003; 37: 893 896

[71] Sapey T, Kabissa D, Fort E et al. Instant diagnosis of spontaneous bacterial peritonitis using leukocyte esterase reagent strips: Nephur-Test vs. MultistixSG. Liver Int 2005; 25: 343 - 348
[72] Thevenot T, Cadranel JF, Nguyen-Khac E et al. Diagnosis of spontaneous bacterial peritonitis in cirrhotic patients by use of two reagent strips. Eur J Gastroenterol Hepatol 2004; 16: 579-583

[73] Vanbiervliet G, Rakotoarisoa C, Filippi J et al. Diagnostic accuracy of a rapid urine-screening test (Multistix8SG) in cirrhotic patients with spontaneous bacterial peritonitis. Eur J Gastroenterol Hepatol 2002; 14: $1257-1260$

[74] Nousbaum JB, Cadranel JF, Nahon P et al. Diagnostic accuracy of the Multistix 8 SG reagent strip in diagnosis of spontaneous bacterial peritonitis. Hepatology 2007; 45: 1275 - 1281

[75] Gulberg V, Gerbes AL, Sauerbruch T et al. Insufficient sensitivity of reagent strips for spontaneous bacterial peritonitis. Hepatology 2007; 46: 1669; author reply 1669-1670

[76] Nguyen-Khac E, Cadranel JF, Thevenot T et al. Review article: the utility of reagent strips in the diagnosis of infected ascites in cirrhotic patients. Aliment Pharmacol Ther 2008; 28: $282-288$

[77] Such J, Frances R, Munoz C et al. Detection and identification of bacterial DNA in patients with cirrhosis and culture-negative, nonneutrocytic ascites. Hepatology 2002; 36: 135-141

[78] Bruns T, Sachse S, Straube E et al. Identification of bacterial DNA in neutrocytic and non- neutrocytic cirrhotic ascites by means of a multiplex polymerase chain reaction. Liver Int 2009; 29: 1206 - 1214

[79] Appenrodt B, Lehmann LE, Thyssen L et al. Is detection of bacterial DNA in ascitic fluid of clinical relevance? Eur J Gastroenterol Hepatol 2010; 22: $1487-1494$

[80] Bruns T, Reuken PA, Stengel S et al. The prognostic significance of bacterial DNA in patients with decompensated cirrhosis and suspected infection. Liver Int 2016; 36: 1133 - 1142

[81] Gerbes AL, Jungst D, Xie YN et al. Ascitic fluid analysis for the differentiation of malignancy- related and nonmalignant ascites. Proposal of a diagnostic sequence. Cancer 1991; 68: 1808-1814

[82] Jungst D, Gerbes AL, Martin R et al. Value of ascitic lipids in the differentiation between cirrhotic and malignant ascites. Hepatology 1986; 6: $239-243$

[83] Jungst D, Xie Y, Gerbes AL. Pathophysiology of elevated ascites fluid cholesterol in malignant ascites. Increased ascites to serum relation of proteins and lipoproteins in patients with peritoneal carcinomatosis as compared to patients with cirrhosis of the liver. J Hepatol 1992; 14: $244-248$

[84] Du L, Zhu S, Lu Z et al. Ascitic cholesterol is superior to serum-ascites albumin gradient in the detection of non-portal-hypertensive ascites and the diagnosis of mixed ascites. Alimentary Pharm Ther [Epub 2018]

[85] Gulyas M, Kaposi AD, Elek G et al. Value of carcinoembryonic antigen (CEA) and cholesterol assays of ascitic fluid in cases of inconclusive cytology. J Clin Pathol 2001; 54: 831 - 835

[86] Gerbes AL, Xie YN, Mezger J et al. Ascitic fluid concentrations of fibronectin and cholesterol: comparison of differential diagnostic value with the conventional protein determination. Liver 1990; 10: 152-157

[87] Soriano G, Castellote J, Alvarez C et al. Secondary bacterial peritonitis in cirrhosis: a retrospective study of clinical and analytical characteristics, diagnosis and management. J Hepatol 2010; 52: 39-44

[88] Caralis PV, Sprung CL, Schiff ER. Secondary bacterial peritonitis in cirrhotic patients with ascites. South Med J 1984; 77: 579-583

[89] Runyon BA, Hoefs JC. Ascitic fluid analysis in the differentiation of spontaneous bacterial peritonitis from gastrointestinal tract perforation into ascitic fluid. Hepatology 1984; 4: $447-450$

[90] Akriviadis EA, Runyon BA. Utility of an algorithm in differentiating spontaneous from secondary bacterial peritonitis. Gastroenterology 1990; 98: $127-133$

[91] Garrison RN, Cryer HM, Howard DA et al. Clarification of risk factors for abdominal operations in patients with hepatic cirrhosis. Ann Surg 1984; 199: $648-655$ 
[92] Wu SS, Lin OS, Chen YY et al. Ascitic fluid carcinoembryonic antigen and alkaline phosphatase levels for the differentiation of primary from secondary bacterial peritonitis with intestinal perforation. J Hepatol 2001; 34: $215-221$

[93] Moreau R, Lebrec D. Diagnosis and treatment of acute renal failure in patients with cirrhosis. Best Pract Res Clin Gastroenterol 2007; 21: $111-123$

[94] Le S, Spelman T, Chong CP et al. Could Adherence to Quality of Care Indicators for Hospitalized Patients With Cirrhosis-Related Ascites Improve Clinical Outcomes? Am J Gastroenterol 2016; 111: 87-92

[95] D’Amico G, Garcia-Tsao G, Pagliaro L. Natural history and prognostic indicators of survival in cirrhosis: a systematic review of 118 studies. J Hepatol 2006; 44: 217-231

[96] Guardiola J, Baliellas C, Xiol X et al. External validation of a prognostic model for predicting survival of cirrhotic patients with refractory ascites. Am J Gastroenterol 2002; 97: 2374-2378

[97] Planas R, Montoliu S, Balleste B et al. Natural history of patients hospitalized for management of cirrhotic ascites. Clin Gastroenterol Hepatol 2006; 4: 1385-1394

[98] Gines P, Cardenas A, Arroyo V et al. Management of cirrhosis and ascites. N Engl J Med 2004; 350: 1646 - 1654

[99] Peng S, Plank LD, McCall JL et al. Body composition, muscle function, and energy expenditure in patients with liver cirrhosis: a comprehensive study. Am J Clin Nutr 2007; 85: 1257-1266

[100] Amodio P, Bemeur C, Butterworth R et al. The nutritional management of hepatic encephalopathy in patients with cirrhosis: International Society for Hepatic Encephalopathy and Nitrogen Metabolism Consensus. Hepatology 2013; 58: 325-336

[101] Montano-Loza AJ, Meza-Junco J, Prado CM et al. Muscle wasting is associated with mortality in patients with cirrhosis. Clin Gastroenterol Hepatol 2012; 10: 166-173, 173 e1

[102] Durand F, Buyse S, Francoz C et al. Prognostic value of muscle atrophy in cirrhosis using psoas muscle thickness on computed tomography. J Hepatol 2014; 60: 1151 - 1157

[103] Carey EJ, Lai JC, Wang CW et al. A multicenter study to define sarcopenia in patients with end- stage liver disease. Liver Transpl 2017; 23: $625-633$

[104] Borhofen SM, Gerner C, Lehmann J et al. The Royal Free Hospital-Nutritional Prioritizing Tool Is an Independent Predictor of Deterioration of Liver Function and Survival in Cirrhosis. Dig Dis Sci 2016; 61: 1735 - 1743

[105] Montano-Loza AJ, Angulo P, Meza-Junco J et al. Sarcopenic obesity and myosteatosis are associated with higher mortality in patients with cirrhosis. J Cachexia Sarcopenia Muscle 2016; 7: 126-135

[106] Selberg O, Selberg D. Norms and correlates of bioimpedance phase angle in healthy human subjects, hospitalized patients, and patients with liver cirrhosis. Eur J Appl Physiol 2002; 86: 509-516

[107] Peres WA, Lento DF, Baluz K et al. Phase angle as a nutritional evaluation tool in all stages of chronic liver disease. Nutr Hosp 2012; 27: $2072-2078$

[108] Ruiz-Margain A, Macias-Rodriguez RU, Duarte-Rojo A et al. Malnutrition assessed through phase angle and its relation to prognosis in patients with compensated liver cirrhosis: a prospective cohort study. Dig Liver Dis 2015; 47: 309-314

[109] Belarmino G, Gonzalez MC, Torrinhas RS et al. Phase angle obtained by bioelectrical impedance analysis independently predicts mortality in patients with cirrhosis. World J Hepatol 2017; 9: 401-408

[110] Figueiredo FA, Dickson ER, Pasha TM et al. Utility of standard nutritional parameters in detecting body cell mass depletion in patients with end-stage liver disease. Liver Transpl 2000; 6: 575-581

[111] Alvares-da-Silva MR, Reverbel da Silveira T. Comparison between handgrip strength, subjective global assessment, and prognostic nu- tritional index in assessing malnutrition and predicting clinical outcome in cirrhotic outpatients. Nutrition 2005; 21: 113-117

[112] Huisman EJ, Trip EJ, Siersema PD et al. Protein energy malnutrition predicts complications in liver cirrhosis. Eur J Gastroenterol Hepatol 2011; 23: $982-989$

[113] Norman K, Kirchner H, Freudenreich M et al. Three month intervention with protein and energy rich supplements improve muscle function and quality of life in malnourished patients with non-neoplastic gastrointestinal disease-a randomized controlled trial. Clin Nutr 2008; 27: 48- 56

[114] Plauth M, Cabre E, Campillo B et al. ESPEN Guidelines on Parenteral Nutrition: hepatology. Clin Nutr 2009; 28: 436-444

[115] Plank LD, Gane EJ, Peng S et al. Nocturnal nutritional supplementation improves total body protein status of patients with liver cirrhosis: a randomized 12-month trial. Hepatology 2008; 48: 557 - 566

[116] Plauth M, Schutz T, Buckendahl DP et al. Weight gain after transjugular intrahepatic portosystemic shunt is associated with improvement in body composition in malnourished patients with cirrhosis and hypermetabolism. J Hepatol 2004; 40: 228-233

[117] Cordoba J, Lopez-Hellin J, Planas M et al. Normal protein diet for episodic hepatic encephalopathy: results of a randomized study. J Hepatol 2004; $41: 38-43$

[118] Everhart JE, Lok AS, Kim HY et al. Weight-related effects on disease progression in the hepatitis $C$ antiviral long-term treatment against cirrhosis trial. Gastroenterology 2009; 137: 549- 557

[119] Berzigotti A, Garcia-Tsao G, Bosch j et al. Obesity is an independent risk factor for clinical decompensation in patients with cirrhosis. Hepatology 2011; 54: 555-561

[120] Sawyer RG, Pelletier S], Pruett TL. Increased early morbidity and mortality with acceptable long-term function in severely obese patients undergoing liver transplantation. Clin Transplant 1999; 13: 126-130

[121] Nair S, Verma S, Thuluvath PJ. Obesity and its effect on survival in patients undergoing orthotopic liver transplantation in the United States. Hepatology 2002; 35: 105 - 109

[122] Dick AA, Spitzer AL, Seifert CF et al. Liver transplantation the extremes of the body mass index. Liver Transpl 2009; 15: 968-977

[123] Berzigotti A, Albillos A, Villanueva C et al. Effects of an intensive lifestyle intervention program on portal hypertension in patients with cirrhosis and obesity: The SportDiet study. Hepatology 2017; 65: 1293 1305

[124] Madden AM, Bradbury W, Morgan MY. Taste perception in cirrhosis: its relationship to circulating micronutrients and food preferences. Hepatology 1997; 26: $40-48$

[125] Bernardi M, Laffi G, Salvagnini M et al. Efficacy and safety of the stepped care medical treatment of ascites in liver cirrhosis: a randomized controlled clinical trial comparing two diets with different sodium content. Liver 1993; 13: 156-162

[126] Gu XB, Yang XJ, Zhu HY et al. Effect of a diet with unrestricted sodium on ascites in patients with hepatic cirrhosis. Gut Liver 2012; 6: 355 361

[127] Sorrentino P, Castaldo G, Tarantino L et al. Preservation of nutritionalstatus in patients with refractory ascites due to hepatic cirrhosis who are undergoing repeated paracentesis. J Gastroenterol Hepatol 2012; 27: $813-822$

[128] Angeli P, Wong F, Watson $\mathrm{H}$ et al. Hyponatremia in cirrhosis: Results of a patient population survey. Hepatology 2006; 44: 1535-1542

[129] Biggins SW, Kim WR, Terrault NA et al. Evidence-based incorporation of serum sodium concentration into MELD. Gastroenterology 2006; 130 : $1652-1660$

[130] Kim WR, Biggins SW, Kremers WK et al. Hyponatremia and mortality among patients on the liver-transplant waiting list. N Engl J Med 2008; 359: $1018-1026$ 
[131] Abbasoglu O, Goldstein RM, Vodapally MS et al. Liver transplantation in hyponatremic patients with emphasis on central pontine myelinolysis. Clin Transplant 1998; 12: 263-269

[132] Perez-Ayuso RM, Arroyo V, Planas R et al. Randomized comparative study of efficacy of furosemide versus spironolactone in nonazotemic cirrhosis with ascites. Relationship between the diuretic response and the activity of the renin-aldosterone system. Gastroenterology 1983; 84: $961-968$

[133] Santos ], Planas R, Pardo A et al. Spironolactone alone or in combination with furosemide in the treatment of moderate ascites in nonazotemic cirrhosis. A randomized comparative study of efficacy and safety. J Hepatol 2003; 39: 187-192

[134] Pockros PJ, Reynolds TB. Rapid diuresis in patients with ascites from chronic liver disease: the importance of peripheral edema. Gastroenterology 1986; 90: 1827-1833

[135] Gatta A, Angeli P, Caregaro L et al. A pathophysiological interpretation of unresponsiveness to spironolactone in a stepped-care approach to the diuretic treatment of ascites in nonazotemic cirrhotic patients. Hepatology 1991; 14: 23123-23126

[136] Daskalopoulos G, Laffi G, Morgan T et al. Immediate effects of furosemide on renal hemodynamics in chronic liver disease with ascites. Gastroenterology 1987; 92: 1859-1863

[137] Licata G, Tuttolomondo A, Licata A et al. Clinical Trial: High-dose furosemide plus small-volume hypertonic saline solutions vs. repeated paracentesis as treatment of refractory ascites. Aliment Pharmacol Ther 2009; 30: 227 - 235

[138] Yakar T, Demir M, Dogan O et al. High Dose Oral Furosemide with Salt Ingestion in the Treatment of Refractory Ascites of Liver Cirrhosis. Clin Invest Med 2016; 39: 27502

[139] Abecasis R, Guevara M, Miguez C et al. Long-term efficacy of torsemide compared with frusemide in cirrhotic patients with ascites. Scand ] Gastroenterol 2001; 36: 309-313

[140] Gerbes AL, Bertheau-Reitha U, Falkner C et al. Advantages of the new loop diuretic torasemide over furosemide in patients with cirrhosis and ascites. A randomized, double blind cross-over trial. J Hepatol 1993; 17: $353-358$

[141] Angeli P, Fasolato S, Mazza E et al. Combined versus sequential diuretic treatment of ascites in non-azotaemic patients with cirrhosis: results of an open randomised clinical trial. Gut 2010; 59: 98-104

[142] Stanley MM, Ochi S, Lee KK et al. Peritoneovenous shunting as compared with medical treatment in patients with alcoholic cirrhosis and massive ascites. Veterans Administration Cooperative Study on Treatment of Alcoholic Cirrhosis with Ascites. N Engl J Med 1989; 321: $1632-1638$

[143] Runyon BA. Care of patients with ascites. N Engl J Med 1994; 330 : 337 342

[144] Yang YY, Lin HC, Lee WP et al. Association of the G-protein and alpha2adrenergic receptor gene and plasma norepinephrine level with clonidine improvement of the effects of diuretics in patients with cirrhosis with refractory ascites: a randomised clinical trial. Gut 2010; 59: $1545-1553$

[145] Singh V, Singh A, Singh B et al. Midodrine and clonidine in patients with cirrhosis and refractory or recurrent ascites: a randomized pilot study. Am J Gastroenterol 2013; 108: 560 - 567

[146] Singh V, Dhungana SP, Singh B et al. Midodrine in patients with cirrhosis and refractory or recurrent ascites: a randomized pilot study. J Hepatol 2012; 56: 348-354

[147] Angeli P, Dalla Pria M, De Bei E et al. Randomized clinical study of the efficacy of amiloride and potassium canrenoate in nonazotemic cirrhotic patients with ascites. Hepatology 1994; 19: 72 - 79

[148] Pizarro M, Solis N, Quintero P et al. Beneficial effects of mineralocorticoid receptor blockade in experimental non-alcoholic steatohepatitis. Liver Int 2015; 35: 2129-2138
[149] Gerbes AL, Gulberg V, Sauerbruch T et al. German S 3-guideline "ascites, spontaneous bacterial peritonitis, hepatorenal syndrome". Z Gastroenterol 2011; 49: 749-779

[150] Gines P, Wong F, Watson $\mathrm{H}$ et al. Effects of satavaptan, a selective vasopressin $\mathrm{V}(2)$ receptor antagonist, on ascites and serum sodium in cirrhosis with hyponatremia: a randomized trial. Hepatology 2008; 48 : $204-213$

[151] Wong F, Gines P, Watson $\mathrm{H}$ et al. Effects of a selective vasopressin V2 receptor antagonist, satavaptan, on ascites recurrence after paracentesis in patients with cirrhosis. J Hepatol 2010; 53: 283-290

[152] Gines P, Wong F, Watson $\mathrm{H}$ et al. Clinical trial: short-term effects of combination of satavaptan, a selective vasopressin V2 receptor antagonist, and diuretics on ascites in patients with cirrhosis without hyponatraemia-a randomized, double-blind, placebo-controlled study. Aliment Pharmacol Ther 2010; 31: 834-845

[153] Wong F, Watson H, Gerbes A et al. Satavaptan for the management of ascites in cirrhosis: efficacy and safety across the spectrum of ascites severity. Gut 2012; 61: 108-116

[154] Cardenas A, Gines P, Marotta P et al. Tolvaptan, an oral vasopressin antagonist, in the treatment of hyponatremia in cirrhosis. J Hepatol 2012; 56: $571-578$

[155] Sakaida I, Yanase M, Kobayashi Y et al. The pharmacokinetics and pharmacodynamics of tolvaptan in patients with liver cirrhosis with insufficient response to conventional diuretics: a multicentre, doubleblind, parallel-group, phase III study. J Int Med Res 2012; 40: 2381 2393

[156] Sakaida I, Yamashita S, Kobayashi T et al. Efficacy and safety of a 14-day administration of tolvaptan in the treatment of patients with ascites in hepatic oedema. J Int Med Res 2013; 41: 835-847

[157] Sakaida I, Kawazoe S, Kajimura K et al. Tolvaptan for improvement of hepatic edema: A phase 3, multicenter, randomized, double-blind, placebo-controlled trial. Hepatol Res 2014; 44: 73-82

[158] Okita K, Kawazoe S, Hasebe C et al. Dose-finding trial of tolvaptan in liver cirrhosis patients with hepatic edema: A randomized, doubleblind, placebo-controlled trial. Hepatol Res 2014; 44: 83-91

[159] Boyer TD, Zia P, Reynolds TB. Effect of indomethacin and prostaglandin A1 on renal function and plasma renin activity in alcoholic liver disease. Gastroenterology 1979; 77: 215-222

[160] Planas R, Arroyo V, Rimola A et al. Acetylsalicylic acid suppresses the renal hemodynamic effect and reduces the diuretic action of furosemide in cirrhosis with ascites. Gastroenterology 1983; 84: 247 - 252

[161] Pariente EA, Bataille C, Bercoff E et al. Acute effects of captopril on systemic and renal hemodynamics and on renal function in cirrhotic patients with ascites. Gastroenterology 1985; 88: 1255-1259

[162] Daskalopoulos G, Pinzani M, Murray N et al. Effects of captopril on rena function in patients with cirrhosis and ascites. J Hepatol 1987; 4: 330 336

[163] Laffi G, La Villa G, Pinzani M et al. Arachidonic acid derivatives and rena function in liver cirrhosis. Semin Nephrol 1997; 17: 530 - 548

[164] Gentilini P, Romanelli RG, La Villa G et al. Effects of low-dose captopril on renal hemodynamics and function in patients with cirrhosis of the liver. Gastroenterology 1993; 104: 588-94

[165] Lee JK, Hsieh JF, Tsai SC et al. Effects of single dose of 50mg captopril in patients with liver cirrhosis and ascites. Hepatogastroenterology 2000; 47: $767-770$

[166] Claria J, Kent JD, Lopez-Parra M et al. Effects of celecoxib and naproxen on renal function in nonazotemic patients with cirrhosis and ascites. Hepatology 2005; 41: 579-587

[167] Zapater P, Llanos L, Barquero C et al. Acute effects of dipyrone on renal function in patients with cirrhosis: a randomized controlled trial. Basic Clin Pharmacol Toxicol 2015; 116: 257-263 
[168] Mandorfer M, Bota S, Schwabl P et al. Nonselective beta blockers increase risk for hepatorenal syndrome and death in patients with cirrhosis and spontaneous bacterial peritonitis. Gastroenterology 2014; 146: $1680-1690$ e1

[169] Serste T, Melot C, Francoz C et al. Deleterious effects of beta-blockers on survival in patients with cirrhosis and refractory ascites. Hepatology 2010; 52: $1017-1022$

[170] Leithead JA, Rajoriya N, Tehami N et al. Non-selective $\beta$-blockers are associated with improved survival in patients with ascites listed for liver transplantation. Gut 2015; 64: 1111 - 1119

[171] Mookerjee RP, Pavesi M, Thomsen KL et al. Treatment with non-selective beta blockers is associated with reduced severity of systemic inflammation and improved survival of patients with acute-on-chronic liver failure. Journal of Hepatology 2016; 64: 574-582

[172] Angeli P, Gines P, Wong F et al. Diagnosis and management of acute kidney injury in patients with cirrhosis: revised consensus recommendations of the International Club of Ascites. Gut 2015; 64: 531 - 537

[173] de Franchis R, Faculty BV. Expanding consensus in portal hypertension: Report of the Baveno VI Consensus Workshop: Stratifying risk and individualizing care for portal hypertension. Journal of Hepatology 2015; 63: $743-752$

[174] Lo EA, Wilby KJ, Ensom MH. Use of proton pump inhibitors in the management of gastroesophageal varices: a systematic review. Ann Pharmacother 2015; 49: 207 - 219

[175] Choi E], Lee HJ, Kim KO et al. Association between acid suppressive therapy and spontaneous bacterial peritonitis in cirrhotic patients with ascites. Scand J Gastroenterol 2011; 46: 616-620

[176] Min YW, Lim KS, Min BH et al. Proton pump inhibitor use significantly increases the risk of spontaneous bacterial peritonitis in 1965 patients with cirrhosis and ascites: a propensity score matched cohort study. Aliment Pharmacol Ther 2014; 40: 695-704

[177] Dam G, Vilstrup H, Watson $\mathrm{H}$ et al. Proton pump inhibitors as a risk factor for hepatic encephalopathy and spontaneous bacterial peritonitis in patients with cirrhosis with ascites. Hepatology 2016; 64: 1265 1272

[178] Mandorfer M, Bota S, Schwabl P et al. Proton pump inhibitor intake neither predisposes to spontaneous bacterial peritonitis or other infections nor increases mortality in patients with cirrhosis and ascites. PLoS One 2014; 9: e110503

[179] Terg R, Casciato P, Garbe C et al. Proton pump inhibitor therapy does not increase the incidence of spontaneous bacterial peritonitis in cirrhosis: a multicenter prospective study. J Hepatol 2015; 62: 1056 - 1060

[180] Caraceni P, Riggio O, Angeli P et al. Long-term albumin administration in decompensated cirrhosis (ANSWER): an open-label randomised trial. Lancet 2018; 391: 2417-2429

[181] Di Pascoli M, Fasolato S, Piano S et al. Long-term administration of human albumin improves survival in patients with cirrhosis and refractory ascites. Liver Int [Epub 2018]

[182] EASL Clinical Practice Guidelines for the management of patients with decompensated cirrhosis. J Hepatol 2018; 69: 406-460

[183] Arroyo V, Gines P, Gerbes AL et al. Definition and diagnostic criteria of refractory ascites and hepatorenal syndrome in cirrhosis. International Ascites Club. Hepatology 1996; 23: 164-176

[184] Bellot P, Welker MW, Soriano G et al. Automated low flow pump system for the treatment of refractory ascites: a multi-center safety and efficacy study. J Hepatol 2013; 58: 922 - 927

[185] Thomas MN, Sauter GH, Gerbes AL et al. Automated low flow pump system for the treatment of refractory ascites: a single-center experience. Langenbecks Arch Surg 2015; 400: 979-983

[186] Bureau C, Adebayo D, Chalret de Rieu M et al. Alfapump(R) system vs. large volume paracentesis for refractory ascites: A multicenter randomized controlled study. J Hepatol 2017; 67: 940-949
[187] Sola E, Sanchez-Cabus S, Rodriguez E et al. Effects of alfapump system on kidney and circulatory function in patients with cirrhosis and refractory ascites. Liver Transpl 2017; 23: 583-593

[188] Solbach P, Honer Zu Siederdissen C, Taubert R et al. Home-based drainage of refractory ascites by a permanent-tunneled peritoneal catheter can safely replace large-volume paracentesis. Eur J Gastroenterol Hepatol 2017; 29: 539-546

[189] Rosemurgy AS, Zervos EE, Clark WC et al. TIPS versus peritoneovenous shunt in the treatment of medically intractable ascites: a prospective randomized trial. Ann Surg 2004; 239: 883-889; discussion 889-891

[190] Nicolaou S, Talsky A, Khashoggi K et al. Ultrasound-guided interventional radiology in critical care. Crit Care Med 2007; 35: S186-S197

[191] Gines A, Fernandez-Esparrach G, Monescillo A et al. Randomized trial comparing albumin, dextran 70, and polygeline in cirrhotic patients with ascites treated by paracentesis. Gastroenterology 1996; 111: $1002-1010$

[192] Gines P, Tito L, Arroyo V et al. Randomized comparative study of therapeutic paracentesis with and without intravenous albumin in cirrhosis. Gastroenterology 1988; 94: 1493 - 1502

[193] Pozzi M, Osculati G, Boari G et al. Time course of circulatory and humoral effects of rapid total paracentesis in cirrhotic patients with tense, refractory ascites. Gastroenterology 1994; 106: 709-719

[194] Tan HK, James PD, Wong F. Albumin May Prevent the Morbidity of Paracentesis-Induced Circulatory Dysfunction in Cirrhosis and Refractory Ascites: A Pilot Study. Dig Dis Sci 2016; 61: 3084-3092

[195] Lebrec D, Giuily N, Hadengue A et al. Transjugular intrahepatic portosystemic shunts: comparison with paracentesis in patients with cirrhosis and refractory ascites: a randomized trial. French Group of Clinicians and a Group of Biologists. J Hepatol 1996; 25: 135-144

[196] Wong F, Sniderman K, Liu P et al. Transjugular intrahepatic portosystemic stent shunt: effects on hemodynamics and sodium homeostasis in cirrhosis and refractory ascites. Ann Intern Med 1995; 122: 816-822

[197] Brensing KA, Textor ], Perz ] et al. Long term outcome after transjugular intrahepatic portosystemic stent-shunt in non-transplant cirrhotics with hepatorenal syndrome: a phase II study. Gut 2000; 47: 288-295

[198] Tan HK, James PD, Sniderman KW et al. Long-term clinical outcome of patients with cirrhosis and refractory ascites treated with transjugular intrahepatic portosystemic shunt insertion. J Gastroenterol Hepatol 2015; 30: 389-395

[199] Allegretti AS, Ortiz G, Cui ] et al. Changes in Kidney Function After Transjugular Intrahepatic Portosystemic Shunts Versus Large-Volume Paracentesis in Cirrhosis: A Matched Cohort Analysis. Am J Kidney Dis 2016; 68: 381 - 391

[200] Gines P, Uriz ], Calahorra B et al. Transjugular intrahepatic portosystemic shunting versus paracentesis plus albumin for refractory ascites in cirrhosis. Gastroenterology 2002; 123: 1839-1847

[201] Rossle M, Ochs A, Gulberg V et al. A comparison of paracentesis and transjugular intrahepatic portosystemic shunting in patients with ascites. N Engl J Med 2000; 342: 1701 - 1707

[202] Salerno F, Camma C, Enea M et al. Transjugular intrahepatic portosystemic shunt for refractory ascites: a meta-analysis of individual patient data. Gastroenterology 2007; 133: 825 - 834

[203] Bureau C, Thabut D, Oberti F et al. Transjugular Intrahepatic Portosystemic Shunts With Covered Stents Increase Transplant-Free Survival of Patients With Cirrhosis and Recurrent Ascites. Gastroenterology 2017; 152: $157-163$

[204] Gulberg V, Liss I, Bilzer M et al. Improved quality of life in patients with refractory or recidivant ascites after insertion of transjugular intrahepatic portosystemic shunts. Digestion 2002; 66: 127-130

[205] Salerno F, Merli M, Riggio O et al. Randomized controlled study of TIPS versus paracentesis plus albumin in cirrhosis with severe ascites. Hepatology 2004; 40: 629-635 
[206] Bai M, Qi XS, Yang ZP et al. TIPS improves liver transplantation-free survival in cirrhotic patients with refractory ascites: an updated metaanalysis. World J Gastroenterol 2014; 20: $2704-2714$

[207] Bureau C, Garcia Pagan JC, Layrargues GP et al. Patency of stents covered with polytetrafluoroethylene in patients treated by transjugular intrahepatic portosystemic shunts: long-term results of a randomized multicentre study. Liver Int 2007; 27: 742-747

[208] Bureau C, Garcia-Pagan JC, Otal P et al. Improved clinical outcome using polytetrafluoroethylene-coated stents for TIPS: results of a randomized study. Gastroenterology 2004; 126: 469-475

[209] Hernandez-Guerra M, Turnes J, Rubinstein P et al. PTFE-covered stents improve TIPS patency in Budd-Chiari syndrome. Hepatology 2004; 40: $1197-1202$

[210] Perarnau JM, Baju A, D’Alteroche L et al. Feasibility and long-term evolution of TIPS in cirrhotic patients with portal thrombosis. Eur J Gastroenterol Hepatol 2010; 22: 1093-1098

[211] Barrio J, Ripoll C, Banares R et al. Comparison of transjugular intrahepatic portosystemic shunt dysfunction in PTFE-covered stent-grafts versus bare stents. Eur J Radiol 2005; 55: 120 - 124

[212] Yang Z, Han G, Wu Q et al. Patency and clinical outcomes of transjugular intrahepatic portosystemic shunt with polytetrafluoroethylenecovered stents versus bare stents: a meta- analysis. J Gastroenterol Hepatol 2010; 25: $1718-1725$

[213] Nardelli S, Lattanzi B, Torrisi S et al. Sarcopenia Is Risk Factor for Development of Hepatic Encephalopathy After Transjugular Intrahepatic Portosystemic Shunt Placement. Clin Gastroenterol Hepatol 2017; 15: 934-936

[214] Wang Q, Lv Y, Bai M et al. Eight millimeter covered TIPS does not compromise shunt function but reduces hepatic encephalopathy in preventing variceal rebleeding. J Hepatol 2017; 67: 508-516

[215] Sauerbruch T, Mengel M, Dollinger $M$ et al. Prevention of Rebleeding From Esophageal Varices in Patients With Cirrhosis Receiving Small-Diameter Stents Versus Hemodynamically Controlled Medical Therapy. Gastroenterology 2015; 149: 660-668 e1

[216] Holster IL, Tjwa ET, Moelker A et al. Covered transjugular intrahepatic portosystemic shunt versus endoscopic therapy + beta-blocker for prevention of variceal rebleeding. Hepatology 2016; 63: 581-589

[217] Chalasani N, Clark WS, Martin LG et al. Determinants of mortality in patients with advanced cirrhosis after transjugular intrahepatic portosystemic shunting. Gastroenterology 2000; 118: 138-144

[218] Rajan DK, Haskal Z], Clark TW. Serum bilirubin and early mortality after transjugular intrahepatic portosystemic shunts: results of a multivariate analysis. J Vasc Interv Radiol 2002; 13: 155-161

[219] Gerbes AL, Gulberg V. Benefit of TIPS for patients with refractory or recidivant ascites: serum bilirubin may make the difference. Hepatology 2005; 41: 217

[220] Bureau C, Metivier S, D’Amico M et al. Serum bilirubin and platelet count: a simple predictive model for survival in patients with refractory ascites treated by TIPS. J Hepatol 2011; 54: $901-907$

[221] Cazzaniga M, Salerno F, Pagnozzi G et al. Diastolic dysfunction is associated with poor survival in patients with cirrhosis with transjugular intrahepatic portosystemic shunt. Gut 2007; 56: 869-875

[222] Lv Y, He C, Wang Z et al. Association of Nonmalignant Portal Vein Thrombosis and Outcomes after Transjugular Intrahepatic Portosystemic Shunt in Patients with Cirrhosis. Radiology 2017; 285: 9991010

[223] Runyon BA. Monomicrobial nonneutrocytic bacterascites: a variant of spontaneous bacterial peritonitis. Hepatology 1990; 12: 710-715

[224] Fernández J, Navasa M, Gómez J et al. Bacterial infections in cirrhosis: epidemiological changes with invasive procedures and norfloxacin prophylaxis. Hepatology 2002; 35: 140-148
[225] Conn HO, Fessel JM. Spontaneous bacterial peritonitis in cirrhosis: variations on a theme. Medicine (Baltimore) 1971; 50: 161-197

[226] Gines P, Rimola A, Planas R et al. Norfloxacin prevents spontaneous bacterial peritonitis recurrence in cirrhosis: results of a double-blind, placebo-controlled trial. Hepatology 1990; 12: 716-724

[227] Titó L, Rimola A, Gines P et al. Recurrence of spontaneous bacterial peritonitis in cirrhosis: frequency and predictive factors. Hepatology 1988; 8: 27-31

[228] Hsieh W], Lin HC, Hwang SJ et al. The effect of ciprofloxacin in the prevention of bacterial infection in patients with cirrhosis after upper gastrointestinal bleeding. Am J Gastroenterol 1998; 93: 962 - 966

[229] Pauwels A, Mostefa-Kara N, Debenes B et al. Systemic antibiotic prophylaxis after gastrointestinal hemorrhage in cirrhotic patients with a high risk of infection. Hepatology 1996; 24: 802-806

[230] Rolachon A, Cordier L, Bacq Y et al. Ciprofloxacin and long-term prevention of spontaneous bacterial peritonitis: results of a prospective controlled trial. Hepatology 1995; 22: 1171 - 1174

[231] Soriano G, GUARNER C, Teixidó M et al. Selective intestinal decontamination prevents spontaneous bacterial peritonitis. Gastroenterology 1991; 100: $477-481$

[232] Obstein KL, Campbell MS, Reddy KR et al. Association between model for end-stage liver disease and spontaneous bacterial peritonitis. The American Journal of Gastroenterology 2007; 102: 2732-2736

[233] Bajaj JS, Zadvornova Y, Heuman DM et al. Association of proton pump inhibitor therapy with spontaneous bacterial peritonitis in cirrhotic patients with ascites. Am J Gastroenterol 2009; 104: 1130-1134

[234] Appenrodt B, Grünhage F, Gentemann MG et al. Nucleotide-binding oligomerization domain containing 2 (NOD2) variants are genetic risk factors for death and spontaneous bacterial peritonitis in liver cirrhosis. Hepatology 2010; 51: 1327-1333

[235] Chu CM, Chang KY, Liaw YF. Prevalence and prognostic significance of bacterascites in cirrhosis with ascites. Digestive Diseases and Sciences 1995; 40: $561-565$

[236] Follo A, Llovet JM, Navasa M et al. Renal impairment after spontaneous bacterial peritonitis in cirrhosis: incidence, clinical course, predictive factors and prognosis. Hepatology 1994; 20: 1495-1501

[237] Nobre SR, Cabral JEP, Gomes JJF et al. In-hospital mortality in spontaneous bacterial peritonitis: a new predictive model. European journal of gastroenterology \& hepatology 2008; 20: 1176-1181

[238] Pinzello G, Simonetti RG, Craxì A et al. Spontaneous bacterial peritonitis: a prospective investigation in predominantly nonalcoholic cirrhotic patients. Hepatology 1983; 3: 545-549

[239] Thuluvath PJ, Morss S, Thompson R. Spontaneous bacterial peritonitisin-hospital mortality, predictors of survival, and health care costs from 1988 to 1998. The American Journal of Gastroenterology 2001; 96: $1232-1236$

[240] Toledo C, Salmeron JM, Rimola A et al. Spontaneous bacterial peritonitis in cirrhosis: predictive factors of infection resolution and survival in patients treated with cefotaxime. Hepatology 1993; 17: 251 - 257

[241] Andreu M, Sola R, Sitges-Serra A et al. Risk factors for spontaneous bacterial peritonitis in cirrhotic patients with ascites. Gastroenterology 1993; 104: $1133-1138$

[242] Silvain C, Besson I, Ingrand P et al. Prognosis and long-term recurrence of spontaneous bacterial peritonitis in cirrhosis. Journal of Hepatology 1993; 19: $188-189$

[243] Terg R, Levi D, Lopez P et al. Analysis of clinical course and prognosis of culture-positive spontaneous bacterial peritonitis and neutrocytic ascites. Evidence of the same disease. Dig Dis Sci 1992; 37: 1499- 504

[244] Altman C, Grangé JD, Amiot X et al. Survival after a first episode of spontaneous bacterial peritonitis. Prognosis of potential candidates for orthotopic liver transplantation. Journal of Gastroenterology and Hepatology 1995; 10: 47-50 
[245] Almdal TP, Skinhøj P. Spontaneous bacterial peritonitis in cirrhosis. Incidence, diagnosis, and prognosis. Scandinavian Journal of Gastroenterology 1987; 22: 295 - 300

[246] Weinstein MP, Iannini PB, Stratton CW et al. Spontaneous bacterial peritonitis. A review of 28 cases with emphasis on improved survival and factors influencing prognosis. Am J Med 1978; 64: 592-598

[247] Terg R, Gadano A, Cartier M et al. Serum creatinine and bilirubin predict renal failure and mortality in patients with spontaneous bacterial peritonitis: a retrospective study. Liver international: official journal of the International Association for the Study of the Liver 2009; 29: 415 419

[248] França AV, De Souza JB, Silva CM et al. Long-term prognosis of cirrhosis after spontaneous bacterial peritonitis treated with ceftriaxone. Journal of clinical gastroenterology 2001; 33: 295-298

[249] Kamani L, Mumtaz K, Ahmed US et al. Outcomes in culture positive and culture negative ascitic fluid infection in patients with viral cirrhosis: cohort study. BMC Gastroenterology 2008; 8: 59

[250] Cho JH, Park KH, Kim SH et al. Bacteremia is a prognostic factor for poor outcome in spontaneous bacterial peritonitis. Scandinavian journal of infectious diseases 2007; 39: 697-702

[251] Gotz M, Anders M, Biecker E et al. S2k Guideline Gastrointestinal Bleeding - Guideline of the German Society of Gastroenterology DGVS. Z Gastroenterol 2017; 55: 883 -936

[252] DuPont HL. Review article: the antimicrobial effects of rifaximin on the gut microbiota. Aliment Pharmacol Ther 2016; 43 (Suppl. 1): 3-10

[253] DuPont HL, Jiang ZD. Influence of rifaximin treatment on the susceptibility of intestinal Gram- negative flora and enterococci. Clin Microbiol Infect 2004; 10: 1009-1011

[254] Tandon P, Delisle A, Topal JE et al. High prevalence of antibiotic-resistant bacterial infections among patients with cirrhosis at a US liver center. Clin Gastroenterol Hepatol 2012; 10: 1291 - 1298

[255] De Leo C, Eftimiadi C, Schito GC. Rapid disappearance from the intestinal tract of bacteria resistant to rifaximin. Drugs Exp Clin Res 1986; 12: $979-981$

[256] Assem M, Elsabaawy M, Abdelrashed M et al. Efficacy and safety of alternating norfloxacin and rifaximin as primary prophylaxis for spontaneous bacterial peritonitis in cirrhotic ascites: a prospective randomized open-label comparative multicenter study. Hepatol Int 2016; 10 : $377-385$

[257] Fernández ], Navasa M, Planas R et al. Primary prophylaxis of spontaneous bacterial peritonitis delays hepatorenal syndrome and improves survival in cirrhosis. Gastroenterology 2007; 133: 818-824

[258] Hanouneh MA, Hanouneh IA, Hashash JG et al. The role of rifaximin in the primary prophylaxis of spontaneous bacterial peritonitis in patients with liver cirrhosis. J Clin Gastroenterol 2012; 46: 709-715

[259] Vlachogiannakos J, Viazis N, Vasianopoulou P et al. Long-term administration of rifaximin improves the prognosis of patients with decompensated alcoholic cirrhosis. J Gastroenterol Hepatol 2013; 28: 450 455

[260] Lontos S, Gow PJ, Vaughan RB et al. Norfloxacin and trimethoprim-sulfamethoxazole therapy have similar efficacy in prevention of spontaneous bacterial peritonitis. J Gastroenterol Hepatol 2008; 23: 252 - 255

[261] Singh N, Gayowski T, Yu VL et al. Trimethoprim-sulfamethoxazole for the prevention of spontaneous bacterial peritonitis in cirrhosis: a randomized trial. Ann Intern Med 1995; 122: 595- 598

[262] Lontos S, Shelton E, Angus PW et al. A randomized controlled study of trimethoprim- sulfamethoxazole versus norfloxacin for the prevention of infection in cirrhotic patients. J Dig Dis 2014; 15: 260-267

[263] Jalan R, Fernández J, Wiest R et al. Bacterial infections in cirrhosis: a position statement based on the EASL Special Conference 2013. Journal of hepatology 2014; 60: 1310 - 1324
[264] Gustot T, Fernández ], Szabo G et al. Sepsis in Alcohol-related Liver Disease. Journal of Hepatology 2017; 67: 1031 - 1050

[265] Navasa M, Follo A, Llovet JM et al. Randomized, comparative study of oral ofloxacin versus intravenous cefotaxime in spontaneous bacterial peritonitis. Gastroenterology 1996; 111: 1011 - 1017

[266] Park YH, Lee HC, Song HG et al. Recent increase in antibiotic-resistant microorganisms in patients with spontaneous bacterial peritonitis adversely affects the clinical outcome in Korea. Journal of Gastroenterology and Hepatology 2003; 18: 927 - 933

[267] Singh N, Wagener MM, Gayowski T. Changing epidemiology and predictors of mortality in patients with spontaneous bacterial peritonitis at a liver transplant unit. Clinical microbiology and infection: the official publication of the European Society of Clinical Microbiology and Infectious Diseases 2003; 9: 531 - 537

[268] Lutz P, Nischalke HD, Krämer B et al. Antibiotic resistance in healthcare-related and nosocomial spontaneous bacterial peritonitis. European journal of clinical investigation 2016; 47: 44-52

[269] Friedrich K, Nüssle S, Rehlen T et al. Microbiology and resistance in first episodes of spontaneous bacterial peritonitis: implications for management and prognosis. Journal of Gastroenterology and Hepatology 2016; 31: $1191-1195$

[270] Reuken PA, Pletz MW, Baier M et al. Emergence of spontaneous bacterial peritonitis due to enterococci - risk factors and outcome in a 12-year retrospective study. Alimentary Pharmacology \& Therapeutics 2012; 35: $1199-1208$

[271] Venditti M, Falcone M, Corrao S et al. Outcomes of patients hospitalized with community- acquired, health care-associated, and hospitalacquired pneumonia. Annals of Internal Medicine 2009; 150: 19-26

[272] Merli M, Lucidi C. Bacterial resistance in cirrhotic patients: an emerging reality. Journal of Hepatology 2012; 56: 756-757

[273] Friedman ND, Kaye KS, Stout JE et al. Health care-associated bloodstream infections in adults: a reason to change the accepted definition of community-acquired infections. Annals of Internal Medicine 2002; 137: $791-797$

[274] Ariza X, Castellote J, Lora-Tamayo J et al. Risk factors for resistance to ceftriaxone and its impact on mortality in community, healthcare and nosocomial spontaneous bacterial peritonitis. Journal of Hepatology 2012; 56: $825-832$

[275] Rimola A, Navasa M, Arroyo V. Experience with cefotaxime in the treatment of spontaneous bacterial peritonitis in cirrhosis. Diagnostic microbiology and infectious disease 1995; 22: 141-145

[276] Rimola A, Salmeron JM, Clemente G et al. Two different dosages of cefotaxime in the treatment of spontaneous bacterial peritonitis in cirrhosis: results of a prospective, randomized, multicenter study. Hepatology 1995; 21: 674-679

[277] Gómez-Jiménez J, Ribera E, Gasser I et al. Randomized trial comparing ceftriaxone with cefonicid for treatment of spontaneous bacterial peritonitis in cirrhotic patients. Antimicrobial agents and chemotherapy 1993; 37: $1587-1592$

[278] Felisart J, Rimola A, Arroyo V et al. Cefotaxime is more effective than is ampicillin-tobramycin in cirrhotics with severe infections. Hepatology 1985; 5: $457-462$

[279] Angeloni S, Leboffe C, Parente A et al. Efficacy of current guidelines for the treatment of spontaneous bacterial peritonitis in the clinical practice. World Journal of Gastroenterology 2008; 14: 2757 - 2762

[280] Yakar T, Güçlü M, Serin E et al. A recent evaluation of empirical cephalosporin treatment and antibiotic resistance of changing bacterial profiles in spontaneous bacterial peritonitis. Digestive Diseases and Sciences 2010; 55: 1149-1154

[281] Piano S, Fasolato S, Salinas F et al. The empirical antibiotic treatment of nosocomial spontaneous bacterial peritonitis: Results of a randomized, controlled clinical trial. Hepatology 2016; 63: 1299-1309 
[282] Jindal A, Kumar M, Bhadoria AS et al. A randomized open label study of 'imipenem vs. cefepime' in spontaneous bacterial peritonitis. Liver Int 2016; 36: $677-687$

[283] Umgelter A, Reindl W, Miedaner M et al. Failure of current antibiotic first-line regimens and mortality in hospitalized patients with spontaneous bacterial peritonitis. Infection 2009; 37: 2 -8

[284] Dupeyron C, Campillo SB, Mangeney N et al. Carriage of Staphylococ cus aureus and of gram- negative bacilli resistant to third-generation cephalosporins in cirrhotic patients: a prospective assessment of hospital-acquired infections. Infection control and hospital epidemiology 2001; 22: $427-432$

[285] Dupeyron C, Mangeney N, Sedrati L et al. Rapid emergence of quinolone resistance in cirrhotic patients treated with norfloxacin to prevent spontaneous bacterial peritonitis. Antimicrobial agents and chemotherapy 1994; 38: $340-344$

[286] Chavez-Tapia NC, Soares-Weiser K, Brezis M et al. Antibiotics for spontaneous bacterial peritonitis in cirrhotic patients. The Cochrane database of systematic reviews 2009; 23: CD002232

[287] Chen TA, Lo GH, Lai KH et al. Single daily amikacin versus cefotaxime in the short-course treatment of spontaneous bacterial peritonitis in cirrhotics. World Journal of Gastroenterology 2005; 11: 6823-6827

[288] Rastegar LA, Umrani G, Dehbashi N et al. Evaluation of the therapeutic effect of pefloxacin in comparison with ampicillin and gentamicin in cirrhotic patients with spontaneous bacterial peritonitis. Hepato-gastroenterology 1998; 45: $783-785$

[289] Antillon MR, Runyon BA. Effect of marked peripheral leukocytosis on the leukocyte count in ascites. Archives of internal medicine 1991; 151: 509-510

[290] Ljubicic N, Spajic D, Vrkljan MM et al. The value of ascitic fluid polymorphonuclear cell count determination during therapy of spontaneous bacterial peritonitis in patients with liver cirrhosis. Hepato-gastroenterology 2000; 47: 1360-1363

[291] Runyon BA, Hoefs JC. Spontaneous vs secondary bacterial peritonitis. Differentiation by response of ascitic fluid neutrophil count to antimicrobial therapy. Archives of internal medicine 1986; 146: 1563-1565

[292] Fong TL, Akriviadis EA, Runyon BA et al. Polymorphonuclear cell count response and duration of antibiotic therapy in spontaneous bacterial peritonitis. Hepatology 1989; 9: 423-426

[293] Runyon BA, McHutchison JG, Antillon MR et al. Short-course versus long-course antibiotic treatment of spontaneous bacterial peritonitis. A randomized controlled study of 100 patients. Gastroenterology 1991; 100: 1737 - 1742

[294] Sort P, Navasa M, Arroyo V et al. Effect of intravenous albumin on renal impairment and mortality in patients with cirrhosis and spontaneous bacterial peritonitis. New England Journal of Medicine 1999; 341: 403 409

[295] Fernández ], Monteagudo ], Bargallo X et al. A randomized unblinded pilot study comparing albumin versus hydroxyethyl starch in spontaneous bacterial peritonitis. Hepatology 2005; 42: 627 - 634

[296] de Araujo A, de Barros Lopes A, Rossi G et al. Low-dose albumin in the treatment of spontaneous bacterial peritonitis: should we change the standard treatment? Gut 2012; 61: 1371 - 1372

[297] Sigal SH, Stanca CM, Fernandez ] et al. Restricted use of albumin for spontaneous bacterial peritonitis. Gut 2007; 56: 597 - 599

[298] Salerno F, Navickis RJ, Wilkes MM. Albumin Infusion Improves Outcomes of Patients With Spontaneous Bacterial Peritonitis: A Meta-analysis of Randomized Trials. Clinical Gastroenterology and Hepatology 2013; 11: 123 -130.e1

[299] Bauer TM, Follo A, Navasa M et al. Daily norfloxacin is more effective than weekly rufloxacin in prevention of spontaneous bacterial peritonitis recurrence. Dig Dis Sci 2002; 47: 1356 - 1361
[300] Elfert A, Abo Ali L, Soliman S et al. Randomized-controlled trial of rifaximin versus norfloxacin for secondary prophylaxis of spontaneous bacterial peritonitis. Eur J Gastroenterol Hepatol 2016; 28: 1450 - 1454

[301] Mostafa T, Badra G, Abdallah M. The efficacy and the immunomodulatory effect of rifaximin in prophylaxis of spontaneous bacterial peritonitis in cirrhotic Egyptian patients. Turk J Gastroenterol 2015; 26: 163 169

[302] Alvarez RF, Mattos AA, Correa EB et al. Trimethoprim-sulfamethoxazole versus norfloxacin in the prophylaxis of spontaneous bacterial peritonitis in cirrhosis. Arq Gastroenterol 2005; 42: 256-262

[303] Shamseya MM, Madkour MA. Rifaximin: A reasonable alternative for norfloxacin in the prevention of spontaneous bacterial peritonitis in patients with HCV-related liver cirrhosis. Alexandria Journal of Medicine 2016; 52: $219-226$

[304] Soriano G, Guarner C, Teixido M et al. Selective intestinal decontamination prevents spontaneous bacterial peritonitis. Gastroenterology 1991; 100: $477-481$

[305] Sidhu GS, Go A, Attar BM et al. Rifaximin versus norfloxacin for prevention of spontaneous bacterial peritonitis: a systematic review. BM] Open Gastroenterol 2017; 4: e000154

[306] Kamal F, Khan MA, Khan Z et al. Rifaximin for the prevention of spontaneous bacterial peritonitis and hepatorenal syndrome in cirrhosis: a systematic review and meta-analysis. Eur ] Gastroenterol Hepatol 2017; 29: $1109-1117$

[307] Salerno F, Gerbes A, Gines P et al. Diagnosis, prevention and treatment of hepatorenal syndrome in cirrhosis. Gut 2007; 56: 1310-1318

[308] Angeli P, Gines P. Hepatorenal syndrome, MELD score and liver transplantation: an evolving issue with relevant implications for clinical practice. J Hepatol 2012; 57: 1135-1140

[309] Wong F, Nadim MK, Kellum JA et al. Working Party proposal for a revised classification system of renal dysfunction in patients with cirrhosis. Gut 2011; 60: $702-709$

[310] Moreau R, Jalan R, Gines P et al. Acute-on-chronic liver failure is a distinct syndrome that develops in patients with acute decompensation of cirrhosis. Gastroenterology 2013; 144: 1426-1437, 1437 e1-9

[311] Jalan R, Saliba F, Pavesi M et al. Development and validation of a prognostic score to predict mortality in patients with acute-on-chronic liver failure. J Hepatol 2014; 61: 1038-1047

[312] Barosa R, Roque Ramos L, Patita M et al. CLIF-C ACLF score is a better mortality predictor than MELD, MELD-Na and CTP in patients with Acute on chronic liver failure admitted to the ward. Rev Esp Enferm Dig 2017; 109: 399-405

[313] Li N, Huang C, Yu KK et al. Validation of prognostic scores to predict short-term mortality in patients with HBV-related acute-on-chronic liver failure: The CLIF-C OF is superior to MELD, CLIF SOFA, and CLIF-C ACLF. Medicine (Baltimore) 2017; 96: e6802

[314] Gerbes AL, Gulberg V, Bilzer M et al. Evaluation of serum cystatin C concentration as a marker of renal function in patients with cirrhosis of the liver. Gut 2002; 50: 106-110

[315] Markwardt D, Holdt L, Steib C et al. Plasma cystatin C is a predictor of renal dysfunction, acute- on-chronic liver failure, and mortality in patients with acutely decompensated liver cirrhosis. Hepatology 2017; 66: $1232-1241$

[316] Maiwall R, Kumar A, Bhardwaj A et al. Cystatin C predicts acute kidney injury and mortality in cirrhotics: A prospective cohort study. Liver Int 2018; 38: $654-664$

[317] Seo YS, Park SY, Kim MY et al. Serum cystatin C level: An excellent predictor of mortality in patients with cirrhotic ascites. J Gastroenterol Hepatol 2018; 33: 910-917

[318] Solanki P, Chawla A, Garg R et al. Beneficial effects of terlipressin in hepatorenal syndrome: a prospective, randomized placebo-controlled clinical trial. J Gastroenterol Hepatol 2003; 18: 152-156 
[319] Sanyal A], Boyer T, Garcia-Tsao G et al. A randomized, prospective, double-blind, placebo- controlled trial of terlipressin for type 1 hepatorenal syndrome. Gastroenterology 2008; 134: 1360-1368

[320] Martin-Llahi M, Pepin MN, Guevara M et al. Terlipressin and albumin vs albumin in patients with cirrhosis and hepatorenal syndrome: a randomized study. Gastroenterology 2008; 134: 1352 -1359

[321] Neri S, Pulvirenti D, Malaguarnera M et al. Terlipressin and albumin in patients with cirrhosis and type I hepatorenal syndrome. Dig Dis Sci 2008; 53: $830-835$

[322] Ortega R, Gines P, Uriz J et al. Terlipressin therapy with and without albumin for patients with hepatorenal syndrome: results of a prospective, nonrandomized study. Hepatology 2002; 36: 941 - 948

[323] Saner F, Kavuk I, Lang $\mathrm{H}$ et al. Terlipressin and gelafundin: safe therapy of hepatorenal syndrome. Eur J Med Res 2004; 9: 78-82

[324] Dart AB, Mutter TC, Ruth CA et al. Hydroxyethyl starch (HES) versus other fluid therapies: effects on kidney function. Cochrane Database Syst Rev 2010; 20: CD007594

[325] Fabrizi F, Dixit V, Messa P et al. Terlipressin for hepatorenal syndrome: A meta-analysis of randomized trials. Int J Artif Organs 2009; 32: 133 140

[326] Gluud LL, Christensen K, Christensen E et al. Systematic review of randomized trials on vasoconstrictor drugs for hepatorenal syndrome. Hepatology 2010; 51: 576-584

[327] Sagi SV, Mittal S, Kasturi KS et al. Terlipressin therapy for reversal of type 1 hepatorenal syndrome: a meta-analysis of randomized controlled trials. J Gastroenterol Hepatol 2010; 25: 880-885

[328] Gerbes AL, Huber E, Gulberg V. Terlipressin for hepatorenal syndrome: continuous infusion as an alternative to i. v. bolus administration. Gastroenterology 2009; 137: 1179; author reply 1179-1181

[329] Cavallin M, Piano S, Romano A et al. Terlipressin given by continuous intravenous infusion versus intravenous boluses in the treatment of hepatorenal syndrome: A randomized controlled study. Hepatology 2016; 63: $983-992$

[330] Nassar Junior AP, Farias AQ, LA DA et al. Terlipressin versus norepinephrine in the treatment of hepatorenal syndrome: a systematic review and meta-analysis. PLoS One 2014; 9: e107466

[331] Gerbes AL, Gulberg V, Waggershauser T et al. Renal effects of transjugular intrahepatic portosystemic shunt in cirrhosis: comparison of patients with ascites, with refractory ascites, or without ascites. Hepatology 1998; 28: 683-688

[332] Rossle M, Gerbes AL. TIPS for the treatment of refractory ascites, hepatorenal syndrome and hepatic hydrothorax: a critical update. Gut 2010; 59: $988-1000$

[333] Guevara M, Gines P, Bandi JC et al. Transjugular intrahepatic portosystemic shunt in hepatorenal syndrome: effects on renal function and vasoactive systems. Hepatology 1998; 28: 416-422

[334] Wong F, Pantea L, Sniderman K. Midodrine, octreotide, albumin, and TIPS in selected patients with cirrhosis and type 1 hepatorenal syndrome. Hepatology 2004; 40: 55-64

[335] Testino G, Ferro C, Sumberaz A et al. Type-2 hepatorenal syndrome and refractory ascites: role of transjugular intrahepatic portosystemic stent-shunt in eighteen patients with advanced cirrhosis awaiting orthotopic liver transplantation. Hepatogastroenterology 2003; 50: $1753-1755$

[336] Witzke O, Baumann M, Patschan $D$ et al. Which patients benefit from hemodialysis therapy in hepatorenal syndrome? J Gastroenterol Hepatol 2004; 19: 1369-1373

[337] Mitzner SR, Stange J, Klammt S et al. Improvement of hepatorenal syndrome with extracorporeal albumin dialysis MARS: results of a prospective, randomized, controlled clinical trial. Liver Transpl 2000; 6: $277-286$
[338] Wong F, Raina N, Richardson R. Molecular adsorbent recirculating system is ineffective in the management of type 1 hepatorenal syndrome in patients with cirrhosis with ascites who have failed vasoconstrictor treatment. Gut 2010; 59: 381-386

[339] Banares R, Nevens F, Larsen FS et al. Extracorporeal albumin dialysis with the molecular adsorbent recirculating system in acute-on-chronic liver failure: the RELIEF trial. Hepatology 2013; 57: 1153-1162

[340] Rifai K, Ernst T, Kretschmer U et al. Prometheus-a new extracorporeal system for the treatment of liver failure. J Hepatol 2003; 39: 984-990

[341] Kribben A, Gerken G, Haag S et al. Effects of fractionated plasma separation and adsorption on survival in patients with acute-on-chronic liver failure. Gastroenterology 2012; 142: 782 - 789 e3

[342] Gonwa TA, Poplawski S, Paulsen W et al. Pathogenesis and outcome of hepatorenal syndrome in patients undergoing orthotopic liver transplant. Transplantation 1989; 47: 395-397

[343] Seu P, Wilkinson AH, Shaked A et al. The hepatorenal syndrome in liver transplant recipients. Am Surg 1991; 57: 806-809

[344] Lafayette RA, Pare G, Schmid CH et al. Pretransplant renal dysfunction predicts poorer outcome in liver transplantation. Clin Nephrol 1997; 48: $159-164$

[345] Restuccia T, Ortega R, Guevara M et al. Effects of treatment of hepatorenal syndrome before transplantation on posttransplantation outcome. A case-control study. J Hepatol 2004; 40: 140-146

[346] Bundesärztekammer. Richtlinien zur Organtransplantation gem. § 16 Abs. 1 S. 1 Nrn. 2, 4u. 5 TPG. Dtsch Arztebl International 2010; 107: $1532-1541$

[347] Davis CL, Feng S, Sung R et al. Simultaneous liver-kidney transplantation: evaluation to decision making. Am J Transplant 2007; 7: 1702 1709

[348] Galie N, Humbert M, Vachiery JL et al. 2015 ESC/ERS Guidelines for the diagnosis and treatment of pulmonary hypertension: The Joint Task Force for the Diagnosis and Treatment of Pulmonary Hypertension of the European Society of Cardiology (ESC) and the European Respiratory Society (ERS): Endorsed by: Association for European Paediatric and Congenital Cardiology (AEPC), International Society for Heart and Lung Transplantation (ISHLT). Eur Heart J 2016; 37: 67-119

[349] Lieberman FL, Hidemura R, Peters RL et al. Pathogenesis and treatment of hydrothorax complicating cirrhosis with ascites. Ann Intern Med 1966; 64: $341-351$

[350] Badillo R, Rockey DC. Hepatic hydrothorax: clinical features, management, and outcomes in 77 patients and review of the literature. Medicine (Baltimore) 2014; 93: 135-142

[351] Malagari K, Nikita A, Alexopoulou E et al. Cirrhosis-related intrathoracic disease. Imaging features in 1038 patients. Hepatogastroenterology 2005; 52: $558-562$

[352] Kiafar C, Gilani N. Hepatic hydrothorax: current concepts of pathophysiology and treatment options. Ann Hepatol 2008; 7: 313-320

[353] Singh A, Bajwa A, Shujaat A. Evidence-based review of the management of hepatic hydrothorax. Respiration 2013; 86: 155-173

[354] Huang PM, Chang YL, Yang CY et al. The morphology of diaphragmatic defects in hepatic hydrothorax: thoracoscopic finding. J Thorac Cardiovasc Surg 2005; 130: $141-145$

[355] Rubinstein D, McInnes IE, Dudley F]. Hepatic hydrothorax in the absence of clinical ascites: diagnosis and management. Gastroenterology 1985; 88: $188-191$

[356] Light RW. Clinical practice. Pleural effusion. N Engl J Med 2002; 346: $1971-1977$

[357] Xiol X, Castellote J, Cortes-Beut R et al. Usefulness and complications of thoracentesis in cirrhotic patients. Am J Med 2001; 111: 67-69

[358] Gordon CE, Feller-Kopman D, Balk EM et al. Pneumothorax following thoracentesis: a systematic review and meta-analysis. Arch Intern Med 2010; 170: 332 -339 
[359] Schildhouse R, Lai A, Barsuk JH et al. Safe and Effective Bedside Thoracentesis: A Review of the Evidence for Practicing Clinicians. J Hosp Med 2017; 12: $266-276$

[360] Gurung P, Goldblatt M, Huggins JT et al. Pleural fluid analysis and radiographic, sonographic, and echocardiographic characteristics of hepatic hydrothorax. Chest 2011; 140: 448-453

[361] Bielsa S, Porcel JM, Castellote J et al. Solving the Light's criteria misclassification rate of cardiac and hepatic transudates. Respirology 2012; $17: 721-726$

[362] Tu CY, Chen CH. Spontaneous bacterial empyema. Curr Opin Pulm Med 2012; 18: $355-358$

[363] Bhattacharya A, Mittal BR, Biswas T et al. Radioisotope scintigraphy in the diagnosis of hepatic hydrothorax. J Gastroenterol Hepatol 2001; 16: $317-321$

[364] Ajmi S, Hassine H, Guezguez M et al. Isotopic exploration of hepatic hydrothorax: ten cases. Gastroenterol Clin Biol 2004; 28: 462-466

[365] Huang PM, Han YY, Kuo SW et al. Color Doppler ultrasonography in detecting transdiaphragmatic flow of hepatic hydrothorax: correlation with thoracoscopic findings. J Thorac Cardiovasc Surg 2009; 138: $1251-1252$

[366] Tamano M, Hashimoto T, Kojima K et al. Diagnosis of hepatic hydrothorax using contrast- enhanced ultrasonography with intraperitoneal injection of Sonazoid. J Gastroenterol Hepatol 2010; 25: 383 - 386

[367] Kaplan LM, Epstein SK, Schwartz SL et al. Clinical, echocardiographic, and hemodynamic evidence of cardiac tamponade caused by large pleural effusions. Am J Respir Crit Care Med 1995; 151: 904 - 908

[368] Atiemo K, Skaro A, Maddur H et al. Mortality Risk Factors Among Patients With Cirrhosis and a Low Model for End-Stage Liver Disease Sodium Score $(</=15)$ : An Analysis of Liver Transplant Allocation Policy Using Aggregated Electronic Health Record Data. Am J Transplant 2017; 17: $2410-2419$

[369] Angueira CE, Kadakia SC. Effects of large-volume paracentesis on pulmonary function in patients with tense cirrhotic ascites. Hepatology 1994; 20: $825-828$

[370] Castellote J, Xiol X, Cortes-Beut R et al. Complications of thoracentesis in cirrhotic patients with pleural effusion. Rev Esp Enferm Dig 2001; 93 : $566-575$

[371] Feller-Kopman D, Berkowitz D, Boiselle P et al. Large-volume thoracentesis and the risk of reexpansion pulmonary edema. Ann Thorac Surg 2007; 84: 1656-1661

[372] Liu LU, Haddadin HA, Bodian CA et al. Outcome analysis of cirrhotic patients undergoing chest tube placement. Chest 2004; 126: 142 148

[373] Orman ES, Lok AS. Outcomes of patients with chest tube insertion for hepatic hydrothorax. Hepatol Int 2009; 3: 582 - 586

[374] Haas KP, Chen AC. Indwelling tunneled pleural catheters for the management of hepatic hydrothorax. Curr Opin Pulm Med 2017; 23: $351-356$

[375] Chen A, Massoni J, Jung D et al. Indwelling Tunneled Pleural Catheters for the Management of Hepatic Hydrothorax. A Pilot Study. Ann Am Thorac Soc 2016; 13: $862-866$

[376] Colombato L. The role of transjugular intrahepatic portosystemic shunt (TIPS) in the management of portal hypertension. J Clin Gastroenterol 2007; 41 (Suppl. 3): S344-S5351

[377] Gordon FD, Anastopoulos HT, Crenshaw W et al. The successful treatment of symptomatic, refractory hepatic hydrothorax with transjugular intrahepatic portosystemic shunt. Hepatology 1997; 25: 1366-1369

[378] Jeffries MA, Kazanjian S, Wilson M et al. Transjugular intrahepatic portosystemic shunts and liver transplantation in patients with refractory hepatic hydrothorax. Liver Transpl Surg 1998; 4: 416-423

[379] Siegerstetter V, Deibert P, Ochs A et al. Treatment of refractory hepatic hydrothorax with transjugular intrahepatic portosystemic shunt: long- term results in 40 patients. Eur J Gastroenterol Hepatol 2001; 13: 529 534

[380] Spencer EB, Cohen DT, Darcy MD. Safety and efficacy of transjugular intrahepatic portosystemic shunt creation for the treatment of hepatic hydrothorax. J Vasc Interv Radiol 2002; 13: 385-390

[381] Wilputte JY, Goffette P, Zech F et al. The outcome after transjugular intrahepatic portosystemic shunt (TIPS) for hepatic hydrothorax is closely related to liver dysfunction: a long-term study in 28 patients. Acta Gastroenterol Belg 2007; 70: 6-10

[382] Dhanasekaran R, West JK, Gonzales PC et al. Transjugular intrahepatic portosystemic shunt for symptomatic refractory hepatic hydrothorax in patients with cirrhosis. Am J Gastroenterol 2010; 105: 635-641

[383] Ditah IC, Al Bawardy BF, Saberi B et al. Transjugular intrahepatic portosystemic stent shunt for medically refractory hepatic hydrothorax: A systematic review and cumulative meta- analysis. World J Hepatol 2015; 7: 1797 - 1806

[384] Falchuk KR, Jacoby I, Colucci WS et al. Tetracycline-induced pleural symphysis for recurrent hydrothorax complicating cirrhosis. A new approach to treatment. Gastroenterology 1977; 72: 319-321

[385] Milanez de Campos JR, Filho LO, de Campos Werebe E et al. Thoracoscopy and talc poudrage in the management of hepatic hydrothorax. Chest 2000; 118: 13-17

[386] Ferrante D, Arguedas MR, Cerfolio RJ et al. Video-assisted thoracoscopic surgery with talc pleurodesis in the management of symptomatic hepatic hydrothorax. Am J Gastroenterol 2002; 97: 3172-3175

[387] Cerfolio RJ, Bryant AS. Efficacy of video-assisted thoracoscopic surgery with talc pleurodesis for porous diaphragm syndrome in patients with refractory hepatic hydrothorax. Ann Thorac Surg 2006; 82: 457-459

[388] Huang PM, Kuo SW, Lee JM. Thoracoscopic diaphragmatic repair for refractory hepatic hydrothorax: application of pleural flap and mesh onlay reinforcement. Thorac Cardiovasc Surg 2006; 54: 47 - 50

[389] Jung Y. Surgical Treatment of Hepatic Hydrothorax: A “Four-Step Approach”. Ann Thorac Surg 2016; 101: 1195-1197

[390] Huang PM, Kuo SW, Chen JS et al. Thoracoscopic Mesh Repair of Diaphragmatic Defects in Hepatic Hydrothorax: A 10-Year Experience. Ann Thorac Surg 2016; 101: 1921-1927

[391] Porcel JM. Management of refractory hepatic hydrothorax. Curr Opin Pulm Med 2014; 20: $352-357$

[392] Hou F, Qi X, Guo X. Effectiveness and Safety of Pleurodesis for Hepatic Hydrothorax: A Systematic Review and Meta-Analysis. Dig Dis Sci 2016; 61: $3321-3334$

[393] Xiol X, Tremosa G, Castellote J et al. Liver transplantation in patients with hepatic hydrothorax. Transpl Int 2005; 18: 672-675

[394] Serste T, Moreno C, Francoz C et al. The impact of preoperative hepatic hydrothorax on the outcome of adult liver transplantation. Eur J Gastroenterol Hepatol 2010; 22: 207-212

[395] Endo K, lida T, Yagi S et al. Impact of preoperative uncontrollable hepatic hydrothorax and massive ascites in adult liver transplantation. Surg Today 2014; 44: 2293-2299

[396] Sese E, Xiol X, Castellote J et al. Low complement levels and opsonic activity in hepatic hydrothorax: its relationship with spontaneous bacterial empyema. J Clin Gastroenterol 2003; 36: 75-77

[397] Ackerman Z, Reynolds TB. Evaluation of pleural fluid in patients with cirrhosis. J Clin Gastroenterol 1997; 25: 619-622

[398] Xiol X, Castellvi JM, Guardiola J et al. Spontaneous bacterial empyema in cirrhotic patients: a prospective study. Hepatology 1996; 23: $719-$ 723

[399] Chen TA, Lo GH, Lai KH. Risk factors for spontaneous bacterial empyema in cirrhotic patients with hydrothorax. J Chin Med Assoc 2003; 66: $579-586$ 
[400] Castellote J, Lopez C, Gornals J et al. Use of reagent strips for the rapid diagnosis of spontaneous bacterial empyema. J Clin Gastroenterol 2005; 39: $278-281$

[401] Chen CH, Shih CM, Chou JW et al. Outcome predictors of cirrhotic patients with spontaneous bacterial empyema. Liver International 2011; 31: $417-424$

[402] Ewig S, Hoffken G, Kern WV et al. Behandlung von erwachsenen Patienten mit ambulant erworbener Pneumonie und Prävention - Update 2016. Pneumologie 2016; 70: $151-200$

[403] Rodriguez-Roisin R, Krowka M], Herve P et al. Pulmonary-Hepatic vascular Disorders (PHD). Eur Respir J 2004; 24: 861 - 880

[404] Fuhrmann V, Madl C, Mueller C et al. Hepatopulmonary syndrome in patients with hypoxic hepatitis. Gastroenterology 2006; 131: 69-75

[405] Kaymakoglu S, Kahraman T, Kudat $\mathrm{H}$ et al. Hepatopulmonary syndrome in noncirrhotic portal hypertensive patients. Dig Dis Sci 2003; 48: $556-560$

[406] Abrams GA, Jaffe CC, Hoffer PB et al. Diagnostic utility of contrast echocardiography and lung perfusion scan in patients with hepatopulmonary syndrome. Gastroenterology 1995; 109: 1283-1288

[407] DuBrock HM, Krowka MJ, Forde KA et al. Clinical Impact of Intrapulmonary Vascular Dilatation in Candidates for Liver Transplant. Chest 2018; 153: 414-426

[408] Fallon MB, Krowka M], Brown RS et al. Impact of hepatopulmonary syndrome on quality of life and survival in liver transplant candidates. Gastroenterology 2008; 135: 1168-1175

[409] Machicao VI, Balakrishnan M, Fallon MB. Pulmonary complications in chronic liver disease. Hepatology 2014; 59: 1627-1637

[410] Palma DT, Philips GM, Arguedas MR et al. Oxygen desaturation during sleep in hepatopulmonary syndrome. Hepatology 2008; 47: 1257 1263

[411] Pascasio JM, Grilo I, Lopez-Pardo FJ et al. Prevalence and severity of hepatopulmonary syndrome and its influence on survival in cirrhotic patients evaluated for liver transplantation. Am J Transplant 2014; 14 : 1391 - 1399

[412] Grilo-Bensusan I, Pascasio-Acevedo JM. Hepatopulmonary syndrome: What we know and what we would like to know. World J Gastroenterol 2016; 22: $5728-57241$

[413] Arguedas MR, Singh H, Faulk DK et al. Utility of pulse oximetry screening for hepatopulmonary syndrome. Clin Gastroenterol Hepatol 2007; 5: $749-754$

[414] Krowka MJ, Fallon MB, Kawut SM et al. International Liver Transplant Society Practice Guidelines: Diagnosis and Management of Hepatopulmonary Syndrome and Portopulmonary Hypertension. Transplantation 2016; 100: 1440 - 1452

[415] Bundesärztekammer. Richtlinien zur Organtransplantation gem. § 16 TPG. Deutsches Ärzteblatt 2017; 114: A1 - A20

[416] Grilo I, Pascasio JM, Lopez-Pardo FJ et al. Hepatopulmonary syndrome: which blood gas analysis criteria and position should we use for diagnosis? Rev Esp Enferm Dig 2017; 109: 843-849

[417] Tonelli AR, Naal T, Dakkak W et al. Assessing the kinetics of microbubble appearance in cirrhotic patients using transthoracic saline contrastenhanced echocardiography. Echocardiography 2017; 34: 1439-1446

[418] Vedrinne JM, Duperret S, Bizollon T et al. Comparison of transesophageal and transthoracic contrast echocardiography for detection of an intrapulmonary shunt in liver disease. Chest 1997; 111: 1236-1240

[419] Abrams GA, Nanda NC, Dubovsky EV et al. Use of macroaggregated albumin lung perfusion scan to diagnose hepatopulmonary syndrome: a new approach. Gastroenterology 1998; 114: 305-310

[420] Krowka MJ, Wiseman GA, Burnett OL et al. Hepatopulmonary syndrome: a prospective study of relationships between severity of liver disease, $\mathrm{PaO}(2)$ response to $100 \%$ oxygen, and brain uptake after (99m)Tc MAA lung scanning. Chest 2000; 118: 615-624
[421] de Queiros AS, Brandao SC, Macedo LG et al. Evaluation of normality and reproducibility parameters of scintigraphy with $(99 \mathrm{~m})$ Tc-MAA in the diagnosis of intrapulmonary vascular dilatations. Ann Nucl Med 2015; 29: $46-51$

[422] Grilo I, Pascasio JM, Tirado JL et al. The utility of the macro-aggregated albumin lung perfusion scan in the diagnosis and prognosis of hepatopulmonary syndrome in cirrhotic patients candidates for liver transplantation. Rev Esp Enferm Dig 2017; 109: 335-343

[423] Koksal D, Kacar S, Koksal AS et al. Evaluation of intrapulmonary vascular dilatations with high- resolution computed thorax tomography in patients with hepatopulmonary syndrome. J Clin Gastroenterol 2006; 40: $77-83$

[424] Surani SR, Mendez Y, Anjum H et al. Pulmonary complications of hepatic diseases. World J Gastroenterol 2016; 22: 6008-6015

[425] Cosarderelioglu C, Cosar AM, Gurakar M et al. Hepatopulmonary Syndrome and Liver Transplantation: A Recent Review of the Literature. J Clin Transl Hepatol 2016; 4: 47-53

[426] Schenk P, Schoniger-Hekele M, Fuhrmann V et al. Prognostic significance of the hepatopulmonary syndrome in patients with cirrhosis. Gastroenterology 2003; 125: $1042-1052$

[427] Swanson KL, Wiesner RH, Krowka MJ. Natural history of hepatopulmonary syndrome: Impact of liver transplantation. Hepatology 2005; 41: $1122-1129$

[428] Boyer TD, Haskal Z], American Association for the Study of Liver D. The Role of Transjugular Intrahepatic Portosystemic Shunt (TIPS) in the Management of Portal Hypertension: update 2009. Hepatology 2010; 51: 306

[429] Grady K, Gowda S, Kingah P et al. Coil embolization of pulmonary arteries as a palliative treatment of diffuse type I hepatopulmonary syndrome. Respir Care 2015; 60: e20-e25

[430] Krowka MJ, Mandell MS, Ramsay MA et al. Hepatopulmonary syndrome and portopulmonary hypertension: a report of the multicenter liver transplant database. Liver Transpl 2004; 10: 174-182

[431] Iyer VN, Swanson KL, Cartin-Ceba R et al. Hepatopulmonary syndrome: favorable outcomes in the MELD exception era. Hepatology 2013; 57 : $2427-2435$

[432] Ferenci P, Lockwood A, Mullen K et al. Hepatic encephalopathy-definition, nomenclature, diagnosis, and quantification: final report of the working party at the 11th World Congresses of Gastroenterology, Vienna, 1998. Hepatology 2002; 35: 716-721

[433] Conn HO, Lieberthal MM. The Syndrome of portal-systemic encephalopathy. In: Conn HO, Lieberthal MM, eds.; The hepatic coma syndromes and lactulose. Williams \& Wilkins; 1979: 1-45

[434] Häussinger DC], Kircheis G et al. Definition and assessment of low-grade hepatic encephalopathy. In: Häussinger DKG, Schliess F, eds.; Hepatic Encephalopathy and Nitrogen Metabolism. Dordrecht: Springer; 2006: $423-432$

[435] Häussinger D, Blei A. Hepatic encephalopathy. In: Rodes JBJP, Blei AT, Reichen J, et al., eds.; Textbook of Hepatology: From Basic Science to Clinical Practice. 3rd Edition Oxford: Wiley-Blackwell; 2007: 728-760

[436] Vilstrup H, Amodio P, Bajaj J et al. Hepatic encephalopathy in chronic liver disease: 2014 Practice Guideline by the American Association for the Study of Liver Diseases and the European Association for the Study of the Liver. Hepatology 2014; 60: 715-735

[437] Haussinger D, Sies H. Hepatic encephalopathy: clinical aspects and pathogenetic concept. Arch Biochem Biophys 2013; 536: 97 - 100

[438] Gorg B, Schliess F, Haussinger D. Osmotic and oxidative/nitrosative stress in ammonia toxicity and hepatic encephalopathy. Arch Biochem Biophys 2013; 536: $158-163$

[439] Gorg B, Qvartskhava N, Bidmon H] et al. Oxidative stress markers in the brain of patients with cirrhosis and hepatic encephalopathy. Hepatology $2010 ; 52: 256-265$ 
[440] Haussinger D, Schliess F. Pathogenetic mechanisms of hepatic encephalopathy. Gut 2008; 57: 1156-1165

[441] Haussinger D, Schliess F. Astrocyte swelling and protein tyrosine nitration in hepatic encephalopathy. Neurochem Int 2005; 47: 64-70

[442] Venturini I, Corsi L, Avallone R et al. Ammonia and endogenous benzodiazepine-like compounds in the pathogenesis of hepatic encephalopathy. Scand J Gastroenterol 2001; 36: 423-425

[443] Haussinger D, Steeb R, Kaiser S et al. Nitrogen metabolism in normal and cirrhotic liver. Adv Exp Med Biol 1990; 272: 47 - 64

[444] Haussinger D, Kircheis G, Fischer R et al. Hepatic encephalopathy in chronic liver disease: a clinical manifestation of astrocyte swelling and low-grade cerebral edema? J Hepatol 2000; 32: 1035-1038

[445] Timmermann L, Gross J, Butz M et al. Mini-asterixis in hepatic encephalopathy induced by pathologic thalamo-motor-cortical coupling. Neurology 2003; 61: 689-692

[446] Timmermann L, Butz M, Gross ] et al. Impaired cerebral oscillatory processing in hepatic encephalopathy. Clin Neurophysiol 2008; 119: $265-272$

[447] Butz M, Timmermann L, Braun M et al. Motor impairment in liver cirrhosis without and with minimal hepatic encephalopathy. Acta Neurol Scand 2010; 122: 27 - 35

[448] Kahlbrock N, Butz M, May ES et al. Lowered frequency and impaired modulation of gamma band oscillations in a bimodal attention task are associated with reduced critical flicker frequency. Neuroimage 2012; $61: 216-227$

[449] Saunders JB, Walters JR, Davies AP et al. A 20-year prospective study of cirrhosis. Br Med J (Clin Res Ed) 1981; 282: 263-266

[450] Romero-Gomez M, Boza F, Garcia-Valdecasas MS et al. Subclinical hepatic encephalopathy predicts the development of overt hepatic encephalopathy. Am J Gastroenterol 2001; 96: 2718-2723

[451] Jepsen P, Ott P, Andersen PK et al. Clinical course of alcoholic liver cirrhosis: a Danish population-based cohort study. Hepatology 2010; 51: $1675-1682$

[452] Labenz C, Worns MA, Schattenberg JM et al. Epidemiology of hepatic encephalopathy in german hospitals - the EpHE study. Z Gastroenterol 2017; 55: 741 - 747

[453] Poordad FF. Review article: the burden of hepatic encephalopathy. Aliment Pharmacol Ther 2007; 25 (Suppl. 1): 3-9

[454] Srivastava A, Mehta R, Rothke SP et al. Fitness to drive in patients with cirrhosis and portal- systemic shunting: a pilot study evaluating driving performance. Journal of Hepatology 1994; 21: 1023-1028

[455] Wein C, Koch H, Popp B et al. Minimal hepatic encephalopathy impairs fitness to drive. Hepatology 2004; 39: 739 - 745

[456] Bajaj JS, Hafeezullah M, Hoffmann RG et al. Navigation skill impairment: Another dimension of the driving difficulties in minimal hepatic encephalopathy. Hepatology 2008; 47: 596-604

[457] Kircheis G, Knoche A, Hilger N et al. Hepatic encephalopathy and fitness to drive. Gastroenterology 2009; 137: 1706 - 1715 e1-9

[458] Cordoba J, Cabrera J, Lataif L et al. High prevalence of sleep disturbance in cirrhosis. Hepatology 1998; 27: 339-345

[459] Moscucci F, Nardelli S, Pentassuglio I et al. Previous overt hepatic encephalopathy rather than minimal hepatic encephalopathy impairs health-related quality of life in cirrhotic patients. Liver Int 2011; 31 : $1505-1510$

[460] Hartmann I], Groeneweg M, Quero JC et al. The prognostic significance of subclinical hepatic encephalopathy. Am J Gastroenterol 2000; 95 : 2029-2034

[461] Bustamante J, Rimola A, Ventura PJ et al. Prognostic significance of hepatic encephalopathy in patients with cirrhosis. J Hepatol 1999; 30: $890-895$
[462] Bajaj JS, Schubert CM, Heuman DM et al. Persistence of cognitive impairment after resolution of overt hepatic encephalopathy. Gastroenterology 2010; 138: 2332 - 2340

[463] Riggio O, Ridola L, Pasquale C et al. Evidence of persistent cognitive impairment after resolution of overt hepatic encephalopathy. Clin Gastroenterol Hepatol 2011; 9: 181 - 183

[464] Amodio P, Del Piccolo F, Pettenò E et al. Prevalence and prognostic value of quantified electroencephalogram (EEG) alterations in cirrhotic patients. Journal of Hepatology 2001; 35: 37-45

[465] Schomerus $\mathrm{H}$, Hamster W, Blunck $\mathrm{H}$ et al. Latent portasystemic encephalopathy. Digestive Diseases and Sciences 1981; 26: 622 - 630

[466] Rikkers L, Jenko P, Rudman D et al. Subclinical hepatic encephalopathy: detection, prevalence, and relationship to nitrogen metabolism. Gastroenterology 1978; 75: $462-469$

[467] Tarter RE, Hegedus AM, Van Thiel DH et al. Nonalcoholic cirrhosis associated with neuropsychological dysfunction in the absence of overt evidence of hepatic encephalopathy. Gastroenterology 1984; 86 : $1421-1427$

[468] Gitlin N, Lewis DC, Hinkley L. The diagnosis and prevalence of subclinical hepatic encephalopathy in apparently healthy, ambulant, nonshunted patients with cirrhosis. J Hepatol 1986; 3: 75-82

[469] Dhiman RK, Chawla YK. Minimal hepatic encephalopathy: time to recognise and treat. Trop Gastroenterol 2008; 29: 6-12

[470] Schomerus H, Hamster W. Quality of life in cirrhotics with minimal hepatic encephalopathy. Metab Brain Dis 2001; 16: 37-41

[471] Wunsch E, Szymanik B, Post M et al. Minimal hepatic encephalopathy does not impair health- related quality of life in patients with cirrhosis: a prospective study. Liver Int 2011; 31: 980 - 984

[472] Marchesini G, Bianchi G, Amodio P et al. Factors associated with poor health-related quality of life of patients with cirrhosis. Gastroenterology $2001 ; 120: 170-178$

[473] Arguedas MR, DeLawrence TG, McGuire BM. Influence of hepatic encephalopathy on health- related quality of life in patients with cirrhosis. Dig Dis Sci 2003; 48: 1622 - 1626

[474] Bao Z], Qiu DK, Ma X et al. Assessment of health-related quality of life in Chinese patients with minimal hepatic encephalopathy. World J Gastroenterol 2007; 13: 3003-3008

[475] Bajaj JS. Minimal hepatic encephalopathy matters in daily life. World ] Gastroenterol 2008; 14: 3609-3615

[476] Groeneweg M, Quero JC, De Bruijn I et al. Subclinical hepatic encephalopathy impairs daily functioning. Hepatology 1998; 28: 45 - 49

[477] Labenz C, Baron JS, Toenges G et al. Prospective evaluation of the impact of covert hepatic encephalopathy on quality of life and sleep in cirrhotic patients. Aliment Pharmacol Ther 2018; 48: 313-321

[478] Gillmann A, Gerharz CD, Müssig K. Diagnostik und Therapie der hepatischen Enzephalopathie. Dtsch med Wochenschr 2012; 137: 29-33

[479] Conn HO. Quantifying the severity of hepatic encephalopathy. In: Conn HO, Bircher J, eds.; Hepatic encephalopathy: Syndromes and therapies. East Lansing, Michigan: Medi-Ed Press; 1994: 13-26

[480] Kircheis G, Hilger N, Haussinger D. Value of critical flicker frequency and psychometric hepatic encephalopathy score in diagnosis of lowgrade hepatic encephalopathy. Gastroenterology 2014; 146: 961 - 969

[481] Montagnese S, Amodio P, Morgan MY. Methods for diagnosing hepatic encephalopathy in patients with cirrhosis: a multidimensional approach. Metab Brain Dis 2004; 19: 281 - 312

[482] Quero JC, Schalm SW. Subclinical Hepatic Encephalopathy. Semin Liver Dis 1996; 16: $321-328$

[483] Elsass P, Lund Y, Ranek L. Encephalopathy in patients with cirrhosis of the liver. A neuropsychological study. Scand J Gastroenterol 1978; 13 : $241-247$ 
[484] Gilberstadt S], Gilberstadt H, Zieve L et al. Psychomotor performance defects in cirrhotic patients without overt encephalopathy. Arch Intern Med 1980; 140: 519-521

[485] Tarter RE, Carra J, Switala J et al. Sequential concept formation capacity in subclinical (latent) portal-systemic encephalopathy. Int J Neurosci 1987; 32: $891-894$

[486] Gundling F, Seidl H, Schmidt T et al. Blood ammonia level in liver cirrhosis: a conditio sine qua non to confirm hepatic encephalopathy? Eur J Gastroenterol Hepatol 2008; 20: 246-247

[487] Bajaj JS, Etemadian A, Hafeezullah M et al. Testing for minimal hepatic encephalopathy in the United States: An AASLD survey. Hepatology 2007; 45: $833-834$

[488] Bajaj JS, Saeian K, Verber MD et al. Inhibitory control test is a simple method to diagnose minimal hepatic encephalopathy and predict development of overt hepatic encephalopathy. Am J Gastroenterol 2007; 102: $754-760$

[489] Bajaj JS, Hafeezullah M, Franco J et al. Inhibitory control test for the diagnosis of minimal hepatic encephalopathy. Gastroenterology 2008; 135: 1591 - 1600 e1

[490] Amodio P, Ridola L, Schiff S et al. Improving the inhibitory control task to detect minimal hepatic encephalopathy. Gastroenterology 2010; 139: $510-518,518$ e1-2

[491] Allampati S, Duarte-Rojo A, Thacker LR et al. 589 Two Testing Strategies for Covert Hepatic Encephalopathy Diagnosis Stabilizes Agreement Between Sites in a Multi-Center Analysis: Validation of the EASL/ AASLD He Guidelines. Gastroenterology 2015; 148: S-988

[492] Weissenborn K, Ennen JC, Schomerus H et al. Neuropsychological characterization of hepatic encephalopathy. J Hepatol 2001; 34: 768-773

[493] Weissenborn K, Ruckert N, Hecker $\mathrm{H}$ et al. The number connection tests $A$ and $B$ : interindividual variability and use for the assessment of early hepatic encephalopathy. J Hepatol 1998; 28: 646-653

[494] Schomerus H, Hamster W. Neuropsychological aspects of portal-systemic encephalopathy. Metab Brain Dis 1998; 13: 361 - 377

[495] Weissenborn K, Scholz M, Hinrichs H et al. Neurophysiological assessment of early hepatic encephalopathy. Electroencephalogr Clin Neurophysiol 1990; 75: 289-295

[496] Guerit JM, Amantini A, Fischer C et al. Neurophysiological investigations of hepatic encephalopathy: ISHEN practice guidelines. Liver Int 2009; 29: 789-796

[497] Randolph C, Hilsabeck R, Kato A et al. Neuropsychological assessment of hepatic encephalopathy: ISHEN practice guidelines. Liver Int 2009; 29: $629-635$

[498] Kircheis G, Wettstein M, Timmermann L et al. Critical flicker frequency for quantification of low-grade hepatic encephalopathy. Hepatology 2002; 35: $357-366$

[499] Kircheis G, Bode JG, Hilger N et al. Diagnostic and prognostic values of critical flicker frequency determination as new diagnostic tool for objective HE evaluation in patients undergoing TIPS implantation. Eur J Gastroenterol Hepatol 2009; 21: $1383-1394$

[500] Romero-Gomez M, Cordoba J, Jover R et al. Value of the critical flicker frequency in patients with minimal hepatic encephalopathy. Hepatology 2007; 45: 879-885

[501] Sharma P, Sharma BC, Puri V et al. Critical flicker frequency: diagnostic tool for minimal hepatic encephalopathy. J Hepatol 2007; 47: 67 - 73

[502] Biecker E, Hausdorfer I, Grunhage F et al. Critical flicker frequency as a marker of hepatic encephalopathy in patients before and after transjugular intrahepatic portosystemic shunt. Digestion 2011; 83: 24 - 31

[503] Berlioux P, Robic MA, Poirson $\mathrm{H}$ et al. Pre-transjugular intrahepatic portosystemic shunts (TIPS) prediction of post-TIPS overt hepatic encephalopathy: the critical flicker frequency is more accurate than psychometric tests. Hepatology 2014; 59: 622-629
[504] Ampuero J, Simon M, Montoliu C et al. Minimal hepatic encephalopathy and critical flicker frequency are associated with survival of patients with cirrhosis. Gastroenterology 2015; 149: 1483-1489

[505] Sharma P, Kumar A, Singh S et al. Inhibitory control test, critical flicker frequency, and psychometric tests in the diagnosis of minimal hepatic encephalopathy in cirrhosis. Saudi J Gastroenterol 2013; 19: 40-44

[506] Parsons-Smith BG, Summerskill WH, Dawson AM et al. The electroencephalograph in liver disease. Lancet 1957; 273: 867 -871

[507] Schiff S, Casa M, Di Caro V et al. A low-cost, user-friendly electroencephalographic recording system for the assessment of hepatic encephalopathy. Hepatology 2016; 63: 1651 - 1659

[508] Amodio P, Quero JC, Del Piccolo F et al. Diagnostic tools for the detection of subclinical hepatic encephalopathy: comparison of standard and computerized psychometric tests with spectral- EEG. Metab Brain Dis 1996; 11: $315-327$

[509] Amodio P, Marchetti P, Del Piccolo F et al. Spectral versus visual EEG analysis in mild hepatic encephalopathy. Clin Neurophysiol 1999; 110: $1334-1344$

[510] Kullmann F, Hollerbach S, Lock G et al. Brain electrical activity mapping of EEG for the diagnosis of (sub)clinical hepatic encephalopathy in chronic liver disease. Eur J Gastroenterol Hepatol 2001; 13: 513-522

[511] Yang SS, Chu NS, Liaw YF. Somatosensory evoked potentials in hepatic encephalopathy. Gastroenterology 1985; 89: 625-630

[512] Yang SS, Chu NS, Liaw YF. Brainstem auditory evoked potentials in hepatic encephalopathy. Hepatology 1986; 6: 1352-1355

[513] Johansson U, Andersson T, Persson A et al. Visual evoked potential a tool in the diagnosis of hepatic encephalopathy? J Hepatol 1989; 9: $227-233$

[514] Stroop JR. Studies of interference in serial verbal reactions. Journal of Experimental Psychology 1935; 18: 643-662

[515] Jensen AR, Rohwer WD Jr. The Stroop color-word test: a review. Acta Psychol (Amst) 1966; 25: 36-93

[516] MacLeod CM. Half a century of research on the Stroop effect: an integrative review. Psychol Bull 1991; 109: 163-203

[517] Amodio P, Cordoba J. Smart applications for assessing minimal hepatic encephalopathy: novelty from the app revolution. Hepatology 2013; 58: $844-846$

[518] Bajaj JS, Heuman DM, Sterling RK et al. Validation of EncephalApp, Smartphone-Based Stroop Test, for the Diagnosis of Covert Hepatic Encephalopathy. Clin Gastroenterol Hepatol 2015; 13: 1828 - 1835 e1

[519] Allampati S, Duarte-Rojo A, Thacker LR et al. Diagnosis of Minimal Hepatic Encephalopathy Using Stroop EncephalApp: A Multicenter US-Based, Norm-Based Study. Am J Gastroenterol 2016; 111: 78-86

[520] Bajaj JS, Frederick RT, Bass NM et al. Overt hepatic encephalopathy: development of a novel clinician reported outcome tool and electronic caregiver diary. Metab Brain Dis 2016; 31: 1081 - 1093

[521] Campagna F, Montagnese S, Ridola L et al. The animal naming test: An easy tool for the assessment of hepatic encephalopathy. Hepatology 2017; 66: 198-208

[522] Nabi E, Thacker LR, Wade JB et al. Diagnosis of covert hepatic encephalopathy without specialized tests. Clin Gastroenterol Hepatol 2014; 12: $1384-1389$ e2

[523] Montagnese S, Balistreri E, Schiff S et al. Covert hepatic encephalopathy: agreement and predictive validity of different indices. World J Gastroenterol 2014; 20: 15756-157562

[524] Iduru S, Mullen KD. The demise of the pencil? New computer-assisted tests for minimal hepatic encephalopathy. Gastroenterology 2008 ; 135: $1455-1456$

[525] Arora S, Martin CL, Herbert M. Myth: interpretation of a single ammonia level in patients with chronic liver disease can confirm or rule out hepatic encephalopathy. CJEM 2006; 8: $433-435$ 
[526] Dhiman RK, Saraswat VA, Sharma BK et al. Minimal hepatic encephalopathy: consensus statement of a working party of the Indian National Association for Study of the Liver. J Gastroenterol Hepatol 2010; 25: $1029-1041$

[527] Gundling F, Zelihic E, Seidl H et al. How to diagnose hepatic encephalopathy in the emergency department. Ann Hepatol 2013; 12: 108 114

[528] Ong JP, Aggarwal A, Krieger D et al. Correlation between ammonia levels and the severity of hepatic encephalopathy. Am J Med 2003; 114 : $188-193$

[529] Kramer L, Tribl B, Gendo A et al. Partial pressure of ammonia versus ammonia in hepatic encephalopathy. Hepatology 2000; 31: $30-34$

[530] Nicolao F, Efrati C, Masini A et al. Role of determination of partial pressure of ammonia in cirrhotic patients with and without hepatic encephalopathy. J Hepatol 2003; 38: 441 - 446

[531] Shah NJ, Neeb H, Kircheis G et al. Quantitative cerebral water content mapping in hepatic encephalopathy. Neuroimage 2008; 41: $706-717$

[532] Kale RA, Gupta RK, Saraswat VA et al. Demonstration of interstitial cerebral edema with diffusion tensor MR imaging in type $C$ hepatic encephalopathy. Hepatology 2006; 43: 698-706

[533] Krieger S, Jauss M, Jansen O et al. Neuropsychiatric profile and hyperintense globus pallidus on T1-weighted magnetic resonance images in liver cirrhosis. Gastroenterology 1996; 111: 147 - 155

[534] Spahr L, Burkhard PR, Grotzsch H et al. Clinical significance of basal ganglia alterations at brain MRI and 1H MRS in cirrhosis and role in the pathogenesis of hepatic encephalopathy. Metab Brain Dis 2002; 17 : $399-413$

[535] Zafiris O, Kircheis G, Rood HA et al. Neural mechanism underlying impaired visual judgement in the dysmetabolic brain: an fMRI study. Neurolmage 2004; 22: 541 - 552

[536] Miese F, Kircheis G, Wittsack H] et al. 1H-MR Spectroscopy, Magnetization Transfer, and Diffusion-Weighted Imaging in Alcoholic and Nonalcoholic Patients with Cirrhosis with Hepatic Encephalopathy. American Journal of Neuroradiology 2006; 27: 1019

[537] Jitkritsadakul O, Bhidayasiri R. Physicians' role in the determination of fitness to drive in patients with Parkinson's disease: systematic review of the assessment tools and a call for national guidelines. J Clin Mov Disord 2016; 3: 14

[538] Riggio O, Nardelli S, Gioia S et al. Management of hepatic encephalopathy as an inpatient. Clinical Liver Disease 2015; 5: 79-82

[539] Ruiz-Margain A, Macias-Rodriguez RU, Ampuero J et al. Low phase angle is associated with the development of hepatic encephalopathy in patients with cirrhosis. World J Gastroenterol 2016; 22: 10064-10070

[540] Pantham G, Post A, Venkat D et al. A New Look at Precipitants of Overt Hepatic Encephalopathy in Cirrhosis. Dig Dis Sci 2017; 62: 2166-2173

[541] Riggio O, Ridola L, Pasquale C. Hepatic encephalopathy therapy: An overview. World J Gastrointest Pharmacol Ther 2010; 1: 54-63

[542] Guevara M, Baccaro ME, Torre A et al. Hyponatremia is a risk factor of hepatic encephalopathy in patients with cirrhosis: a prospective study with time-dependent analysis. Am J Gastroenterol 2009; 104: 1382 1389

[543] Strauss E, Gomes de Sa Ribeiro Mde F. Bacterial infections associated with hepatic encephalopathy: prevalence and outcome. Ann Hepatol 2003; $2: 41-45$

[544] Strauss E, da Costa MF. The importance of bacterial infections as precipating factors of chronic hepatic encephalopathy in cirrhosis. Hepatogastroenterology 1998; 45: 900 - 904

[545] Rolando N, Wade J, Davalos M et al. The systemic inflammatory response syndrome in acute liver failure. Hepatology 2000; 32: $734-739$

[546] Merli M, Lucidi C, Pentassuglio I et al. Increased risk of cognitive impairment in cirrhotic patients with bacterial infections. J Hepatol 2013; 59: $243-250$
[547] Hung TH, Lay C], Chang CM et al. The effect of infections on the mortality of cirrhotic patients with hepatic encephalopathy. Epidemiol Infect 2013; 141: $2671-2678$

[548] Dieuvil M, Malaty J. Uncommon cause of acute encephalopathy in liver cirrhosis. BMJ Case Rep 2016; 2016

[549] del Olmo JA, Pena A, Serra MA et al. Predictors of morbidity and mortality after the first episode of upper gastrointestinal bleeding in liver cirrhosis. J Hepatol 2000; 32: 19-24

[550] Wen J, Liu Q, Song J et al. Lactulose is highly potential in prophylaxis of hepatic encephalopathy in patients with cirrhosis and upper gastrointestinal bleeding: results of a controlled randomized trial. Digestion 2013; 87: $132-138$

[551] Sharma P, Agrawal A, Sharma BC et al. Prophylaxis of hepatic encephalopathy in acute variceal bleed: a randomized controlled trial of lactulose versus no lactulose. J Gastroenterol Hepatol 2011; 26: 996 1003

[552] Micklefield GH, Schwegler U, Huppe D et al. Orthograde intestinal irrigation with a mannitol solution in reducing hepatic encephalopathy in patients with liver cirrhosis and gastrointestinal hemorrhage. Z Gastroenterol 1989; 27: $374-377$

[553] Tromm A, Griga T, Greving I et al. Orthograde whole gut irrigation with mannite versus paromomycine + lactulose as prophylaxis of hepatic encephalopathy in patients with cirrhosis and upper gastrointestinal bleeding: results of a controlled randomized trial. Hepatogastroenterology 2000; 47: $473-477$

[554] Rahimi RS, Singal AG, Cuthbert JA et al. Lactulose vs polyethylene glycol 3350-electrolyte solution for treatment of overt hepatic encephalopathy: the HELP randomized clinical trial. JAMA Intern Med 2014; 174: $1727-1733$

[555] Guevara M, Baccaro ME, Rios J et al. Risk factors for hepatic encephalopathy in patients with cirrhosis and refractory ascites: relevance of serum sodium concentration. Liver Int 2010; 30: 1137-1142

[556] Hung TH, Tsai CC, Tseng KC et al. High Mortality of Cirrhotic Patients With End-Stage Renal Disease. Medicine (Baltimore) 2016; 95: e3057

[557] Hung TH, Tseng CW, Tseng KC et al. Effect of renal function impairment on the mortality of cirrhotic patients with hepatic encephalopathy: a population-based 3-year follow-up study. Medicine (Baltimore) 2014; 93: e79

[558] Sponholz C, Matthes K, Rupp D et al. Molecular adsorbent recirculating system and single-pass albumin dialysis in liver failure - a prospective, randomised crossover study. Crit Care 2016; 20 : 2

[559] Butterworth RF. Neurosteroids in hepatic encephalopathy: Novel insights and new therapeutic opportunities. J Steroid Biochem Mol Biol 2016; 160: $94-97$

[560] Goh ET, Andersen ML, Morgan MY et al. Flumazenil versus placebo or no intervention for people with cirrhosis and hepatic encephalopathy. Cochrane Database Syst Rev 2017; 8: CD002798

[561] Grimm G, Ferenci P, Katzenschlager R et al. Improvement of hepatic encephalopathy treated with flumazenil. Lancet 1988; 2: $1392-1394$

[562] Groeneweg M, Gyr K, Amrein R et al. Effect of flumazenil on the electroencephalogram of patients with portosystemic encephalopathy. Results of a double blind, randomised, placebo- controlled multicentre trial. Electroencephalogr Clin Neurophysiol 1996; 98: 29-34

[563] Gyr K, Meier R, Haussler J et al. Evaluation of the efficacy and safety of flumazenil in the treatment of portal systemic encephalopathy: a double blind, randomised, placebo controlled multicentre study. Gut 1996; 39: $319-324$

[564] Khan MA, Cholankeril G, Howden CW. Proton Pump Inhibitors and the Possible Development of Hepatic Encephalopathy in Cirrhotic Patients: True Association or Residual Confounding? Gastroenterology 2017; 152: 2076 
[565] Tsai CF, Chen MH, Wang YP et al. Proton Pump Inhibitors Increase Risk for Hepatic Encephalopathy in Patients With Cirrhosis in A Population Study. Gastroenterology 2017; 152: 134-141

[566] Bian J, Wang A, Lin J et al. Association between proton pump inhibitors and hepatic encephalopathy: A meta-analysis. Medicine (Baltimore) 2017; 96: e6723

[567] Quirino M, Rossi S, Schinzari G et al. Unexpected side effect in mCRC: A care-compliant case report of regorafenib-induced hyperammonemic encephalopathy. Medicine (Baltimore) 2017; 96: e6522

[568] Jain S, Jain S, Kapoor G. Imatinib-associated massive upper gastrointestinal hemorrhage and hepatic encephalopathy in a child with Philadelphia positive acute lymphoblastic leukemia: A case report and review of the literature. South Asian J Cancer 2014; 3: 234-235

[569] Seymour CA, Whelan K. Dietary management of hepatic encephalopathy. BMJ 1999; 318: 1364-1365

[570] Campollo O, Sprengers D, Dam G et al. Protein tolerance to standard and high protein meals in patients with liver cirrhosis. World J Hepatol 2017; 9: $667-676$

[571] Jepsen P, Christensen J, Weissenborn K et al. Epilepsy as a risk factor for hepatic encephalopathy in patients with cirrhosis: a cohort study. BMC Gastroenterol 2016; 16: 77

[572] Montano-Loza AJ, Duarte-Rojo A, Rose CF. Sarcopenia and Myosteatosis Increase the Risk of Hepatic Encephalopathy in Cirrhotic Patients (in Poster Session 1: Encephalopathy and Other Complications). Hepatology; Special Issue: The 65th Annual Meeting of the American Association for the Study of Liver Diseases: The Liver Meeting 2014. 2014; 60: $384 \mathrm{~A}-385 \mathrm{~A}$

[573] Montano-Loza AJ, Duarte-Rojo A, Bhanji RA et al. Cirrhotic patients with sarcopenia and sarcopenic-obesity have an increased risk of hyperammonemia and hepatic encephalopathy. Am J Gastroenterol 2015; 110 (Suppl. 1): S875-S5877

[574] Gines P, Guevara M. Hyponatremia in cirrhosis: pathogenesis, clinical significance, and management. Hepatology 2008; 48: $1002-1010$

[575] Iwasa M, Sugimoto R, Mifuji-Moroka R et al. Factors contributing to the development of overt encephalopathy in liver cirrhosis patients. Metab Brain Dis 2016; 31: 1151 - 1156

[576] Merola J, Chaudhary N, Qian M et al. Hyponatremia: A Risk Factor for Early Overt Encephalopathy after Transjugular Intrahepatic Portosystemic Shunt Creation. J Clin Med 2014; 3: 359-372

[577] Jimenez JV, Carrillo-Perez DL, Rosado-Canto R et al. Electrolyte and Acid-Base Disturbances in End-Stage Liver Disease: A Physiopathological Approach. Dig Dis Sci 2017; 62: 1855-1871

[578] Patidar KR, Bajaj JS. Covert and Overt Hepatic Encephalopathy: Diagnosis and Management. Clin Gastroenterol Hepatol 2015; 13: 2048 2061

[579] European Association for the Study of the Liver. Electronic address eee, Clinical practice guidelines p, Wendon J et al. EASL Clinical Practical Guidelines on the management of acute (fulminant) liver failure. J Hepatol 2017; 66: 1047 - 1081

[580] Maheshwari R, Subramanian RM. On the Brink of Death: Managing Acute Liver Failure. Am J Gastroenterol 2017; 112: 200-206

[581] Lautz HU, Selberg O, Korber J et al. Protein-calorie malnutrition in liver cirrhosis. Clin Investig 1992; 70: 478-486

[582] Owen OE, Trapp VE, Reichard GA Jr et al. Nature and quantity of fuels consumed in patients with alcoholic cirrhosis. J Clin Invest 1983; 72 : $1821-1832$

[583] Plauth M, Cabre E, Riggio O et al. ESPEN Guidelines on Enteral Nutrition: Liver disease. Clin Nutr 2006; 25: 285-294

[584] Nguyen DL, Morgan T. Protein restriction in hepatic encephalopathy is appropriate for selected patients: a point of view. Hepatol Int 2014; 8: $447-451$
[585] Olde Damink SW, Jalan R, Redhead DN et al. Interorgan ammonia and amino acid metabolism in metabolically stable patients with cirrhosis and a TIPSS. Hepatology 2002; 36: 1163-1171

[586] Merli M, Giusto M, Lucidi C et al. Muscle depletion increases the risk of overt and minimal hepatic encephalopathy: results of a prospective study. Metab Brain Dis 2013; 28: 281 - 284

[587] Hanai T, Shiraki M, Watanabe S et al. Sarcopenia predicts minimal hepatic encephalopathy in patients with liver cirrhosis. Hepatol Res 2017 47: $1359-1367$

[588] Dasarathy S. Consilience in sarcopenia of cirrhosis. J Cachexia Sarcopenia Muscle 2012; 3: 225-237

[589] Koretz RL, Avenell A, Lipman TO. Nutritional support for liver disease. Cochrane Database Syst Rev 2012; 16: CD008344

[590] Ney M, Vandermeer B, van Zanten S] et al. Meta-analysis: oral or enteral nutritional supplementation in cirrhosis. Aliment Pharmacol Ther 2013; 37: $672-679$

[591] Tsien CD, McCullough AJ, Dasarathy S. Late evening snack: exploiting a period of anabolic opportunity in cirrhosis. J Gastroenterol Hepatol 2012; $27: 430-441$

[592] Gluud LL, Dam G, Les I et al. Branched-chain amino acids for people with hepatic encephalopathy. Cochrane Database Syst Rev 2017; 5: CD001939

[593] Zenith L, Meena N, Ramadi A et al. Eight weeks of exercise training increases aerobic capacity and muscle mass and reduces fatigue in patients with cirrhosis. Clin Gastroenterol Hepatol 2014; 12: 1920 1926 e2

[594] Kumar A, Davuluri G, Silva RNE et al. Ammonia lowering reverses sarcopenia of cirrhosis by restoring skeletal muscle proteostasis. Hepatology 2017; 65: 2045-2058

[595] Bianchi GP, Marchesini G, Fabbri A et al. Vegetable versus animal protein diet in cirrhotic patients with chronic encephalopathy. A randomized cross-over comparison. J Intern Med 1993; 233: 385-392

[596] Gheorghe L, lacob R, Vadan R et al. Improvement of hepatic encephalopathy using a modified high-calorie high-protein diet. Rom J Gastroenterol 2005; 14: $231-238$

[597] Maharshi S, Sharma BC, Sachdeva S et al. Efficacy of Nutritional Therapy for Patients With Cirrhosis and Minimal Hepatic Encephalopathy in a Randomized Trial. Clin Gastroenterol Hepatol 2016; 14: 454-460 e3; quiz e33

[598] Merli M, lebba V, Giusto M. What is new about diet in hepatic encephalopathy. Metab Brain Dis 2016; 31: 1289-1294

[599] Grungreiff K, Reinhold D, Wedemeyer $\mathrm{H}$. The role of zinc in liver cirrhosis. Ann Hepatol 2016; 15: 7 - 16

[600] Chavez-Tapia NC, Cesar-Arce A, Barrientos-Gutierrez T et al. A systematic review and meta- analysis of the use of oral zinc in the treatment of hepatic encephalopathy. Nutr ] 2013; 12: 74

[601] Peres WA, Chaves GV, Goncalves JC et al. Vitamin A deficiency in patients with hepatitis C virus-related chronic liver disease. Br J Nutr 2011 106: $1724-1731$

[602] Bemeur C, Butterworth RF. Reprint of: Nutrition in the Management of Cirrhosis and its Neurological Complications. J Clin Exp Hepatol 2015; 5: $\$ 131-S 140$

[603] AASLD, EASL. Hepatic Encephalopathy in Chronic Liver Disease: 2014 Practice Guideline by the European Association for the Study of the Liver and the American Association for the Study of Liver Diseases. Journal of Hepatology 2014; 61: 642-659

[604] Goldbecker A, Weissenborn K, Hamidi Shahrezaei G et al. Comparison of the most favoured methods for the diagnosis of hepatic encephalopathy in liver transplantation candidates. Gut 2013; 62: 1497 - 1504

[605] Mette ML, Hendrik V. Diagnosing covert hepatic encephalopathy. Clinical Liver Disease 2015; 5: 71 - 74 
[606] Soriano G, Bajaj JS. Grading the range of hepatic encephalopathy from overt to covert: Animals to the rescue! Hepatology 2017; 66: 10-12

[607] Bajaj JS, Cordoba J, Mullen KD et al. Review article: the design of clinical trials in hepatic encephalopathy-an International Society for Hepatic Encephalopathy and Nitrogen Metabolism (ISHEN) consensus statement. Aliment Pharmacol Ther 2011; 33: 739-747

[608] Bajaj JS, Kassam Z, Fagan A et al. Fecal microbiota transplant from a rational stool donor improves hepatic encephalopathy: A randomized clinical trial. Hepatology 2017; 66: $1727-1738$

[609] Wijdicks EF. Hepatic Encephalopathy. N Engl J Med 2016; 375: 1660 1670

[610] Bai M, He C, Yin Z et al. Randomised clinical trial: L-ornithine-L-aspartate reduces significantly the increase of venous ammonia concentration after TIPSS. Aliment Pharmacol Ther 2014; 40: 63-71

[611] Stauch S, Kircheis G, Adler G et al. Oral L-ornithine-L-aspartate therapy of chronic hepatic encephalopathy: results of a placebo-controlled double-blind study. J Hepatol 1998; 28: 856-864

[612] Kircheis G, Nilius R, Held C et al. Therapeutic efficacy of L-ornithine-Laspartate infusions in patients with cirrhosis and hepatic encephalopathy: results of a placebo-controlled, double- blind study. Hepatology 1997; 25: $1351-1360$

[613] Romero-Gomez M, Jover M, Del Campo JA et al. Variations in the promoter region of the glutaminase gene and the development of hepatic encephalopathy in patients with cirrhosis: a cohort study. Ann Intern Med 2010; 153: $281-288$

[614] Morgan MY. Current state of knowledge of hepatic encephalopathy (part III): non-absorbable disaccharides. Metab Brain Dis 2016; 31 : $1361-1364$

[615] Bothe MK, Maathuis AJH, Bellmann S et al. Dose-Dependent Prebiotic Effect of Lactulose in a Computer-Controlled In Vitro Model of the Human Large Intestine. Nutrients 2017; 9: 767

[616] Gluud LL, Vilstrup H, Morgan MY. Nonabsorbable disaccharides for hepatic encephalopathy: A systematic review and meta-analysis. Hepatology 2016; 64: 908 -922

[617] Gluud LL, Vilstrup H, Morgan MY. Non-absorbable disaccharides versus placebo/no intervention and lactulose versus lactitol for the prevention and treatment of hepatic encephalopathy in people with cirrhosis. Cochrane Database Syst Rev 2016; 4: CD003044

[618] Luo M, Li L, Lu CZ et al. Clinical efficacy and safety of lactulose for minimal hepatic encephalopathy: a meta-analysis. Eur ] Gastroenterol Hepatol 2011; 23: $1250-1257$

[619] Jiang Q, Jiang XH, Zheng MH et al. Rifaximin versus nonabsorbable disaccharides in the management of hepatic encephalopathy: a metaanalysis. Eur J Gastroenterol Hepatol 2008; 20: 1064-1070

[620] Eltawil KM, Laryea M, Peltekian K et al. Rifaximin vs. conventional ora therapy for hepatic encephalopathy: a meta-analysis. World J Gastroenterol 2012; 18: 767 - 777

[621] Wu D, Wu SM, Lu J et al. Rifaximin versus Nonabsorbable Disaccharides for the Treatment of Hepatic Encephalopathy: A Meta-Analysis. Gastroenterol Res Pract 2013; 2013: 236963

[622] 22. ROTE LISTE 2016. Frankfurt/Main: Rote Liste Service GmbH (Verlag). 2016

[623] Lachar J, Bajaj JS. Changes in the Microbiome in Cirrhosis and Relationship to Complications: Hepatic Encephalopathy, Spontaneous Bacterial Peritonitis, and Sepsis. Semin Liver Dis 2016; 36: 327-330

[624] Sharma BC, Singh J. Probiotics in management of hepatic encephalopathy. Metab Brain Dis 2016; 31: 1295 - 1301

[625] Xu J, Ma R, Chen LF et al. Effects of probiotic therapy on hepatic encephalopathy in patients with liver cirrhosis: an updated meta-analysis of six randomized controlled trials. Hepatobiliary Pancreat Dis Int 2014; 13: $354-60$
[626] Dalal R, McGee RG, Riordan SM et al. Probiotics for people with hepatic encephalopathy. Cochrane Database Syst Rev 2017; 2: CD008716

[627] Viramontes Horner D, Avery A, Stow R. The Effects of Probiotics and Symbiotics on Risk Factors for Hepatic Encephalopathy: A Systematic Review. J Clin Gastroenterol 2017; 51: 312 - 323

[628] Bajaj JS. Review article: potential mechanisms of action of rifaximin in the management of hepatic encephalopathy and other complications of cirrhosis. Aliment Pharmacol Ther 2016; 43 (Suppl. 1): 11-26

[629] Kimer N, Pedersen JS, Tavenier J et al. Rifaximin has minor effects on bacterial composition, inflammation, and bacterial translocation in cirrhosis: A randomized trial. J Gastroenterol Hepatol 2018; 33: 307 314

[630] Kimer N, Pedersen JS, Busk TM et al. Rifaximin has no effect on hemodynamics in decompensated cirrhosis: A randomized, double-blind, placebo-controlled trial. Hepatology 2017; 65: 592-603

[631] Kimer N, Krag A, Moller S et al. Systematic review with meta-analysis: the effects of rifaximin in hepatic encephalopathy. Aliment Pharmacol Ther 2014; 40: $123-132$

[632] Sharma BC, Sharma P, Lunia MK et al. A randomized, double-blind, controlled trial comparing rifaximin plus lactulose with lactulose alone in treatment of overt hepatic encephalopathy. Am J Gastroenterol 2013; 108: $1458-1463$

[633] Festi D, Vestito A, Mazzella G et al. Management of hepatic encephalopathy: focus on antibiotic therapy. Digestion 2006; 73 (Suppl. 1): 94- 101

[634] Zullo A, Hassan C, Ridola L et al. Rifaximin therapy and hepatic encephalopathy: Pros and cons. World J Gastrointest Pharmacol Ther 2012; 3: $62-67$

[635] Cacciottolo TM, Kingdon A, Alexander G]. Rifaximin is largely safe and well tolerated but caution is necessary when taken with statins. Clin Gastroenterol Hepatol 2014; 12: 1765

[636] Bass NM, Mullen KD, Sanyal A et al. Rifaximin treatment in hepatic encephalopathy. N Engl J Med 2010; 362: 1071 - 1081

[637] Manning RT, Delp M. Management of hepatocerebral intoxication. N Engl J Med 1958; 258: 55-62

[638] Rolachon A, Zarski JP, Lutz JM et al. Is the intestinal lavage with a solution of mannitol effective in the prevention of post-hemorrhagic hepatic encephalopathy in patients with liver cirrhosis? Results of a randomized prospective study. Gastroenterol Clin Biol 1994; 18: 1057 1062

[639] Naderian M, Akbari H, Saeedi M et al. Polyethylene Glycol and Lactulose versus Lactulose Alone in the Treatment of Hepatic Encephalopathy in Patients with Cirrhosis: A Non-Inferiority Randomized Controlled Trial. Middle East J Dig Dis 2017; 9: 12 - 19

[640] Kersh ES, Rifkin H. Lactulose enemas. Ann Intern Med 1973; 78: 81 - 84

[641] Ratnaike RN, Hicks EP, Hislop IG. The rectal administration of lactulose. Aust N Z J Med 1975; 5: 137-140

[642] Van Waes L, van Egmond J, Demeulenaere L. Emergency treatment of portal-systemic encephalopathy with lactulose enemas. A controlled study. Acta Clin Belg 1979; 34: 122 - 129

[643] Jover-Cobos M, Khetan V, Jalan R. Treatment of hyperammonemia in liver failure. Curr Opin Clin Nutr Metab Care 2014; 17: 105 - 110

[644] Rahimi RS, Rockey DC. Hepatic Encephalopathy: Pharmacological Therapies Targeting Ammonia. Semin Liver Dis 2016; 36: 48 - 55

[645] Sidhu SS, Sharma BC, Goyal O et al. L-ornithine L-aspartate in bouts of overt hepatic encephalopathy. Hepatology 2017; 67: 700 - 710

[646] Bai M, Yang Z, Qi X et al. I-ornithine-l-aspartate for hepatic encephalopathy in patients with cirrhosis: a meta-analysis of randomized controlled trials. J Gastroenterol Hepatol 2013; 28: 783 - 792

[647] Goh ET, Stokes CS, Vilstrup H et al. I-Ornithine I-Aspartate for Hepatic Encephalopathy: A Systematic Review with Meta-Analyses of Rando- 
mised Controlled Trials. Journal of Clinical and Experimental Hepatology 2017; 7: S65 - S66

[648] Alvares-da-Silva MR, de Araujo A, Vicenzi JR et al. Oral I-ornithineI-aspartate in minimal hepatic encephalopathy: A randomized, doubleblind, placebo-controlled trial. Hepatol Res 2014; 44: 956-963

[649] Poo JL, Gongora J, Sanchez-Avila F et al. Efficacy of oral L-ornithine-Laspartate in cirrhotic patients with hyperammonemic hepatic encephalopathy. Results of a randomized, lactulose- controlled study. Ann Hepatol 2006; 5: $281-288$

[650] Jiang Q, Jiang XH, Zheng $\mathrm{MH}$ et al. L-Ornithine-I-aspartate in the management of hepatic encephalopathy: a meta-analysis. J Gastroenterol Hepatol 2009; 24: 9-14

[651] Acharya SK, Bhatia V, Sreenivas V et al. Efficacy of L-ornithine L-aspartate in acute liver failure: a double-blind, randomized, placebo-controlled study. Gastroenterology 2009; 136: 2159-2168

[652] Rockey DC, Vierling JM, Mantry P et al. Randomized, double-blind, controlled study of glycerol phenylbutyrate in hepatic encephalopathy. Hepatology 2014; 59: 1073-1083

[653] McGuire BM, Zupanets IA, Lowe ME et al. Pharmacology and safety of glycerol phenylbutyrate in healthy adults and adults with cirrhosis. Hepatology 2010; 51: $2077-2085$

[654] Ventura-Cots M, Concepcion M, Arranz JA et al. Impact of ornithine phenylacetate (OCR-002) in lowering plasma ammonia after upper gastrointestinal bleeding in cirrhotic patients. Therap Adv Gastroenterol 2016; 9: $823-835$

[655] Ventura-Cots M, Arranz JA, Simon-Talero M et al. Safety of ornithine phenylacetate in cirrhotic decompensated patients: an open-label, dose-escalating, single-cohort study. J Clin Gastroenterol 2013; 47: $881-887$

[656] Kawaguchi T, Izumi N, Charlton MR et al. Branched-chain amino acids as pharmacological nutrients in chronic liver disease. Hepatology 2011; 54: $1063-1070$

[657] Kawaguchi T, Taniguchi E, Sata M. Effects of oral branched-chain amino acids on hepatic encephalopathy and outcome in patients with liver cirrhosis. Nutr Clin Pract 2013; 28: 580 - 588

[658] Park JG, Tak WY, Park SY et al. Effects of branched-chain amino acids (BCAAs) on the progression of advanced liver disease: A Korean nationwide, multicenter, retrospective, observational, cohort study. Medicine (Baltimore) 2017; 96: e6580

[659] Marchesini G, Bianchi G, Merli M et al. Nutritional supplementation with branched-chain amino acids in advanced cirrhosis: a double-blind, randomized trial. Gastroenterology 2003; 124: 1792-1801

[660] Tsien C, Davuluri G, Singh D et al. Metabolic and molecular responses to leucine-enriched branched chain amino acid supplementation in the skeletal muscle of alcoholic cirrhosis. Hepatology 2015; 61: 2018 2029

[661] Courson A, Jones GM, Twilla JD. Treatment of Acute Hepatic Encephalopathy: Comparing the Effects of Adding Rifaximin to Lactulose on Patient Outcomes. J Pharm Pract 2016; 29: 212-217

[662] Butt NI, Butt UI, Kakar A et al. Is Lactulose Plus Rifaximin Better than Lactulose Alone in the Management of Hepatic Encephalopathy? J Coll Physicians Surg Pak 2018; 28: 115-117

[663] Ahire K, Sonawale A. Comparison of Rifaximin Plus Lactulose with the Lactulose Alone for the Treatment of Hepatic Encephalopathy. J Assoc Physicians India 2017; 65: 42 - 46

[664] Sharma BC, Singh J, Srivastava S et al. Randomized controlled trial comparing lactulose plus albumin versus lactulose alone for treatment of hepatic encephalopathy. J Gastroenterol Hepatol 2017; 32: 1234 1239

[665] Abid S, Jafri W, Mumtaz K et al. Efficacy of L-ornithine-L-aspartate as an adjuvant therapy in cirrhotic patients with hepatic encephalopathy. J Coll Physicians Surg Pak 2011; 21: 666-671
[666] Sharma BC, Sharma P, Agrawal A et al. Secondary prophylaxis of hepatic encephalopathy: an open-label randomized controlled trial of lactulose versus placebo. Gastroenterology 2009; 137: 885-891, 891 e1

[667] Agrawal A, Sharma BC, Sharma P et al. Secondary prophylaxis of hepatic encephalopathy in cirrhosis: an open-label, randomized controlled trial of lactulose, probiotics, and no therapy. Am J Gastroenterol 2012; 107: $1043-1050$

[668] Tapper EB, Finkelstein D, Mittleman MA et al. A Quality Improvement Initiative Reduces 30- Day Rate of Readmission for Patients With Cirrhosis. Clin Gastroenterol Hepatol 2016; 14: 753 - 759

[669] Sharma Barjesh C, Maharshi S. Prevention of hepatic encephalopathy recurrence. Clinical Liver Disease 2015; 5: 64-67

[670] Les I, Doval E, Garcia-Martinez R et al. Effects of branched-chain amino acids supplementation in patients with cirrhosis and a previous episode of hepatic encephalopathy: a randomized study. Am J Gastroenterol 2011; 106: 1081 - 1088

[671] Dhiman RK, Rana B, Agrawal S et al. Probiotic VSL\#3 reduces liver disease severity and hospitalization in patients with cirrhosis: a randomized, controlled trial. Gastroenterology 2014; 147: 1327 - 1337 e3

[672] Ali B, Zaidi YA, Alam A et al. Efficacy of Rifaximin in prevention of recurrence of hepatic encephalopathy in patients with cirrhosis of liver. J Coll Physicians Surg Pak 2014; 24: 269-273

[673] Riggio O, Masini A, Efrati C et al. Pharmacological prophylaxis of hepatic encephalopathy after transjugular intrahepatic portosystemic shunt: a randomized controlled study. J Hepatol 2005; 42: 674-679

[674] Leise MD, Kim WR. Rifaximin in hepatic encephalopathy: is an ounce of prevention worth a pretty penny? Gastroenterology 2010; 139: 1416 1418

[675] Khokhar N, Qureshi MO, Ahmad S et al. Comparison of once a day rifaximin to twice a day dosage in the prevention of recurrence of hepatic encephalopathy in patients with chronic liver disease. J Gastroenterol Hepatol 2015; 30: 1420-1422

[676] Neff GW, Jones M, Broda T et al. Durability of rifaximin response in hepatic encephalopathy. J Clin Gastroenterol 2012; 46: 168-171

[677] Varakanahalli S, Sharma BC, Dahale AS. Secondary Prophylaxis of Hepatic Encephalopathy in Cirrhosis: A Double Blind Randomized Controlled Trial of L-Ornithine L-Aspartate vs. Placebo. Journal of Clinical and Experimental Hepatology 2017; 7: S60 - S61

[678] Varakanahalli S, Sharma BC, Srivastava S et al. Secondary prophylaxis of hepatic encephalopathy in cirrhosis of liver: a double-blind randomized controlled trial of L-ornithine L-aspartate versus placebo. Eur J Gastroenterol Hepatol 2018; 30: 951 - 958

[679] Mukund A, Rajesh S, Arora A et al. Efficacy of balloon-occluded retrograde transvenous obliteration of large spontaneous lienorenal shunt in patients with severe recurrent hepatic encephalopathy with foam sclerotherapy: initial experience. J Vasc Interv Radiol 2012; 23: 1200 1206

[680] Amodio P, Caregaro L, Pettenó E et al. Vegetarian diets in hepatic encephalopathy: facts or fantasies? Digestive and Liver Disease 2001; 33 492-500

[681] Goyal O, Sidhu SS, Kishore H. Minimal hepatic encephalopathy in cirrhosis- how long to treat? Ann Hepatol 2017; 16: 115-122

[682] Khanna R, Sarin SK. Non-cirrhotic portal hypertension - diagnosis and management. J Hepatol 2014; 60: 421 -441

[683] Sharma P, Sharma BC, Puri V et al. Natural history of minimal hepatic encephalopathy in patients with extrahepatic portal vein obstruction. Am J Gastroenterol 2009; 104: 885-890

[684] Yadav SK, Goel A, Saraswat VA et al. Evaluation of cognitivity, proinflammatory cytokines, and brain magnetic resonance imaging in minimal hepatic encephalopathy induced by cirrhosis and extrahepatic portal vein obstruction. J Gastroenterol Hepatol 2016; 31: 1986-1994 
[685] Faughnan ME, Palda VA, Garcia-Tsao G et al. International guidelines for the diagnosis and management of hereditary haemorrhagic telangiectasia. J Med Genet 2011; 48: 73-87

[686] Chavan A, Caselitz M, Gratz KF et al. Hepatic artery embolization for treatment of patients with hereditary hemorrhagic telangiectasia and symptomatic hepatic vascular malformations. Eur Radiol 2004; 14: 2079-2085

[687] El-Karaksy HM, Afifi O, Bakry A et al. A pilot study using lactulose in management of minimal hepatic encephalopathy in children with extrahepatic portal vein obstruction. World J Pediatr 2017; 13: 70-75

[688] Knirsch W, Benz DC, Buhr P et al. Catheter interventional treatment of congenital portosystemic venous shunts in childhood. Catheter Cardiovasc Interv 2016; 87: 1281 - 1292

[689] Brader RA, Kim KR. Transhepatic embolization of a congenital intrahepatic portosystemic shunt for the treatment of hepatic encephalopathy in a noncirrhotic patient using Amplatzer vascular plug device. Radiol Case Rep 2017; 12: 318-322

[690] Matsuura T, Takahashi Y, Yanagi Y et al. Surgical strategy according to the anatomical types of congenital portosystemic shunts in children. J Pediatr Surg 2016; 51: 2099-2104

[691] Lam KC, Juttner HU, Reynolds TB. Spontaneous portosystemic shunt: relationship to spontaneous encephalopathy and gastrointestinal hemorrhage. Dig Dis Sci 1981; 26: 346-352

[692] Riggio O, Efrati C, Catalano C et al. High prevalence of spontaneous portal-systemic shunts in persistent hepatic encephalopathy: a casecontrol study. Hepatology 2005; 42: 1158-1165

[693] Qi X, Qi X, Zhang Y et al. Prevalence and Clinical Characteristics of Spontaneous Splenorenal Shunt in Liver Cirrhosis: A Retrospective Observational Study Based on Contrast-Enhanced Computed Tomography (CT) and Magnetic Resonance Imaging (MRI) Scans. Med Sci Monit 2017; 23: 2527-2534

[694] Ohnishi K, Sato S, Saito M et al. Clinical and portal hemodynamic features in cirrhotic patients having a large spontaneous splenorenal and/ or gastrorenal shunt. Am J Gastroenterol 1986; 81: 450-455

[695] Gupta P, Sinha A, Sodhi KS et al. Congenital Extrahepatic Portosystemic Shunts: Spectrum of Findings on Ultrasound, Computed Tomography, and Magnetic Resonance Imaging. Radiology Research and Practice 2015; 2015: 7

[696] Laleman W, Simon-Talero M, Maleux G et al. Embolization of large spontaneous portosystemic shunts for refractory hepatic encephalopathy: a multicenter survey on safety and efficacy. Hepatology 2013; 57: $2448-2457$

[697] Moriya K, Kojima H, Matsumura M et al. Disappearance of hepatic encephalopathy and improvement of liver function after surgical treatment of portal-systemic shunt in a patient with liver cirrhosis. Hepatogastroenterology 2003; 50: 1128-1132

[698] Rossle M. TIPS: 25 years later. J Hepatol 2013; 59: 1081 - 1093

[699] Somberg KA, Riegler JL, LaBerge JM et al. Hepatic encephalopathy after transjugular intrahepatic portosystemic shunts: incidence and risk factors. Am J Gastroenterol 1995; 90: 549-555

[700] Riggio O, Ridola L, Angeloni S et al. Clinical efficacy of transjugular intrahepatic portosystemic shunt created with covered stents with different diameters: results of a randomized controlled trial. J Hepatol 2010; 53: $267-272$

[701] Casado M, Bosch J, Garcia-Pagan JC et al. Clinical events after transjugular intrahepatic portosystemic shunt: correlation with hemodynamic findings. Gastroenterology 1998; 114: $1296-1303$

[702] Chung HH, Razavi MK, Sze DY et al. Portosystemic pressure gradient during transjugular intrahepatic portosystemic shunt with Viatorr stent graft: what is the critical low threshold to avoid medically uncontrolled low pressure gradient related complications? J Gastroenterol Hepatol 2008; 23: 95-101
[703] Bai M, Qi X, Yang Z et al. Predictors of hepatic encephalopathy after transjugular intrahepatic portosystemic shunt in cirrhotic patients: a systematic review. J Gastroenterol Hepatol 2011; 26: 943-951

[704] Suraweera D, Jimenez M, Viramontes M et al. Age-related Morbidity and Mortality After Transjugular Intrahepatic Portosystemic Shunts. J Clin Gastroenterol 2017; 51: 360-363

[705] Nardelli S, Gioia S, Pasquale C et al. Cognitive Impairment Predicts The Occurrence Of Hepatic Encephalopathy After Transjugular Intrahepatic Portosystemic Shunt. Am J Gastroenterol 2016; 111: 523 - 528

[706] Fanelli F, Salvatori FM, Rabuffi P et al. Management of refractory hepatic encephalopathy after insertion of TIPS: long-term results of shunt reduction with hourglass-shaped balloon- expandable stent-graft. Am J Roentgenol 2009; 193: 1696-1702

[707] LaBerge JM, Somberg KA, Lake JR et al. Two-year outcome following transjugular intrahepatic portosystemic shunt for variceal bleeding: results in 90 patients. Gastroenterology 1995; 108: 1143-1151

[708] Riggio O, Nardelli S, Moscucci F et al. Hepatic encephalopathy after transjugular intrahepatic portosystemic shunt. Clin Liver Dis 2012; 16: $133-146$

[709] Pereira K, Carrion AF, Salsamendi J et al. Endovascular Management of Refractory Hepatic Encephalopathy Complication of Transjugular Intrahepatic Portosystemic Shunt (TIPS): Comprehensive Review and Clinical Practice Algorithm. Cardiovasc Intervent Radiol 2016; 39: 170-182

[710] Pereira K, Carrion AF, Martin P et al. Current diagnosis and management of post-transjugular intrahepatic portosystemic shunt refractory hepatic encephalopathy. Liver Int 2015; 35: 2487-2494

[711] Bajaj JS, Saeian K, Christensen KM et al. Probiotic yogurt for the treatment of minimal hepatic encephalopathy. Am J Gastroenterol 2008; 103: $1707-1715$

[712] Mittal VV, Sharma BC, Sharma P et al. A randomized controlled trial comparing lactulose, probiotics, and L-ornithine L-aspartate in treatment of minimal hepatic encephalopathy. Eur ] Gastroenterol Hepatol 2011; 23: $725-732$

[713] Saji S, Kumar S, Thomas V. A randomized double blind placebo controlled trial of probiotics in minimal hepatic encephalopathy. Trop Gastroenterol 2011; 32: 128-132

[714] Shukla S, Shukla A, Mehboob S et al. Meta-analysis: the effects of gut flora modulation using prebiotics, probiotics and synbiotics on minimal hepatic encephalopathy. Aliment Pharmacol Ther 2011; 33: 662-671

[715] Sharma K, Pant S, Misra S et al. Effect of rifaximin, probiotics, and I-ornithine I-aspartate on minimal hepatic encephalopathy: a randomized controlled trial. Saudi J Gastroenterol 2014; 20: 225-232

[716] Sidhu SS, Goyal O, Mishra BP et al. Rifaximin improves psychometric performance and health- related quality of life in patients with minimal hepatic encephalopathy (the RIME Trial). Am J Gastroenterol 2011; 106: $307-316$

[717] Bajaj JS, Heuman DM, Wade JB et al. Rifaximin improves driving simulator performance in a randomized trial of patients with minimal hepatic encephalopathy. Gastroenterology 2011; 140: 478-487 e1

[718] Nardone R, Taylor AC, Holler Y et al. Minimal hepatic encephalopathy: A review. Neurosci Res 2016; 111: 1-12

[719] Ferenci P. Diagnosis of minimal hepatic encephalopathy: still a challenge. Gut 2013; 62: 1394

[720] Thuluvath PJ, Nuthalapati A, Price J et al. Driving Performance Among Patients with Cirrhosis Who Drove to Their Outpatient Hepatology Clinic Appointments. J Clin Exp Hepatol 2016; 6: 3 -9

[721] Maharshi S, Sharma BC, Srivastava S et al. Randomised controlled trial of lactulose versus rifaximin for prophylaxis of hepatic encephalopathy in patients with acute variceal bleed. Gut 2015; 64: 1341-1342 
ERRATUM

Aktualisierte S2k-Leitlinie der Deutschen Gesellschaft für Gastroenterologie, Verdauungs- und Stoffwechselkrankheiten (DGVS) „Komplikationen der Leberzirrhose“

AWMF-Nr.: 021-017

Alexander L. Gerbes, Joachim Labenz, Beate Appenrodt et al. Z Gastroenterol 2019; 57(05): 611 - 680; DOI:10.1055/a-0873-4658

Im oben genannten Artikel wurde der Name eines Koautors falsch angegeben. Der korrekte Name lautet: Manuel Dafotakis. 